\author{
UNIVERSIDADE DE SÃO PAULO \\ ESCOLA DE ENGENHARIA DE SÃO CARLOS \\ DEPARTAMENTO DE HIDRÁULICA E SANEAMENTO
}

JEAN CARLOS DUARTE CARVAJALINO

Avaliação de estimativas de evapotranspiração dos métodos baseados na flutuação diária do nível piezométrico comparando com o método de balanço de energia - Razão de Bowen em zona ripária

VERSÃO CORRIGIDA

São Carlos, SP 

JEAN CARLOS DUARTE CARVAJALINO

\section{Avaliação de estimativas de evapotranspiração dos métodos baseados na flutuação diária do nível piezométrico comparando com o método de balanço de energia - Razão de Bowen em zona ripária}

Dissertação apresentada à Escola de Engenharia de São Carlos, da Universidade de São Paulo, como parte dos requisitos para obtenção do título de Mestre em Ciências: Engenharia Hidráulica e Saneamento.

Orientador: Prof. Titular Edson Wendland.

São Carlos, SP 
AUTORIZO A REPRODUÇÃO TOTAL OU PARCIAL DESTE TRABALHO POR QUALQUER MEIO CONVENCIONAL OU ELETRÔNICO, PARA FINS DE ESTUDO E PESQUISA, DESDE QUE CITADA A FONTE.

Ficha catalográfica elaborada pela Biblioteca Prof. Dr. Sérgio Rodrigues Fontes da EESC/USP com os dados inseridos pelo(a) autor(a).

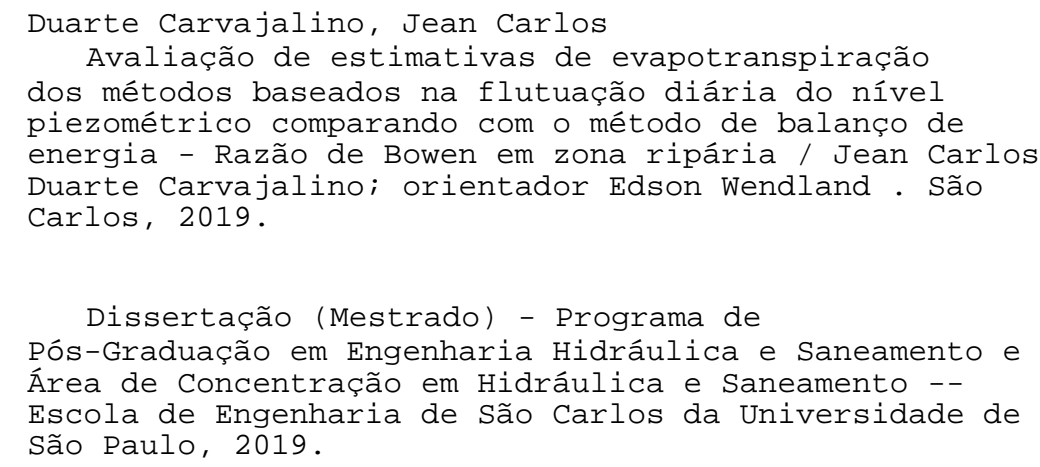

1. Evapotranspiração. 2. Bowen. 3. Flutuação diária do nível piezométrico. 4. Reconstrução de estimativas rejeitadas. 5. Python. I. Título.

Eduardo Graziosi Silva - CRB - 8/8907 
FOLHA DE JULGAMENTO

Candidato: Engenheiro JEAN CARLOS DUARTE CARVAJALINO.

Título da dissertação: "Avaliação de estimativas de evapotranspiração dos métodos baseados na flutuação diário do nível piezométrico usando o método de balanço de energia - Razão de Bowen em zona ripária".

Data da defesa: 04/06/2019.

Comissão Julgadora:

Prof. Titular Edson Cezar Wendland (Orientador)

(Escola de Engenharia de São Carlos/EESC)

Prof. Titular Humberto Ribeiro da Rocha

(Instituto de Astronomia, Geofísica e Ciências Atmosféricas/IAG-USP)

Prof. Dr. Ademir Paceli Barbassa

(Universidade Federal de São Carlos/UFSCar)
Resultado:

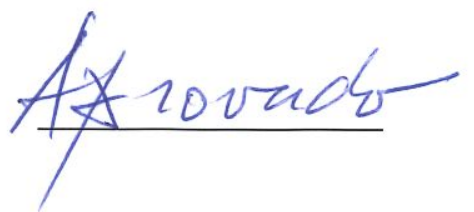

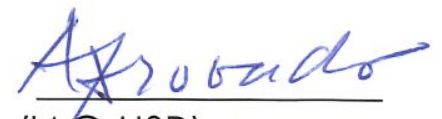

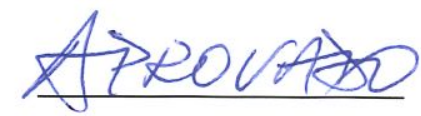

Coordenador do Programa de Pós-Graduação em Engenharia Hidráulica e Saneamento:

Prof. Dr. Eduardo Mario Mendiondo

Presidente da Comissão de Pós-Graduação:

Prof. Titular Murilo Araujo Romero 



\section{Agradecimentos}

Agradeço a Deus, em primeiro lugar, por tudo na vida, por ter me guiado no caminho e por ter me permitido finalizar mais uma etapa. À Virgem Maria por todas as suas bênçãos e pela proteção.

Agradeço aos meus pais, Martha Cecilia Carvajalino Cardona e Carlos Alberto Duarte Sanchez, por ser esse apoio incondicional na vida, por ter me brindado tanto amor, por ter me ensinado as coisas realmente importantes na vida, por ter me permitido perseguir meus sonhos, por ter sido tão exigentes em todos os aspectos, o que me permitiu ser o que sou hoje em dia.

Agradeço aos meus avós e, em especial, à minha avó Ana Isabel Cardona de Carvajalino, e ao meu avô Antonio de Jesus Carvajalino por toda sua sabedoria, por ter me permitido ter a melhor infância possível, cheia de amor, carinho, conselhos e puxadas de orelha, por ter me ensinado a sonhar, a ser corajoso para afrontar as novas aventuras, a não desistir e a acreditar que tudo é possível.

Ao meu irmão Omar Giovanni Duarte Carvajalino "El Mono", por todos os momentos de riso, por estar sempre presente para brincar e brigar, por todas as aventuras que vivemos quando crianças, por ter me ensinado o amor de irmão.

Aos demais integrantes da minha família por suas orações e desejos.

A minha namorada, Diana Karina Correa Villamizar por ter me apoiado demais nesta aventura, pelos bons momentos ao teu lado, por todo o apoio, carinho e amor brindados.

Ao professor Dr. Edson Wendland pela oportunidade e confiança depositada.

Aos amigos na Colômbia que, ainda na distância, me apoiam e motivam a seguir adiante. Aos amigos do Laboratório de Hidráulica Computacional, João, Jaqueline, David, Gabriel, Lívia, Camila, Ana, Lazarini, Kalyl, Alice, Jamil, Natália, Juliana, Andres, Derly, Hélio, Dimaghi, Alan, Davi, Balarin, Alex, Erick, Yuri e Julian, pelas grandes amizades que levarei comigo e que sei que vão durar muito tempo, pelos incríveis momentos que passei na minha curta estadia em São Carlos, por terem feito me sentir em casa.

Ao Bergamo por ter me ajudado nas diferentes etapas do projeto, por ter compartilhado um pouco da sua sabedoria e apoio, ao Téo e André pelo apoio técnico no campo.

Às secretárias do SHS, Sá, Priscila e Rose, pela paciência que tiveram comigo no processo de inscrição, pela boa disposição nas diferentes funções e acompanhamento.

Ao departamento de Transportes da EESC, em especial, ao motorista Iagil Dahora, 
pela sua boa disposição e ajuda nos campos.

Aos funcionários da biblioteca da EESC.

À Universidad Francisco de Paula Santander, pela formação de Engenheiro Civil, base essencial para a realização do mestrado.

À Fundação de Amparo à Pesquisa do Estado de São Paulo (FAPESP) e ao Conselho Nacional de Desenvolvimento Científico e Tecnológico (CNPq) pelo suporte financeiro ao projeto de pesquisa.

Ao programa de Pós-Graduação do Departamento de Hidráulica e Saneamento da Escola de Engenharia de São Carlos e à USP, pela excelência acadêmica e crescimento profissional. 


\section{Resumo}

DUARTE-CARVAJALINO, J. C. Avaliação de estimativas de evapotranspiração dos métodos baseados na flutuação diária do nível piezométrico comparando com o método de balanço de energia - Razão de Bowen em zona ripária. 2019. 137p. Dissertação (Mestrado) - Escola de Engenharia de São Carlos, Universidade de São Paulo.

No ciclo hidrológico, o processo de evapotranspiração $(E T)$ representa a maior percentagem do total de precipitação. As maiores percentagens de ET são encontradas nas zonas ripárias visto a alta disponibilidade hídrica. Embora existam métodos acessíveis para estimativa da ET em zona ripária, como os baseados na flutuação diária do nível piezométrico, poucos estudos têm sido desenvolvidos devido à complexidade teórica da variável, ao elevado custo de equipamentos, e à reduzida largura dessas áreas. Desta forma, o objetivo deste trabalho foi avaliar 10 métodos baseados na flutuação diária do nível piezométrico usando o método de balanço de energia - Razão de Bowen. Para tal fim, foram construídos cinco poços e uma torre de monitoramento em uma área de zona ripária da bacia hidrográfica do Ribeirão da Onça (Brotas, São Paulo). Os dados dos poços e da torre de monitoramento foram coletados, a cada 15 minutos, no período de, respectivamente, abril de 2018 e junho de 2018, a janeiro de 2019. Para o processamento dos dados, foi feito um programa em linguagem Python. Nos dados do método de balanço de energia - Razão de Bowen foram utilizados o critério de propagação de erros para a rejeição de estimativas, e o método de amostragem direta para a posterior reconstrução da série temporal. No período seco e chuvoso, as taxas médias de ET obtidas pelo método de balanço de energia - Razão de Bowen foram, respectivamente, de 3,62 0,93 $\mathrm{mm} /$ dia e 5, $09 \pm 2,34 \mathrm{~mm} /$ dia. Entre os métodos baseados na flutuação diária do nível piezométrico, o método de Gribovski apresentou as melhores métricas na avaliação $\left(\bar{\rho}=0.69, \overline{\tau_{s}}=0.55, \overline{M A E}=1.77 \mathrm{~mm} /\right.$ dia, $\overline{R M S E}=2.07 \mathrm{~mm} /$ dia e $\overline{M B E}=1.63 \mathrm{~mm} /$ dia $)$, o qual mostra o potencial desse tipo de métodos para estimar a $E T$ em zonas ripárias.

Palavras-chave: Evapotranspiração. Bowen. Flutuação diária do nível piezométrico. Reconstrução de estimativas rejeitadas. Python. 



\section{Abstract}

DUARTE-CARVAJALINO, J. C. Evaluation of evapotranspiration estimates of the methods based on the daily fluctuation of the piezometric level comparing with the energy balance method - Bowen ratio in riparian zone.. 2019. 137p. Dissertation (Master's degree) - São Carlos School of Engineering, University of São Paulo.

Evapotranspiration rate $(E T)$ represents a significant percentage of precipitation in the water balance. At the riparian zones, ET slightly increases due to high water availability. Although there are available methods to ET estimation, such as the based on groundwater level variation, few studies have developed because of theorical complexity, high equipment cost and narrow band of the riparian zones. Thus, this work aims to evaluate 10 groundwater level variation methods using the energy balance - Bowen ratio method. For that, five wells and one monitoring tower were installed in a riparian zone of the Onça Creek basin (Brotas, São Paulo, Brazil). Data from wells and monitoring tower were collected at each 15 minutes from, respectively, April/2018 and June/2018 to January/2019. For data processing, a Python languague programme was developed. Error propagation method was applied to reject unreliable estimation of ET. Also, direct sampling was used to temporal serie rebuilding. The ET estimations from Bowen ration method range from 3,62 $\pm 0,93 \mathrm{~mm} /$ day and 5,09 $\pm 2,34 \mathrm{~mm} /$ day (dry and wet period, respectively). Among the groundwater level variation methods, the Gribovski method reached the smallest error $\left(\bar{\rho}=0.69, \overline{\tau_{s}}=0.55\right.$, $\overline{M A E}=1.77 \mathrm{~mm} /$ day, $\overline{R M S E}=2.07 \mathrm{~mm} /$ day e $\overline{M B E}=1.63 \mathrm{~mm} /$ day). Then, the Griboski method may be used to ET estimation in riparian zones.

Keywords: Evapotranspiration. Bowen. Groundwater level variation. Temporal serie rebuilding. Python. 



\section{Lista de ilustrações}

Figura 1 - Representação esquemática do balanço energético . . . . . . . . . . . 28

Figura 2 - Representação esquemática dos fluxos de energia sobre área florestada . 32

Figura 3 - Processo do algoritmo de amostragem direta $(D S) \ldots$. . . . . . . 37

Figura 4 - Variação do nível piezométrico . . . . . . . . . . . . . . . . . 39

Figura 5 - Representação esquemática de 6 métodos para o cálculo da ET em base às flutuações diárias do nível piezométrico . . . . . . . . . . . . . . . 40

Figura 6 - Representação do conceito de rendimento especifico . . . . . . . . . . 43

Figura 7 - Localização da bacia hidrográfica do Ribeirão da Onça $(B R O)$. . . . . 45

Figura 8 - Bacia hidrográfica do Ribeirão da Onça $(B R O) \ldots$. . . . . . . . . 46

Figura 9 - Equipamentos instalados na torre de monitoramento . . . . . . . . . 47

Figura 10 - a) Construção da base e do pedestal, b) Equipamentos instalados na torre metálica . . . . . . . . . . . . . . . . . . . . . . 48 48

Figura 11 - Tamanho das áreas de bordadura necessária (azul) e disponível (amarelo) 49

Figura 12 - Construção e instalação de poços de monitoramento . . . . . . . . . . . 50

Figura 13 - Interface do programa em linguagem Python . . . . . . . . . . . . . 55

Figura 14 - Evolução temporal do monitoramento na zona ripária . . . . . . . . . . 56

Figura 15 - Temperatura $\left({ }^{\circ} \mathrm{C}\right)$ dos sensores inferior $(1)$ e superior $(2) \ldots \ldots$. . . 57

Figura 16 - Umidade relativa (\%) dos sensores inferior (1) e superior (2) . . . . . 57

Figura 17 - Radiação liquida $\left(R_{N}\right)$ e fluxo de calor no solo $(G) \ldots \ldots$. . . . . 58

Figura 18 - Relação entre o limite de rejeição e a percentagem de medições de $E T$ rejeitadas pelo critério de Romano e Giudici . . . . . . . . . . . . . . 62

Figura 19 - Gráficos $Q-Q$ da $E T$ reconstruída $\left(E T_{\text {sim }}\right)$ x $E T$ não rejeitada $\left(E T_{T I}\right)$ para diferentes limites de rejeição . . . . . . . . . . . . . . . . 63

Figura 20 - Resultados da reconstrução das estimativas rejeitadas para dois limites de rejeição do critério de Romano e Giudici . . . . . . . . . . . . . . . 64

Figura 21 - ET acumulada no período de monitoramento considerando diferentes limites de rejeição do critério de Romano e Giudici . . . . . . . . . . . 64

Figura 22 - Comparação da ET acumulada com e sem reconstrução das estimativas rejeitadas para diferentes limites de rejeição do critério de Romano e Giudici . . . . . . . . . . . . . . . . . . .

Figura 23 - Comparação entre os resultados de ET acumulada das 10 simulações para vários limites de rejeição $(\varepsilon), a) \varepsilon=0,5, b) \varepsilon=1, c) \varepsilon=5$ e d)

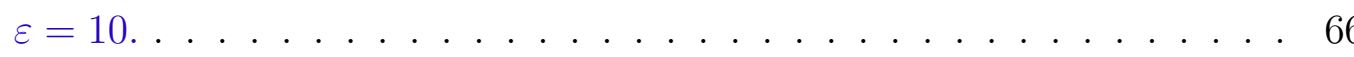

Figura 24 - Gráficos $Q-Q$ de $E T$ reconstruída $\left(E T_{\text {sim }}\right)$ x $E T$ não rejeitada $\left(E T_{\text {val }}\right)$ para diferentes percentagens rejeição . . . . . . . . . . . . . 67

Figura 25 - ET calculada pelo método de balanço de energia - Razão de Bowen . . 67 
Figura 26 - Nível piezométrico no poço P31 . . . . . . . . . . . . . . . . 68

Figura 27 - Remoção dos dados de nível do poço P31 em dias com eventos de precipitação . . . . . . . . . . . . . . . . . . . . . . . . 69

Figura 28 - ET calculada pelo método de White . . . . . . . . . . . . . 70

Figura 29 - ET calculada pela adaptação de Rushton . . . . . . . . . . . . . . . . . 71

Figura 30 - ET calculada pela adaptação de Hays . . . . . . . . . . . . . . . . . . 72

Figura 31 - ET calculada pela adaptação de Miller . . . . . . . . . . . . . . . . . 72

Figura 32 - ET calculada pela adaptação de Loheide II . . . . . . . . . . . . . . 73

Figura 33 - ET calculada pelo método de Dolan . . . . . . . . . . . . . . . 73

Figura 34 - ET calculada pelo método de Hays . . . . . . . . . . . . . . . . . . 74

Figura 35 - ET calculada pelo método de Gribovski . . . . . . . . . . . . . 75

Figura 36 - ET calculada pelo método de Loheide II . . . . . . . . . . . . . . 75

Figura 37 - ET calculada pelo método de Soylu . . . . . . . . . . . . . . 76

Figura 38 - Correlação entre as estimativas de ET do método de balanço de energia - Razão de Bowen e o método de White . . . . . . . . . . . . . . . . . 78

Figura 39 - Correlação entre as estimativas de ET do método de balanço de energia - Razão de Bowen e da adaptação de Loheide II . . . . . . . . . . . . . 78

Figura 40 - Correlação entre as estimativas de ET do método de balanço de energia - Razão de Bowen e da adaptação de Miller . . . . . . . . . . . . . . . 79

Figura 41 - Correlação entre as estimativas de ET do método de balanço de energia - Razão de Bowen e da adaptação de Hays . . . . . . . . . . . . . . . . 79

Figura 42 - Correlação entre as estimativas de ET do método de balanço de energia - Razão de Bowen e da adaptação de Rushton . . . . . . . . . . . . . . 80

Figura 43 - Correlação entre as estimativas de ET do método de balanço de energia - Razão de Bowen e o método de Dolan . . . . . . . . . . . . . . . . . . 81

Figura 44 - Correlação entre as estimativas de ET do método de balanço de energia - Razão de Bowen e o método de Hays

Figura 45 - Correlação entre as estimativas de ET do método de balanço de energia - Razão de Bowen e o método de Soylu . . . . . . . . . . . . . . . . . . 82

Figura 46 - Correlação entre as estimativas de ET do método de balanço de energia - Razão de Bowen e o método de Loheide II

Figura 47 - Correlação entre as estimativas de ET do método de balanço de energia - Razão de Bowen e o método de Gribovski . . . . . . . . . . . . . . . . 84

Figura 48 - Detalhes da base da torre de monitoramento . . . . . . . . . . . . . . 105

Figura 49 - Nível piezométrico poço P27 . . . . . . . . . . . . . . . . . 111

Figura 50 - Nível piezométrico poço P30 . . . . . . . . . . . . . . . . . . . 112

Figura 51 - Nível piezométrico poço P31 . . . . . . . . . . . . . . . . . . . . 112

Figura 52 - Nível piezométrico poço P32 . . . . . . . . . . . . . . . . . 113

Figura 53 - Nível piezométrico poço P33 . . . . . . . . . . . . . . . . 113 
Figura 54 - Nível piezométrico poço P35 . . . . . . . . . . . . . . . . . . 114 



\section{Lista de tabelas}

Tabela 1 - Escalas espaciais e métodos para a estimativa da ET . . . . . . . . 26

Tabela 2 - Equipamentos necessários para coleta e armazenamento dos dados . . . 48

Tabela 3 - Dados de exemplo da aplicação do método de balanço de energia Razão de Bowen . . . . . . . . . . . . . . . . . . . 58 58

Tabela 4 - Resultados da aplicação do método de balanço de energia - Razão de Bowen, parte $1 \ldots \ldots \ldots$. . . . . . . . . . . . . 59

Tabela 5 - Resultados da aplicação do método de balanço de energia - Razão de Bowen, parte $2 \ldots \ldots \ldots$. . . . . . . . . . . . 60

Tabela 6 - Resultados da aplicação do método de balanço de energia - Razão de Bowen, parte $3 \ldots \ldots \ldots$. . . . . . . . . . . . . 6 61

Tabela 7 - Percentagem de dados de ET rejeitados pelo critério de Romano e Giudici 62

Tabela 8 - Resultados de evapotranspiração ET ( $\mathrm{mm} /$ dia) estimadas pelos métodos baseados na flutuação diária do nível piezométrico . . . . . . . . . . . . 77

Tabela 9 - Resultados do coeficiente de correlação de Pearson $(\rho)$ entre o método de balanço de energia - Razão de Bowen e os métodos testados . . . . 85

Tabela 10 - Resultados do coeficiente de correlação de postos de Spearman $\left(\tau_{s}\right)$ entre o método de balanço de energia - Razão de Bowen e os métodos testados . . . . . . . . . . . . . . . . . 85

Tabela 11 - Erro absoluto médio $(M A E)$ entre o método de balanço de energia Razão de Bowen e os métodos testados . . . . . . . . . . . . . . 86

Tabela 12 - Resultados da raiz do erro quadrático médio (RMSE) entre o método de balanço de energia - Razão de Bowen e os métodos testados . . . . 86

Tabela 13 - Resultados do erro de viés médio $(M B E)$ entre o método de balanço de energia - Razão de Bowen e os métodos testados . . . . . . . . . . . 87

Tabela 14 - Dados coletados na torre de monitoramento no dia 30/06/2018 . . . 107

Tabela 14 - Dados coletados na torre de monitoramento no dia 30/06/2018 . . . . 108

Tabela 14 - Dados coletados na torre de monitoramento no dia 30/06/2018 . . . 109

Tabela 15 - Resultados de evapotranspiração do método de balanço de energia Razão de Bowen . . . . . . . . . . . . . . . . . . . . . . 117

Tabela 15 - Resultados de evapotranspiração do método de balanço de energia Razão de Bowen . . . . . . . . . . . . . . . . . . . 118

Tabela 15 - Resultados de evapotranspiração do método de balanço de energia Razão de Bowen . . . . . . . . . . . . . . . . . . . . . . . . . 119

Tabela 16 - Resultados de evapotranspiração do método de White . . . . . . . . . 121

Tabela 16 - Resultados de evapotranspiração do método de White . . . . . . . . . 122

Tabela 17 - Resultados de evapotranspiração da adaptação de Rushton . . . . . . . 122 
Tabela 17 - Resultados de evapotranspiração da adaptação de Rushton . . . . . . . 123

Tabela 17 - Resultados de evapotranspiração da adaptação de Rushton . . . . . . . 124

Tabela 18 - Resultados de evapotranspiração da adaptação de Hays . . . . . . . . . 124

Tabela 18 - Resultados de evapotranspiração da adaptação de Hays . . . . . . . . . 125

Tabela 18 - Resultados de evapotranspiração da adaptação de Hays . . . . . . . . . 126

Tabela 19 - Resultados de evapotranspiração da adaptação de Loheide II . . . . . . 126

Tabela 19 - Resultados de evapotranspiração da adaptação de Loheide II . . . . . . 127

Tabela 20 - Resultados de evapotranspiração da adaptação de Miller . . . . . . . . 127

Tabela 20 - Resultados de evapotranspiração da adaptação de Miller . . . . . . . . 128

Tabela 20 - Resultados de evapotranspiração da adaptação de Miller . . . . . . . . 129

Tabela 21 - Resultados de evapotranspiração do método de Dolan . . . . . . . . . . 129

Tabela 21 - Resultados de evapotranspiração do método de Dolan . . . . . . . . . . 130

Tabela 21 - Resultados de evapotranspiração do método de Dolan . . . . . . . . . . 131

Tabela 22 - Resultados de evapotranspiração do método de Hays . . . . . . . . . . 131

Tabela 22 - Resultados de evapotranspiração do método de Hays . . . . . . . . . . 132

Tabela 23 - Resultados de evapotranspiração do método de Gribovski ..... . 133

Tabela 23 - Resultados de evapotranspiração do método de Gribovski ..... 134

Tabela 24 - Resultados de evapotranspiração do método de Loheide II . . . . . . . 134

Tabela 24 - Resultados de evapotranspiração do método de Loheide II . . . . . . . 135

Tabela 24 - Resultados de evapotranspiração do método de Loheide II . . . . . . . 136

Tabela 25 - Resultados de evapotranspiração do método de Soylu . . . . . . . . . . 136

Tabela 25 - Resultados de evapotranspiração do método de Soylu . . . . . . . . . . 137 


\section{Lista de abreviaturas e siglas}

FAO Food and Agriculture Organization

WAVE Water and Agrochemicals in soil, crop and Vadose Environment

SWAP Soil, Water, Atmosphere and Plant

SVAT Soil-Vegetation-Atmosphere-Transfer models

SWAT Soil and Water Assessment Tool

MIKE-SHE European Hydrological System Model

SEBAL Surface Energy Balance Algorithm for Land

PROMET Process Oriented Models for Evapotranspiration

SAG Sistema Aquífero Guarani

BRO Bacia hidrográfica do Ribeirão da Onça

CRHEA Centro de Recursos Hídricos e Estudos Ambientais 



\section{Lista de símbolos}

\begin{tabular}{|c|c|}
\hline ET & Evapotranspiração \\
\hline$P$ & Precipitação \\
\hline$R_{N}$ & Radiação liquida \\
\hline$G$ & Fluxo de calor sensível no solo \\
\hline$\lambda E T$ & Fluxo de calor latente no ar \\
\hline$H$ & Fluxo de calor sensível no ar \\
\hline$S_{y}$ & Rendimento específico \\
\hline$S_{y}^{*}$ & Rendimento específico transiente \\
\hline$\beta$ & Razão de Bowen \\
\hline$e$ & Pressão parcial de vapor d'água no ar \\
\hline$e$ & Pressão de saturação de vapor d'água no ar \\
\hline$T$ & Temperatura \\
\hline$\gamma$ & Coeficiente psicométrico \\
\hline$\Delta T$ & Gradiente de temperatura \\
\hline$\Delta e$ & Gradiente de pressão parcial de vapor d'água no ar \\
\hline$\varepsilon$ & Limite de aceitação \\
\hline$\sigma_{E T}$ & Incerteza associada à medição de evapotranspiração \\
\hline$S G$ & Grid da imagem de simulação \\
\hline$T I$ & Grid da imagem de treinamento \\
\hline$r$ & Recarga lateral \\
\hline$\frac{d h}{d t}$ & Variação do nível piezometrico \\
\hline$N S E$ & Coeficiente de eficiência de Nash-Sutcliffe \\
\hline$W T$ & Nível piezométrico \\
\hline
\end{tabular}


$\tau_{s}$ Coeficiente de correlação de postos de Spearman

$M A E \quad$ Erro absoluto médio

RMSE Raiz do erro quadrático médio

$M B E \quad$ Erro de viés médio 


\section{Sumário}

INTRODUÇÃO $\ldots \ldots \ldots \ldots \ldots \ldots \ldots \ldots \ldots$

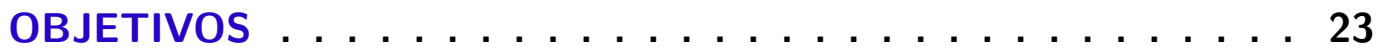

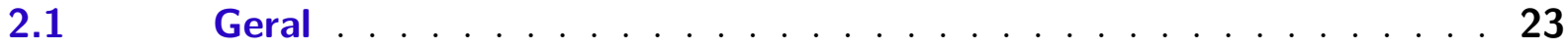

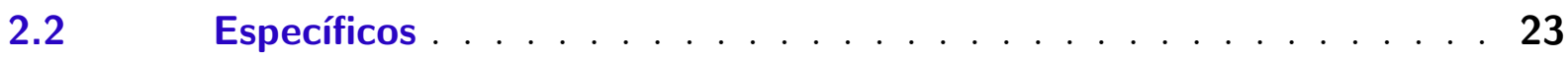

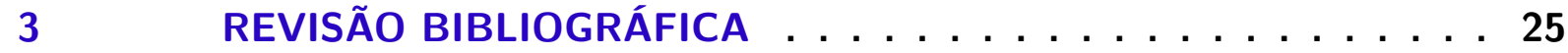

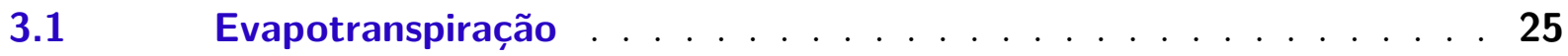

3.2 Método de balanço de energia - Razão de Bowen . . . . . . . . . . 27

3.2.1 Fluxo de calor latente . . . . . . . . . . . . . . . . . . . . . 29

3.2.2 Fluxo de calor sensível . . . . . . . . . . . . . . . 30

3.2.3 Razão de Bowen . . . . . . . . . . . . . . . . . . . . . 31

3.2.4 Critérios de rejeição de estimativas . . . . . . . . . . . . . . 33

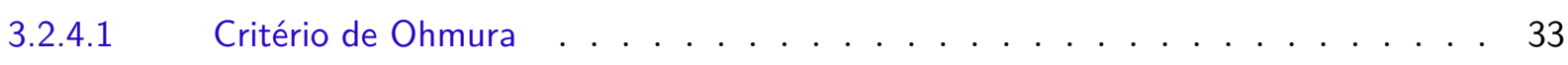

3.2.4.2 Critério de Perez . . . . . . . . . . . . . . . . . . . . . 34

3.2.4.3 Critério de Tanner . . . . . . . . . . . . . . . . . . . . . 34

3.2.4.4 Critério de Romano . . . . . . . . . . . . . . . . . . 34

3.2.5 Critérios para a reconstrução das estimativas rejeitadas . . . . . . . . 35

3.2.5.1 Método de amostragem direta . . . . . . . . . . . . 36

3.3 Métodos baseados na flutuação diária do nível piezométrico . . . . . 38

3.3.1 Método de White . . . . . . . . . . . . . . . . . . . 40

3.3.2 Método de Dolan . . . . . . . . . . . . . . . . . . . . . 41

3.3.3 Método de Hays . . . . . . . . . . . . . . . . . . . . . 41

3.3.4 Método de Gribovski . . . . . . . . . . . . . . . . . . . . . . 41

3.3.5 Método de Loheide II . . . . . . . . . . . . . . . . . . . . 42

3.3.6 Método de Soylu . . . . . . . . . . . . . . . . . . . . . . . . 42

3.3.7 Rendimento específico transiente . . . . . . . . . . . . . . 43

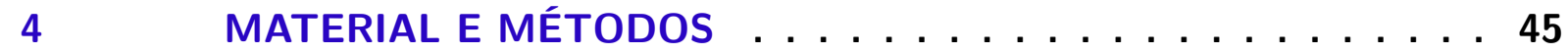

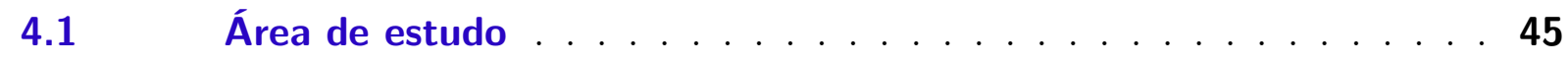

$4.1 .1 \quad$ Localização . . . . . . . . . . . . . . . . . . . . . . . 45

$4.2 \quad$ Climatologia . . . . . . . . . . . . . . . 46

$4.3 \quad$ Rede de monitoramento na zona ripária . . . . . . . . . . 47

4.3.1 Torre de monitoramento . . . . . . . . . . . . . . . . . 47

4.3.1.1 Aquisição de dados . . . . . . . . . . . . . . . . . . . . . . 48

4.3.2 Poços de monitoramento . . . . . . . . . . . . . . . . . 49 
$4.4 \quad$ Estimativas de evapotranspiração . . . . . . . . . . . . 50

4.4.1 Método de balanço de energia - Razão de Bowen . . . . . . . . . . . . . 50

4.4.1.1 Validação da reconstrução . . . . . . . . . . . . . . . . 50

4.4.2 Métodos baseados na flutuação diária do nível piezométrico . . . . . . . . . 51

$4.5 \quad$ Validação das estimativas . . . . . . . . . . . . . . 51

4.5.1 Metricas para medir a correlação entre duas variáveis . . . . . . . . . . . 52

4.5.1.1 Coeficiente de correlação de Pearson . . . . . . . . . . . . . . 52

4.5.1.2 Coeficiente de correlação de postos de Spearman . . . . . . . . . . . . . . . 52

4.5.2 Metricas para medir a diferença entre duas variáveis . . . . . . . . . . . . 52

4.5.2.1 Erro absoluto médio . . . . . . . . . . . . . . . . . 52

4.5.2.2 Raiz do erro quadrático médio . . . . . . . . . . . . . . . 52

4.5.2.3 Erro de viés médio . . . . . . . . . . . . . . . . . . . . 53

5 RESUltAdOS E DISCUSSÕES . . . . . . . . . . . . 55

5.1 Monitoramento da zona ripária . . . . . . . . . . . . . 56

5.2 Evapotranspiração pelo método de balanço de energia - Razão de Bowen . . . . . . . . . . . . . . . . . . . 58

5.2.1 Rejeição de estimativas . . . . . . . . . . . . . . . 61

5.2 .2 Reconstrução de estimativas rejeitadas . . . . . . . . . . . . . . . 62

5.3 Evapotranspiração pelos métodos baseados na flutuação diária do nível piezométrico . . . . . . . . . . . . . . . . . 68

5.3.1 Preparação dos dados para a aplicação dos métodos . . . . . . . . . . 68

5.3.2 Evapotranspiração pelo método de White . . . . . . . . . . . . 70

5.3.3 Evapotranspiração pelo método de Dolan . . . . . . . . . . . . . . 73

5.3.4 Evapotranspiração pelo método de Hays . . . . . . . . . . . . . . . 74

5.3.5 Evapotranspiração pelo método de Gribovski . . . . . . . . . . . . . 74

5.3.6 Evapotranspiração pelo método de Loheide II . . . . . . . . . . . . . . 75

5.3.7 Evapotranspiração pelo método de Soylu . . . . . . . . . . . . . 76

5.3.8 Resultados de evapotranspiração dos métodos baseados na flutuação diária do nível piezométrico . . . . . . . . . . . . . . . . . . 76

5.4 Avaliação dos métodos baseados nas flutuações diárias do nível piezométrico usando o método de balanço de energia - Razão de Bowen . . . . . . . . . . . . . . . . . . . . 77

5.4.1 Avaliação do método de White e suas adaptações . . . . . . . . . . . . 78

5.4.2 Avaliação do método de Dolan . . . . . . . . . . . . . . . . . . . 80

5.4.3 Avaliação do método de Hays . . . . . . . . . . . . . . 81

5.4.4 Avaliação do método de Soylu . . . . . . . . . . . . . . . . . . 82

5.4.5 Avaliação do método de Loheide II . . . . . . . . . . . . . . . . . . 82

5.4.6 Avaliação do método de Gribovski . . . . . . . . . . . . . . . . . . 83

5.4.7 Métricas da avaliação . . . . . . . . . . . . . . . . . . 84 
APÊNDICE A - PROJETO DA BASE DA TORRE DE MONITORAMENTO105

APÊNDICE B - DADOS COLETADOS NA TORRE DE MONITORAMENTO PARA O DIA $30 / 06 / 2018 \ldots \ldots 107$

APÊNDICE C - PROFUNDIDADE DO NÍVEL PIEZOMÉTRICO . 111

C.1 Poço P27

C.2

Poço P30

C.3

Poço P31

C. 4

Poço P32

C.5

Poço P33

C.6

Poço P35

APÊNDICE D - CÓDIGO EM PYTHON . . . . . . . . . . 115

APÊNDICE E - RESULTADOS DE EVAPOTRANSPIRAÇÃO DO MÉTODO DA RAZÃO DE BOWEN . . . . . . 117

APÊNDICE F - RESULTADOS DE EVAPOTRANSPIRAÇÃO DOS MÉTODOS BASEADOS NA FLUTUAÇÃO DIÁRIA DO NÍVEL PIEZOMÉTRICO . . . . . . . . . 121

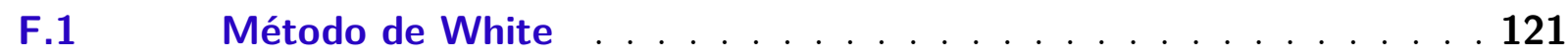

F.1.1 Adaptação de Rushton . . . . . . . . . . . . . . . . . . . . 122

F.1.2 Adaptação de Hays . . . . . . . . . . . . . . . . . . . . . 124

F.1.3 Adaptação de Loheide II . . . . . . . . . . . . . . . . . 126

F.1.4 Adaptação de Miller . . . . . . . . . . . . . . . . . . . 127

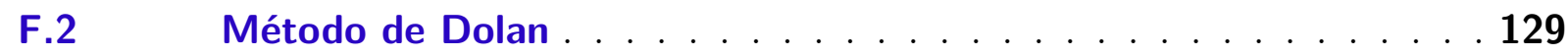

F.3 Método de Hays . . . . . . . . . . . . . . . . . . 131

F.4 Método de Gribovski . . . . . . . . . . . . . . . . . . 132

F.5 Método de Loheide II . . . . . . . . . . . . . . . . . . 134

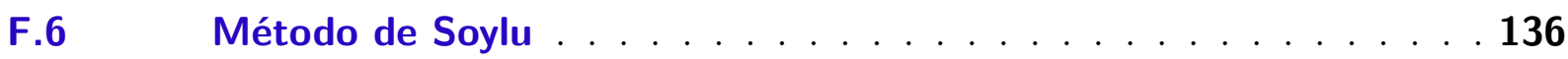





\section{Introdução}

Depois da precipitação, a evapotranspiração $(E T)$ é o principal componente do ciclo hidrológico, além de ser o segundo em ordem de grandeza, representa o intercâmbio de fluxos entre o sistema solo-planta-atmosfera. A ET é a ligação entre os ciclos energéticos e de carbono (YANG; ZHANG; HAO, 2016), varia de acordo com o clima, o tipo de vegetação e a fase fenológica das plantas. Dada sua importância, é necessário compreender os processos e as dinâmicas envolvidas.

Muitos estudos têm sido conduzidos para estimar a ET em diferentes tipos de vegetação e condições climáticas (NOSETTO; JOBBáGY; PARUELO, 2005; SAHA, 2015; WILSON et al., 2001). Mas, apesar das zonas ripárias apresentarem as maiores taxas de ET (JOHNSON et al., 2013; DEVITT et al., 1998; POBLADOR et al., 2019; HUXMAN et al., 2005; ZHANG; DAWES; WALKER, 2001), poucos estudos têm sido feitos nessas áreas.

Uma possível causa da pouca investigação nessas áreas é o alto custo do monitoramento da variável, pois devido a sua complexidade, requer-se o uso de equipamentos comerciais geralmente custosos e de difícil implementação. Adicionalmente, o pequeno tamanho das zonas ripárias, dificulta a aplicação dos métodos mais robustos existentes na atualidade (o Método de balanço de energia - Razão de Bowen e o Método de Eddy Covariance), pois precisam que a zona ripária tenha o tamanho suficiente para garantir que as características do ar na vizinhança dos equipamentos são representativas da zona ripária (WANG; DICKINSON, 2012).

Por outra parte, existem métodos mais acessíveis e de fácil implementação, como os baseados na flutuação diária do nível piezométrico, porém, as estimativas desses métodos ainda não foram avaliadas com as estimativas de algum dos métodos mais robustos.

Com o objetivo de avaliar os métodos baseados na flutuação diária do nível piezométrico, foi usado o método de balanço de energia - Razão de Bowen para estimar as taxas confiáveis de ET. Para tal fim, foram construídos uma torre e cinco poços de monitoramento em uma zona ripária da bacia hidrográfica do Ribeirão da Onça $(B R O)$, no município de Brotas, São Paulo, Brasil. 



\section{Objetivos}

\subsection{Geral}

- Avaliar as estimativas de evapotranspiração dos métodos baseados na flutuação diária do nível piezométrico comparando com o método de balanço de energia - Razão de Bowen em zona riparia;

\subsection{Específicos}

- Desenvolver uma ferramenta computacional, para facilitar a implementação dos métodos e realização de análises estatísticas;

- Estimar a evapotranspiração em zona ripária usando o método de balanço de energia - Razão de Bowen;

- Estimar a evapotranspiração em zona ripária usando os métodos baseados na flutuação diária do nível piezométrico;

- Comparar as estimativas de evapotranspiração dos métodos baseados na flutuação diária do nível piezométrico com as estimativas do método de balanço de energia Razão de Bowen. 



\section{Revisão bibliográfica}

\subsection{Evapotranspiração}

A ET é um conjunto de dois processos naturais: a vaporização a transpiração vegetal. A vaporização é um fenômeno físico de mudança de fase, do estado líquido para o gasoso, que ocorre numa extensa variedade de superfícies. A transpiração vegetal é um processo biológico, no qual, a água é removida do solo pelas raízes da planta, para depois, ser liberada na atmosfera em forma de vapor por meio dos estômatos (ALLEN et al., 1998).

Para que ocorra a ET, é necessária a separação das moléculas de água em estado líquido. A separação, é feita pela adição de energia ao sistema, sendo as principais formas de energia: o calor, a radiação, a pressão e a ação convectiva do ar (FISHER; WHITTAKER; MALHI, 2011).

Depois da precipitação, a ET é o maior componente do ciclo hidrológico (LUPON; LEDESMA; BERNAL, 2018; WANG; DICKINSON, 2012; YANG et al., 2017). Portanto, o entendimento do seu comportamento é essencial para uma melhor compreensão dos demais componentes e ciclos ligados à ET (FANG et al., 2016; LUPON et al., 2016).

A ET é controlada pelas características físicas da vegetação e do solo. Entre as características da vegetação, resalta-se a profundidade do sistema radicular, a quantidade de folhas, o índice de área foliar, a condutância estomatal, a área foliar exposta e o albedo (VERSTRAETEN; VEROUSTRAETE; FEYEN, 2008), e entre os fatores climáticos, resalta-se a radiação solar, a pressão atmosférica, a temperatura, a umidade e a velocidade do ar (MONTEITH, 1981; VERSTRAETEN; VEROUSTRAETE; FEYEN, 2008).

Segundo Trenberth, Fasullo e Kiehl (2009) entre $48 \%$ e $88 \%$ da radiação solar absorvida pela superfície terrestre e entre $50 \%$ e 90\% da precipitação (FORD et al., 2007; GHOLZ; CLARK, 2002; LU et al., 2003; SUN et al., 2002; YANG; ZHANG; HAO, 2016), são utilizadas no processo de $E T$.

Os maiores valores de ET são encontrados nas zonas ripárias devido à densa vegetação presente nessas áreas e ao fato de o sistema radicular estar em contato direto com o nível piezométrico ou com a zona de capilaridade (HUXMAN et al., 2005; JOHNSON et al., 2013; YEPEZ et al., 2003; ZHANG; DAWES; WALKER, 2001).

As zonas ripárias localizam-se entre os ecossistemas terrestres e aquáticos, como uma zona de transição que regula a transferência de energia e material entre os ecossistemas (PUSEY; ARTHINGTON, 2003). Adicionalmente, regulam a descarga e a quantidade de 
poluentes proveniente das zonas a montante (LUPON et al., 2016; POBLADOR et al., 2019), proveem estabilidade nos taludes (BEESON; DOYLE, 1995; LUPON et al., 2016), melhoram aspectos como a qualidade d'água, o habitat e a diversidade das espécies, e controlam a taxa metabólica dos micro-organismos, ou seja, alocam os recursos e definem o tamanho das populações (LUPON et al., 2016).

Apesar dos poucos estudos de ET feitos nas zonas ripárias (LAUTZ, 2008; PETRONE et al., 2006), nos últimos anos tem havido um crescente interesse na sua estimativa (GOODRICH et al., 2000; GRIBOVSZKI et al., 2008; LAUTZ, 2008; II, 2008; LUPON et al., 2016; LUPON; LEDESMA; BERNAL, 2018; MARTINET et al., 2009; NAGLER et al., 2005a; PETRONE et al., 2006; PUSEY; ARTHINGTON, 2003; SCOTT et al., 2008; SOYLU et al., 2012; ZHU et al., 2011; NAGLER et al., 2005b; JR. et al., 2007).

Os principais métodos de estimativa da ET são: o balanço hídrico, o lisimetro, o método de balanço de energia - Razão de Bowen, o Eddy covariance, o cintilômetro, o fluxo de seiva e o sensoriamento remoto (ALLEN et al., 2011). A ET é estimada em diferentes escalas espaciais (Tabela 1), desde a escala de folha até a escala regional/continental (FANG et al., 2016; VERSTRAETEN; VEROUSTRAETE; FEYEN, 2008).

Tabela 1 - Escalas espaciais e métodos para a estimativa da ET

\begin{tabular}{ccc}
\hline Escala & Princípio & Método \\
\hline \multirow{2}{*}{ Pontual, } & Balanço de massa & Porômetro \\
individual & Balanço de energia & Razão de Bódrico \\
& Combinação de balanços de & Plintômetro \\
& massa e energia & Penman-Monteith \\
& Balanço de energia & WAVE \& SWAP e SVATs \\
Floresta & Balanço hídrico & Eddy covariance \\
& Combinação de balanços de & Balanço hídrico \\
& massa e energia & SEBAL, PROMET, SWAP, \\
Regional $/$ & Combinação de balanços de & etc \\
Continental & massa e energia & SEBAL, PROMET, etc \\
\hline
\end{tabular}

Os métodos mais utilizados para o cálculo da ET nas zonas ripárias são os métodos baseados na flutuação diária do nível piezométrico (DOLAN et al., 1984; GRIBOVSZKI et al., 2008; HAYS, 2003; II, 2008; SOYLU et al., 2012; WHITE, 1932) e os métodos baseados em sensoriamento remoto (GOODRICH et al., 2000; NAGLER et al., 2005a; SCOTT et al., 2008; NAGLER et al., 2005b).

Outros métodos que foram utilizados nas zonas ripárias incluem o método de balanço 
hídrico (DOODY; BENYON, 2011), o método de fluxo de seiva (MOORE; CLEVERLY; OWENS, 2008), o método de balanço de energia - Razão de Bowen (DEVITT et al., 1998; GOODRICH et al., 2000; GUO et al., 2007; SCOTT et al., 2000) e o método de Eddy covariance (DEVITT et al., 2011; MARTINET et al., 2009; NAGLER et al., 2005a).

Na maioria dos métodos é aplicada alguma lei de conservação (massa ou energia) ou a combinação de ambas. A lei de conservação da massa para o sistema hidrológico é representada pela equação 3.1 .

$$
P-E T-E s c-Q-\frac{d S}{d t}=0
$$

Em que $P$ representa a precipitação $[L], E T$ a evapotranspiração $[L], E s c$ o escoamento superficial $[L], Q$ o fluxo lateral $[L]$ e $\frac{d S}{d t}$ a mudança de armazenamento de água no solo em um volume de controle $[L]$.

A lei de conservação da energia para uma superfície vegetada, é representada mediante a equação 3.2 .

$$
R_{N}-G-H-\lambda E T-M-S=0
$$

Em que $R_{N}$ representa a radiação liquida $\left[M T^{-3}\right], G$ o fluxo de calor sensível no solo $\left[M T^{-3}\right], H$ o fluxo de calor sensível no ar $\left[M T^{-3}\right], \lambda E T$ o fluxo de calor latente no ar $\left[M T^{-3}\right], M$ o fluxo de energia utilizado pelas plantas no processo de respiração e fotossíntese $\left[M T^{-3}\right]$ e $S$ a energia convertida em fito-massa $\left[M T^{-3}\right]$.

Com o fim de aprimorar as estimativas de ET em zonas ripárias, foi escolhido o método de balanço de energia - Razão de Bowen, pois é um dos métodos mais robustos existentes na atualidade, e dispõe-se do tamanho necessário para a aplicação do método na zona ripária em estudo.

\subsection{Método de balanço de energia - Razão de Bowen}

O método de balanço de energia - razão de Bowen determina as quantidades de energia que são trocadas e armazenadas no sistema. Em um sistema hidrológico, a energia interna é dividida em dois componentes: calor sensível e calor latente.

O calor sensível é a parte de energia interna que responde às variações de temperatura, e o calor latente é a parte da energia interna que muda o estado de fase (CHOW; MAIDMENT; MAYS, 2010).

Dado que o fluxo de energia utilizado pelas plantas no processo de respiração e fotossíntese $(M)$, e a energia convertida em fito-massa $(S)$, representam menos do $3 \%$ da 
energia absorvida pela vegetação (PEREIRA; SEDIYAMA; NOVA, 2013), seus termos podem ser desconsiderados da equaçaõ 3.2 sem induzir uma incerteza considerável.

Portanto, o balanço de energia simplificado para uma superfície vegetada (Figura 1) é expresso matematicamente na equação 3.3.

Figura 1 - Representação esquemática do balanço energético

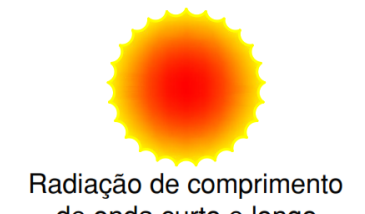

de onda curto e longo
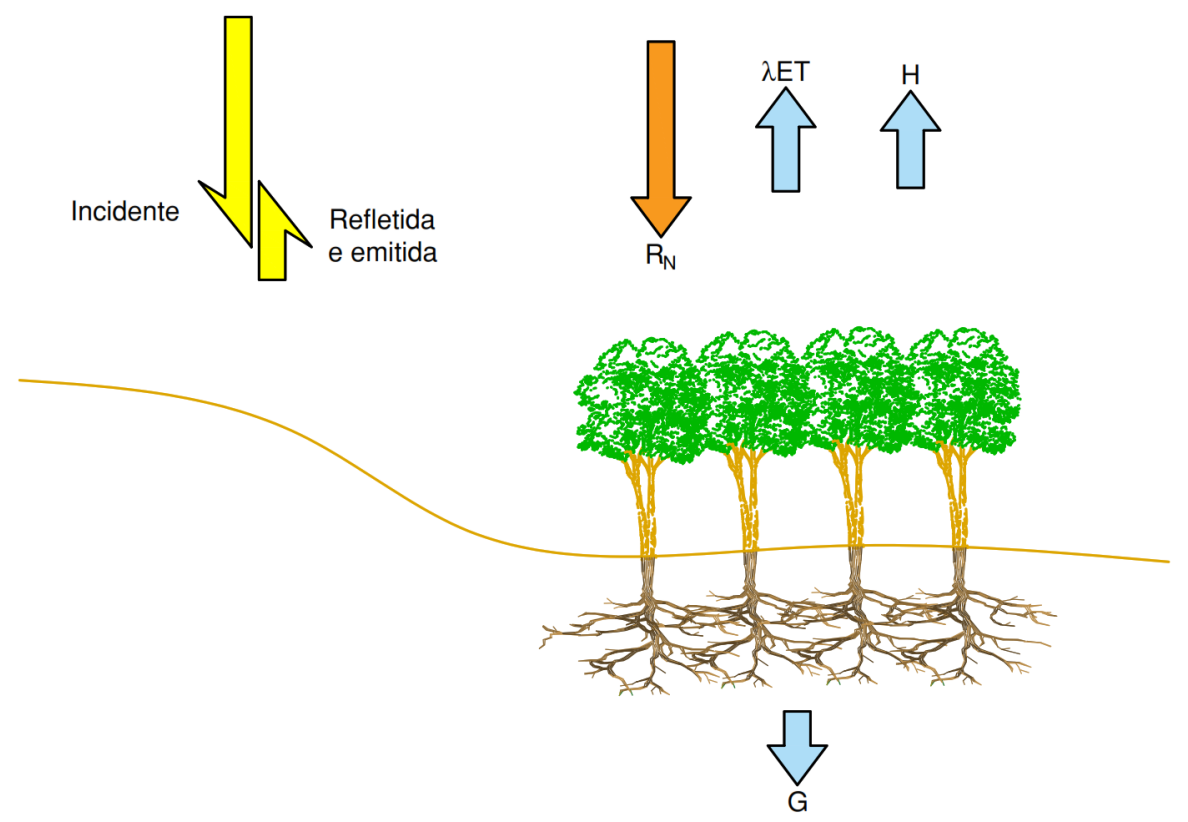

Fonte: Adaptado de DeMeo et al. (2003)

$$
R_{N} \approx \lambda E T+H+G
$$

Alguns termos da equação 3.3 são obtidos com relativa facilidade mediante equipamentos comercias (PEREIRA; SEDIYAMA; NOVA, 2013). A radiação líquida $\left(R_{N}\right)$ é obtida utilizando saldo radiômetro, o fluxo de calor sensível no solo $(G)$ é obtido por placas de fluxo, mas os fluxos de calor sensível $(H)$ e latente $(\lambda E T)$ apresentam muitos problemas na sua medição, devido à complexidade teórica envolvida no transporte turbulento de energia.

Bowen (1926) propôs uma solução ao problema de medição dos fluxos de calor ( $\lambda E T$ e $H$ ) mediante a introdução da chamada razão de Bowen $(\beta)$ (equação 3.4), a qual descreve o particionamento da energia disponível em cada um dos fluxos (TANNER; GREENE; BINGHAM, 1987). A razão de Bowen ( $\beta$ ), permite obter as magnitudes dos 
fluxos de calor de forma indireta, utilizando dados de temperatura e umidade relativa em duas alturas acima do dossel da vegetação.

$$
\beta=\frac{H}{\lambda E T}
$$

Introduzindo a razão de Bowen (equação 3.4) no balanço de energia para uma superficie vegetada (equação 3.3), é possivel expresar o fluxo de calor latente $(\lambda E T)$ em função da energia disponível $\left(R_{N}-G\right)$ (equação 3.5).

$$
\lambda E T=\frac{R_{N}-G}{1+\beta}
$$

O calculo da razão de ( $\beta$ ) Bowen (1926) baseia-se na teoria fluxo-gradiente (equação 3.6), a qual prevê que haverá um fluxo de uma propriedade no sentido da maior para a menor concentração (PEREIRA; SEDIYAMA; NOVA, 2013).

$$
F_{x}=-K_{x} \frac{d X}{d Z}
$$

Em que os sub índices $x$ representam a propriedade, $F_{X}$ o fluxo da propriedade, $K_{X}$ o coeficiente de difusão turbulenta da propriedade, $X$ o meio de deslocamento e $\frac{d X}{d Z}$ o gradiente de concentração da propriedade na direção $Z$. O sinal negativo na equação é utilizado para compensar o sinal negativo do gradiente, pois a concentração é maior na menor altura (PEREIRA; SEDIYAMA; NOVA, 2013).

\subsubsection{Fluxo de calor latente}

Aplicando a teoria do fluxo-gradiente no fluxo de calor latente $(\lambda E T)$,

$$
F_{X}=\lambda E T
$$

No meio de deslocamento $X$,

$$
X=\rho \lambda q
$$

Incluindo as equações 3.7 e 3.8 na equação 3.6, obtém-se a equação 3.9 ,

$$
\lambda E T=-K_{E} \frac{d(\rho \lambda q)}{d Z}
$$

Em que $K_{E}$ representa o coeficiente de difusão turbulenta de calor latente $\left[L^{2} T^{-1}\right]$, $\rho$ a densidade do ar $\left[M L^{-3}\right], \lambda$ o calor latente de evaporação (equação 3.10, tomada de 
Allen et al. (1998)) $\left[L^{2} T^{-2}\right]$ e $q$ a umidade específica (equação 3.11, tomada de PEREIRA, SEDIYAMA e NOVA (2013)).

$$
\begin{gathered}
\lambda=2,501-2,361 \times 10^{-3} T \\
q=\frac{0,622 e}{P}
\end{gathered}
$$

Em que $T$ representa a temperatura do ar $[K]$, e a pressão parcial do vapor d'água no ar (equação 3.12, tomada de Chow, Maidment e Mays (2010)) $\left[M L^{-1} T^{-2}\right]$ e $P$ a pressão atmosférica $\left[M L^{-1} T^{-2}\right]$.

$$
e=R H \times e_{s}
$$

Em que $R H$ representa a umidade relativa [\%] e $e_{s}$ a pressão de saturação do ar (equação 3.13, tomada de Ambaum (2010)) $\left[M L^{-1} T^{-2}\right]$.

$$
e_{s}=611,2 \exp \left(\frac{17.67 T}{T+243,5}\right)
$$

\subsubsection{Fluxo de calor sensível}

Aplicando a teoria do fluxo-gradiente no calor sensível $(H)$,

$$
F_{X}=H
$$

No meio de deslocamento $X$,

$$
X=\rho C_{p} T
$$

Incluindo as equações 3.14 e 3.15 na equação 3.6, obtém-se a equação 3.16,

$$
H=-K_{H} \frac{d\left(\rho C_{p} T\right)}{d Z}
$$

Em que $K_{H}$ representa o coeficiente de difusão turbulenta de calor sensível $\left[L^{2} T^{-1}\right]$, $C_{p}$ representa a capacidade de calor da mistura do ar a pressao constante (equação 3.17, tomada de Ambaum (2010)) $\left[L^{2} T^{-2} K^{-1}\right]$.

$$
C_{p}=(1-q) c_{p d}+q c_{p v}
$$

Em que $c_{p d}$ e $c_{p v}$ representam as capacidades de calor especifico do ar seco e da água $\left[L^{2} T^{-2} K^{-1}\right]$, respectivamente $\left(c_{p d}=1004, c_{p v}=1865\right)$ (AMBAUM, 2010). 


\subsubsection{Razão de Bowen}

Incluindo as equações 3.9 e 3.16 na equação 3.4, é obtida a equação 3.18,

$$
\beta=\frac{-K_{H} \frac{d\left(\rho C_{p} T\right)}{d Z}}{-K_{E} \frac{d(\rho \lambda q)}{d Z}}
$$

Considerando $\rho, C_{p}$ e $\lambda$ independentes da altura $Z$, e $K_{E}=K_{H}$, obtém-se a equação 3.19

$$
\beta=\frac{C_{p} d T}{\lambda d q}
$$

Introduzindo a definição do coeficiente psicométrico (equação 3.20),

$$
\gamma=\frac{C_{p} P}{0,622 \lambda} \times 10^{-3}
$$

Incluindo as equações 3.11 e 3.20 na equação 3.19 é gerada a equação 3.21 ,

$$
\beta=\gamma \frac{d T}{d e_{a}}
$$

Essa equação infinitesimal (equação 3.21) pode ser aproximada usando um quociente de diferenças na forma da equação 3.22 ,

$$
\beta=\gamma \frac{T_{1}-T_{2}}{e_{1}-e_{2}}
$$

Em que os subscritos 1 e 2 representam a posição do sensor inferior e superior, respectivamente, $T_{1}$ e $T_{2}$ representam as temperaturas e $e_{1}$ e $e_{2}$ representam as pressões de vapor d'água no ar.

No equacionamento feito por Bowen, os fluxos seguem a seguinte convenção, $R_{N}$ e $G$ são considerados positivos para baixo e $H$ e $\lambda E T$ são considerados positivos para cima (Figura 2). 
Figura 2 - Representação esquemática dos fluxos de energia sobre área florestada

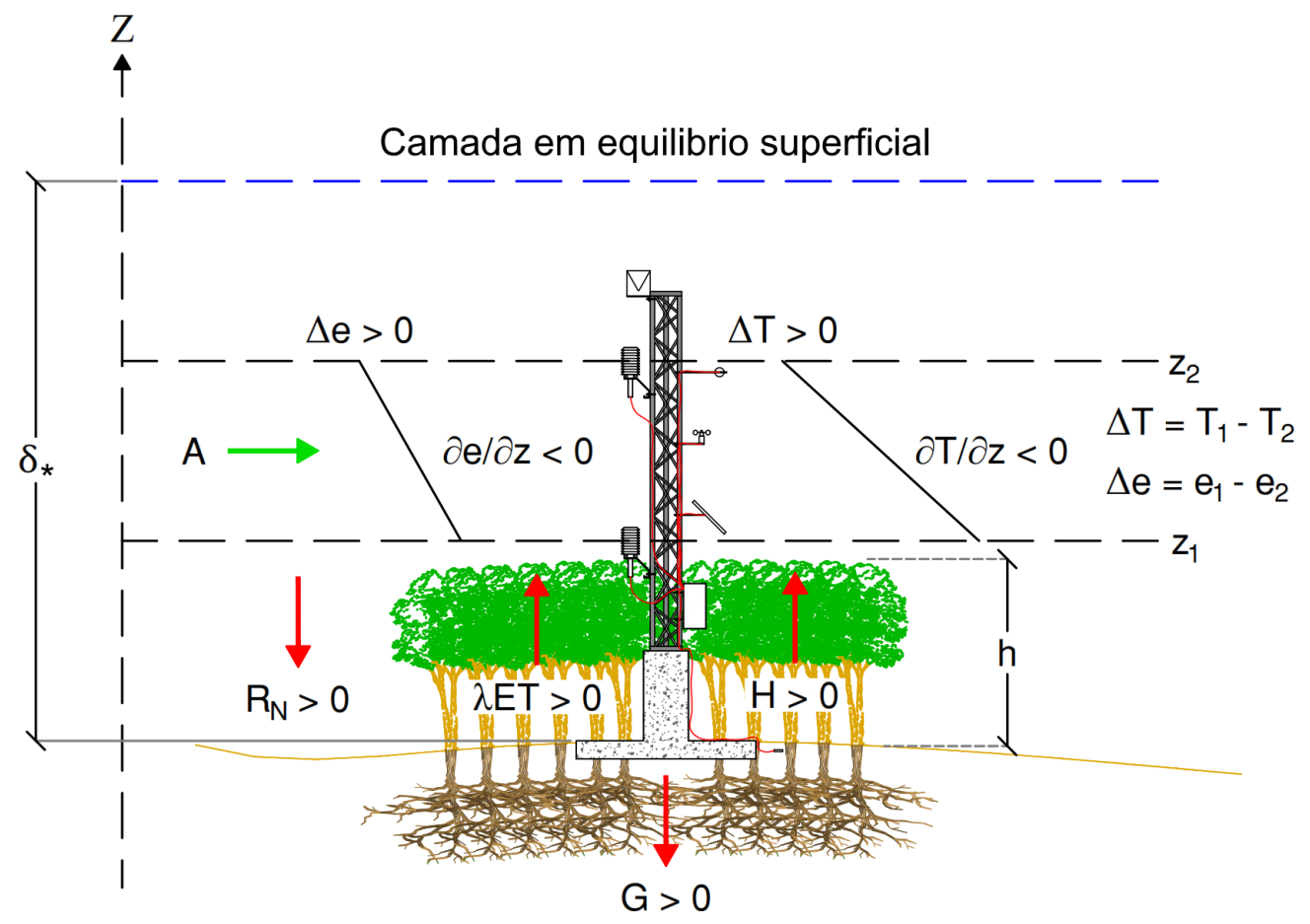

Fonte: Adaptado de Perez et al. (1999).

Para a aplicação correta do método de balanço de energia - razão de bowen, os gradientes de temperatura e umidade devem ser medidos dentro da camada limite interna $(\delta)$, preferencialmente na parte da camada em equilíbrio com a superfície $\left(\delta_{*}\right)$ (HEILMAN; BRITTIN; NEALE, 1989; PEREIRA; SEDIYAMA; NOVA, 2013).

A camada em equilíbrio com a superfície $\left(\delta_{*}\right)$ localiza-se nos primeiros $5 \%$ da altura da camada limite interna para transições de superfícies de alta a baixa rugosidade e nos primeiros $10 \%$ da altura da camada limite interna para transições de superfícies de baixa a alta rugosidade (HEILMAN; BRITTIN; NEALE, 1989).

A altura da camada limite interna é expressa pela equação de Munro e Oke (1975) (Equação 3.23).

$$
\delta=z_{o}^{0,2} x^{0,8}+d
$$

Em que $\delta$ representa a altura da camada limite interna $[L], z_{o}$ a altura que caracteriza a rugosidade da superfície $[L], x$ a bordadura necessária para que as medições sejam representativas da superfície $[L]$ e $d$ o deslocamento do plano de velocidade zero $[L]$.

Resultados de estudos aplicados sobre diferentes tipos de cultivo (PEREIRA; SEDIYAMA; NOVA, 2013) mostraram que pode-se considerar, 


$$
\begin{gathered}
d=0,67 h \\
z_{0}=a h \quad 0,10<a<0,15
\end{gathered}
$$

Com base na altura da vegetação $(h)$, é possível calcular todos os termos da equação 3.23 e isolar o termo $x$, para dessa forma, conhecer a tamanho mínimo necessário para a aplicação do método.

\subsubsection{Critérios de rejeição de estimativas}

O método de balanço de energia - Razão de Bowen apresenta três problemas principais. O primeiro deles é o inerente em todos os métodos de balanço: as incertezas na medição das variáveis de entrada são propagadas para as variáveis de saída (OHMURA, 1982; ORIANI et al., 2014; PEREZ et al., 1999; PAYERO et al., 2003).

O segundo problema refere-se ao sentido dos gradientes (Figura 2), isto é, à possibilidade de obter medições numericamente coerentes, mas com gradientes invertidos (OHMURA, 1982; PEREZ et al., 1999; PAYERO et al., 2003).

O terceiro problema refere-se à natureza assintótica da equação de balanço de energia com a inclusão da razão de Bowen, pois valores de $\beta$ perto de -1 produzem magnitudes discrepantes nos fluxos de calor (CELLIER; OLIOSO, 1993; OHMURA, 1982; ORTEGA-FARIAS; CUENCA; EK, 1996; PEREIRA; SEDIYAMA; NOVA, 2013; ROMANO; GIUDICI, 2009; TANNER; GREENE; BINGHAM, 1987).

Devido aos problemas anteriormente mencionados, existem critérios que devem ser cumpridos para que o conjunto de medições, em um instante de tempo, seja aceitável.

Entre os critérios existentes, é possível diferenciar 3 tipos de critérios: os baseados em princípios físicos (OHMURA, 1982; PEREZ et al., 1999), os baseados no valor da razão de Bowen (CELLIER; OLIOSO, 1993; ORTEGA-FARIAS; CUENCA; EK, 1996; TANNER; GREENE; BINGHAM, 1987) e os relacionados à lei de propagação de erros (ROMANO; GIUDICI, 2009).

\subsubsection{Critério de Ohmura}

Ohmura (1982) propôs uma série de critérios para a rejeição das estimativas, baseando-se nos três problemas mencionados anteriormente.

A primeira condição (inequação 3.26) considera o sentido dos gradientes, e a segunda (inequação 3.27), considera as incertezas nos instrumentos de medição e a distância da condição $\beta=-1$. As medições são aceitas, se a primeira condição é satisfeita e a segunda não. 


$$
\begin{gathered}
(\Delta e+\gamma \Delta T)\left(R_{N}-G\right)>0 \\
-\frac{1}{\gamma} \Delta R H-2\left(\frac{1}{\gamma} \delta \Delta R H+\delta \Delta T\right)<\Delta T<-\frac{1}{\gamma} \Delta R H+2\left(\frac{1}{\gamma} \delta \Delta R H+\delta \Delta T\right)
\end{gathered}
$$

Em que $\Delta R H$ representa o gradiente de umidade relativa do ar, $\delta \Delta R H$ e $\delta \Delta T$ representam as incertezas de umidade relativa e temperatura dos equipamentos de medição, respectivamente.

\subsubsection{Critério de Perez}

Perez et al. (1999), propuseram uma série de critérios baseando-se nos três anteriormente problemas mencionados.

A primeira condição é a mesma apresentada por Ohmura (1982) (inequação 3.26) e a segunda (inequação 3.28), apesar de basear-se no mesmo princípio, é expresso de outra forma. As medições são aceitas se a primeira condição for satisfeita e a segunda não.

$$
-1-|\varepsilon|<\beta<-1+|\varepsilon|
$$

Em que $\varepsilon$ representa o limite de aceitação (equação 3.29), $\delta \Delta e$ e $\delta \Delta T$ representam a incerteza dos equipamentos utilizados na medição da pressão de vapor de água no ar e a temperatura, respectivamente.

$$
\varepsilon=\frac{\delta \Delta e-\delta \Delta T}{\Delta e}
$$

\subsubsection{Critério de Tanner}

Tanner, Greene e Bingham (1987) propuseram um critério de rejeição simples, baseado unicamente no valor da razão de Bowen. As medições são rejeitadas, se a inequação 3.30 for satisfeita.

$$
-1,25<\beta<-0,75
$$

\subsubsection{Critério de Romano}

Romano e Giudici (2009), baseando-se na lei de propagação de erros, e diferente dos critérios de rejeição apresentados, propuseram um critério variável em função da razão entre a $E T$ e sua incerteza $\left(\sigma_{E T}\right)$ em cada instante de tempo.

Dada uma função $x$ definida em função das variáveis $u, v, \ldots$, 


$$
x=f(u, v, \ldots)
$$

A lei de propagação de erro é representada mediante a equação 3.32,

$$
\sigma_{x}^{2} \simeq \sigma_{u}^{2}\left(\frac{\partial x}{\partial u}\right)^{2}+\sigma_{v}^{2}\left(\frac{\partial x}{\partial v}\right)^{2}+\ldots+2 \sigma_{u v}^{2}\left(\frac{\partial x}{\partial u}\right)\left(\frac{\partial x}{\partial v}\right)+\ldots
$$

Em que $\sigma_{x}^{2}$ representa a variância da função $x, \sigma_{u}^{2}$ e $\sigma_{v}^{2}$ representam as variâncias das variáveis $u$ e $v$ respectivamente, e $\sigma_{u v}^{2}$ representa a covariância entre as variáveis $u$ e $v$.

Assumindo que as flutuações das variáveis $u$ e $v$ não estão correlacionadas, e que a distribuição dos valores positivos e negativos é a mesma (BEVINGTON et al., 1993), ou seja, o termo $\sigma_{u v}^{2} \approx 0$, a equação 3.32 pode ser reescrita na forma da equação 3.33 ,

$$
\sigma_{x}^{2} \simeq \sigma_{u}^{2}\left(\frac{\partial x}{\partial u}\right)^{2}+\sigma_{v}^{2}\left(\frac{\partial x}{\partial v}\right)^{2}+\ldots
$$

Romano e Giudici (2009) aplicaram a lei de propagação de erros (equação 3.33) nas equações utilizadas para estimar a ET. Finalmente as estimativas de ET são rejeitadas se a inequação 3.34 for satisfeita.

$$
\frac{\sigma_{E T}}{|E T|}>\varepsilon
$$

Em que $\sigma_{E T}[L]$ representa a incerteza associada à medição de $E T[L]$ e $\varepsilon$ representa o limite de aceitação $\left[L L^{-1}\right]$.

\subsubsection{Critérios para a reconstrução das estimativas rejeitadas}

Na maioria dos estudos em que é aplicado o método de balanço de energia - Razão de Bowen, não há grande preocupação com respeito à reconstrução das estimativas rejeitadas. Por exemplo, no estudo do Perez et al. (1999) foi avaliado o critério de rejeição proposto pelo mesmo autor em 4 estações de monitoramento localizadas na Catalunha, na região Nordeste da Espanha. Como resultado, entre 55,5\% e 69,0\% das medições foram rejeitadas, mas, nada foi discutido a respeito da reconstrução das mesmas.

Para a reconstrução de séries temporais de ET provenientes do método de balanço de energia - Razão de Bowen, trabalhos na literatura sugerem metodologias para tal finalidade com certas limitações. Por exemplo, Guo et al. (2007) recomendaram calibrar o coeficiente de Priestley-Taylor para algumas faixas horárias utilizando o conjunto de medições não rejeitadas, com o fim de aplicar o modelo nos instantes de tempo em que o conjunto de medições foi rejeitado. Porém, assumir que os valores do coeficiente de Priestley-Taylor (nas faixas horárias calibradas) permanecem constantes durante todo o 
período de monitoramento produz uma alta incerteza, pois não consideram a variabilidade das condições atmosféricas existentes durante grandes períodos de monitoramento.

Já PEREIRA, SEDIYAMA e NOVA (2013) recomendaram utilizar a média das medidas adjacentes, mas, apesar da sua simplicidade, o total de ET é subestimado dessa forma, devido à incapacidade de reconstruir corretamente as medições rejeitadas, se várias medições sucessivas forem excluídas da série temporal.

Como alternativa para evitar essas limitações, Comunian et al. (2018), Oriani et al. (2014), Oriani et al. (2016) recomendaram a aplicação de uma adaptação do método de amostragem direta (Direct Sampling, DS), o qual é uma técnica de geo-estatística de pontos múltiplos. O $D S$ foi desenvolvido originalmente como uma melhora dos métodos existentes na simulação do comportamento espacial de estruturas complexas (MARIETHOZ; RENARD; STRAUBHAAR, 2010; MARIETHOZ; CAERS, 2014).

A adaptação do Comunian et al. (2018), mostrou bons resulados $(N S E=0,72)$ na reconstrução de séries temporais de $E T$. Entre as características do método de amostragem direta resalta-se, $i$ ) a natureza estocástica do método, permite ter uma boa diversidade nos resultados das simulações, $i i$ ) o uso de um conjunto de medições não rejeitadas maior e a definição do limite de aceitação, permitem encontrar medições com valores similares entre o conjunto analizado e o conjunto na vizinhança do instante a ser reconstruído, iii) o fato de não utilizar equações ou princípios físicos adicionais que possam introduzir um erro sistemático na reconstrução.

Dessa forma o método de amostragem direta, apresenta a maior aplicabilidade dos métodos usados na reconstrução de series temporais de ET do método de balanço de energia - Razão de Bowen.

\subsubsection{Método de amostragem direta}

O processo do método de amostragem direta (Figura 3), simula uma função aleatória $Z(x)$ para representar os complexos comportamentos das estruturas presentes na simulação (MARIETHOZ; RENARD; STRAUBHAAR, 2010). Os dados de entrada são:

- O grid de simulação $(S G)\left(x_{i}\right)$,

- Os grids correspondentes às imagens de treinamento $(T I)\left(y_{i}\right)$,

- O número máximo de vizinhos $(N)$,

- A distância limite de aceitação entre eventos $(\sigma)$ e,

- A fração da imagem de treinamento que será percorrida $(f)$. 
Figura 3 - Processo do algoritmo de amostragem direta $(D S)$
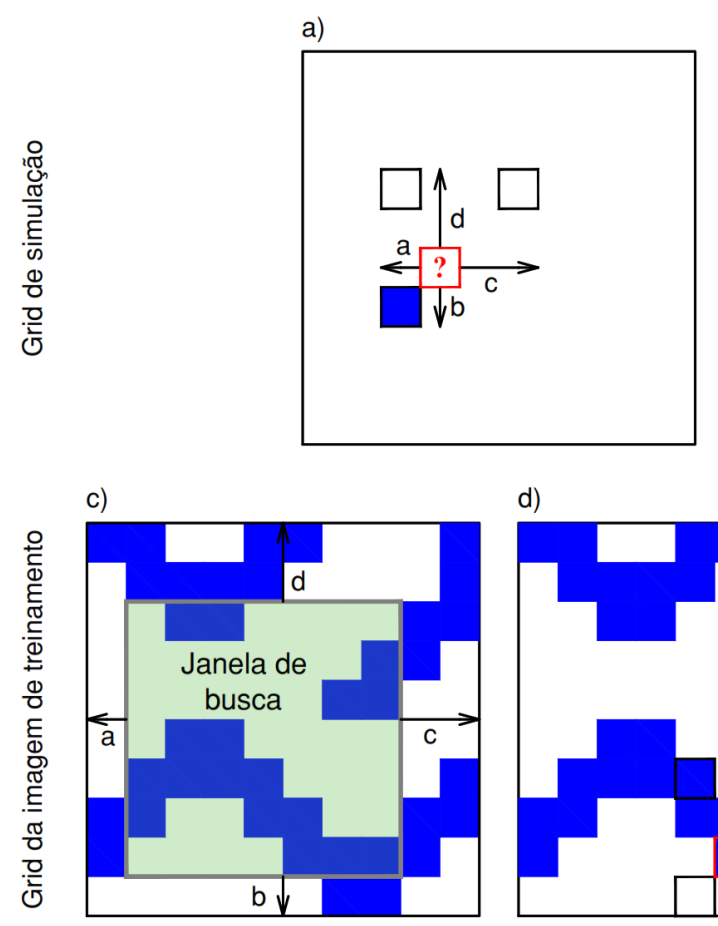

d)

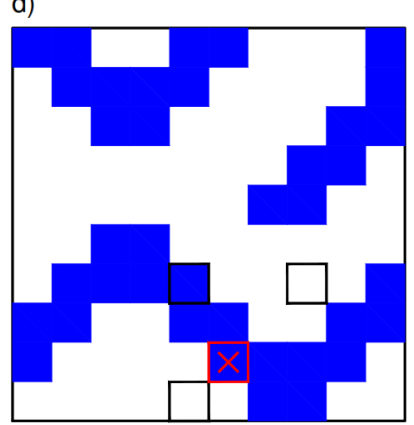

e)

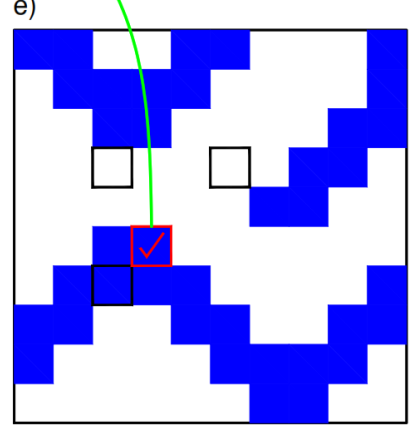

Fonte: Adaptado do Mariethoz, Renard e Straubhaar (2010)

Para a correta aplicação do algoritmo na reconstrução de falhas em séries temporais, Oriani et al. (2014) propuseram as seguintes modificações:

1. A TI corresponde aos instantes de tempo com os valores não rejeitados de $E T$,

2. O $S G$ corresponde a todos os instantes da série temporal (valores aceitados e rejeitados),

3. O $f$ corresponde ao raio de busca $(R)$.

A seguir, são apresentados os principais passos do método de amostragem direta,

Sendo $t=\left\{t_{1}, t_{2}, t_{3}, \ldots, t_{n}\right\}$ os instantes de tempo com valores rejeitados, e $\tau=$ $\left\{\tau_{1}, \tau_{2}, \tau_{3}, \ldots, \tau_{n}\right\}$ a série temporal inteira.

1. É feita uma normalização com uma relação de escala linear $(-1<E T<1)$. Se existem covariáveis, devem ser normalizadas a fim de homogeneizar as distâncias entre os eventos.

2. Aleatoriamente é escolhido um instante de tempo rejeitado, $t_{i}$.

3. A partir de $t_{i}$ é selecionado o conjunto de $\tau$ tais que $\tau_{j} \epsilon \tau,\left|t_{i}-\tau_{j}\right|<R$ e $i \leq N$ para determinar os dados do evento $d(S G)_{i}=E T\left(\tau_{j}\right)$. 
4. A $T I$ é percorrida aleatoriamente até um instante $\tau_{k}\left(\tau_{k} \epsilon \tau\right)$ em que $\left|d(S G)_{i}-d(T I)_{k}\right|<$ $\sigma$.
a) Se a condição anterior for satisfeita $E T\left(t_{i}\right)=E T\left(\tau_{j}\right)$,
b) Se não, é escolhido o $\min \left(\left|d(S G)_{i}-d(T I)_{k}\right|\right)$ para reconstruir o instante $t_{i}$.

5. O instante de tempo preenchido é adicionado aos instantes de tempo com valores não rejeitados e o processo continua até que todos os instantes de tempo rejeitados sejam reconstruídos.

\subsection{Métodos baseados na flutuação diária do nível piezométrico}

A estimativa da ET em zonas ripárias baseada na flutuação diária do nível piezométrico é feita usando poços de monitoramento. Os poços de monitoramento, são considerados uma fonte importante de informação para o entendimento dos processos ecossistêmicos, hidrológicos e bioquímicos envolvidos (DREXLER et al., 2004; GOODRICH et al., 2000; LAUTZ, 2008; II, 2008; LUPON; LEDESMA; BERNAL, 2018; MARTINET et al., 2009; PETRONE et al., 2006; PUSEY; ARTHINGTON, 2003; RAHGOZAR; SHAH; ROSS, 2012; TROXELL, 1936; WHITE, 1932).

Os métodos baseados na flutuação diária do nível piezométrico, apresentam vantagens em comparação aos demais métodos, como o baixo custo de monitoramento, a fácil implementação das metodologias e a simplicidade dos cálculos (LAUTZ, 2008; SATCHITHANANTHAM; WILSON; GLENN, 2017; SOYLU et al., 2012; II; JR.; GORELICK, 2005). Embora, apresentam desvantagens como o alto grau de incertezas relacionadas à determinação do rendimento específico transiente (FAHLE; DIETRICH, 2014; GRIBOVSZKI et al., 2008; II, 2008; II; JR.; GORELICK, 2005) e a perda de dados em eventos de precipitação e dias subsequentes.

O primeiro estudo que explorou a possibilidade de utilizar as flutuações diárias do nível piezométrico para a estimativa da ET foi realizado por White (1932), o qual observou a partir do comportamento ondulatório do nível piezométrico (Figura 4) que durante as horas de sol, o nível sofria um rebaixamento, e após o pôr-do-sol, sofria uma recuperação. O rebaixamento é relacionado com a $E T(E T>r)$ e a recuperação com a recarga lateral $(E T<r)$ das áreas vizinhas. 
Figura 4 - Variação do nível piezométrico

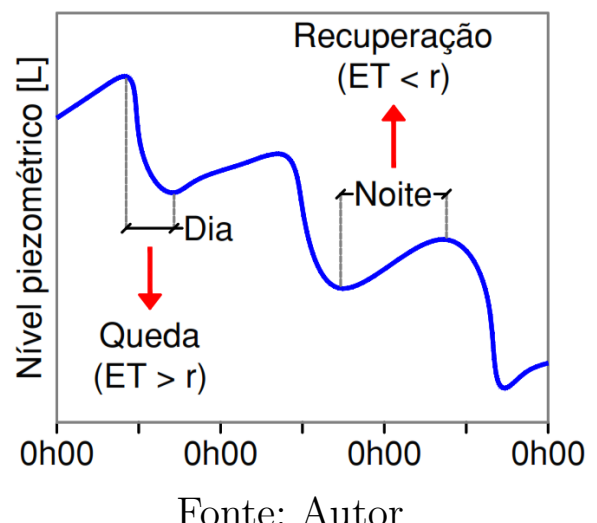

A partir do estudo do White (1932) surgiram modificações ou novos métodos para estimar a ET em base às flutuações diárias do nível piezométrico (DOLAN et al., 1984; GRIBOVSZKI et al., 2008; HAYS, 2003; II, 2008; MILLER et al., 2010; RUSHTON, 1996; SOYLU et al., 2012).

Uma limitação desses métodos é que só podem ser aplicados em dias sem eventos de precipitação, devido à alteração que a chuva causa no comportamento do nível piezométrico na zona ripária. Nos dias sem precipitação, a ET pode ser estimada com os dados do nível piezométrico a partir da lei de conservação de massa (equação 3.1) na forma da equação 3.35 .

$$
E T=r-\frac{d h}{d t}
$$

Em que $r$ representa a recarga lateral das áreas vizinhas $[L]$ e $\frac{d h}{d t}$ a variação do nível piezometrico.

A partir desse raciocínio, diversos autores propuseram estimar a recarga lateral no período de recuperação (DOLAN et al., 1984; HAYS, 2003; II, 2008; WHITE, 1932), pois nesse período a $E T$ é tão pequena em comparação à recarga lateral que pode ser considerada como zero.

Outros autores (GRIBOVSZKI et al., 2008; II, 2008) propuseram estimar a recarga lateral como uma função do tempo, dado que Troxell (1936) demostrou, que a recarga lateral varia ao longo do dia.

Para o cálculo da ET na zona ripária a partir dos dados da flutuação diária do nível piezométrico, foram escolhidos 6 métodos (Figura 5), com o objetivo de avaliar as estimativas de ET de cada um dos métodos, com as estimativas de ET do método de balanço de energia - Razão de Bowen. 
Figura 5 - Representação esquemática de 6 métodos para o cálculo da $E T$ em base às flutuações diárias do nível piezométrico
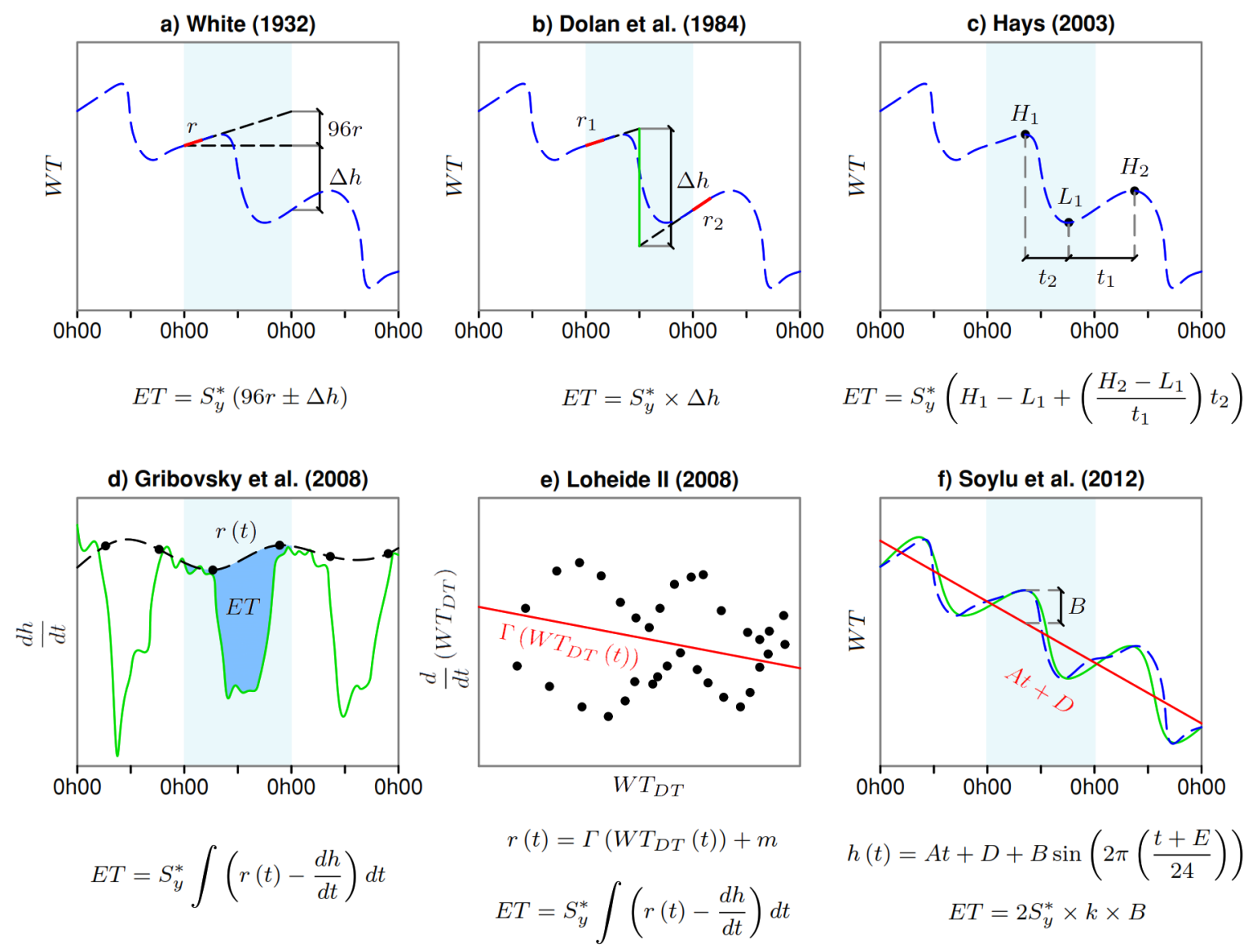

Cada um das $0 h 00$ presentes no eixo das abscissas corresponde a dias diferentes Fonte: Adaptado do Fahle e Dietrich (2014)

\subsubsection{Método de White}

White (1932) a partir das flutuações diárias do nível piezométrico, propôs o cálculo da ET (Figura 5a) na foma da equação 3.36.

$$
E T=S_{y}^{*}(96 r \pm \Delta h)
$$

Em que $S_{y}^{*}$ representa o rendimento específico transiente [\%] (item 3.3.7), $r$ a recarga lateral $[L]$ e $\Delta h$ a queda diária do nível piezométrico $[L]$ entre a meia-noite do dia em questão e meia-noite do dia seguinte. A recarga lateral $(r)$, é obtida estimando a tendência do nível piezométrico entre $0 h 00$ - $4 h 00$ do dia em questão.

Os autores seguintes, propuseram mudanças no período de tempo utilizado no cálculo da recarga lateral no método de White (1932). Rushton (1996) considerou um período de tempo entre as $18 h 00$ do dia anterior e as $6 h 00$ do dia em questão, Hays (2003) considerou um período de tempo entre $0 h 00-4 h 00$ do dia seguinte, II (2008) considerou 
o cálculo da recarga lateral, como a média das tendências do dia em questão e do dia seguinte entre $0 h 00-6 h 00$, Miller et al. (2010) diferente dos outros autores, considerou o cálculo da recarga lateral, como a média das tendências do dia em questão e do dia seguinte entre as $20 h 00-7 h 00$.

\subsubsection{Método de Dolan}

Dolan et al. (1984) propuseram o cálculo da ET (Figura 5b) na forma da equação 3.37 .

$$
E T=S_{y}^{*} \times \Delta h
$$

Em que $\Delta h$ representa a queda do nível piezométrico $[L]$ entre as extrapolações das recargas laterais às $12 h 00$ do dia em questão.

As recargas laterais são calculadas da mesma forma e no mesmo período que no método de White (1932).

\subsubsection{Método de Hays}

Hays (2003) propôs o cálculo da ET (Figura 5c) na forma da equação 3.38.

$$
E T=S_{y}^{*}\left(H_{1}-L_{1}+\left(\frac{H_{2}-L_{1}}{t_{1}}\right) t_{2}\right)
$$

Em que, $H_{1}$ representa o nível máximo $[L]$ do dia em questão, $L_{1}$ o nível mínimo $[L]$ do dia em questão, $H_{2}$ o nível máximo $[L]$ do dia seguinte, $t_{1}$ o tempo $[T]$ entre $L_{1}$ e $H_{2}$, e $t_{2}$ o tempo [T] entre $H_{1}$ e $L_{1}$.

A recarga lateral é considerada no termo $\frac{H_{2}-L_{1}}{t_{1}}$ e a variação no armazenamento no termo $H_{1}-L_{1}$.

\subsubsection{Método de Gribovski}

Gribovszki et al. (2008) propuseram o cálculo da taxa de recarga lateral com duas abordagens, uma empírica e outra hidráulica.

A abordagem empírica emprega a equação de Darcy, se o fluxo é predominantemente vertical, caso contrário, é utilizada a equação de Darcy na forma da aproximação de Dupuit.

A abordagem hidráulica calcula a maior e a menor recarga lateral do dia, escolhendo a maior taxa de variação do nível piezométrico $\max \left(\frac{d h}{d t}\right)$ e a média das taxas de variação entre $0 h 00-6 h 00$, respectivamente. A maior e a menor recarga lateral são assignadas aos instantes de tempo correspondentes ao nível mínimo e máximo, respectivamente. 
Finalmente a recarga lateral horária é obtida pela interpolação spline quadrática das recarga laterais.

Dado que os parâmetros necessários para aplicação da abordagem hidráulica não estão disponíveis para o sítio em estudo, a recarga lateral foi calculada utilizando a abordagem empírica.

Em conclusão, a ET (Figura 5d) é obtida usando a equação 3.39.

$$
E T=S_{y}^{*} \int\left(r(t)-\frac{d h}{d t}\right) d t
$$

\subsubsection{Método de Loheide II}

II (2008) definiu a taxa de recarga lateral como uma função do gradiente hidráulico entre o ponto de medição e a fonte de recuperação. Assumindo que nos pontos mencionados a variação dos níveis piezométricos é similar, II (2008) propôs remover a tendência horária do nível piezométrico, para dessa forma, fazer que o gradiente dependa apenas do ponto de medição (Figura 5e).

A remoção da tendência é feita considerando um intervalo de tempo de $6 h 00$ antes e depois do dia em questão.

A recarga lateral horária é obtida usando equação 3.40.

$$
r(t)=\Gamma\left(W T_{D T}(t)\right)+m
$$

Em que $r(t)$ representa a recarga lateral horária $[L], \Gamma\left(W T_{D T}(t)\right)$ o modelo linear que descreve a relação existente entre o nível piezométrico sem tendência $\left(W T_{D T}\right)$ e sua variação temporal $\left(\frac{d}{d t}\left(W T_{D T}\right)\right)$ entre $0 h 00-6 h 00$ para o dia em estudo e o dia seguinte e $m$ representa a tendência do nível piezométrico do dia em questão.

A ET é calculada com a equação 3.39 do método de Gribovszki et al. (2008).

\subsubsection{Método de Soylu}

Soylu et al. (2012) propuseram utilizar técnicas de Fourier para estimar a ET, dado o comportamento periódico e frequentemente ondulatório do nível piezométrico. A recarga lateral é considerada constante ao longo do dia, mas seu valor não é determinado explicitamente.

Para estimar a ET é necessario ajustar o nível piezométrico à equação 3.41 (Figura 5f) usando uma janela móvel de um dia.

$$
h(t)=A t+D+B \sin \left(2 \pi\left(\frac{t+E}{24}\right)\right)
$$


Em que $A$ representa a tendência do nível piezométrico $\left[L T^{-1}\right], t$ o tempo em horas $[T], D$ o viés médio $[L], B$ a amplitude diária $[L]$, e $E$ a fase diária do sinal $[T]$.

A ET é estimada mediante a equação 3.42 .

$$
E T=2 \times S_{y}^{*} \times k \times B
$$

Em que $k$ representa o fator de escala, o qual depende do ciclo de radiação solar. O fator de escala pode ser estimado como $i$ ) a somatória da radiação solar dividida pelo tempo de radiação solar sem tendência, ii) em base à teoria de radiação de céu limpo, ou iii) pode ser assumido como 1,90 (SOYLU et al., 2012). Para esse trabalho foi assumido $k=1,90$.

\subsubsection{Rendimento específico transiente}

Nos métodos anteriores, o valor de ET estimado deve ser multiplicado pelo rendimento específico $\left(S_{y}\right)$ (Figura 6) para converter a variação de armazenamento d'água no solo em volume d'água (FAHLE; DIETRICH, 2014).

Figura 6 - Representação do conceito de rendimento especifico

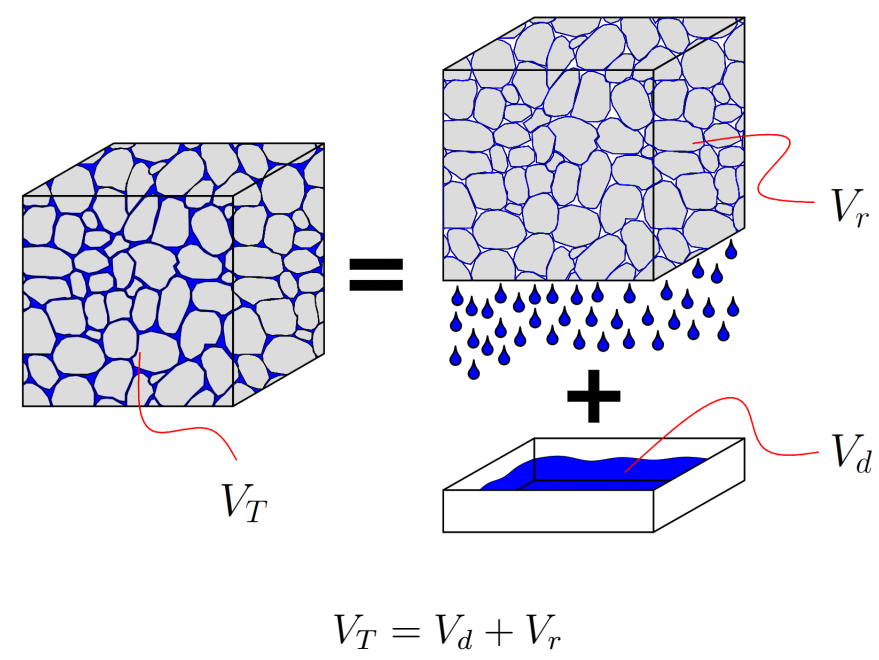

Fonte: Autor

O rendimento específico representa a relação existente entre o volume d'água drenado por gravidade $\left(V_{d}\right)$ e o volume total de uma amostra $\left(V_{T}\right)$ (HEALY; COOK, 2002), ou seja, representa a diferença entre a porosidade total e a retenção específica $\left(\frac{V_{r}}{V_{T}}\right)$ (CROSBIE; BINNING; KALMA, 2005).

No conceito dado, o rendimento específico representa um valor constante, mas na realidade, é variável, pois depende da fatores como a profundidade do nível d'água, o tempo de drenagem, as condições de umidade antecedentes e as atividades das plantas 
(CHILDS, 1960; DUKE, 1972; LOGSDON et al., 2010; MEYBOOM, 1965; NACHABE, 2002; II; JR.; GORELICK, 2005).

Meyboom (1965) propôs um novo termo que considerasse os fatores anteriormente mencionados, o novo termo foi chamado de rendimento especifico transiente, e representa a quantidade d'água liberada na zona vadosa a partir das flutuações diárias do nível piezométrico, com dependência temporal.

Mediante uma modernização do funil de Haines, uma balança de precisão e um computador, Ponton (2017) determinou o rendimento especifico transiente $\left(S_{y}^{*}=13,90 \pm 0,31 \%\right)$ da zona ripária da Bacia do Ribeirão da Onça $(B R O)$, mesma área de estudo da presente dissertação. 


\section{Material e métodos}

\section{1 Área de estudo}

\subsubsection{Localização}

O presente estudo foi desenvolvido na bacia hidrográfica do Ribeirão da Onça $(B R O)$, uma sub-bacia do rio Jacaré-Guaçu, afluente do rio Tietê. Essa bacia está localizada no município de Brotas, São Paulo, Brasil entre as coordenadas $22^{\circ} 10^{\prime}$ e $22^{\circ} 15^{\prime}$ de latitude sul, e $47^{\circ} 55^{\prime}$ e $48^{\circ} 00^{\prime}$ de longitude oeste (Figura 7). A BRO tem a característica especial de estar dentro da área de afloramento do Sistema Aquífero Guarani $(S A G)$, o qual é um dos principais aquíferos no mundo, já que possui um volume de, aproximadamente, $57 * 10^{2} \mathrm{~km}^{3}$ de água (PONTON, 2017).

Figura 7 - Localização da bacia hidrográfica do Ribeirão da Onça $(B R O)$

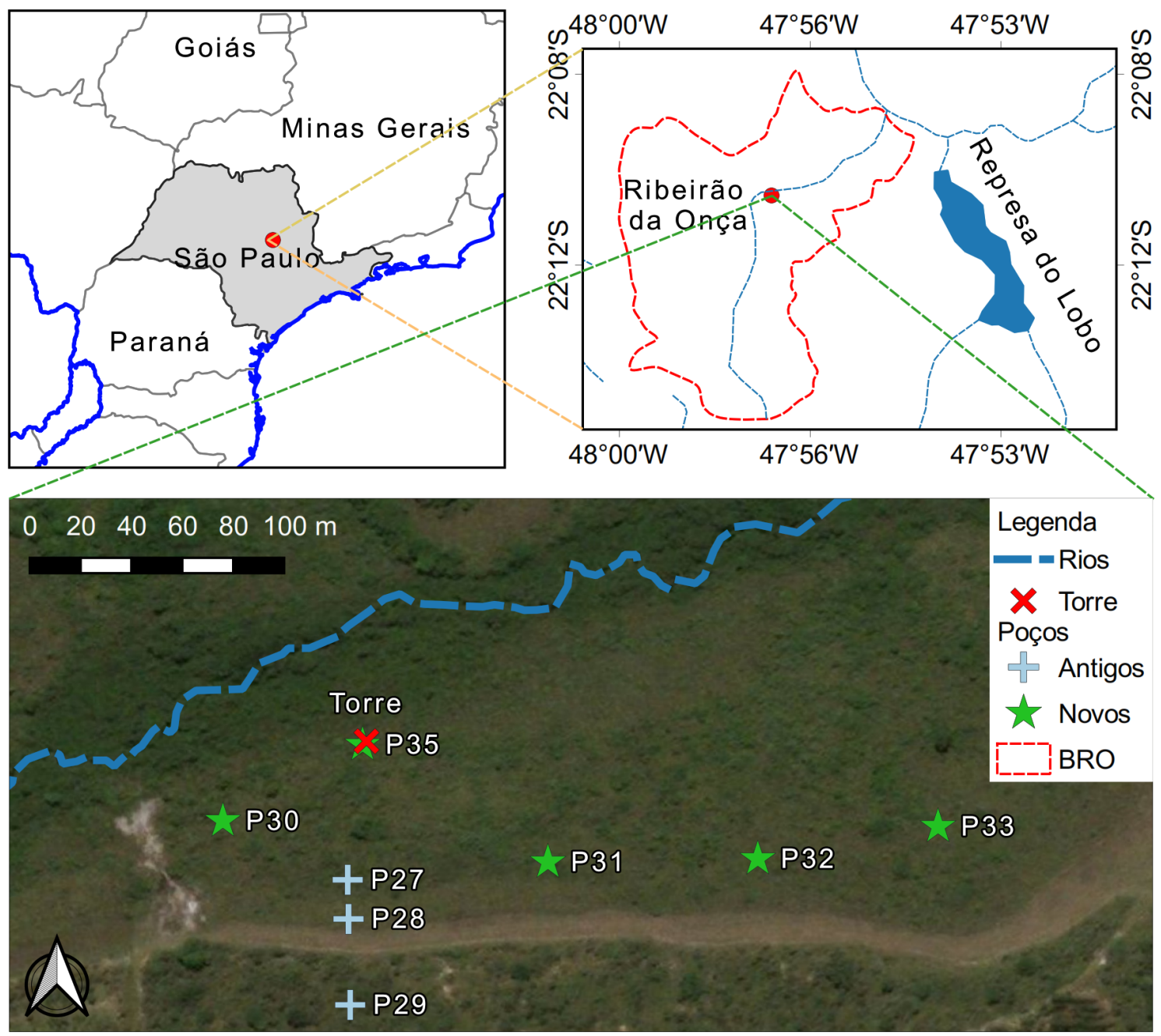

Fonte: Autor 
Figura 8 - Bacia hidrográfica do Ribeirão da Onça (BRO)

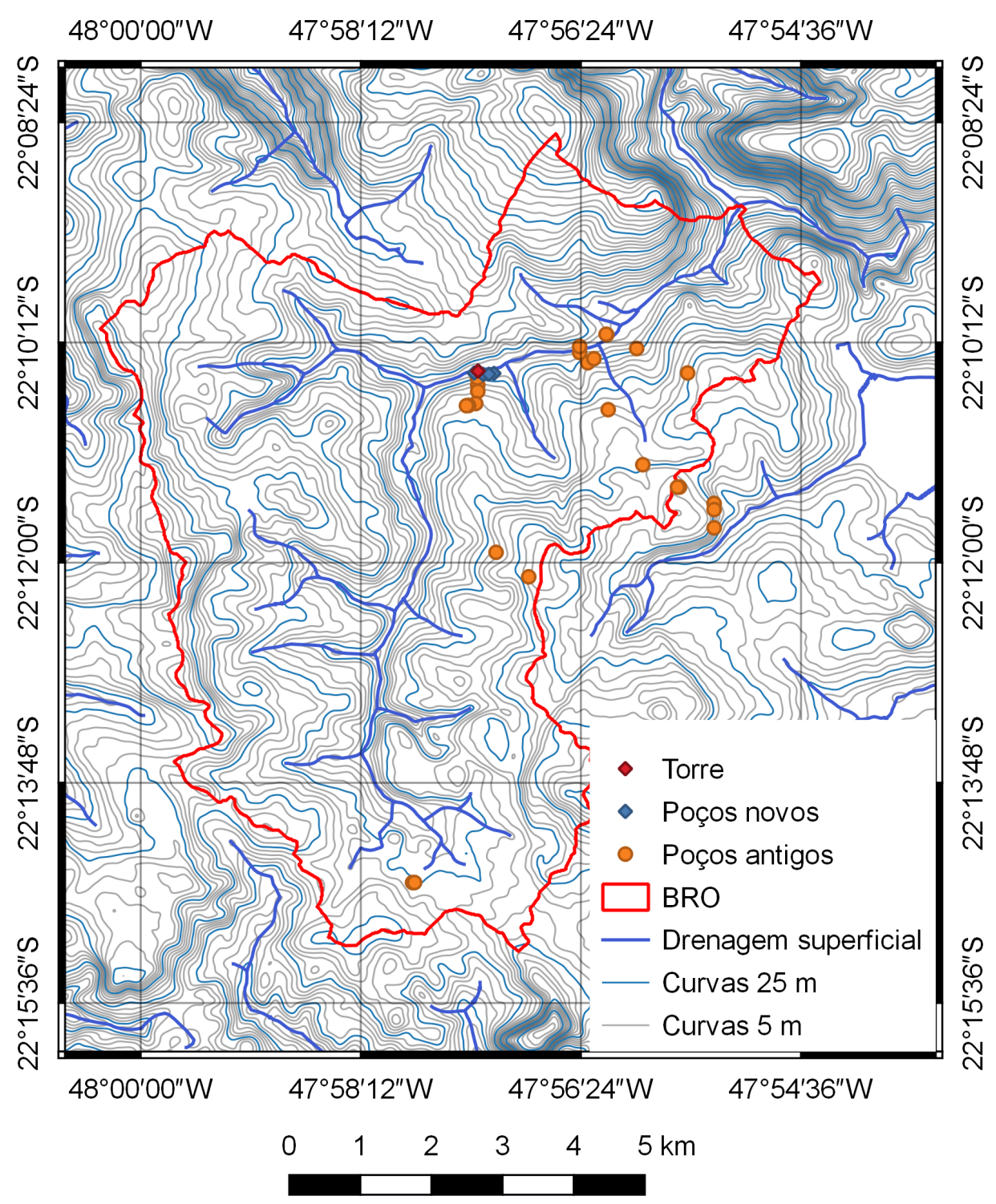

Fonte: Autor

\subsection{Climatologia}

Segundo a classificação climática Köppen-Geiger, o clima da bacia hidrográfica do Ribeirão da Onça é Cwa, sendo subtropical com chuvas de verão e um inverno seco (OLIVEIRA et al., 1997). Mediante a análise dos dados da estação climatológica, do Centro de Recursos Hídricos e Estudos Ambientais (CRHEA-USP), observaram-se médias anuais para temperatura e umidade relativa de, respectivamente, $21,6{ }^{\circ} \mathrm{C}$ e $71 \%$ (CABRERA et al., 2016). 


\subsection{Rede de monitoramento na zona ripária}

\subsubsection{Torre de monitoramento}

A fim de estimar a ET utilizando o método de balanço de energia - Razão de Bowen, foi construída uma torre de monitoramento (Figura 9), na qual foram instalados equipamentos de medição (Tabela 2) para coletar dados de radiação, umidade, temperatura e calor no solo.

Figura 9 - Equipamentos instalados na torre de monitoramento

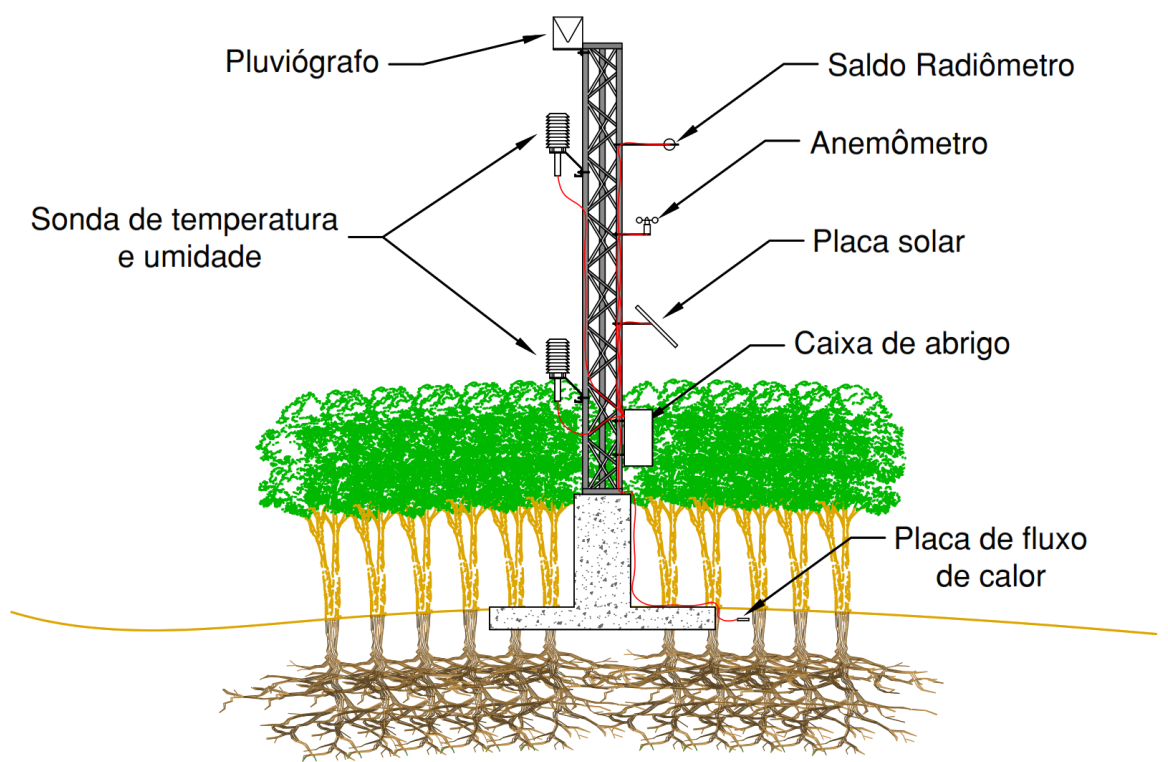

Fonte: Autor

A estrutura da torre de monitoramento consta de 3 partes: $i)$ a base $(2,00 \times 2,00 \mathrm{x}$ $0,30 \mathrm{~m})$ e o pedestal $(0,50 \times 0,50 \times 1,00 \mathrm{~m})$ em concreto reforçado de $21 \mathrm{MPa}$ (Figura 10a) (Apêndice A), ii) a estrutura metálica $(0,30 \times 0,30 \times 5,00 \mathrm{~m})$ no qual foram fixados os equipamentos de medição (Figura 10b), e iii) os três blocos de contrapeso $(0,30$ x 0,30 x $0,60 \mathrm{~m})$. 
Figura $10-a$ ) Construção da base e do pedestal, b) Equipamentos instalados na torre metálica

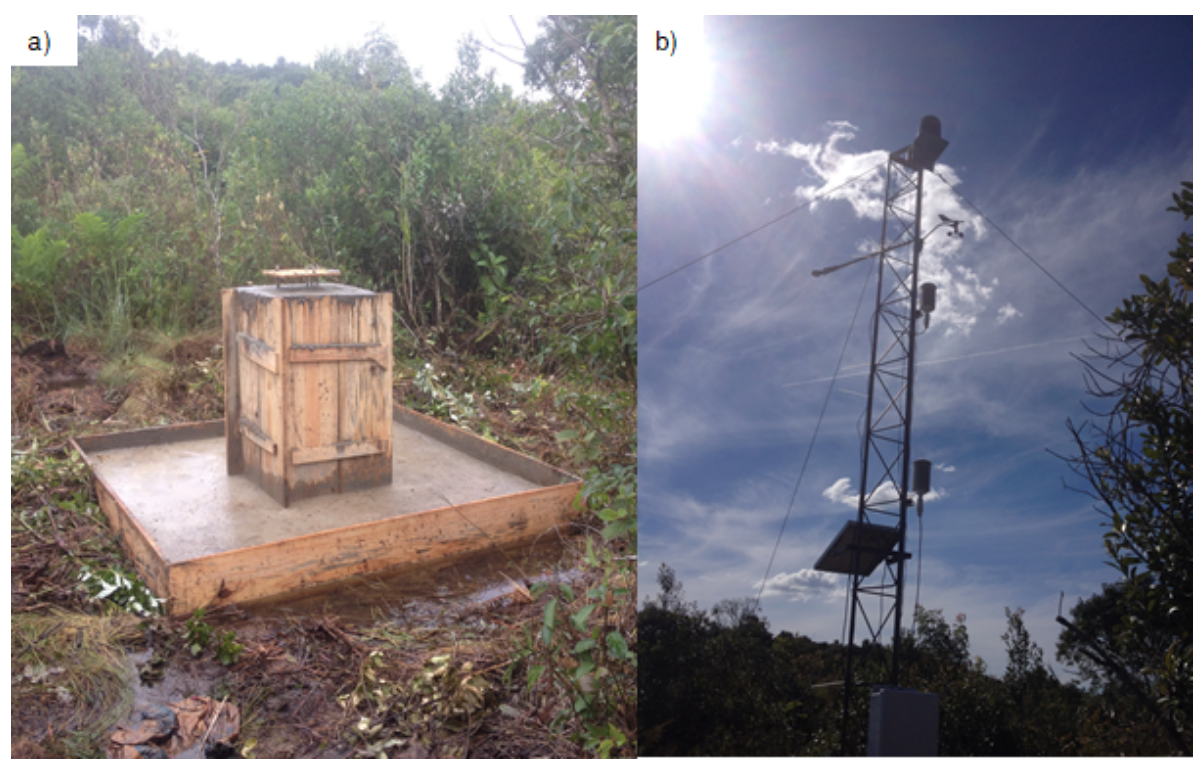

Fonte: Autor

\subsubsection{Aquisição de dados}

Para a aplicação do método de balanço de energia - Razão de Bowen, foram coletadas as variáveis do balanço de energia mencionadas no item 3.2. A frequência de coleta ds equipamentos de medição (Tabela 2) foi de 15 min. A radiação liquida foi medida com um saldo radiômetro modelo Q7.1 (Radiation and Energy Balance Systems, Seattle, WA, USA), as duas medições de temperatura e umidade do ar foram obtidas por duas sondas de temperatura e umidade HMP155A com acuracia nominal de 0,20。C e 1,2\% para a temperatura e umidade respectivamente (Campbell Scientific, Inc.) e o fluxo de calor no solo foi medido por um platô de fluxo de calor HFP01 (Hukseflux).

Tabela 2 - Equipamentos necessários para coleta e armazenamento dos dados

\begin{tabular}{ccc}
\hline Equipamento & Quantidade & Altura $^{*}(m)$ \\
\hline Pluvíografo & 1 & 6,00 \\
Anemômetro & 1 & 5,25 \\
Saldo radiômetro Q7,1 & 1 & 5,00 \\
Sonda de temperatura e umidade HMP155A & 2 & $3,15 \mathrm{e} 4,65$ \\
Placa solar & 1 & 2,75 \\
Caixa selada & 1 & 1,75 \\
Datalogger CR1000 & 1 & 1,75 \\
Controlador de carga & 1 & 1,75 \\
Bateria 12V & 2 & 1,75 \\
Placa de fluxo de calor HFP01 & 1 & $-0,05$ \\
\hline
\end{tabular}

*As alturas foram medidas considerando o nível do terreno como o nível de referência Fonte: Autor

Para a determinação da altura dos sensores foi necessário determinar a altura da 
camada limite interna (Item 3.2.3) no local da torre de monitoramento, para tal fim foi utilizada a equação 3.23 considerando que a altura média da vegetação é de 3,00 m.

Mediante a análise dos dados de direção do vento da estação Monte Alegre localizada a 1,50 km de distância do local da torre de monitoramento, foi observada uma direção predominante no sentido sul-norte, portanto para a determinação da altura da camada em equilíbrio foi considerada uma transição de alta a baixa rugosidade $\left(\delta_{*}=0,10 \delta\right)$. Finalmente utilizando os $75 \mathrm{~m}$ (Figura 11) de raio bordadura disponíveis foi determinada a altura da camada em equilíbrio, a localiza-se a 4,70 m de altura.

Dado que os sensores devem estar localizados em uma altura inferior à altura da camada limite em equilíbrio, os sensores inferior e superior foram posicionados em alturas de $3,15 \mathrm{~m}$ e 4,65 $\mathrm{m}$, respectivamente.

Figura 11 - Tamanho das áreas de bordadura necessária (azul) e disponível (amarelo)

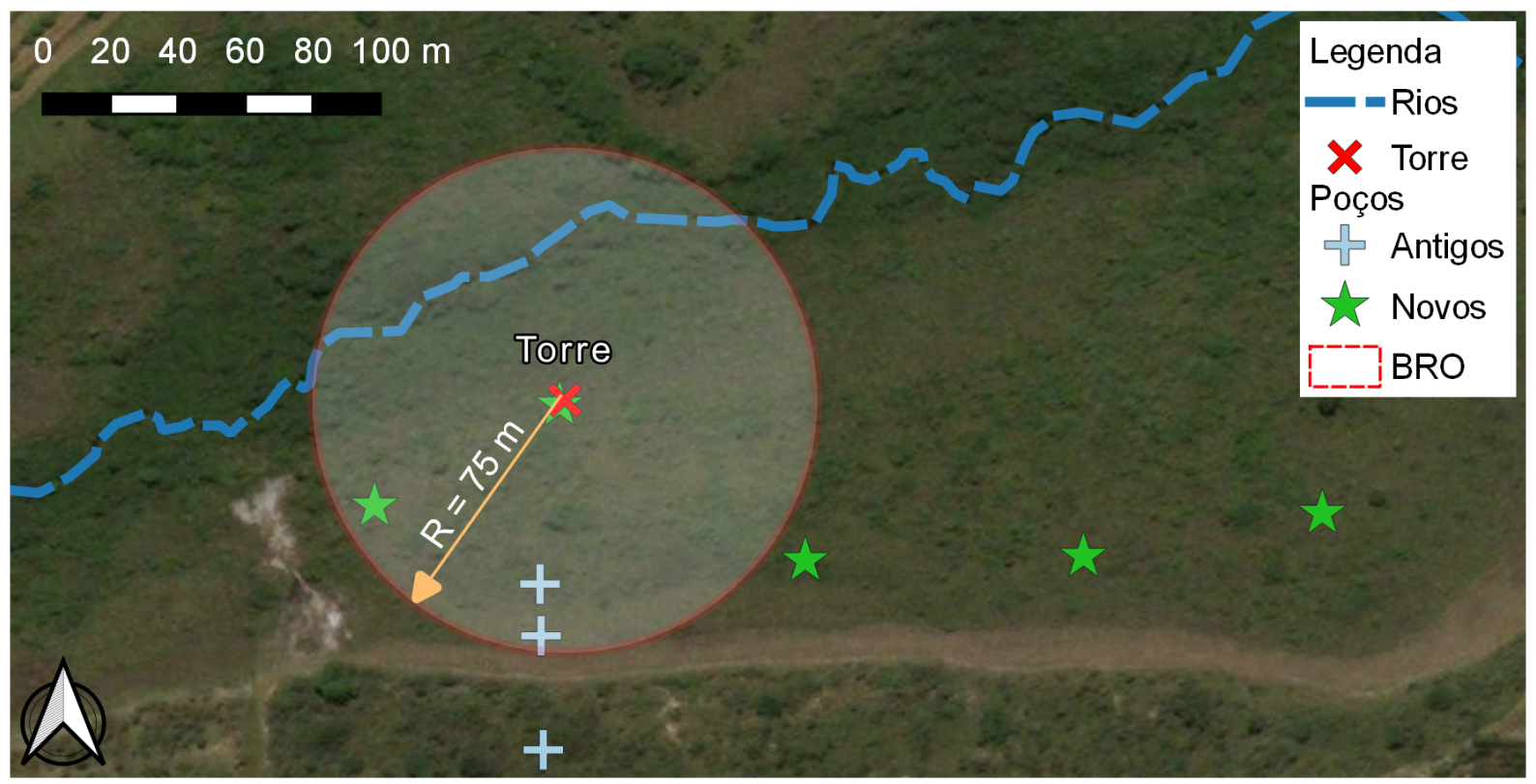

Fonte: Autor

\subsubsection{Poços de monitoramento}

Para a estimativa da ET na zona ripária usando os métodos baseados na flutuação diária do nível piezométrico, foi necessária a construção de 5 poços de monitoramento (P30, P31, P32, P33 e P35), nos quais foram instalados 5 transdutores de pressão Model 3001 Levelogger Edge para medir a pressão absoluta e 1 transdutor de pressão Model 3001 Barologger Edge para medir a pressão barométrica, o qual foi instalado no poço P31. Todos os transdutores de pressão foram sincronizados e configurados para fazer a leitura em intervalos de 15 minutos.

Os poços, feitos de tubos de polietileno $(P V C)$, com $50 \mathrm{~cm}$ de filtro a partir da sua base, possuem diâmetro de 4", e comprimento de 1,50 m. (Figura 12a e Figura 12b). Para 
evitar a entrada de solo no poço, foi fixada uma manta geotêxtil no filtro (Figura 12b). A instalação dos poços foi feita manualmente com o trado. Adicionalmente, foi feita uma proteção com tubo de aço, concreto e cadeado (Figura 12c).

Figura 12 - Construção e instalação de poços de monitoramento

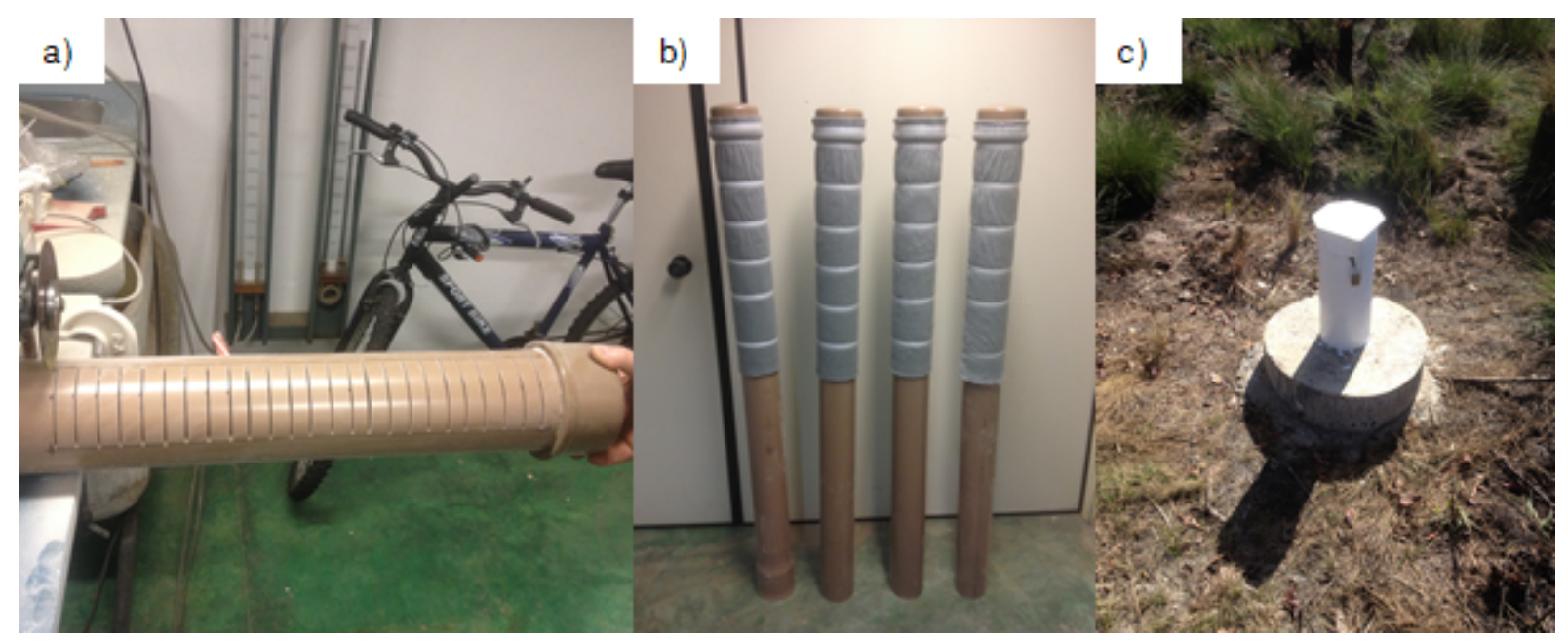

Fonte: Autor

\subsection{Estimativas de evapotranspiração}

\subsubsection{Método de balanço de energia - Razão de Bowen}

A partir dos dados dos sensores instalados na torre de monitoramento, foram aplicadas as equações para a obtenção do fluxo de calor latente ( $\lambda E T$ ) (item 3.2).

Foram avaliados os quatro critérios de rejeição apresentados no item 3.2.4 para o conjunto de medições de cada instante da série temporal.

Finalmente, a reconstrução das estimativas rejeitadas foi feita usando o método de amostragem direta (item 3.2.5.1) adequado para series temporais.

\subsubsection{Validação da reconstrução}

Para a validação do processo de reconstrução pelo método de amostragem direta, uma percentagem dos valores de ET não rejeitados foram excluídos do $S G$ e da $T I$ de forma aleatória, mas, foram armazenados para seu posterior uso na validação cruzada. A validação foi feita mediante o coeficiente de eficiência de Nash-Sutcliffe (NSE, equação 4.1) (NASH; SUTCLIFFE, 1970).

$$
N S E=1-\frac{\sum\left(E T_{\text {val }}\left(t_{i}\right)-E T_{\text {rec }}\left(t_{i}\right)\right)^{2}}{\sum\left(E T_{\text {val }}\left(t_{i}\right)-\overline{E T_{\text {val }}}\left(t_{i}\right)\right)^{2}}
$$


Em que $E T_{\text {val }}$ representa os valores de $E T$ excluídos e $E T_{\text {rec }}$ representa os valores de $E T$ reconstruídos, $\overline{E T_{\text {val }}}$ representa a média dos valores de $E T$ excluídos. O NSE varia desde $-\infty$ até 1 , em que valores perto de 1 indicam um bom ajuste entre os dados observados e recnstruídos.

\subsubsection{Métodos baseados na flutuação diária do nível piezométrico}

Para a obtenção do nível d'água, a partir dos dados provenientes dos poços de monitoramento, foi realizada a compensação barométrica $\left(P_{b a r}\right)$, a qual consiste em remover a $P_{b a r}$ segundo a equação 4.2 dos dados de pressão absoluta $\left(P_{a b s}\right)$.

$$
W T=P_{a b s}-P_{b a r}
$$

Em que $W T[L]$ representa o nível freático nos poços tomando como referência o levelogger instalado em cada um dos poços.

Devido às pequenas variações atmosféricas diárias (temperatura, densidade do ar, pressão atmosférica, etc) foi observado um ruído nos dados do nível piezométrico. O ruído foi removido por um método de filtragem passa baixo (Loess).

Os pesquisadores Cleveland (1979), Cleveland e Devlin (1988) apresentaram um método local de regressão polinomial ponderada (Loess), no qual para cada valor a estimar, é escolhido um conjunto de dados vizinhos, para ajustar os valores a um polinômio, utilizando o método de mínimos quadrados ponderados, em que, um maior peso na ponderação é dado a valores mais próximos do ponto a ser estimado, e um menor peso para os valores mais distantes.

A função de peso utilizada, é a função de peso tri-cúbica $\left(w_{t}(z)\right)$ proposta por Altman (1992) (Equação 4.3).

$$
w_{t}\left(x_{k}\right)=\left(1-\left|\frac{x_{i}-x_{k}}{d_{i}}\right|^{3}\right)^{3}
$$

Em que $x_{i}$ representa os valores do subconjunto, $x_{k}$ o valor a ser estimado e $d_{i}$ a distância entre $x_{i}$ e $x_{k}$.

\subsection{Validação das estimativas}

A validação das estimativas foi feita utilizando dois tipos de métricas, as que medem a correlação e as que medem a diferença entre duas estimativas.

Nas seguintes equações $x_{i}$ representa as estimativas de ET de algum dos métodos baseados na flutuação diária do nível piezométrico e $\bar{x}$ sua média, $y_{i}$ representa as 
estimativas de ET do método de balanço de energia - Razão de Bowen e $\bar{y}$ sua média e $n$ representa o número de estimativas em comum.

\subsubsection{Metricas para medir a correlação entre duas variáveis}

Variam desde -1 até 1, valores próximos de 1, indicam uma boa relação diretamente proporcional, valores próximos de 0 , indicam que não existe nenhuma relação e valores próximos de -1 , indicam uma boa relação inversamente proporcional entre as variáveis.

\subsubsection{Coeficiente de correlação de Pearson}

O coeficiente de correlação de Pearson $(\rho)$ mede a relação linear entre duas variáveis. O coeficiente $(\rho)$ é obtido usando a equação 4.4 .

$$
\rho=\frac{\sum_{i=1}^{n}\left(x_{i}-\bar{x}\right)\left(y_{i}-\bar{y}\right)}{\sqrt{\sum_{i=1}^{n}\left(x_{i}-\bar{x}\right)^{2} \sum_{i=1}^{n}\left(y_{i}-\bar{y}\right)^{2}}}
$$

\subsubsection{Coeficiente de correlação de postos de Spearman}

O coeficiente de correlação de postos de Spearman $\left(\tau_{s}\right)$ mede a intensidade da existência de uma função monotona que descreva uma variavel em função da outra. $\mathrm{O}$ coeficiente $\left(\tau_{s}\right)$ é obtido usando a equação 4.5 (ZWILLINGER; KOKOSKA, 1999).

$$
\tau_{s}=\frac{n \sum_{i=1}^{n} x_{i} y_{i}-\left(\sum_{i=1}^{n} x_{i}\right)\left(\sum_{i=1}^{n} y_{i}\right)}{\sqrt{\left[n \sum_{i=1}^{n} x_{i}^{2}-\left(\sum_{i=1}^{n} x_{i}\right)^{2}\right]\left[n \sum_{i=1}^{n} y_{i}^{2}-\left(\sum_{i=1}^{n} y_{i}\right)^{2}\right]}}
$$

\subsubsection{Metricas para medir a diferença entre duas variáveis}

Variam desde $-\infty$ até $\infty$. Valores próximos de zero indicam uma menor diferença entre as duas estimativas.

\subsubsection{Erro absoluto médio}

O coeficiente $M A E$ (equação 4.6), mede a diferença em termos de valor absoluto entre as variáveis. É pouco sensível a valores extremos.

$$
M A E=\frac{1}{n} \sum_{i=1}^{n}\left|x_{i}-y_{i}\right|
$$

\subsubsection{Raiz do erro quadrático médio}

O coeficiente RMSE (equação 4.7), mede o quadrado da diferença entre as variáveis. É sensível a valores extremos. 


$$
R M S E=\left(\frac{1}{n} \sum_{i=1}^{n}\left(x_{i}-y_{i}\right)^{2}\right)^{\frac{1}{2}}
$$

\subsubsection{Erro de viés médio}

O coeficiente $M B E$ (equação 4.8), mede o grau de viés entre as duas variáveis.

$$
M B E=\frac{1}{n} \sum_{i=1}^{n}\left(x_{i}-y_{i}\right)
$$





\section{Resultados e discussões}

Para o cálculo da ET pelas metodologias apresentadas, foi desenvolvido um código computacional na linguagem Python (Figura 13), que cobre todos os processos, desde a entrada dos dados, até a comparação entre as estimativas do método de balanço de energia - Razão de Bowen e as estimativas dos métodos baseados na flutuação diária do nível piezométrico.

Figura 13 - Interface do programa em linguagem Python

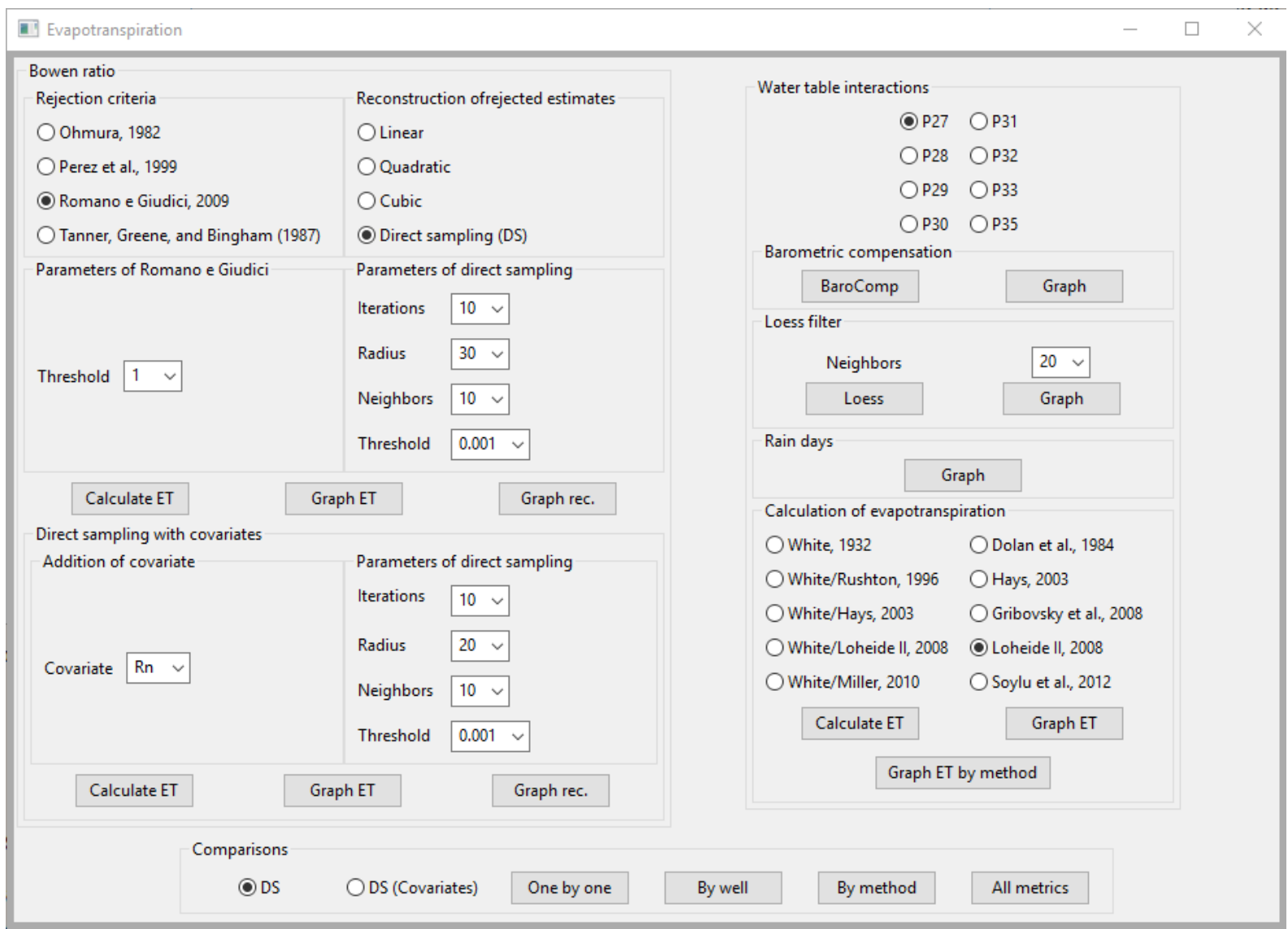

Fonte: Autor

A interface foi feita em 3 blocos, o bloco superior esquerdo processa os dados provenientes da torre de monitoramento, realiza processos como: a rejeição das estimativas e a reconstrução das estimativas rejeitadas. Também, são apresentados alguns parâmetros necessários para o método de amostragem direta, com uma variável e com covariáveis.

O bloco superior direito processa os dados provenientes dos poços de monitoramento, realiza processos como: a compensação barométrica, o filtro de Loess, a exclusão dos dias com precipitação e alguns dias posteriores, e finalmente, estima ET pelos diferentes métodos apresentados. 
O bloco inferior realiza as comparações entre as estimativas provenientes dos outros blocos, a comparação é apresentada de três formas, a primeira forma, compara as estimativas do método de balanço de energia - Razão de Bowen com as estimativas de um único método e poço, a segunda, compara as estimativas do método de balanço de energia - Razão de Bowen com as estimativas de todos os métodos para um único poço e a terceira, compara as estimativas do método de balanço de energia - Razão de Bowen com as estimativas de todos os poços para um único método. Por último são obtidas todas as métricas de comparação mencionadas no item 4.5.

\subsection{Monitoramento da zona ripária}

$\mathrm{Na}$ área de estudo, onde foram construídos os cinco poços de monitoramento, havia um poço de monitoramento (P27), em funcionamento desde outubro de 2015, destinado a estimar as taxas de ET na zona ripária.

O monitoramento do nível piezométrico nos poços P30, P31, P32, P33 e P35 teve início em abril de 2018 (20/04/2018), enquanto que o monitoramento da torre teve início em junho de 2018 (01/06/2018). Os dados dos poços e da torre foram coletados até janeiro de 2019 (09/01/2019) (Figura 14).

Figura 14 - Evolução temporal do monitoramento na zona ripária

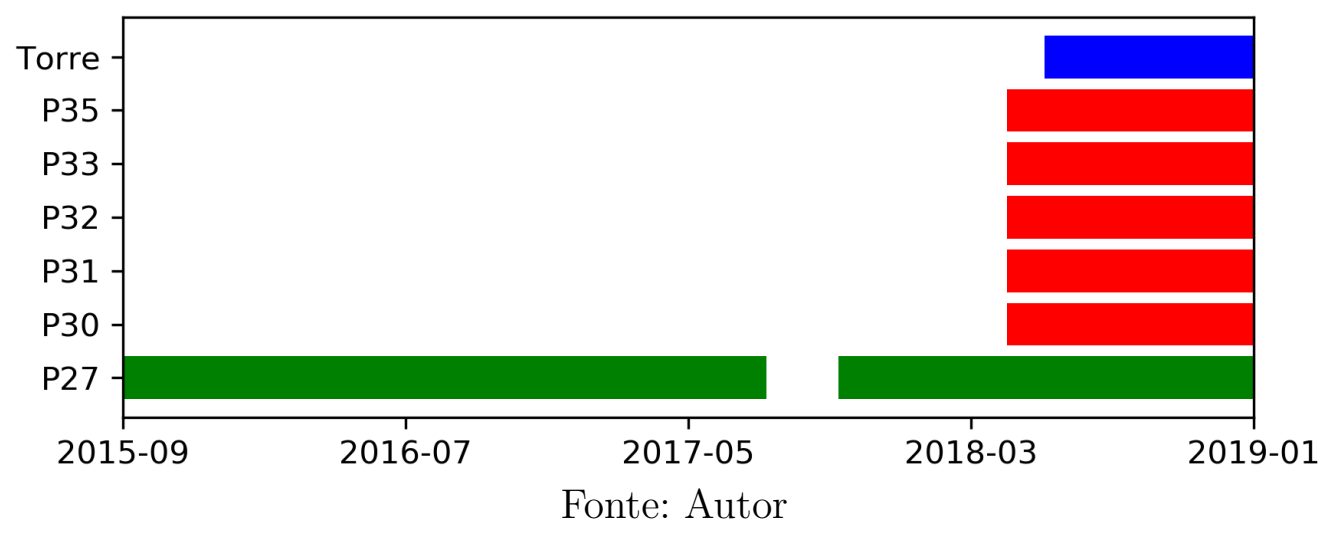

Os períodos com sombreado laranja e azul das Nas figuras 15, 16 e 17 representam os períodos seco e chuvoso do local da área em estudo.

A temperatura do ar oscilou de 9,0 a 25,0 ○C com um valor médio de 17,5 ○C no período seco e entre 17,5 e 25,0 ○C no período chuvoso com um valor médio de 22,0 ○C. O aumento da temperatura no período chuvoso junto com a alta disponibilidade hídrica produto das precipitações pressupõe um aumento nos valores de evapotranspiração nesse período. Os gradientes de temperatura entre os sensores inferior e superior foram em torno de $0,2 \circ \mathrm{C}$ de média. 
Figura 15 - Temperatura $\left({ }^{\circ} C\right)$ dos sensores inferior (1) e superior (2)

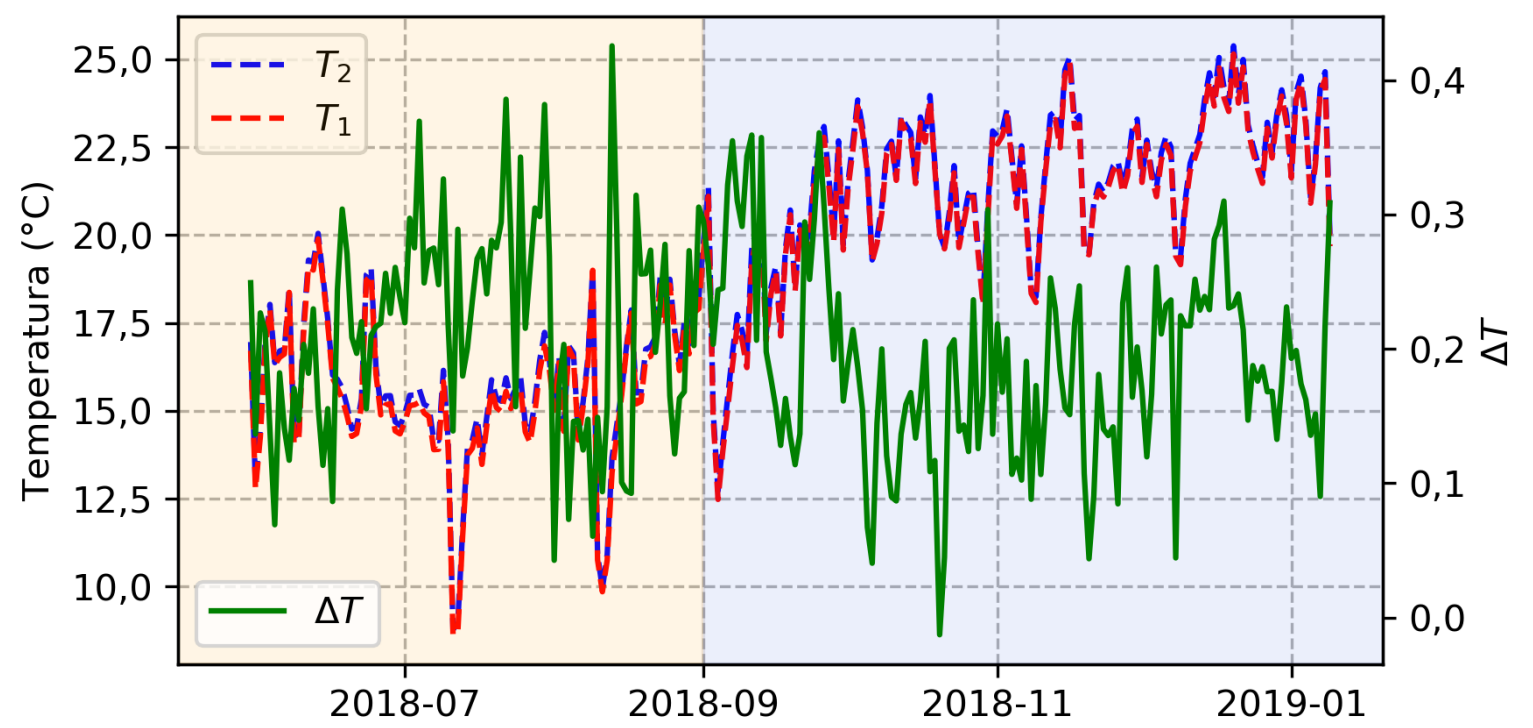

Fonte: Autor

A umidade relativa do ar oscilou entre $65 \%$ e $100 \%$ nos períodos seco e chuvoso, embora a faixa de variação de umidade relativa seja a mesma suas medias são diferentes, no período seco foi de $77 \%$ enquanto no período chuvoso foi de $85 \%$. Os gradientes de umidade relativa dos sensores superior e inferior oscilaram entre $-0.5 \%$ e $1 \%$, os valores negativos indicam a presença de turbilhoes na área.

Figura 16 - Umidade relativa (\%) dos sensores inferior (1) e superior (2)

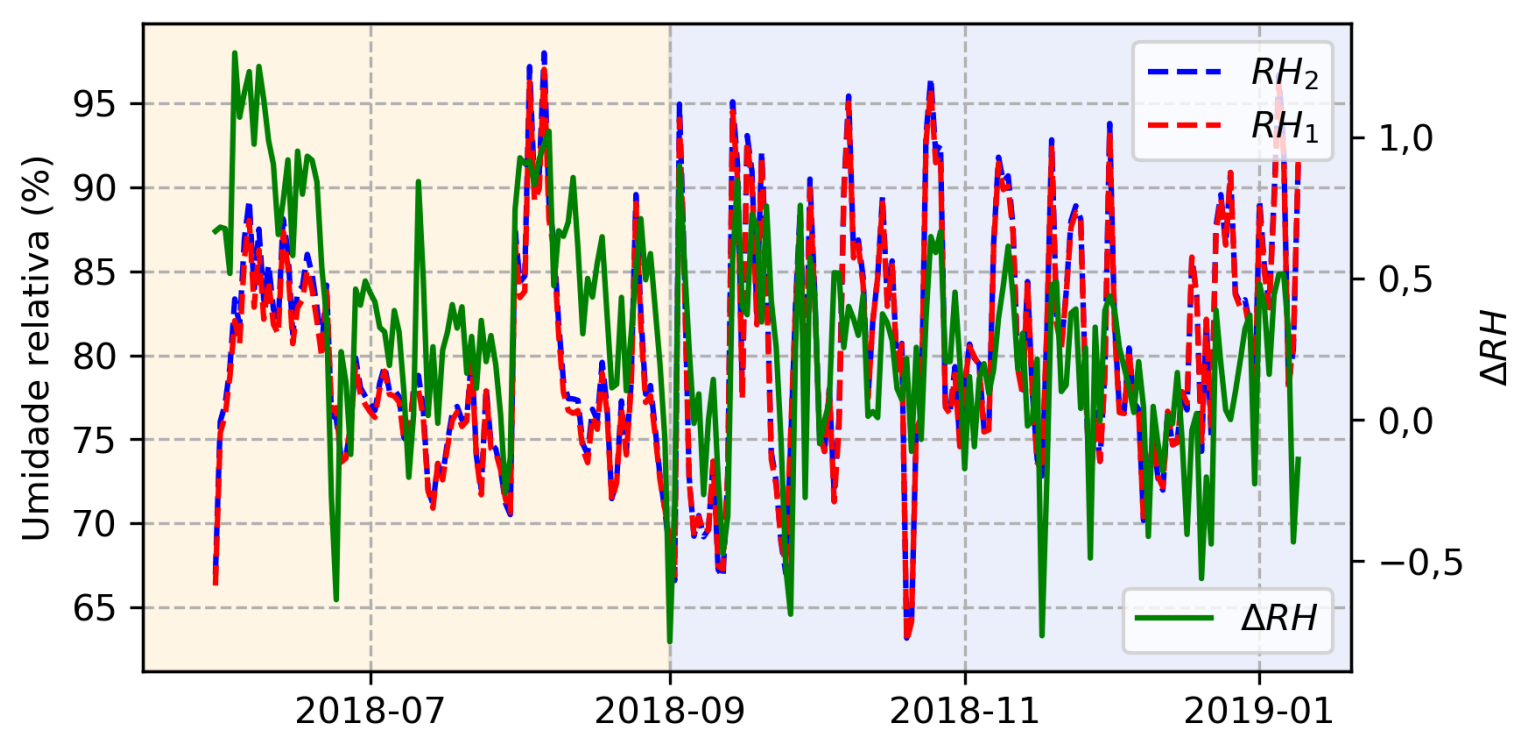

Fonte: Autor

A radiação liquida oscilou entre 0 e $180 \mathrm{Wm}^{2}$ no período seco com uma média de $100 \mathrm{Wm}^{2}$, enquanto no período chuvoso oscilou entre 0 e $350 \mathrm{Wm}^{2}$ com uma média de 
$150 \mathrm{Wm}^{2}$. Os maiores valores de radiação liquida ocorreram no período chuvoso, é dizer existe uma alta disponibilidade energética para os processos físico-químicos das plantas, o que se traduz em um aumento dos valores de evapotranspiração nesta época do ano. Por outra parte o fluxo de calor no solo se manteve quase constante em $-5 \mathrm{Wm}^{2}$, o qual indica mostra o da água nas trocas de calor no solo.

Figura 17 - Radiação liquida $\left(R_{N}\right)$ e fluxo de calor no solo $(G)$

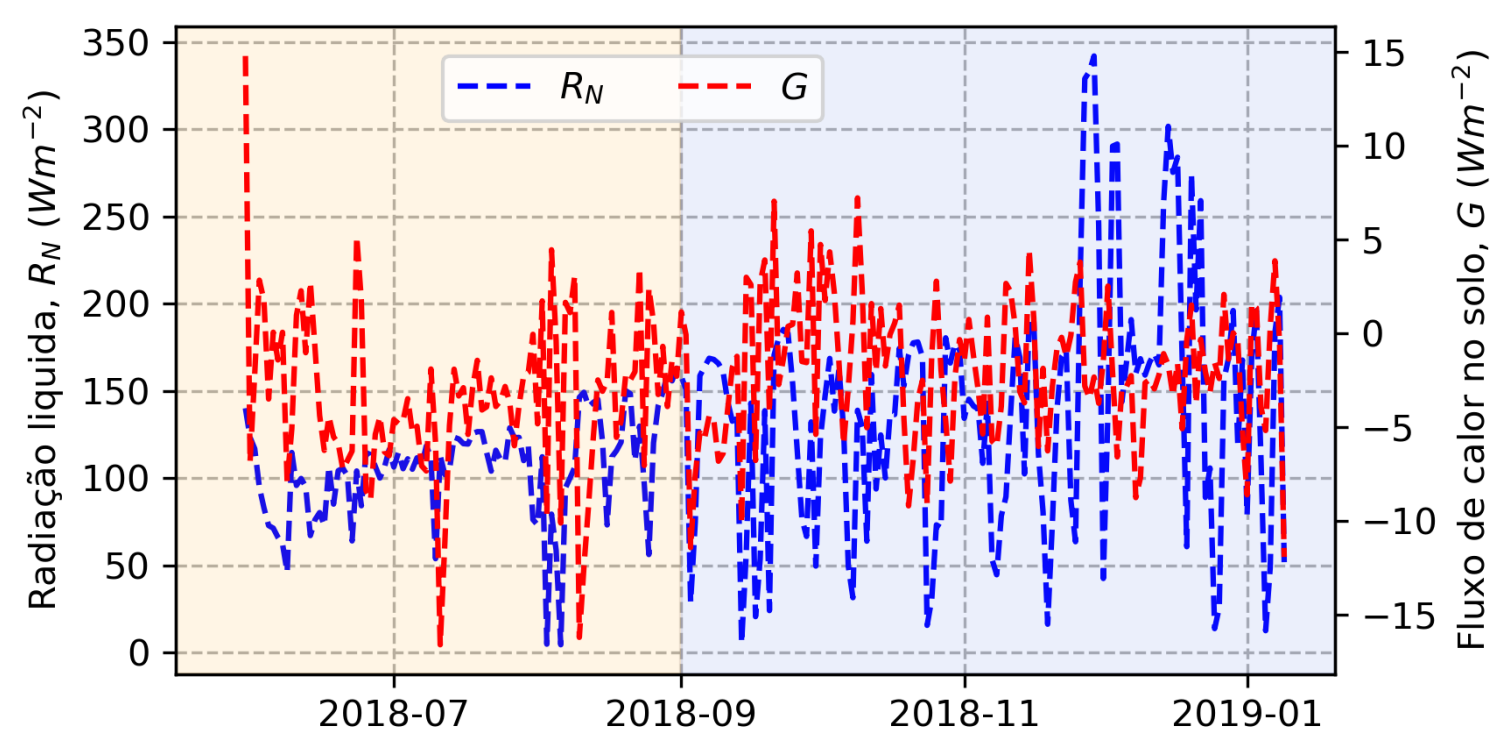

Fonte: Autor

\subsection{Evapotranspiração pelo método de balanço de energia - Razão de Bowen}

Para exemplificar os cálculos feitos para estimar a ET pelo método de balanço de energia - Razão de Bowen, foram selecionados dois períodos do dia 30/06/2018. O primeiro corresponde aos dados das 5 h00 e o segundo, aos dados das $14 h 00$ (Tabela 3).

Tabela 3 - Dados de exemplo da aplicação do método de balanço de energia - Razão de Bowen

\begin{tabular}{c|cccccc}
\hline Timestamp & $R_{N}$ & $G$ & $T_{2}$ & $T_{1}$ & $R H_{2}$ & $R H_{1}$ \\
\hline 30/06/2018 05:00 & $-12,73$ & $-30,47$ & 5,76 & 5,57 & 99,70 & 98,50 \\
30/06/2018 14:00 & 425,60 & 40,67 & 26,96 & 26,92 & 37,16 & 36,04 \\
\hline
\end{tabular}

Para o período das $14 h 00$, usando a equação 3.13 foi obtida a pressão de saturação de vapor de água no ar $\left(e_{s}\right)$ para os dois sensores,

$$
e_{s 2}=611,2 \exp \left(\frac{17.67 \times 26,96}{26,96+243,5}\right)=3557,47 \mathrm{~Pa}
$$




$$
e_{s 1}=611,2 \exp \left(\frac{17.67 \times 26,92}{26,92+243,5}\right)=3549,11 P a
$$

Usando a equação 3.12 é obtida a pressão de vapor de água no ar,

$$
\begin{aligned}
& e_{2}=\frac{37,16}{100} \times 3557,47=1321,96 \mathrm{~Pa} \\
& e_{1}=\frac{36,04}{100} \times 3549,11=1279,10 \mathrm{~Pa}
\end{aligned}
$$

São obtidos os gradientes de umidade relativa $(\Delta R H)$, temperatura $(\Delta T)$ e pressão de vapor de água no ar $(\Delta e)$,

$$
\begin{gathered}
\Delta R H=\frac{\Delta R H_{1}-\Delta R H_{2}}{100}=\frac{37,16-36,04}{100}=-0,011 \% \\
\Delta T=\Delta T_{1}-\Delta T_{2}=26,96-26,92=-0,040{ }^{\circ} \mathrm{C} \\
\Delta e=\Delta e_{1}-\Delta e_{2}=1279,10-1321,96=-42,86 \mathrm{~Pa}
\end{gathered}
$$

Os anteriores cálculos foram aplicados para o período das $5 h 00$ e os resultados foram compilados na tabela 4.

Tabela 4 - Resultados da aplicação do método de balanço de energia - Razão de Bowen, parte 1

\begin{tabular}{c|ccccccc}
\hline Timestamp & $e_{s 2}$ & $e_{s 1}$ & $e_{2}$ & $e_{1}$ & $\Delta R H$ & $\Delta T$ & $\Delta e$ \\
\hline 30/06/2018 05:00 & 919,24 & 907,08 & 916,48 & 893,48 & $-0,012$ & $-0,192$ & $-23,00$ \\
30/06/2018 14:00 & 3557,47 & 3549,11 & 1321,96 & 1279,10 & $-0,011$ & $-0,040$ & $-42,86$ \\
\hline
\end{tabular}

Fonte: Autor

São obtidos os valores médios de pressão de vapor de água no ar (e), temperatura $(T)$ e umidade relativa $(R H)$,

$$
\begin{gathered}
e=\frac{e_{2}+e_{1}}{2}=\frac{1321,96+1279,10}{2}=1300,53 \mathrm{~Pa} \\
T=\frac{T_{2}+T_{1}}{2}=\frac{26,96+26,92}{2}=26,94^{\circ} \mathrm{C} \\
R H=\frac{R H_{2}+R H_{1}}{2}=\frac{37,16+36,04}{2}=36,60 \%
\end{gathered}
$$


A pressão atmosférica foi obtida calculando o valor médio dos dados provenientes do Model 3001 Barologger Edge instalado no poço P31, o qual foi de $P=93652,63 \mathrm{~Pa}$.

São obtidos os valores de umidade específica $(q)$ (equação 3.11), capacidade de calor da mistura do ar a pressão constante $\left(C_{p}\right)$ (equação 3.17), calor latente de vaporização $(\lambda)$ (equação 3.10) e coeficiente psicométrico $(\gamma)$ (equação 3.20).

$$
\begin{gathered}
q=\frac{0,622 \times 1300,53}{93652,63}=0,00864 \\
C_{p}=(1-0,00864) \times 1004+0,00864 \times 1865=1,011 \mathrm{kJkg}^{-1} \mathrm{~K}^{-1} \\
\lambda=2,501-2,361 \times 10^{-3}(26,94)=2,437 \mathrm{MJkg}^{-1} \\
\gamma=\frac{1,011 \times 93652,63}{0,622 \times 2,437} \times 10^{-6}=0,062 \mathrm{kPa}^{\circ} \mathrm{C}^{-1}
\end{gathered}
$$

Os anteriores cálculos foram aplicados para o período das $5 h 00$ e os resultados foram compilados na tabela 5 .

Tabela 5 - Resultados da aplicação do método de balanço de energia - Razão de Bowen, parte 2

\begin{tabular}{c|cccccccc}
\hline Timestamp & $e$ & $T$ & $R H$ & $e_{s}$ & $q$ & $C_{p}$ & $\lambda$ & $\gamma$ \\
\hline $30 / 06 / 2018$ 05:00 & 904,98 & 5,66 & 99,10 & 913,16 & 0,00601 & 1,009 & 2,488 & 0,061 \\
30/06/2018 14:00 & 1300,53 & 26,94 & 36,60 & 3553,29 & 0,00864 & 1,011 & 2,437 & 0,062 \\
\hline \multicolumn{1}{c}{ Fonte: Autor }
\end{tabular}

É utilizada a equação 3.22 para obter a razão de Bowen $(\beta)$, a equação 3.5 para obter o fluxo de calor latente $(\lambda E T)$, e finalmente, o fluxo de calor latente é divido pelo calor latente de vaporização $(\lambda)$ e multiplicando por $900(15 \mathrm{~min} \times 60 \mathrm{seg} / \mathrm{min})$ para obter o valor total de ET em lugar do valor médio.

$$
\begin{gathered}
\beta=0,062 \frac{-0,040}{-42,86} \times 10^{3}=0,058 \\
\lambda E T=\frac{384,93}{1+0,058}=363,72 \mathrm{Wm}^{-2} \\
E T=900 \times \frac{363,72}{2,437} \times 10^{-6}=0,0043 \mathrm{~mm} / 15 \mathrm{~min}
\end{gathered}
$$


Os anteriores cálculos foram aplicados para o período das $5 h 00$ e os resultados foram compilados na tabela 6.

Tabela 6 - Resultados da aplicação do método de balanço de energia - Razão de Bowen, parte 3

\begin{tabular}{c|cccc}
\hline Timestamp & $\beta$ & $R_{N}-G$ & $\lambda E T$ & $E T$ \\
\hline 30/06/2018 05:00 & 0,510 & 17,74 & 11,75 & 0,0043 \\
30/06/2018 14:00 & 0,058 & 384,93 & 363,72 & 0,1343 \\
\hline \multicolumn{5}{c}{ Fonte: Autor }
\end{tabular}

No Apêndice B são apresentados em forma de tabela, os valores horários das variáveis monitoradas no dia 30/06/2018.

\subsubsection{Rejeição de estimativas}

Após a obtenção das taxas de ET pelo método de balanço de energia - Razão de Bowen, foram analisados os critérios de rejeição, com o fim de escolher o adequado para os dados de $E T$. Os critérios baseados em princípios físicos rejeitaram uma alta percentagem de dados. Aplicando os critérios de Ohmura (1982), Perez et al. (1999), foram rejeitados $\approx 87 \%$ e $\approx 66 \%$ dos dados, respectivamente.

Dado que no método de balanço de energia - Razão de Bowen, a ET é devida à quantidade de energia disponível em forma de radiação solar, no período entre o pôr do sol e o amanhecer, a ET é tão pequena que pode ser considerada como zero, ou seja, os dados de ET nesse período não são relevantes na estimativa final da ET. Com períodos sem radiação (noite) médios de 12 horas, é factível que um critério de rejeição físico, exclua mais do 50\% dos dados, embora os critérios excluíram a maior parte dos dados no período com radiação solar, deixando poucos dados disponíveis (13\% e 34\%) para estimar taxas confiáveis de ET.

O critério baseado no valor da razão de Bowen, o critério de Tanner, Greene e Bingham (1987), excluiu aproximadamente $5 \%$ dos dados. Ao analisar os dados que não foram excluídos, foram detectadas uma quantidade significativa de discrepâncias, taxas de ET de -1 e 1 ( $\mathrm{mm} / 15 \mathrm{~min})$.

O critério baseado na propagação dos erros, o critério de Romano e Giudici (2009), permitiu obter várias percentagens de rejeição (Figura 18), de acordo ao valor do limite de rejeição $(\varepsilon)$.

O critério de rejeição escolhido para os dados de ET da torre de monitoramento, foi o critério de Romano e Giudici (2009), pois diferente dos critérios físicos, que rejeitam uma alta percentagem dos dados e do critério baseado no valor da razão de Bowen, que não filtra os valores discrepantes, o critério de Romano e Giudici (2009), permite definir o grau de incerteza máximo que terão os dados de $E T$. 
Figura 18 - Relação entre o limite de rejeição e a percentagem de medições de $E T$ rejeitadas pelo critério de Romano e Giudici

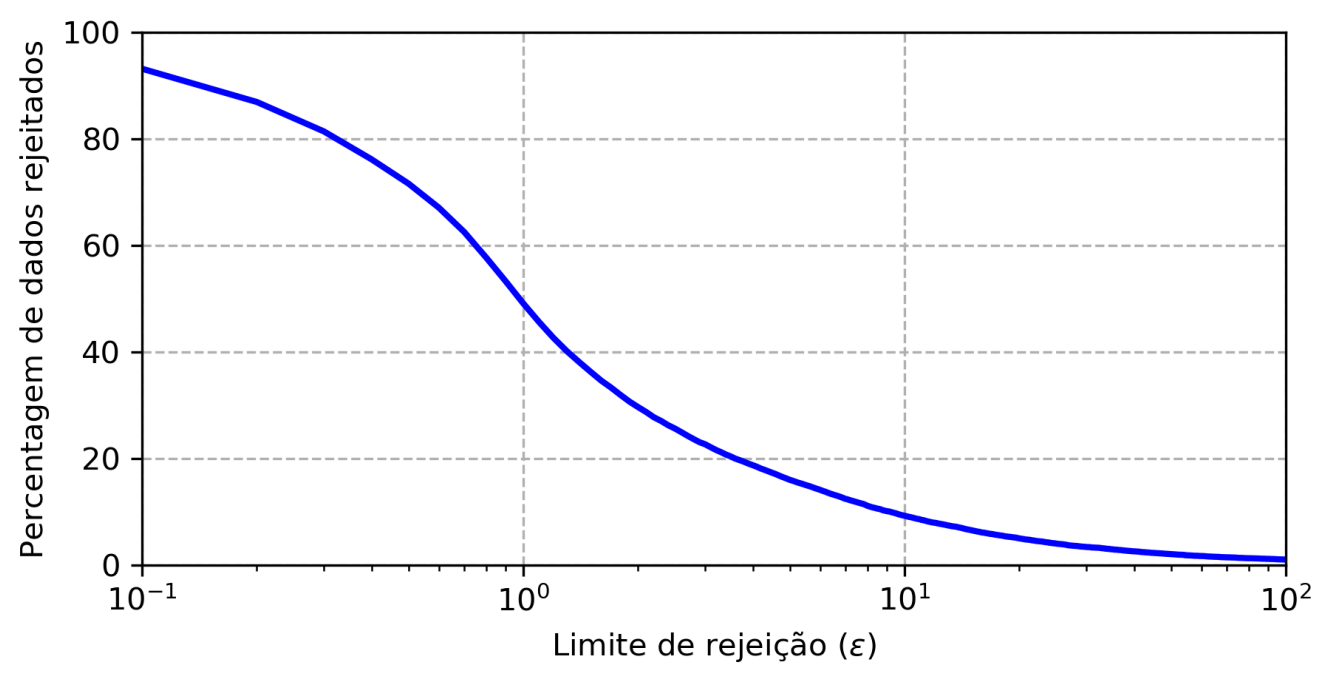

Fonte: Autor

\subsubsection{Reconstrução de estimativas rejeitadas}

Após a escolha do critério de rejeição, foi realizada a reconstrução das taxas de ET rejeitadas. Para tal fim, foram escolhidos 4 limites de rejeição $(\varepsilon)$ (Tabela 7) para avaliar o rendimento do método de amostragem direta para cada limite.

Tabela 7 - Percentagem de dados de ET rejeitados pelo critério de Romano e Giudici

\begin{tabular}{lcccc}
\hline & \multicolumn{4}{c}{$\varepsilon$} \\
\cline { 2 - 5 } & 0,5 & 1 & 5 & 10 \\
\hline Percentagem de rejeição (\%) & 72,6 & 50,8 & 18,9 & 12,4 \\
\hline
\end{tabular}

Fonte: Autor

Os parâmetros utilizados na reconstrução das estimativas depois de várias tentativas de diferentes combinações, foram:

- Um raio de busca $R=30$ dias,

- Uma distância limite de aceitação entre eventos $\sigma=0,001$,

- Um número de dados vizinhos $n=10$,

Finalmente para suavizar os resultados da reconstrução, foi calculada a média de 10 reconstruções com os mesmos parâmetros.

Os resultados em forma de percentis, para os limites de rejeição são apresentados nos gráficos Quantil-Quantil $(Q-Q)$ da Figura 19. A abscissa, corresponde aos valores de $E T$ reconstruídos $\left(E T_{r e c}\right)$, a ordenada, corresponde aos valores de $E T$ ( $\left.E T_{T I}\right)$ que não foram rejeitados e a linha vermelha corresponde ao caso em que $E T_{\text {rec }}=E T_{T I}$. 
Figura 19 - Gráficos $Q-Q$ da $E T$ reconstruída $\left(E T_{\text {sim }}\right)$ x $E T$ não rejeitada $\left(E T_{T I}\right)$ para diferentes limites de rejeição
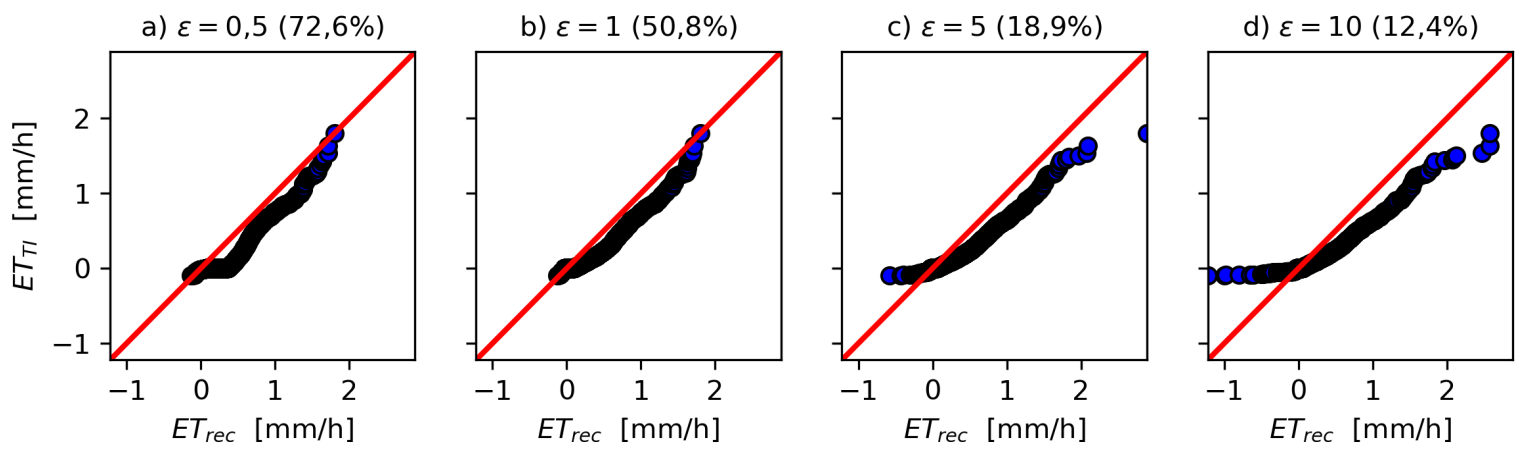

Fonte: Autor

A reconstrução das taxas de ET para baixos limites de rejeição (Figura 19a e Figura 19b) tende a estimar melhor os valores extremos (perto de 0 e $2 \mathrm{~mm} / \mathrm{h}$ ) e os valores centrais (perto de $1 \mathrm{~mm} / \mathrm{h}$ ), enquanto que os outros valores são superestimados (perto de $0,5$ e $1,25 \mathrm{~mm} / \mathrm{h})$.

Para limites de rejeição altos (Figura 19c e Figura 19d), os valores menores foram subestimados e os valores maiores superestimados. Para os valores centrais, a reconstrução tende a superestimar de forma sistemática os valores de $E T$, devido à existência de grandes incertezas nas taxas de $E T$ para esses limites $\left(\frac{\sigma_{E T}}{|E T|}<5, \frac{\sigma_{E T}}{|E T|}<10\right)$.

A reconstrução com limite de rejeição $\varepsilon=1$ (Figura 19b), apresentou os melhores resultados dos limites avaliados, pois, visualmente os pontos estão mais perto da linha $1: 1$ ao longo de toda a faixa de valores do que nos outros limites.

Outra forma de avaliar a eficiência da reconstrução das estimativas de ET rejeitadas é pela inspeção visual da série temporal reconstruída (Figura 20). O impacto da magnitude do limite de rejeição, afeta de forma considerável as taxas de $E T$, dado que, um limite mais restritivo $(\varepsilon=1)$ filtra melhor os valores discrepantes da série temporal, enquanto que um limite menos restritivo $(\varepsilon=10)$ filtra só as maiores discrepâncias da série temporal.

A rejeição de estimativas apresenta dois tipos de comportamento ao longo da série temporal. Em dias sem eventos de precipitação, a rejeição se dá de forma intercalada, enquanto que, em dias com eventos de precipitação, a rejeição se dá de forma sucessiva. O raio de busca para intervalos de tempo com uma rejeição sucessiva deve ser maior do que para intervalos com rejeição intercalada. O raio de busca escolhido ( $R=30$ dias) apresentou bons resultados na reconstrução das estimativas, em ambos períodos (seco e chuvoso).

Após as reconstruções, foi avaliada a ET acumulada para cada um dos limites de rejeição escolhidos (Figura 21). O limite de rejeição $\varepsilon=0,5$, superestimou a ET (1842 $\mathrm{mm})$, devido à alta percentagem de valores rejeitados (72,6\%). Apesar de ser o limite de 
rejeição com a menor incerteza, o fato de ter poucos valores introduz uma incerteza global ao respeito do padrão nos dados.

Figura 20 - Resultados da reconstrução das estimativas rejeitadas para dois limites de rejeição do critério de Romano e Giudici
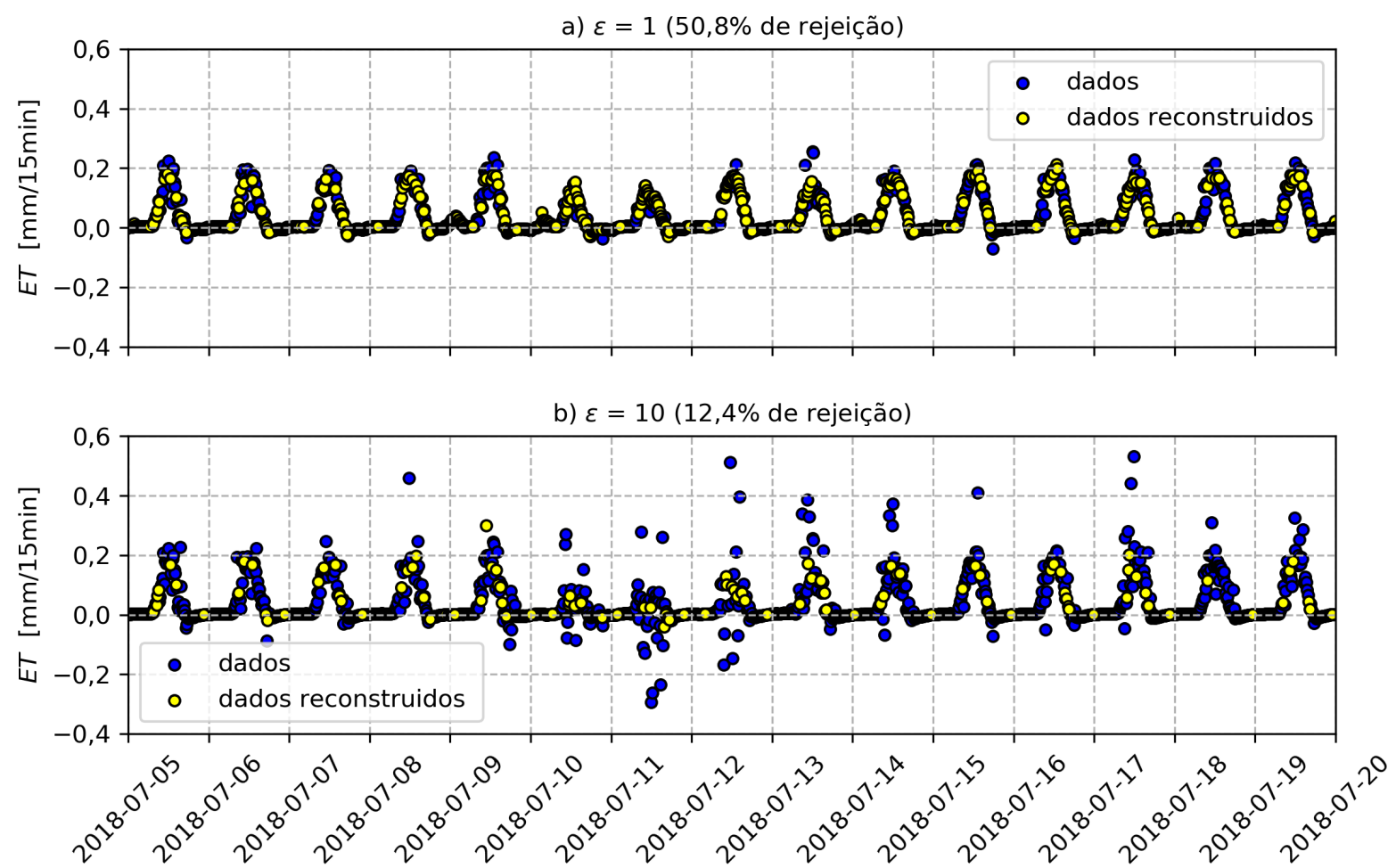

Fonte: Autor

Os limites de rejeição $\varepsilon=1(50,8 \%), \varepsilon=5(18,9 \%)$ e $\varepsilon=10(12,4 \%)$, apresentaram uma ET acumulada similar, com valores de $1003 \mathrm{~mm}, 987 \mathrm{~mm}$ e $957 \mathrm{~mm}$, respectivamente. Apesar da diferença observada na existência de valores discrepantes (Figura 20b) para cada limite de rejeição, a ET acumulada foi quase a mesma, devido à distribuição aproximadamente igual, de discrepâncias positivas e negativas.

Figura 21 - ET acumulada no período de monitoramento considerando diferentes limites de rejeição do critério de Romano e Giudici

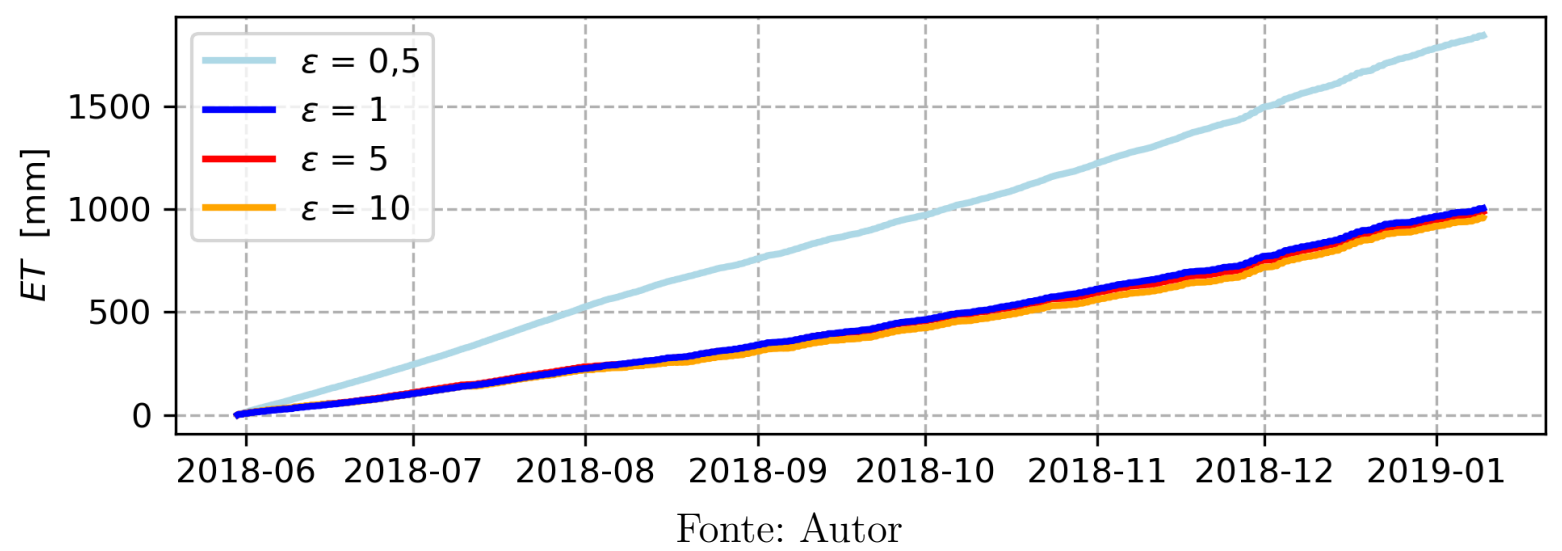


Adicionalmente, foi avaliado o incremento da ET acumulada em comparação à ET sem reconstrução para cada limite de rejeição (Figura 22). Como foi mencionado anteriormente, a reconstrução da $E T$ para o limite $\varepsilon=0,5$ (Figura 22a) superestimou a ET sem reconstrução em mais de 3 vezes. No caso dos limites de rejeição $\varepsilon=1$ (Figura 22b), $\varepsilon=5$ (Figura 22c) e $\varepsilon=10$ (Figura 22d), a reconstrução conseguiu chegar, aproximadamente, ao mesmo total de ET independente do limite de rejeição utilizado.

Figura 22 - Comparação da ET acumulada com e sem reconstrução das estimativas rejeitadas para diferentes limites de rejeição do critério de Romano e Giudici

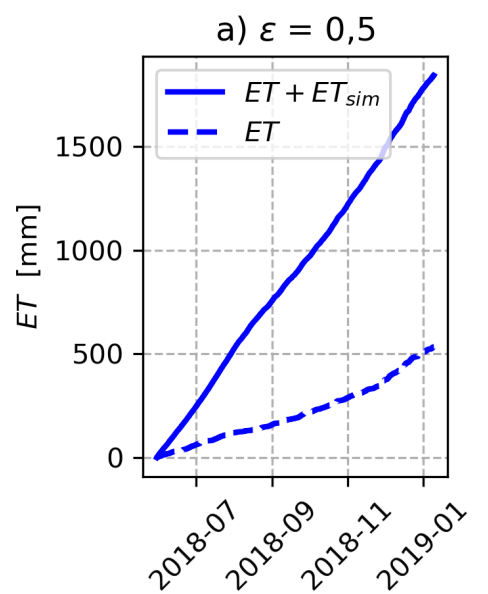

b) $\varepsilon=1$

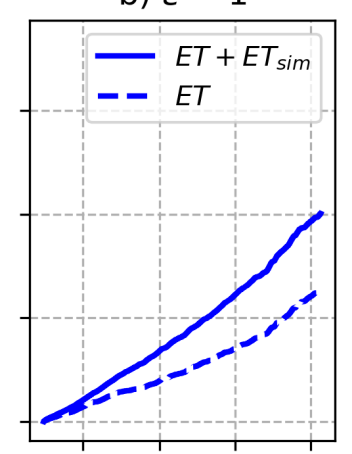

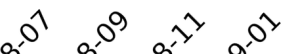

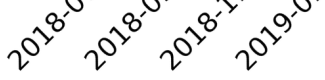

c) $\varepsilon=5$

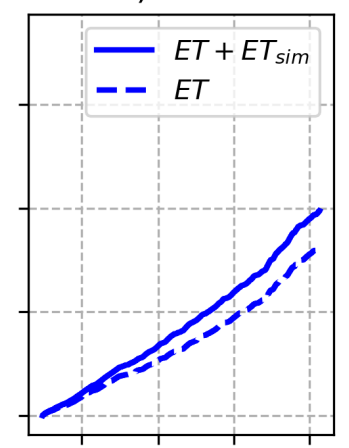

$00^{1}, 0900$

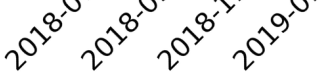

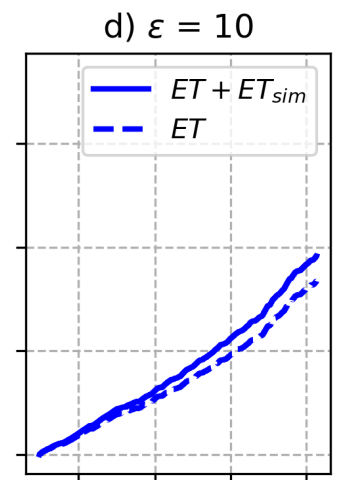

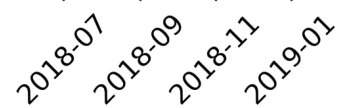

Fonte: Autor

Também, foi analisado o rendimento das 10 reconstruções para cada limite de rejeição, mediante indicadores estatísticos (Quantil $Q_{1,2,3}$ ) (Figura 23), observando a existência de uma relação inversa entre, a dispersão dos resultados de ET acumulada e o valor do limite de rejeição.

A dispersão do limite de rejeição $\varepsilon=0,5$ (Figura 23a) foi a maior, devido à incerteza global no comportamento dos dados. A rescontrução para limite de rejeição $\varepsilon=1$ (Figura 23b) reduziu consideravelmente a dispersão, e a ET média coincidiu com a mediana da reconstrução $\left(Q_{2}\right)$. Os limites de rejeição $\varepsilon=5$ (Figura 23c) e $\varepsilon=10$ (Figura 23d) apresentaram a menor dispersão, e as curvas dos indicadores estatísticos foram quase as mesmas.

A partir desses resultados pôde-se observar que limites de rejeição menores introduzem uma incerteza global no comportamento dos dados, enquanto que, limites maiores, apresentam pouca aleatoriedade no resultado. 
Figura 23 - Comparação entre os resultados de ET acumulada das 10 simulações para vários limites de rejeição $(\varepsilon), a) \varepsilon=0,5, b) \varepsilon=1, c) \varepsilon=5$ e d) $\varepsilon=10$.

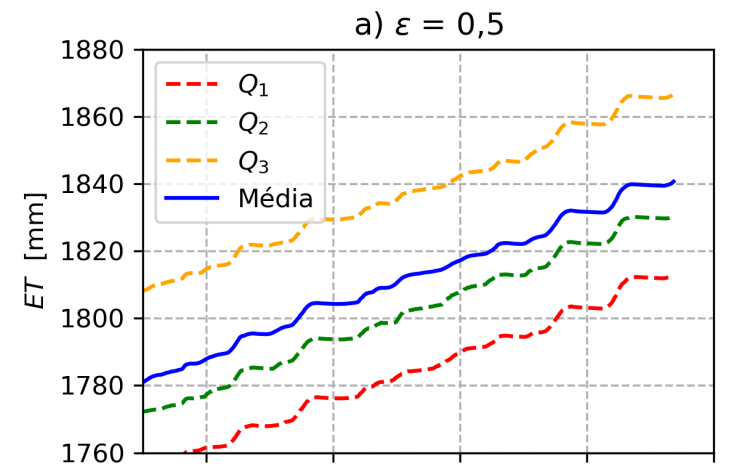

c) $\varepsilon=5$

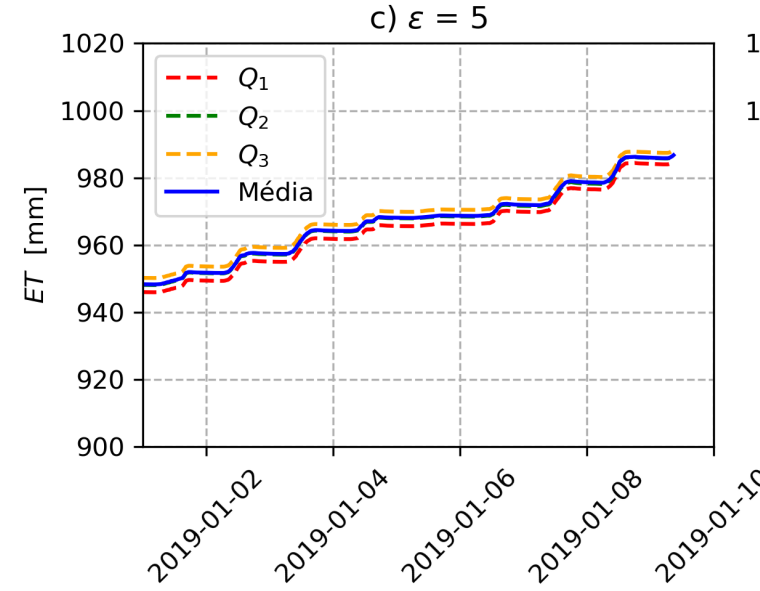

b) $\varepsilon=1$

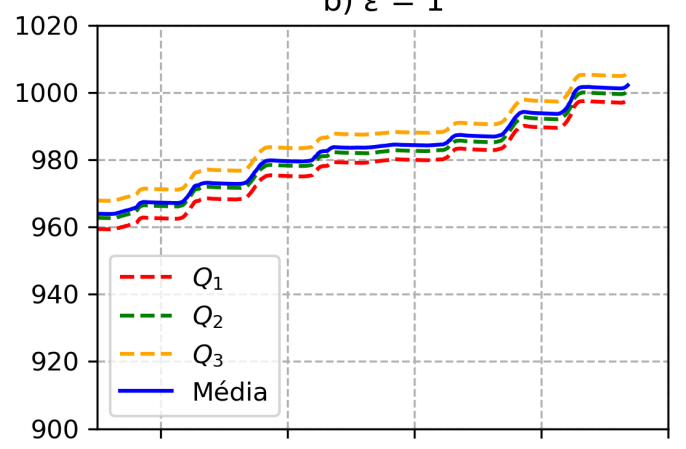

d) $\varepsilon=10$

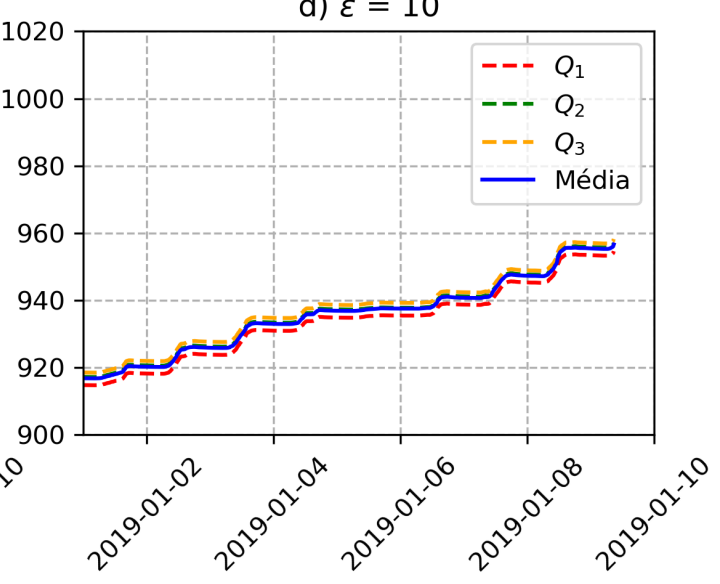

Fonte: Autor

Finalmente, foi feita a validação da reconstrução das taxas de ET (Figura 24) usando o coeficiente de eficiência de Nash-Sutcliffe (equação 4.1). Para isso, foram selecionados, aleatoriamente, $10 \%$ dos dados não rejeitados, para excluí-los da série temporal e realizar as reconstruções. Os dados selecionados $\left(E T_{\text {val }}\right)$ foram armazenados para calcular o $N S E$ em relação à média das 10 reconstruções $\left(E T_{r e c}\right)$.

Foram testadas várias percentagens para a validação, os resultados em forma de gráfico $Q-Q$ (Quantil) foram similares entre eles, apresentando-se maiores discrepâncias para percentagens maiores.

A validação apresentou bons resultados para os menores limites de rejeição, apresentando seu valor máximo $(N S E=0,77)$ para o limite de rejeição $\varepsilon=1$. Para limites de rejeição maiores, houve uma redução considerável no valor do $N S E$.

Os baixos valores do $N S E$ para limites de rejeição maiores, foram devidos ao alto número de discrepâncias não filtradas pelos limites de rejeição, as quais foram carregadas para os valores reconstruídos. Em contrapartida, os altos valores do NSE para limites de rejeição menores, foram devidos a uma boa filtragem das discrepâncias, pois a reconstrução foi feita com os valores com a menor incerteza. 
Figura 24 - Gráficos $Q-Q$ de $E T$ reconstruída $\left(E T_{\text {sim }}\right)$ x $E T$ não rejeitada $\left(E T_{\text {val }}\right)$ para diferentes percentagens rejeição
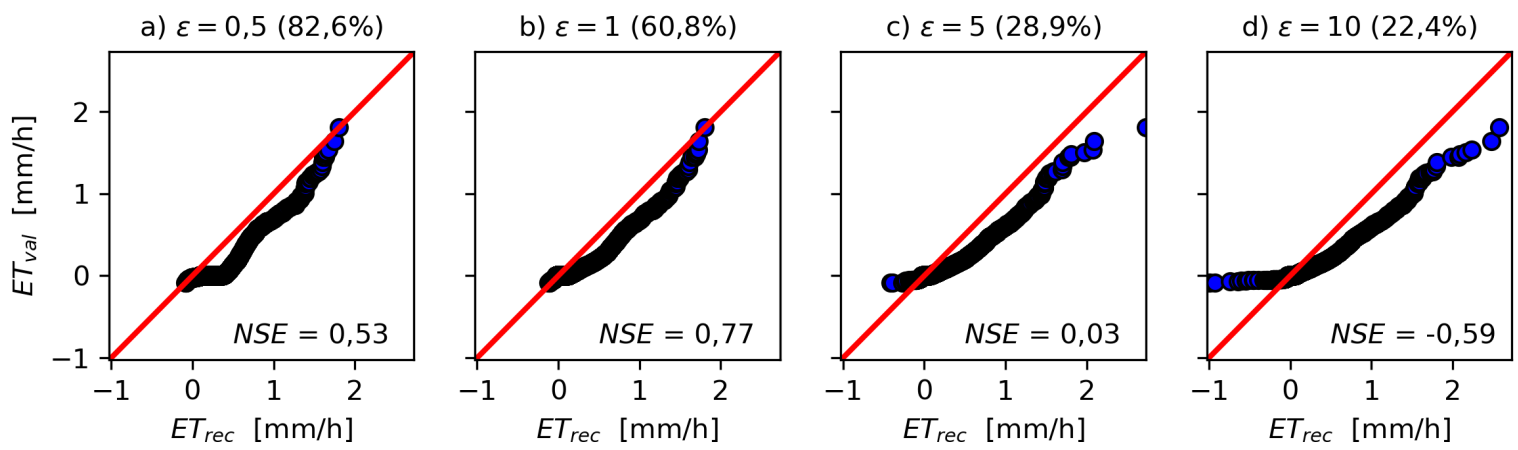

Fonte: Autor

Dado que o limite de rejeição $\varepsilon=1$ apresentou os melhores resultados em todas as avaliações feitas, foram escolhidos os resultados da reconstrução para esse limite de rejeição como os valores finais de ET pelo método de balanço de energia - Razão de Bowen.

Os resultados finais de ET pelo método de balanço de energia - Razão de Bowen são apresentados em forma de tabela no Apêndice E e na figura 25. Os períodos seco e chuvoso foram representados como os sombreados laranja e azul, respectivamente.

No período seco, a ET teve um comportamento crescente com um valor médio de 3,62 \pm 0,93 $\mathrm{mm} /$ dia. No período chuvoso, a ET teve um comportamento crescente até o mês de dezembro de 2018, entre dezembro de 2018 e janeiro de 2019, as taxas de ET foram as mais altas, atingindo seu valor máximo de aproximadamente $12 \mathrm{~mm} /$ dia, devido à combinação do elevado número de eventos de precipitação e às altas temperaturas, a ET média para o período chuvoso foi de 5, $09 \pm 2,34 \mathrm{~mm} /$ dia. Observa-se que, devido aos eventos de precipitação intermitentes, o período chuvoso teve uma maior dispersão das taxas de ET do que no período seco.

Figura 25 - ET calculada pelo método de balanço de energia - Razão de Bowen

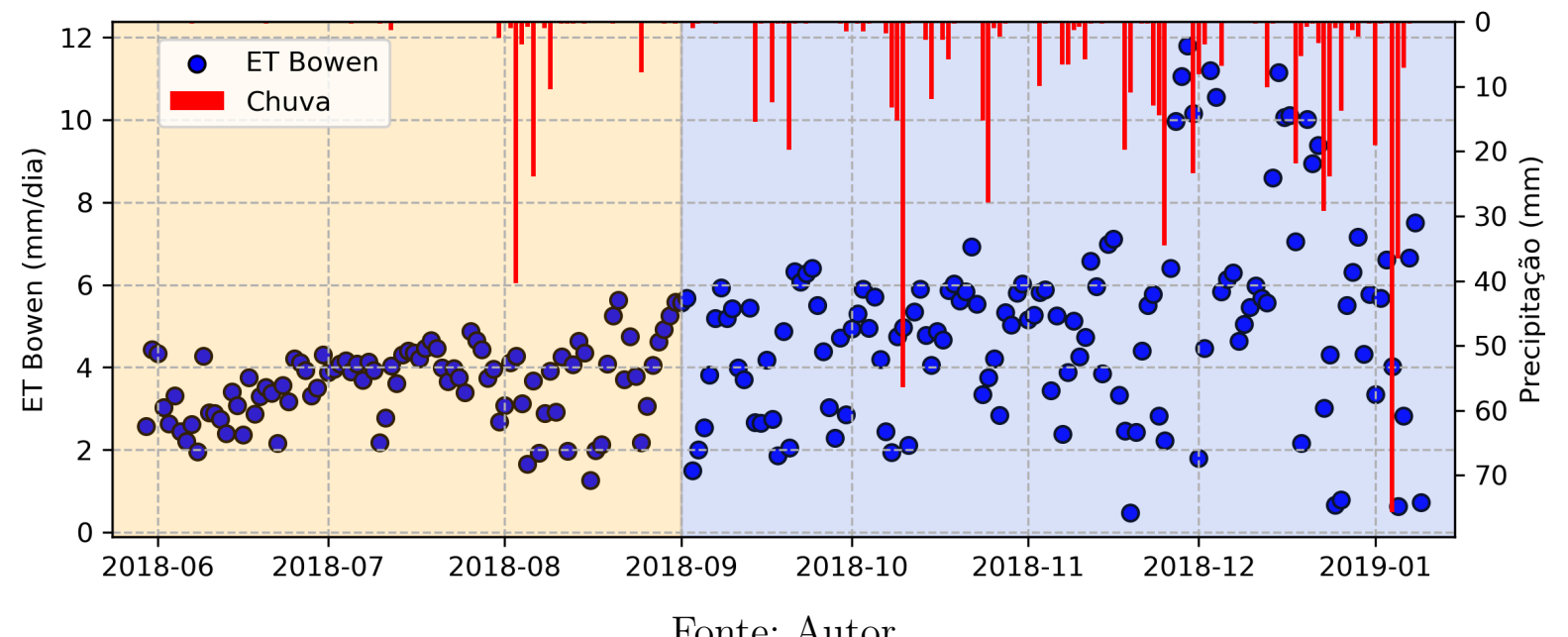

Fonte: Autor 


\subsection{Evapotranspiração pelos métodos baseados na flutuação diária do nível piezométrico}

\subsubsection{Preparação dos dados para a aplicação dos métodos}

Antes de calcular a ET pelos métodos mencionados no item 3.3, foi feita a compensação barométrica e foi aplicado o filtro de Loess nos dados dos poços de monitoramento (Figura 26).

Figura 26 - Nível piezométrico no poço P31

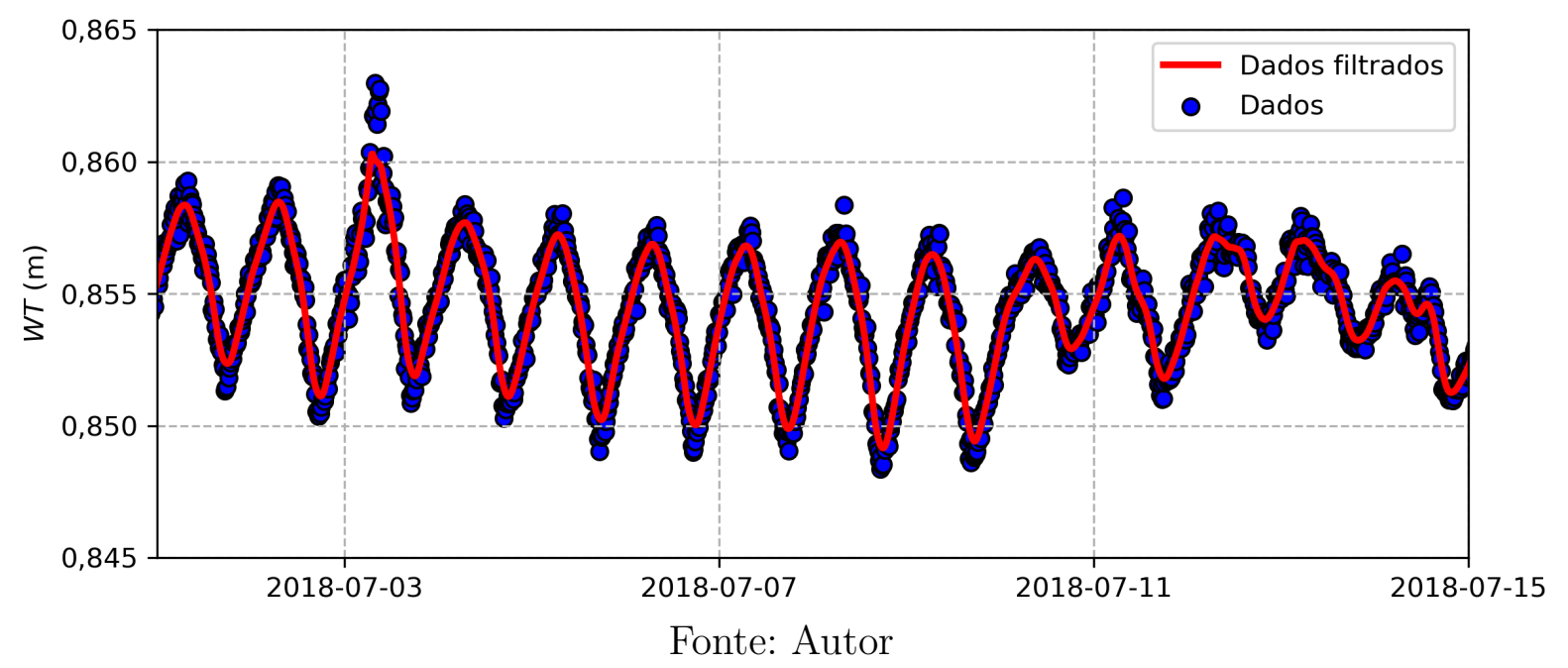

Depois de analisar os resultados de $E T$ para diferentes valores de $n$, conclui-se que, o impacto é baixo para os métodos que consideram a recarga lateral como fixa, dado que estimam a recarga ajustando o nível piezométrico a uma reta. Dessa forma os dados são ajustados duas vezes, a primeira pelo filtro de Loess e a segunda pelo próprio método. O segundo ajuste corrige o grau de ruído remanescente nos dados, independentemente do valor de $n$ escolhido no filtro de Loess.

Nos métodos que consideram a recarga lateral como variável, o impacto é alto, dado que a recarga é estimada em função da variação temporal do nível piezométrico $\left(\frac{d h}{d t}\right)$. A diferença dos métodos com recarga fixa, não é aplicado um segundo ajuste. Portanto, é necessário garantir na aplicação do filtro de Loess, um alto grau de suavidade com o fim de que as taxas de recarga estimadas resultem em taxas de $E T$ coerentes.

Finalmente, foi escolhido para cada poço um $n$ diferente em base ao analise dos resultados de $E T$ dos métodos que consideram a recarga lateral como variável, variando entre 16 e 24. No apêndice C são apresentados os gráficos correspondentes ao nível piezométrico após a aplicação do filtro de Loess, para cada um dos poços monitorados.

Com base nos dados de precipitação obtidos do pluviógrafo instalado na torre de monitoramento, foram excluídos os dias com eventos de precipitação e alguns dias 
posteriores, até que o nível piezométrico apresentasse o comportamento ondulatório normal, em vez de uma queda contínua do nível (Figura 27).

Figura 27 - Remoção dos dados de nível do poço P31 em dias com eventos de precipitação

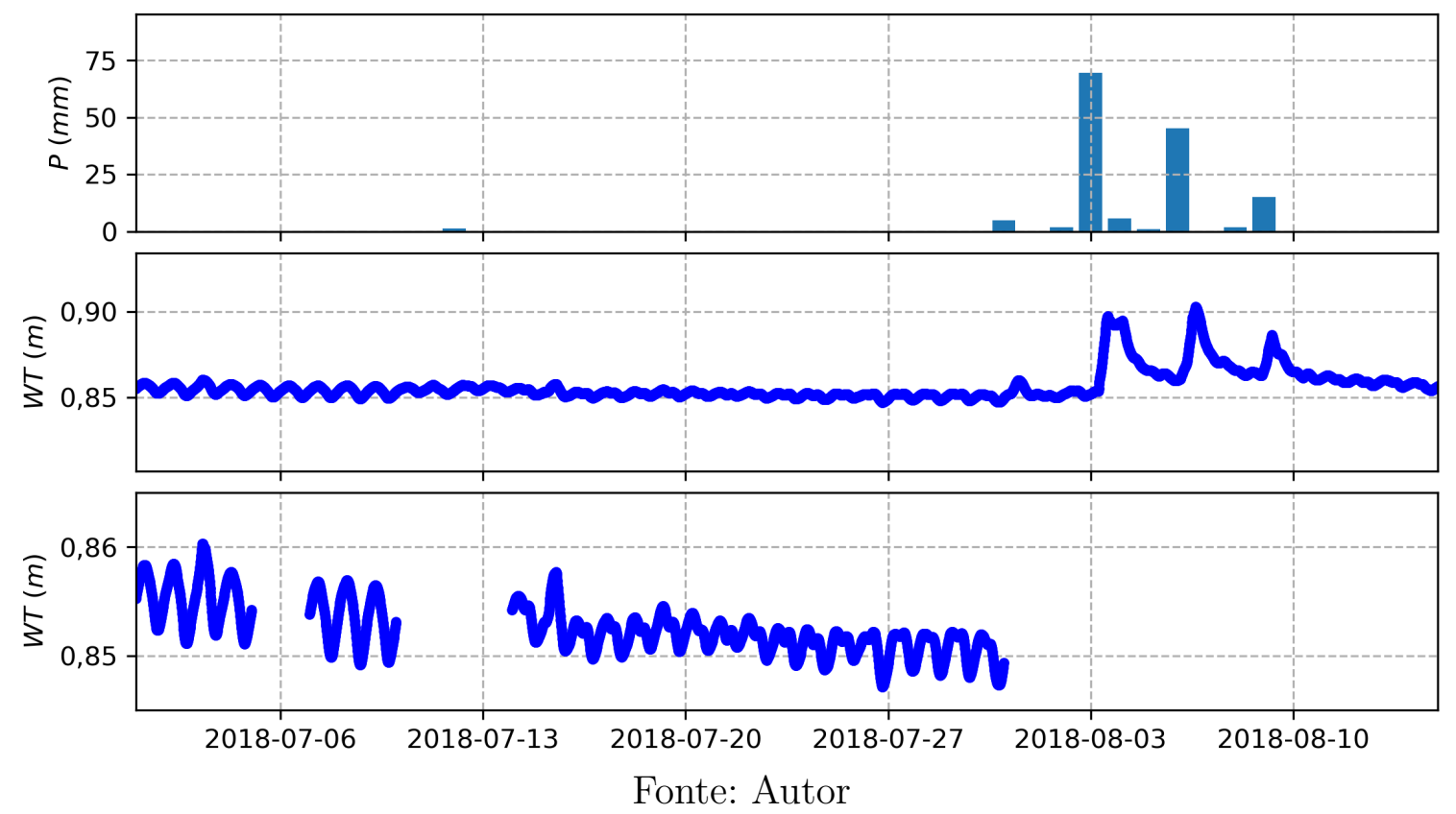

Os resultados de $E T$ foram agrupados em dois grupos de poços devido à semelhança no seu comportamento. O primeiro grupo, que apresentou um comportamento similar, contém os poços P27, P31, P32 e P33. O segundo grupo, que apresentou um comportamento discrepante, contém os poços P30 e P35. Devido ao comportamento do segundo grupo, foram consideradas as taxas de ET apenas do primeiro grupo.

Em todos os métodos, os poços P30 e P35 apresentaram as maiores e menores taxas de ET, respectivamente. Entre os possíveis motivos que explicam o anormal comportamento desses poços, destacam-se a localização e a natureza da camada de solo na qual flutua o nível piezométrico.

Como foi observado na figura 7, os poços P30 e P35 localizam-se mais perto do rio do que os outros poços. Adicionalmente, o poço P30 localiza-se aproximadamente a $30 \mathrm{~m}$ de uma das nascentes do ribeirão da Onça, portanto, as linhas de fluxo e as características físicas do solo na vizinhança do poço P30 diferem dos outros poços.

Por outra parte, foi observado em campo, diferentes profundidades do nível piezométrico e diferentes tipos de solo na vizinhança dos poços P30 e P35. Para o poço P30, o nível piezométrico é mais profundo que os outros poços e flutua em uma camada de solo predominantemente arenosa. Para o poço P35, o nível piezométrico é o mais superficial que os outros poços e flutua em uma camada de solo com um alto teor de matéria orgânica, enquanto para o primeiro grupo de poços, o nível piezométrico flutua em uma camada de transição entre a camada orgânica e a camada arenosa. 
Foram identificas as maiores taxas de ET no período chuvoso (outubro-março), e menores no período seco (abril-setembro). Em contrapartida, foi identificada uma maior densidade de pontos no período seco do que no período chuvoso.

Os períodos seco e chuvoso foram representados nos gráficos do item 5.3 como os sombreados laranja e azul, respectivamente. Nessas figuras, a escala na ordenada é diferente para os dois grupos de poços, devido a que, no segundo grupo de poços, os resultados de ET do poço P30 são maiores do que no primeiro grupo de poços e como foi dito somente foi considerado o primero grupo de poços.

Para o segundo grupo de poços, não foi possível estimar as taxas de ET no período chuvoso, pois a estabilização do nível piezométrico tardou mais do que no primeiro grupo de poços.

Os resultados de ET de todos os métodos é apresentado em forma de tabela no Apêndice F.

\subsubsection{Evapotranspiração pelo método de White}

Nos resultados do método de White (Figura 28), os poços P27 e P32 apresentaram um comportamento decrescente no período seco, enquanto que os poços P31 e P33 apresentaram um comportamento crescente no mesmo período. No período chuvoso, o comportamento do primeiro grupo de poços foi irregular. Em alguns dias, as taxas de ET aumentaram consideravelmente, mas em outros, as taxas de ET, foram da mesma magnitude que no período seco. Os resultados de ET do método de White, são apresentados em forma de tabela no item F.1.

Figura 28 - ET calculada pelo método de White
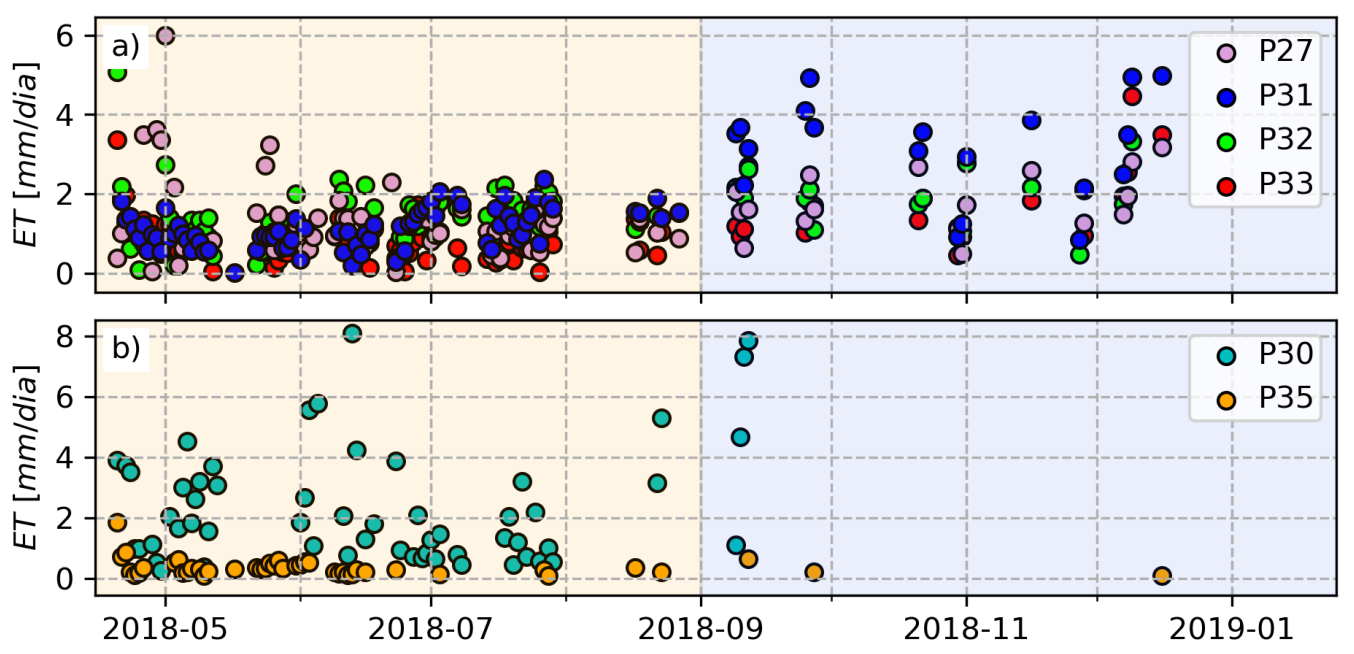

Fonte: Autor

Para o período seco, a taxa média diária de ET pelo método de White foi de $1,11 \pm 0,50 \mathrm{~mm} /$ dia e para o período chuvoso foi de $2,17 \pm 0,93 \mathrm{~mm} /$ dia . 
Nos resultados de ET da adaptação de Rushton (Figura 29), o primeiro grupo de poços (P27, P31, P32, P35) apresentou um comportamento crescente no período seco. No período chuvoso, o comportamento do primeiro grupo de poços foi mais irregular que no método de White (Figura 28). Em alguns dias, as taxas de ET aumentaram consideravelmente, mas em outros, as taxas de $E T$, foram da mesma magnitude que no período seco. Os resultados de ET da adaptação de Rushton, são apresentados em forma de tabela no item F.1.1.

Para o período seco, a taxa média diária de ET pela adaptação de Rushton foi de 0,83 \pm 0, $42 \mathrm{~mm} /$ dia e para o período chuvoso foi de $2,51 \pm 0,97 \mathrm{~mm} /$ dia.

Figura 29 - ET calculada pela adaptação de Rushton

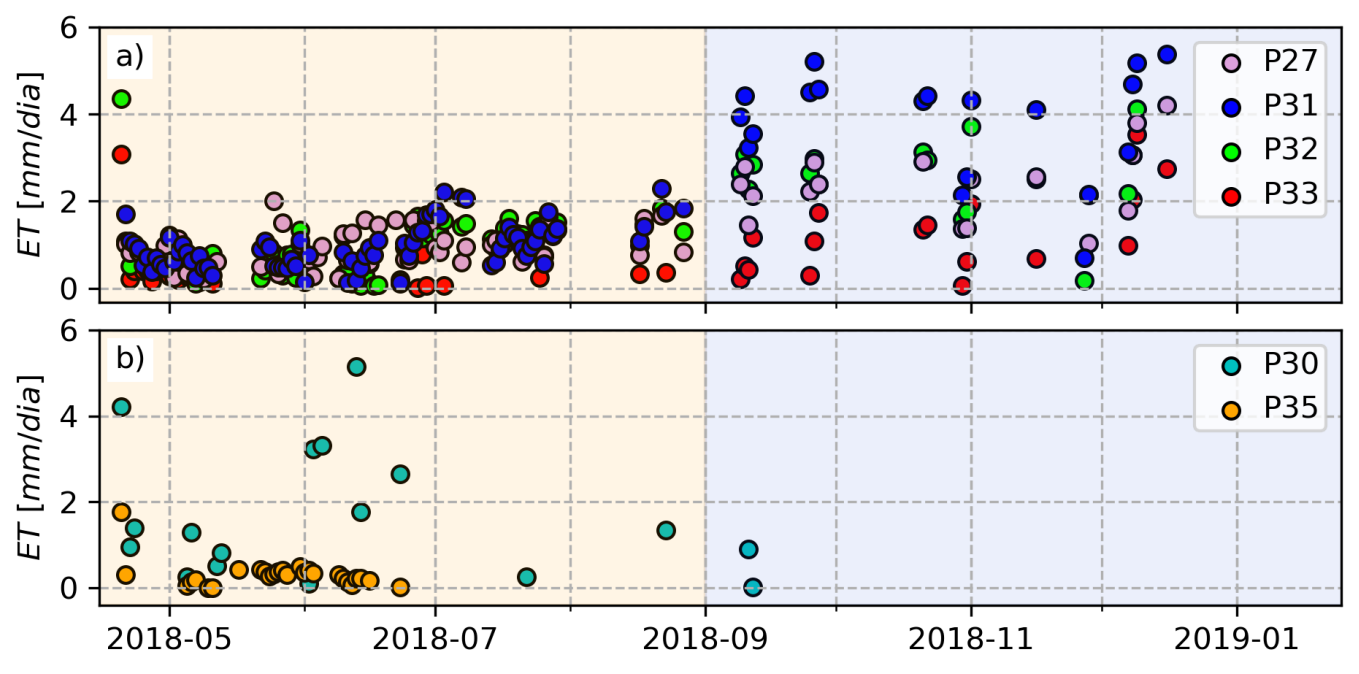

Fonte: Autor

Nos resultados de ET da adaptação de Hays (Figura 30) e da adaptação do Miller (Figura 31), os poços P31, P32 e P33 apresentaram um comportamento crescente no período seco, enquanto que o poço P27 apresentou um comportamento decrescente até a metade do período seco e crescente no resto do período. No período chuvoso, o comportamento do primeiro grupo de poços foi irregular, semelhante ao dos outros métodos anteriormente comentados. Os resultados de ET da adaptação de Hays e de Miller, são apresentados em forma de tabela nos itens F.1.2 e F.1.4, respectivamente.

Para o período seco, a taxa média diária de ET pela adaptação de Hays foi de $1,08 \pm 0,48 \mathrm{~mm} /$ dia e para o período chuvoso foi de $2,28 \pm 0,88 \mathrm{~mm} /$ dia. Para a adaptação de Miller, a taxa de ET média diária para o período seco foi de 0,80 \pm 0,36 $\mathrm{mm} /$ dia e para o período chuvoso foi de $1,92 \pm 0,73 \mathrm{~mm} /$ dia. 
Figura 30 - ET calculada pela adaptação de Hays
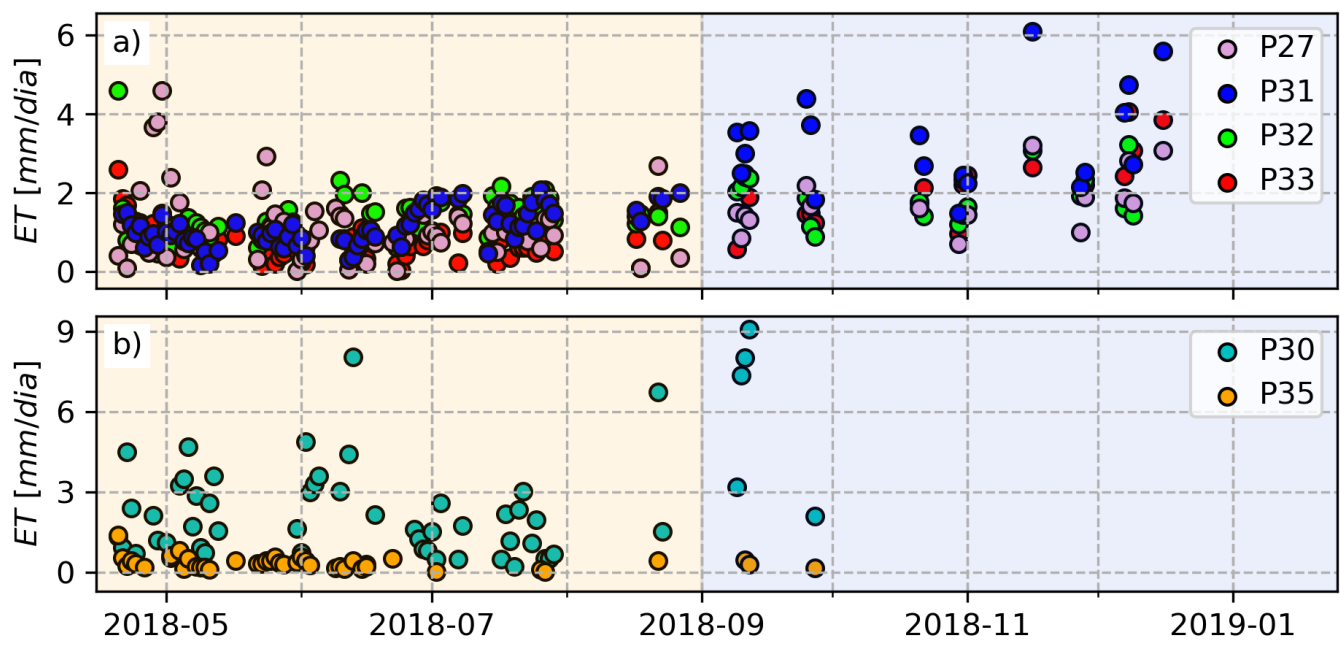

Fonte: Autor

Figura 31 - ET calculada pela adaptação de Miller
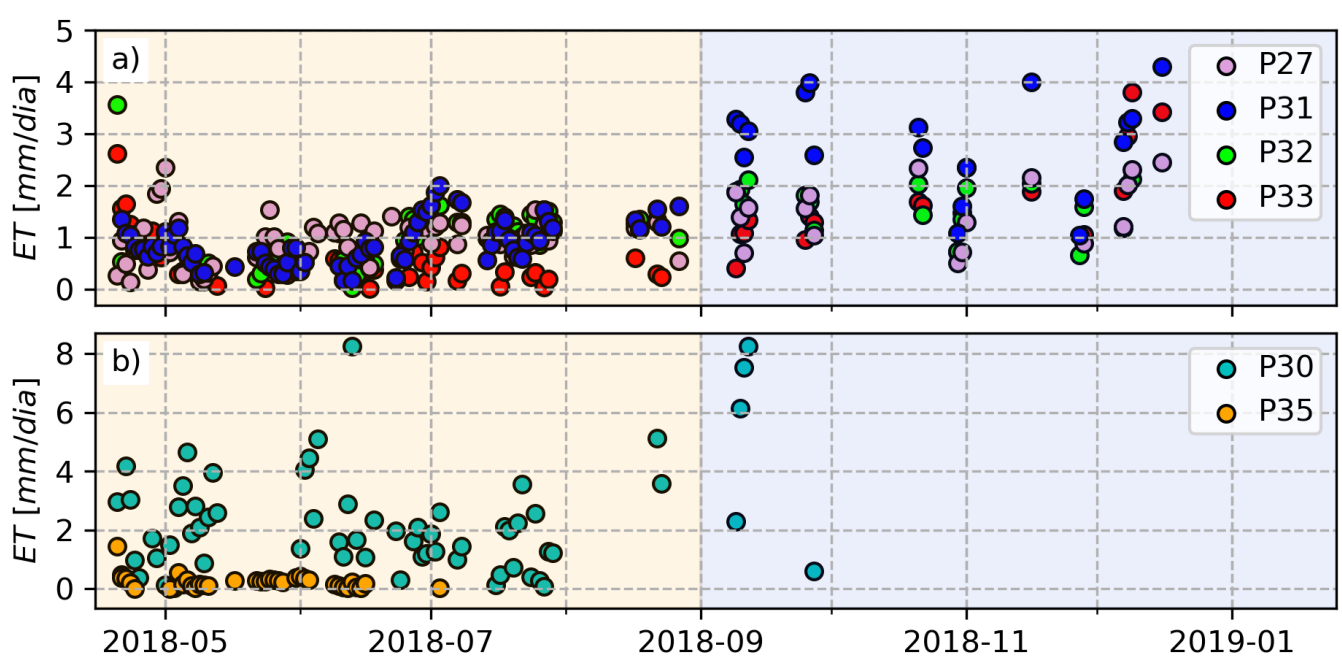

Fonte: Autor

Nos resultados da adaptação de Loheide II (Figura 32), os poços P27 e P33 apresentaram um comportamento decrescente no período seco, enquanto que os poços P31 e P32 apresentaram um comportamento crescente no mesmo período. No período chuvoso, o comportamento do primeiro grupo de poços foi irregular. Os resultados de ET da adaptação de Loheide II, são apresentados em forma de tabela no item F.1.3.

Para o período seco a taxa média diária de ET pela adaptação de Loheide II foi de $0,82 \pm 0,38 \mathrm{~mm} /$ dia e para o período chuvoso foi de $1,72 \pm 0,80 \mathrm{~mm} /$ dia. 
Figura 32 - ET calculada pela adaptação de Loheide II
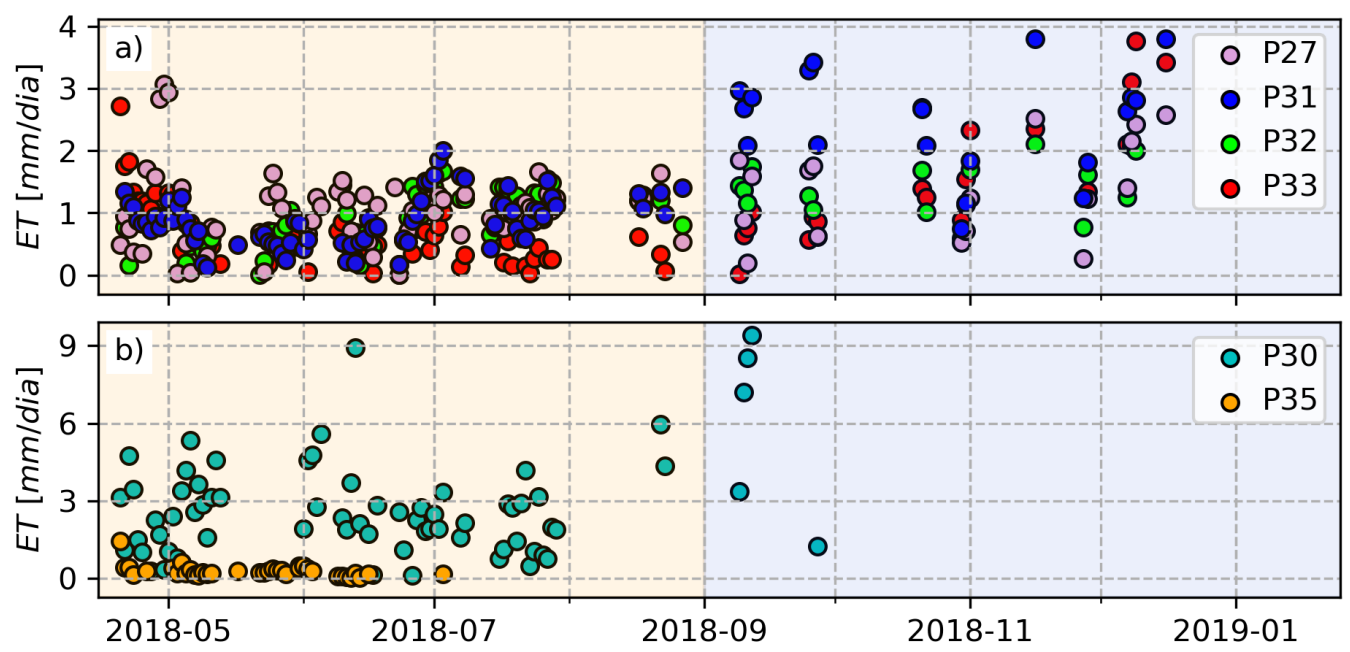

Fonte: Autor

\subsubsection{Evapotranspiração pelo método de Dolan}

Nos resultados do método de Dolan (Figura 33), o primeiro grupo de poços apresentou um comportamento crescente no período seco. No período chuvoso, o comportamento foi crescente, as taxas de ET aumentaram a partir do início das chuvas e a faixa de variação foi menor em comparação ao método de White e suas adaptações. Os resultados de ET do método de Dolan, são apresentados em forma de tabela no item F.2.

Figura 33 - ET calculada pelo método de Dolan

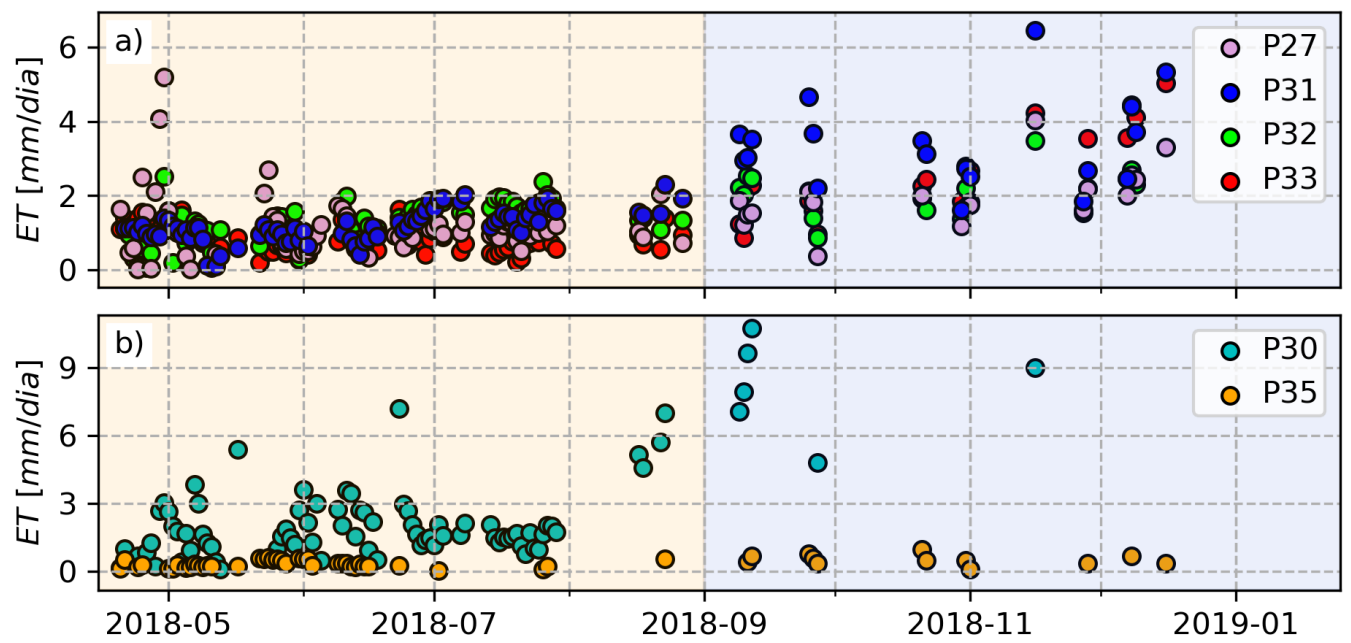

Fonte: Autor

Para o período seco, a taxa média diária de ET pelo método de Dolan foi de $1,14 \pm 0,39 \mathrm{~mm} /$ dia e para o período chuvoso foi de $2,52 \pm 0,96 \mathrm{~mm} /$ dia. 


\subsubsection{Evapotranspiração pelo método de Hays}

Nos resultados do método de Hays (Figura 34), os poços P27 e P32 apresentaram um comportamento decrescente no período seco, o poço P33 apresentou um comportamento constate e o poço P31 apresentou um comportamento crescente no mesmo período. No período chuvoso, o comportamento foi crescente, as taxas de ET aumentaram a partir do início das chuvas e a faixa de variação foi menor em comparação aos métodos apresentados anteriormente. Os resultados de ET do método de Hays, são apresentados em forma de tabela no item F.3.

Figura 34 - ET calculada pelo método de Hays
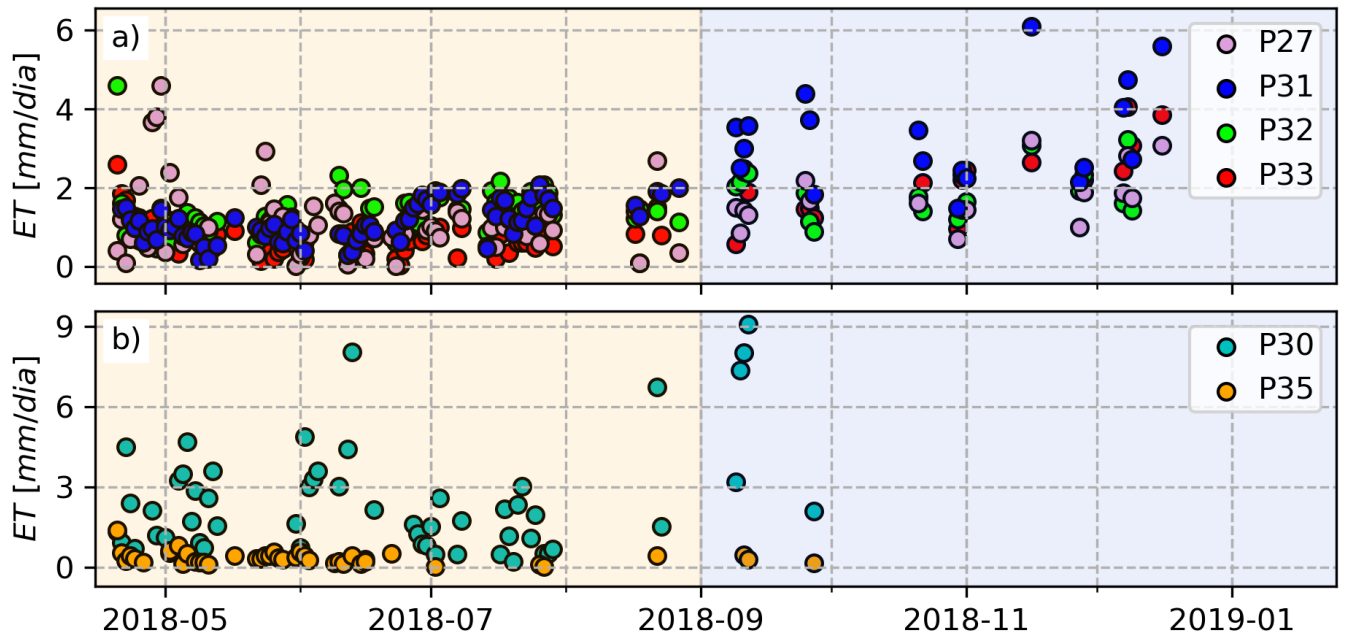

Fonte: Autor

Para o período seco, a taxa média diária de ET pelo método de Hays foi de No instante em que o nível é máximo, a vizinhança e a zona ripária têm aproximadamente o mesmo nível piezométrico, portanto, o gradiente hidráulico é mínimo, ou seja, o fluxo lateral é mínimo. Em contrapartida, no instante em que o nível é mínimo, o gradiente hidráulico é máximo, ou seja, o fluxo lateral é máximo.1, $35 \pm 0,59 \mathrm{~mm} /$ dia e para o período chuvoso foi de $3,06 \pm 0,94 \mathrm{~mm} /$ dia.

\subsubsection{Evapotranspiração pelo método de Gribovski}

Nos resultados do método de Gribovski (Figura 35), os poços P27 e P32 apresentaram um comportamento decrescente no período seco, enquanto que os poços P31 e P33 apresentaram um comportamento crescente no mesmo período. No período chuvoso, o comportamento foi crescente, as taxas de ET aumentaram a partir do início das chuvas. Comparativamente, a faixa de variação foi menor que no método de Hays (Figura 34). Os resultados de ET do método de Gribovsky, são apresentados em forma de tabela no item F.4. 
Para o período seco, a taxa média diária de ET pelo método de Gribovski foi de 1,95 \pm 0,58 $\mathrm{mm} /$ dia e para o período chuvoso, foi de 4,60 $\pm 1,69 \mathrm{~mm} /$ dia, sendo as maiores taxas apresentadas dos métodos anteriores.

Figura 35 - ET calculada pelo método de Gribovski
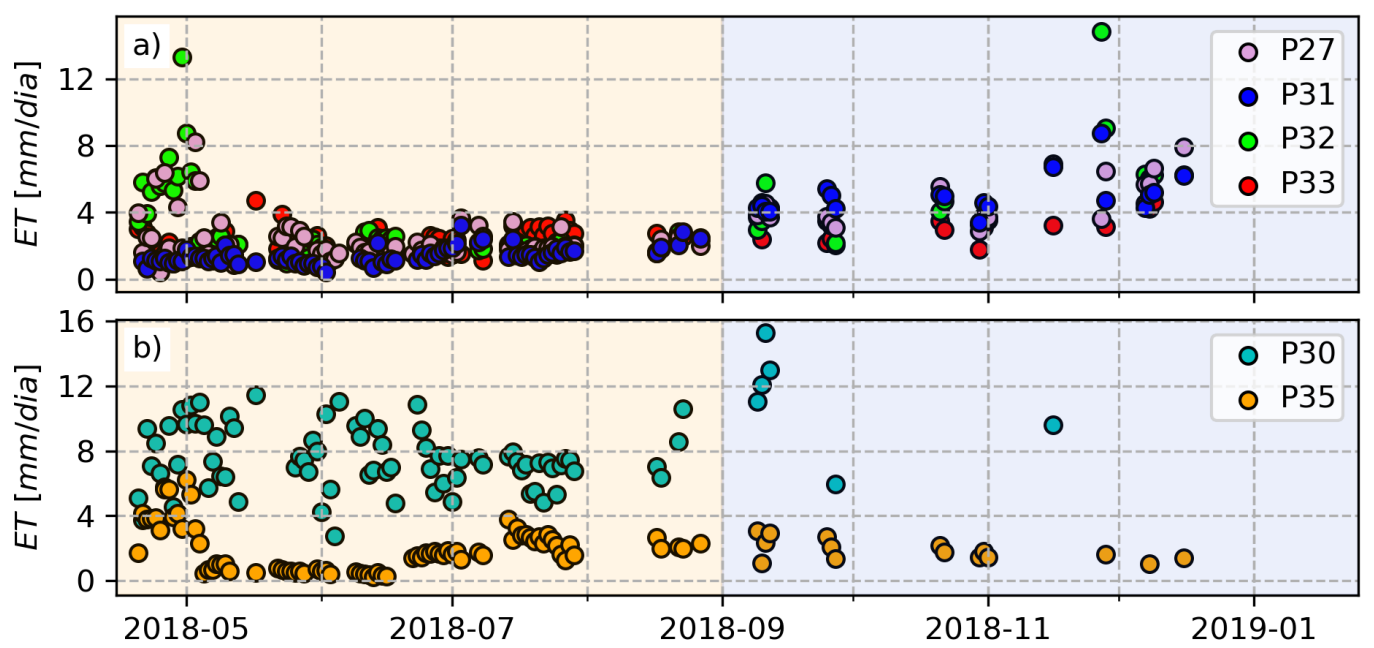

Fonte: Autor

\subsubsection{Evapotranspiração pelo método de Loheide II}

Nos resultados do método do Loheide II (Figura 36), todos os poços apresentaram um comportamento crescente no período seco. No período chuvoso, o comportamento foi crescente, as taxas de ET aumentaram até $19 \mathrm{~mm} /$ dia, aproximadamente, e a faixa de variação aumentou gradualmente com o tempo transcorrido desde o começo das chuvas. Os resultados de ET do método de Loheide II, são apresentados em forma de tabela no item F.5. Para o período seco, a taxa média diária de ET pelo método de Loheide II foi de 1,96 \pm 0,77 $\mathrm{mm} /$ dia e para o período chuvoso foi de $6,30 \pm 3,00 \mathrm{~mm} /$ dia.

Figura 36 - ET calculada pelo método de Loheide II

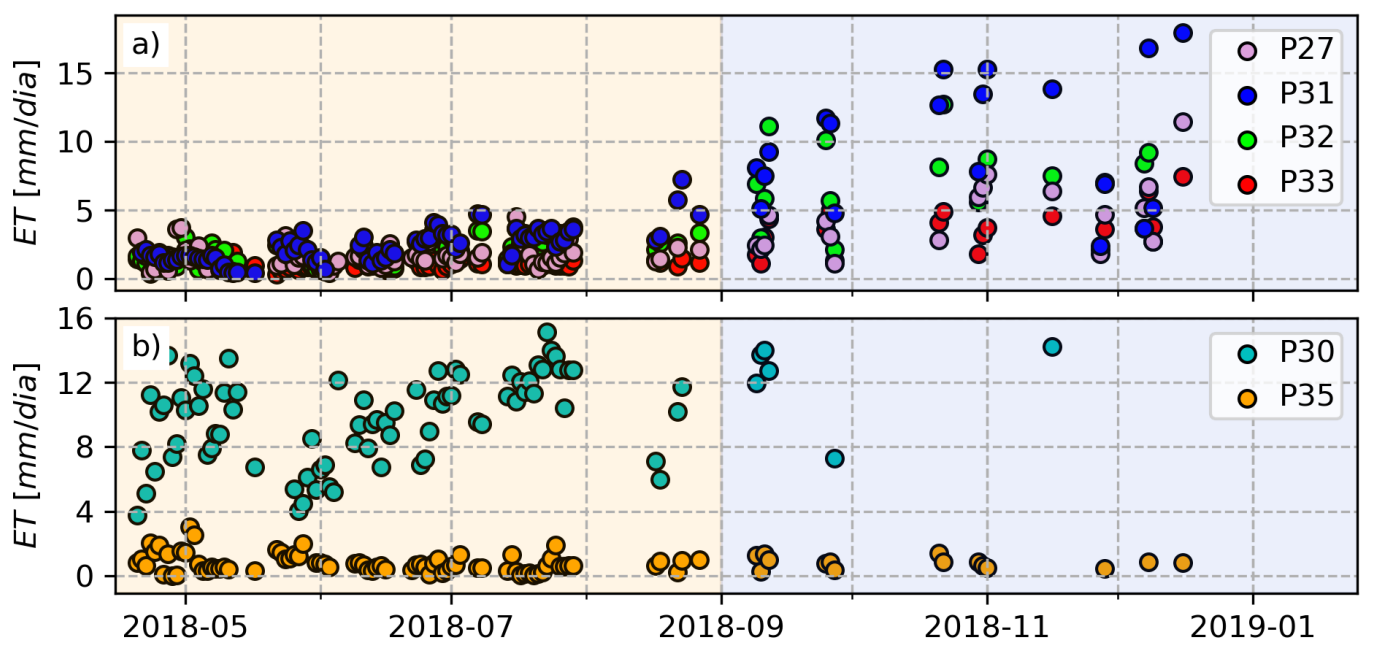

Fonte: Autor 


\subsubsection{Evapotranspiração pelo método de Soylu}

Nos resultados do método de Soylu (Figura 37), os poços P31 e P32 apresentaram um comportamento constante para vários intervalos de tempo no período seco, enquanto que os poços P27 e P33 apresentaram um comportamento crescente no mesmo período.

Figura 37 - ET calculada pelo método de Soylu
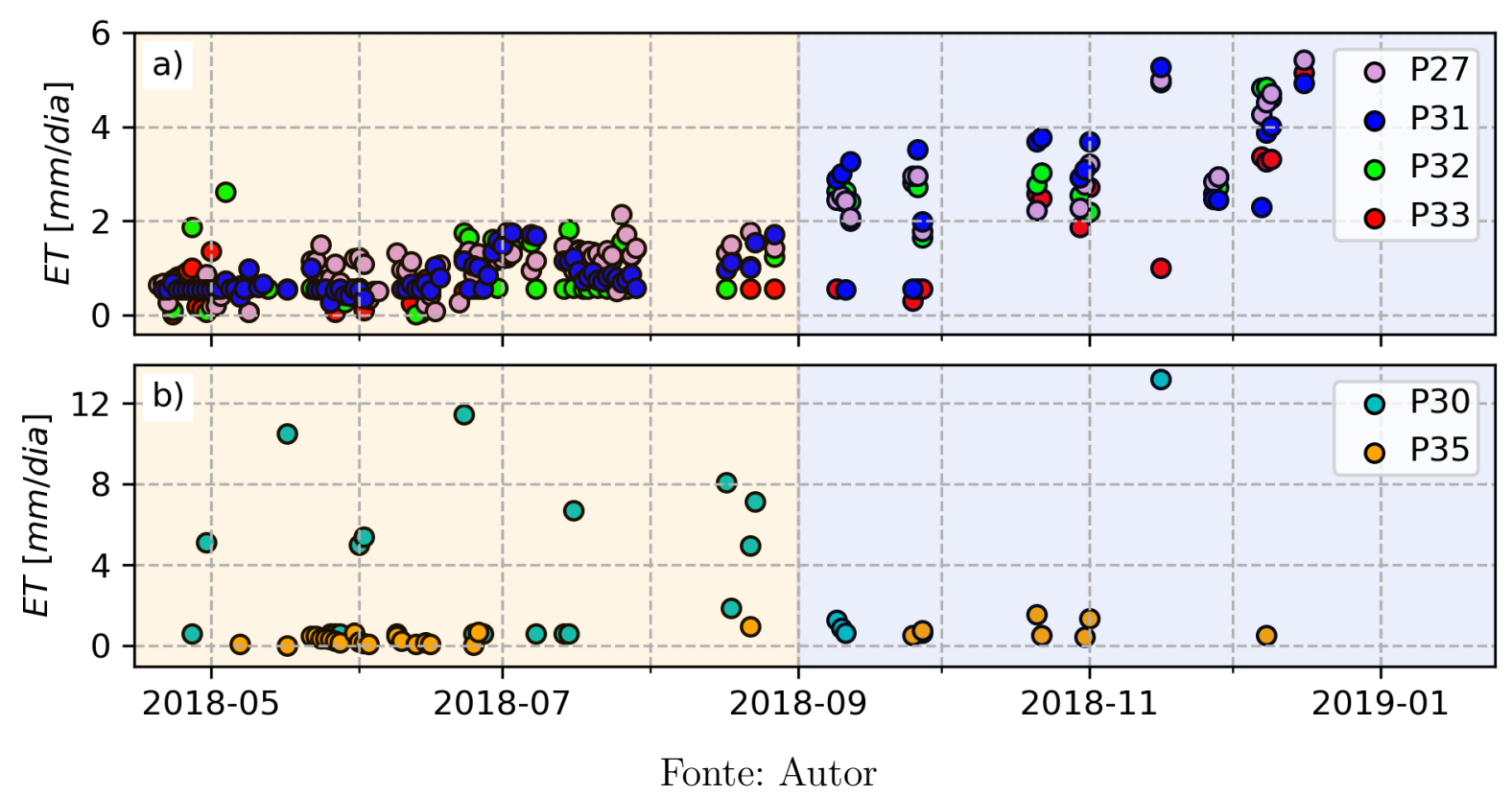

No período chuvoso, o comportamento foi crescente para todos os poços. Os resultados de ET do método de Soylu, são apresentados em forma de tabela no item F.6. Para o período seco, a taxa média diária de ET pelo método de Soylu foi de 0,84 \pm 0,40 $\mathrm{mm} /$ dia e para o período chuvoso foi de 2,88 $\pm 1,17 \mathrm{~mm} /$ dia.

\subsubsection{Resultados de evapotranspiração dos métodos baseados na flutuação diária do nível piezométrico}

As diferenças entre as estimativas de ET de cada um dos métodos são devidas à forma de considerar e estimar a recarga lateral $(r)$, a qual, como foi demostrada por Troxell (1936), varia ao longo do dia, sendo os métodos de Gribovszki et al. (2008) e II (2008) os únicos que consideram esse fato.

Entre os métodos de Gribovski e Loheide II, a melhor representação da recarga lateral é dada pelo método de Gribovski, o qual, realizando o menor número de supostos, consegue estimar a recarga em função do gradiente hidráulico existente entre a zona ripária e sua vizinhança.

Os valores médios de ET pelos diferentes métodos foram compilados na Tabela 8. Os métodos de Gribovski e Loheide II apresentaram as maiores taxas de ET nos períodos 
5.4. Avaliação dos métodos baseados nas flutuações diárias do nível piezométrico usando o método de balanço de energia - Razão de Bowen

seco e chuvoso. Em contrapartida, a adaptação de Miller apresentou as menores taxas de ET nos períodos seco e chuvoso. O método com a menor razão entre o desvio padrão e a média foi o método de Gribovski no período seco e o método de Hays no período chuvoso.

Tabela 8 - Resultados de evapotranspiração ET ( $\mathrm{mm} /$ dia $)$ estimadas pelos métodos baseados na flutuação diária do nível piezométrico

\begin{tabular}{lcccc}
\hline \multirow{2}{*}{ Método } & \multicolumn{2}{c}{ Período seco } & \multicolumn{2}{c}{ Período chuvoso } \\
\cline { 2 - 5 } & Média & Desvio & Média & Desvio \\
\hline White & 1,11 & 0,50 & 2,17 & 0,93 \\
White/Rushton & 0,83 & 0,42 & 2,51 & 0,97 \\
White/Hays & 1,08 & 0,48 & 2,28 & 0,88 \\
White/Loheide II & 0,82 & 0,38 & 1,72 & 0,80 \\
White/Miller & 0,80 & 0,36 & 1,92 & 0,73 \\
Dolan & 1,14 & 0,39 & 2,52 & 0,96 \\
Hays & 1,35 & 0,59 & 3,06 & 0,94 \\
Gribovski & 1,95 & 0,58 & 4,60 & 1,69 \\
Loheide II & 1,96 & 0,77 & 6,30 & 3,00 \\
Soylu & 0,84 & 0,40 & 2,88 & 1,17 \\
\hline \multicolumn{1}{c}{ Média } & 1,19 & 0,49 & 3,00 & 1,21 \\
\hline \multicolumn{2}{c}{ Fonte: Autor } & &
\end{tabular}

\subsection{Avaliação dos métodos baseados nas flutuações diárias do nível piezométrico usando o método de balanço de energia - Razão de Bowen}

Para a validação das estimativas dos métodos baseados nas flutuações diárias do nível piezométrico, foram consideradas as estimativas dos poços P27, P31, P32 e P33, pelos motivos mencionados no item 5.3.1. Nos itens seguintes serão apresentados os resultados da correlação existente entre os resultados de ET de cada um dos métodos e os resultados de ET do método de balanço de energia - Razão de Bowen em forma de figuras.

Nessas figuras, o eixo das abscissas corresponde às estimativas de ET do método de balanço de energia - Razão de Bowen e o eixo das ordenadas corresponde às estimativas de ET calculada por algum dos métodos baseados na flutuação diária do nível piezométrico. A linha vermelha corresponde à tendência do ajuste do conjunto de dados ao modelo linear, a linha cinza tracejada corresponde à linha $1: 1$ e o valor $\rho$ apresentado nos gráficos corresponde ao coeficiente de correlação de Pearson (equação 4.4). Por último, os pontos laranjas e azuis representam os períodos seco e chuvoso, respectivamente. 


\subsubsection{Avaliação do método de White e suas adaptações}

De forma geral, os coeficientes de correlação do método de White (Figura 38) foram os menores $\left(\bar{\rho}=0,30 e \overline{\tau_{s}}=0,28\right)$, devido à escolha do dia em que acontece a $E T$ e ao curto periodo de tempo utilizado para estimar a recarga lateral $(r)$. Os erros entre as estimativas $(\overline{M A E}=2,90 \mathrm{~mm} /$ dia $, \overline{R M S E}=3,28 \mathrm{~mm} /$ dia e $\overline{M B E}=-2,89 \mathrm{~mm} /$ dia $)$ mostraram que, a diferença foi devida, principalmente, à subestimativa das taxas de $E T$ pelo método $(\overline{M A E} \approx|\overline{M B E}|)$. Além disso, o número de pontos com grandes diferenças ortogonais da linha vermelha foram poucos $(\overline{M A E}=0,88 \overline{R M S E})$.

Figura 38 - Correlação entre as estimativas de ET do método de balanço de energia Razão de Bowen e o método de White

a) P27

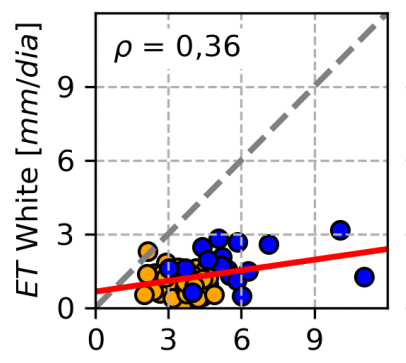

b) P31

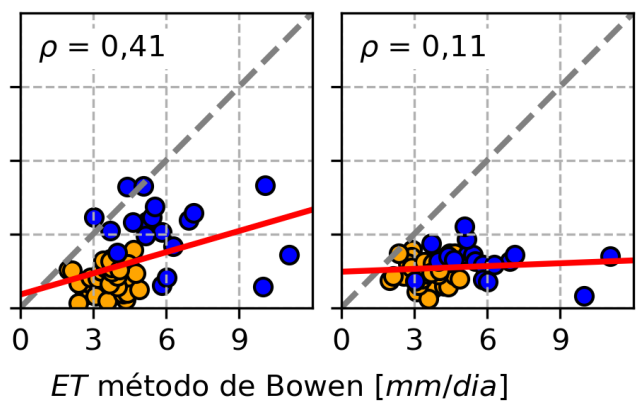

d) P33

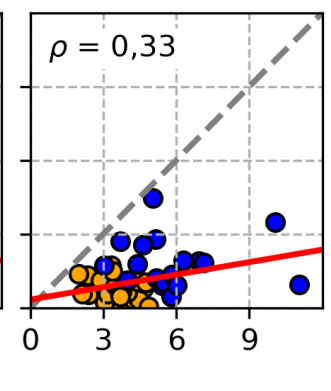

Fonte: Autor

As adaptações de Loheide II (Figura 39) e de Miller (Figura 40) diferente do método de White, estimam a taxa de recarga lateral considerando tanto o dia em que acontece a $E T$ como o dia subsequente. O fato de considerar o dia subsequente melhorou os coeficientes de correlação (Loheide II, $\bar{\rho}=0,30 e \overline{\tau_{s}}=0,28$ e Miller $\bar{\rho}=0,42 e \overline{\tau_{s}}=0,45$ ) em comparação com o método de White.

Figura 39 - Correlação entre as estimativas de ET do método de balanço de energia Razão de Bowen e da adaptação de Loheide II

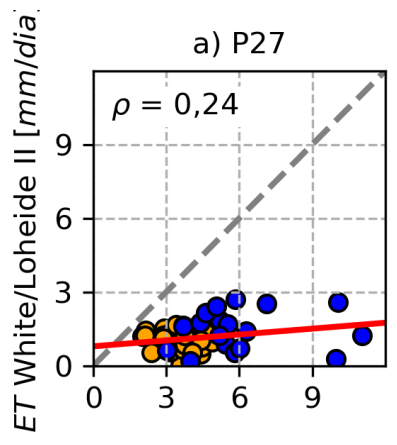

b) P31

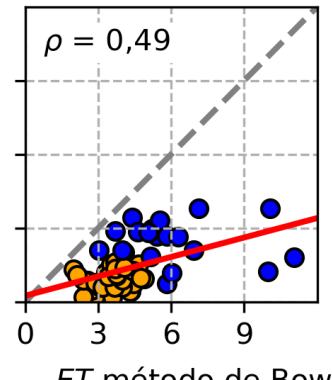

ET método de Bowen $[\mathrm{mm} / \mathrm{dia}]$ c) P32

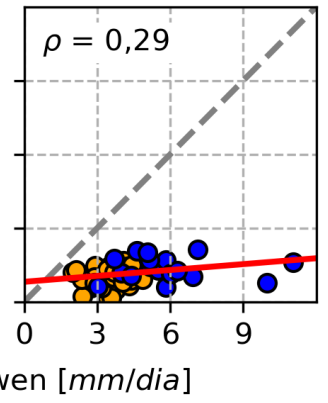

d) P33

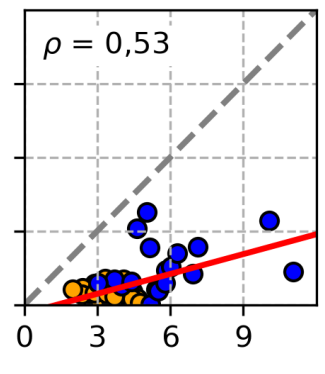

Fonte: Autor

Os erros entre as estimativas da adaptação de Loheide II $(\overline{M A E}=3,23 \mathrm{~mm} /$ dia, $\overline{R M S E}=3,56 \mathrm{~mm} /$ dia e $\overline{M B E}=-3,23 \mathrm{~mm} /$ dia) mostraram que a diferença foi devida, 
5.4. Avaliação dos métodos baseados nas flutuações diárias do nível piezométrico usando o método de balanço de energia - Razão de Bowen

principalmente, à subestimativa das taxas de $E T$ pela adaptação $(\overline{M A E} \approx|\overline{M B E}|)$. Além disso, o número de pontos com grandes diferenças ortogonais da linha vermelha foram poucos $(\overline{M A E}=0,91 \overline{R M S E})$.

Figura 40 - Correlação entre as estimativas de ET do método de balanço de energia Razão de Bowen e da adaptação de Miller

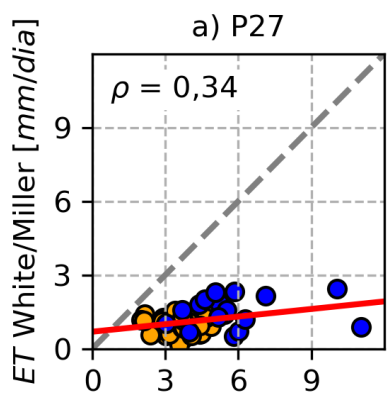

b) P31

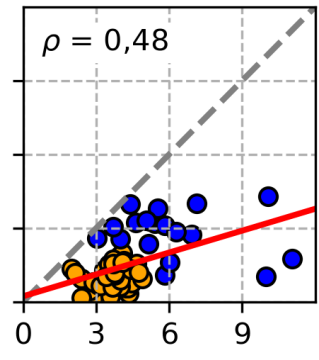

ET método de Bowen [mm/dia] c) P32

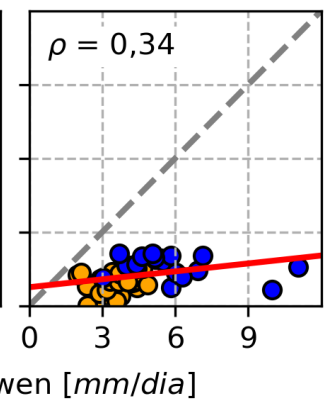

d) P33

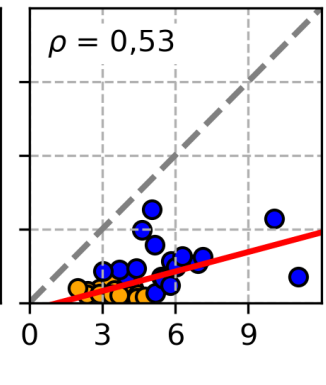

Fonte: Autor

Os erros entre as estimativas da adaptação de Miller $(\overline{M A E}=3,17 \mathrm{~mm} /$ dia, $\overline{R M S E}=3,49 \mathrm{~mm} /$ dia e $\overline{M B E}=-3,17 \mathrm{~mm} /$ dia) mostraram que a diferença foi devida, principalmente, à subestimativa das taxas de $E T$ pela adaptação $(\overline{M A E} \approx|\overline{M B E}|)$. Além disso, o número de pontos com grandes diferenças ortogonais da linha vermelha são poucos $(\overline{M A E}=0,91 \overline{R M S E})$.

A adaptação de Hays (Figura 41) propôs, acertadamente $\left(\bar{\rho}=0,51\right.$ e $\left.\overline{\tau_{s}}=0,47\right)$, que a taxa de recarga lateral, mesmo sendo em um período de tempo curto (4h00), devia ser estimada considerando somente os dados do nível do dia seguinte. A melhora no coeficiente de correlação, em comparação às adaptações de Rushton e Loheide II, evidencia que o comportamento do nível piezométrico no período entre o pôr do sol e o amanhecer do dia seguinte, foi controlado pela ET do dia.

Figura 41 - Correlação entre as estimativas de ET do método de balanço de energia Razão de Bowen e da adaptação de Hays

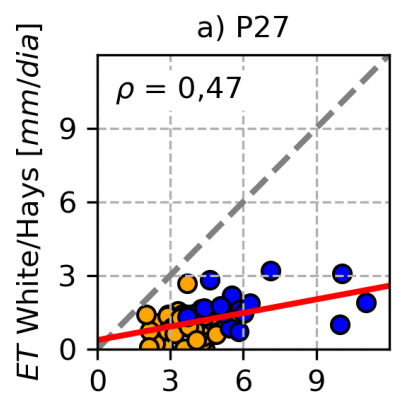

b) P31

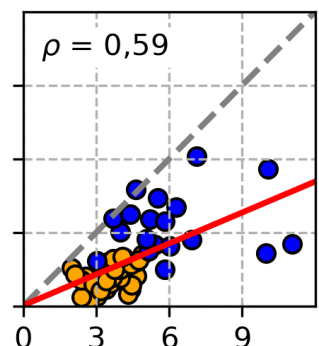

$E T$ método de Bowen [ $\mathrm{mm} / \mathrm{dia}]$ c) P32

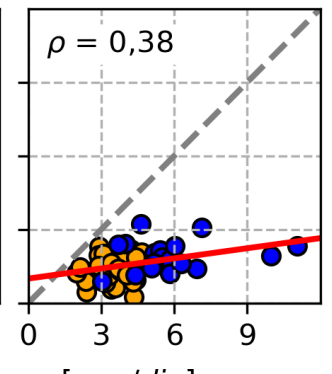

d) P33

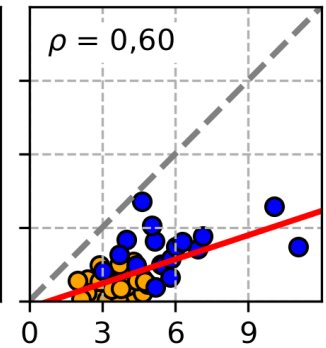

Fonte: Autor 
Os erros entre as estimativas da adaptação de Hays $(\overline{M A E}=2,91 \mathrm{~mm} /$ dia , $\overline{R M S E}=3,23 \mathrm{~mm} /$ dia e $\overline{M B E}=-2,91 \mathrm{~mm} /$ dia) mostraram que a diferença foi devida, principalmente, à subestimativa das taxas de $E T$ pela adaptação $(\overline{M A E} \approx|\overline{M B E}|)$. Além disso, o número de pontos com grandes diferenças ortogonais da linha vermelha foram poucos $(\overline{M A E}=0,90 \overline{R M S E})$.

Figura 42 - Correlação entre as estimativas de ET do método de balanço de energia Razão de Bowen e da adaptação de Rushton

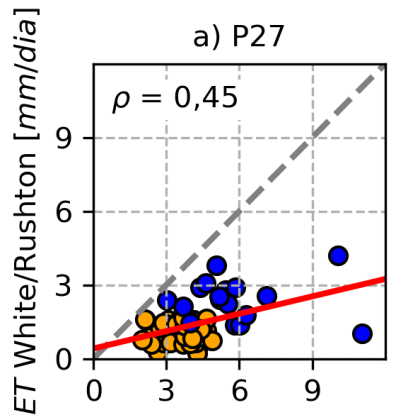

b) P31

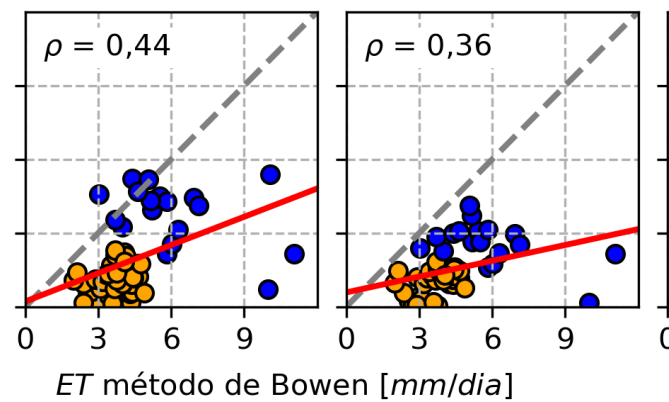

d) P33

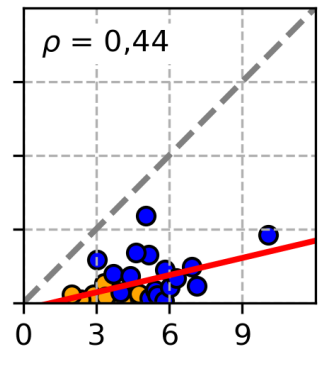

Fonte: Autor

A adaptação de Rushton (Figura 42) apesar de estimar a taxa de recarga lateral sem considerar o dia subsequente, incrementou o intervalo de tempo para 12h00, melhorando os coeficientes de correlação $\left(\bar{\rho}=0,42 e \overline{\tau_{s}}=0,45\right)$. Esse aumento nos coeficientes de correlação, em comparação ao método original de White, provavelmente se deve a que a taxa de ET em dias sucessivos (sem alterações significativas nas variáveis meteorológicas), é quase a mesma, ou seja, estimar a recarga lateral considerando o dia anterior, reflete, o efeito de estimar a recarga lateral considerando o dia subsequente.

Os erros entre as estimativas da adaptação de Rushton $(\overline{M A E}=3,04 \mathrm{~mm} / \mathrm{dia}$, $\overline{R M S E}=3,38 \mathrm{~mm} /$ dia e $\overline{M B E}=-3,02 \mathrm{~mm} /$ dia) mostraram que a diferença foi devida, principalmente, à subestimativa das taxas de $E T$ pela adaptação $(\overline{M A E} \approx|\overline{M B E}|)$. Além disso, o número de pontos com grandes diferenças ortogonais da linha vermelha são poucos $(\overline{M A E}=0,90 \overline{R M S E})$.

As diferenças existentes entre os coeficientes de correlação do método de White e suas adaptações foram devidas ao intervalo de tempo utilizado para estimar a recarga lateral em cada um dos métodos.

\subsubsection{Avaliação do método de Dolan}

O método de Dolan (Figura 43) ao mudar um pouco a ideia de White, propôs a existência de duas taxas de recarga lateral no dia, entre $0 h 00-12 h 00$ e entre $12 h 00-24 h 00$. Adicionalmente, propôs que a variação no armazenamento devia ser estimada como a diferença das extrapolações das taxas de recarga lateral às 12h00. Essa abordagem 
5.4. Avaliação dos métodos baseados nas flutuações diárias do nível piezométrico usando o método de balanço de energia - Razão de Bowen

mostrou, novamente, um aumento nos coeficientes de correlação $\left(\bar{\rho}=0,58 e \overline{\tau_{s}}=0,54\right)$, pela consideração do dia subsequente no cálculo da recarga lateral.

Figura 43 - Correlação entre as estimativas de ET do método de balanço de energia Razão de Bowen e o método de Dolan
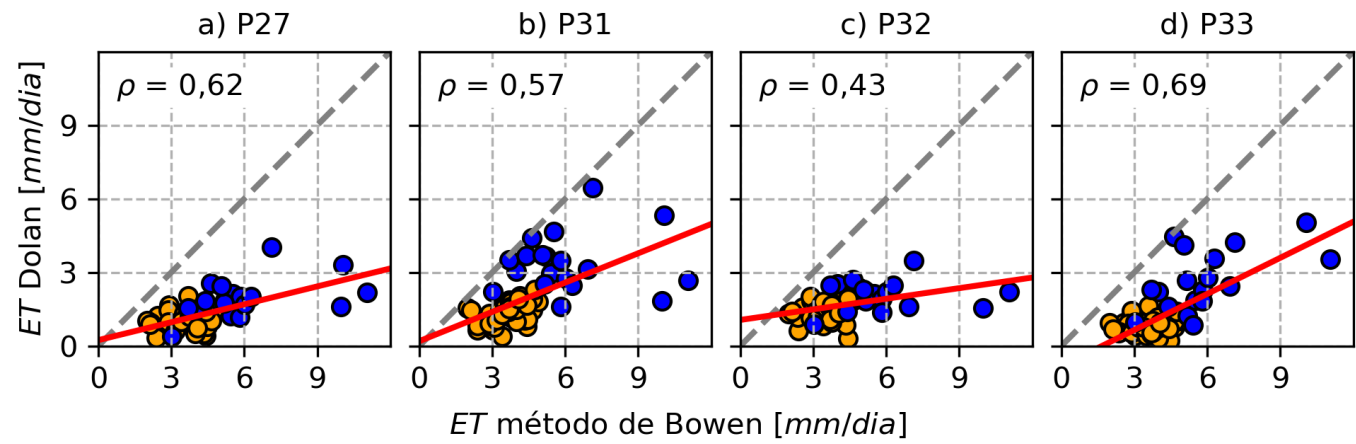

Fonte: Autor

Os erros entre as estimativas do método de Dolan $(\overline{M A E}=2,78 \mathrm{~mm} /$ dia , $\overline{R M S E}=3,09 \mathrm{~mm} /$ dia e $\overline{M B E}=-2,78 \mathrm{~mm} /$ dia) mostraram que a diferença é devida, principalmente, à subestimativa das taxas de $E T$ pelo método $(\overline{M A E} \approx|\overline{M B E}|)$. Além disso, os pontos com grandes diferenças ortogonais da linha vermelha foram poucos $(\overline{M A E}=0,90 \overline{R M S E})$.

\subsubsection{Avaliação do método de Hays}

O método de Hays (Figura 44) propôs estimar a taxa de recarga lateral no período de recuperação do nível piezométrico. Novamente, foram melhorados os coeficientes de correlação $\left(\bar{\rho}=0,58 e \overline{\tau_{s}}=0,54\right)$ pela consideração do dia subsequente no cálculo da recarga lateral. Adicionalmente, a variação de armazenamento é calculada da forma mais próxima possível da realidade, considerando o período em que realmente acontece a $E T$ (queda do nível piezométrico).

Figura 44 - Correlação entre as estimativas de ET do método de balanço de energia Razão de Bowen e o método de Hays
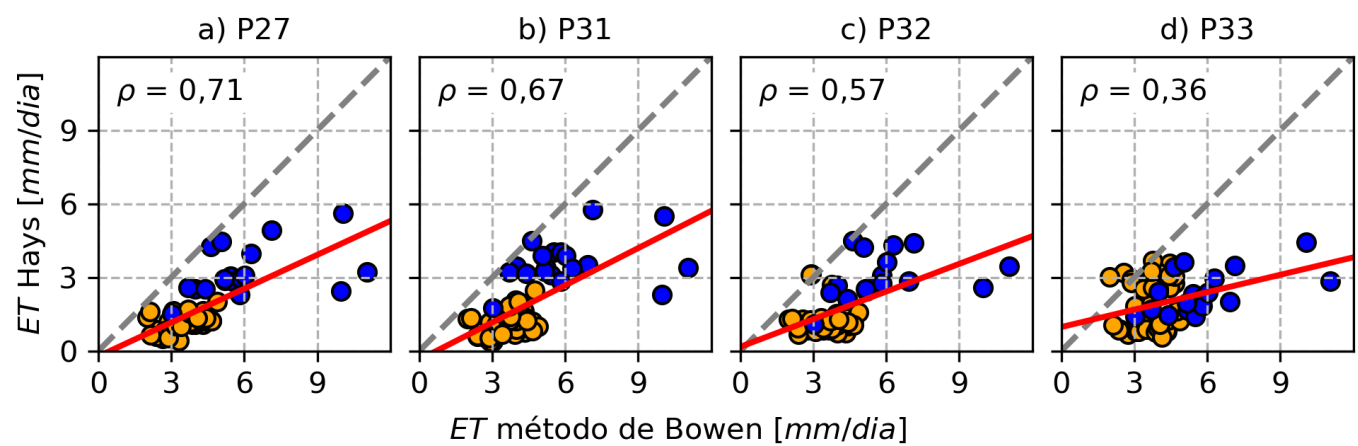

Fonte: Autor 
Os erros entre as estimativas do método de Hays $(\overline{M A E}=2,50 \mathrm{~mm} / \mathrm{dia}, \overline{R M S E}=$ 2,80 mm/dia e $\overline{M B E}=-2,48 \mathrm{~mm} /$ dia) mostraram que a diferença foi devida, principalmente, à subestimativa das taxas de $E T$ pelo método $(\overline{M A E} \approx|\overline{M B E}|)$. Além disso, os pontos com grandes diferenças ortogonais da linha vermelha são poucos $(\overline{M A E}=0,89 \overline{R M S E})$.

\subsubsection{Avaliação do método de Soylu}

O método de Soylu (Figura 45) apresentou maiores coeficientes de correlação $\left(\bar{\rho}=0,64 e \overline{\tau_{s}}=0,62\right)$ que os anteriores métodos, os quais mostram as vantagens da aplicação de transformadas de Fourier, na estimativa da ET em zonas ripárias. Apesar de não explicitar a taxa de recarga lateral, ela foi calculada como a tendência do nível ao longo de vários dias sucessivos. Neste trabalho, foi considerado um dia antes e depois do dia em analise.

Figura 45 - Correlação entre as estimativas de ET do método de balanço de energia Razão de Bowen e o método de Soylu

a) P27

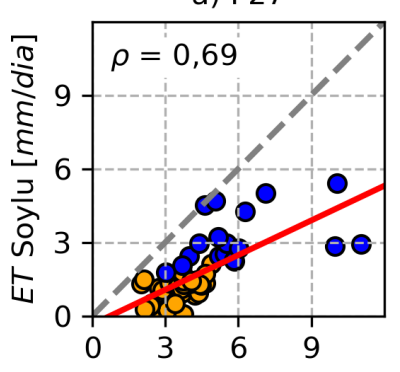

b) P31

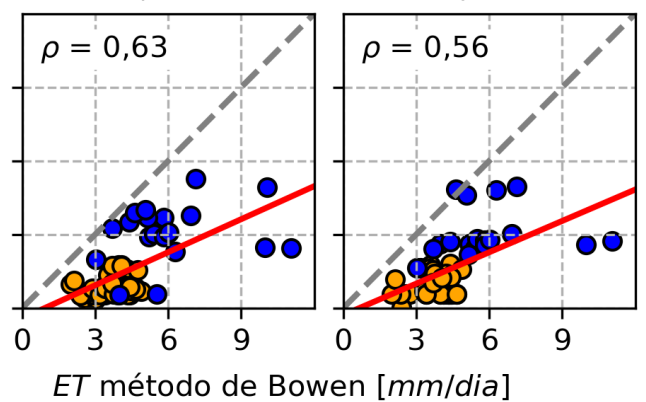

d) P33

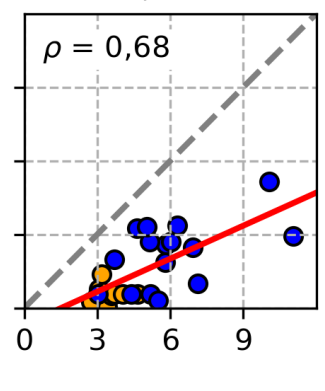

Fonte: Autor

Os erros entre as estimativas do método de Soylu $(\overline{M A E}=2,95 \mathrm{~mm} / \mathrm{dia}$, $\overline{R M S E}=3,24 \mathrm{~mm} /$ dia e $\overline{M B E}=-2,95 \mathrm{~mm} /$ dia) mostraram que a diferença foi devida, principalmente, à subestimativa das taxas de $E T$ pelo método $(\overline{M A E} \approx|\overline{M B E}|)$. Além disso, os pontos com grandes diferenças ortogonais da linha vermelha são poucos $(\overline{M A E}=0,91 \overline{R M S E})$.

\subsubsection{Avaliação do método de Loheide II}

O método de Loheide II (Figura 46) apresentou menores coeficientes de correlação em comparação ao método de Soylu $\left(\bar{\rho}=0,58 e \overline{\tau_{s}}=0,57\right)$. O método de Loheide II estima a taxa de recarga lateral e a variação do armazenamento para cada instante da série temporal.

A recarga lateral pelo método de Loheide II é obtida a partir do ajuste ao modelo linear dos dados do nível piezométrico do período de recuperação. Dessa forma, a recarga é estimada com o modelo linear, para os períodos de recuperação e queda do nível 
5.4. Avaliação dos métodos baseados nas flutuações diárias do nível piezométrico usando o método de balanço de energia - Razão de Bowen

piezométrico. O fato de estimar a recarga lateral somente com o período de recuperação introduz uma alta incerteza na estimativa da recarga no periodo de queda do nível piezometrico. Por essa razão o método de Loheide II (Figura 46) foi o único dos métodos estudados que superestimou as estimativas de ET do método de balanço de energia Razão de Bowen.

Os erros entre as estimativas do método de Loheide II $(\overline{M A E}=2,25 \mathrm{~mm} /$ dia, $\overline{R M S E}=2,82 \mathrm{~mm} /$ dia e $\overline{M B E}=-1,12 \mathrm{~mm} /$ dia) mostraram que a $E T$ pode ser subestimada e superestimada nos períodos seco e chuvoso $(\overline{M A E} \approx 2|\overline{M B E}|)$. Além disso, o número de pontos com grandes diferenças ortogonais da linha vermelha foi maior dos métodos anteriormente analisados $(\overline{M A E}=0,80 \overline{R M S E})$.

Figura 46 - Correlação entre as estimativas de ET do método de balanço de energia Razão de Bowen e o método de Loheide II

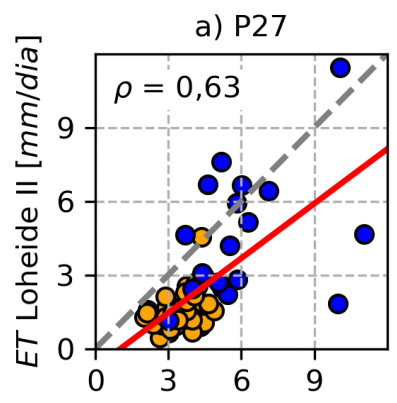

b) P31

c) P32

d) P33
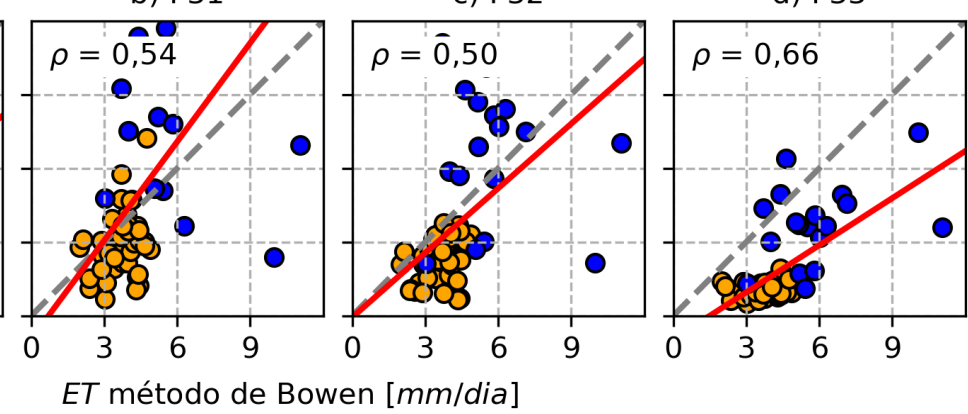

Fonte: Autor

\subsubsection{Avaliação do método de Gribovski}

O método de Gribovski (Figura 47), da mesma forma que o método de Loheide II, estima a taxa de recarga lateral e considera a variação do armazenamento para cada instante da série temporal. A taxa de recarga lateral é obtida a partir da variação temporal do nível piezométrico, assumindo que a recarga lateral é máxima e mínima nos instantes em que acontecem o nível mínimo e máximo, respectivamente.

O método de Gribovski apresentou uma forte correlação com os dados do método de balanço de energia - Razão de Bowen. Os maiores coeficientes foram observados para os poços P27 ( $\rho=0,72$ e $\left.\tau_{s}=0,60\right), \mathrm{P} 31\left(\rho=0,74\right.$ e $\left.\tau_{s}=0,63\right)$ e P32 $\left(\rho=0,77\right.$ e $\left.\tau_{s}=0,47\right)$. Já o poço P33, que é o mais distante da torre de monitoramento e do Ribeirão da Onça (Figura 7) apresentou os menores coeficientes de correlação $\left(\rho=0,54\right.$ e $\left.\tau_{s}=0,51\right)$ em comparação aos outros poços. 
Figura 47 - Correlação entre as estimativas de ET do método de balanço de energia Razão de Bowen e o método de Gribovski

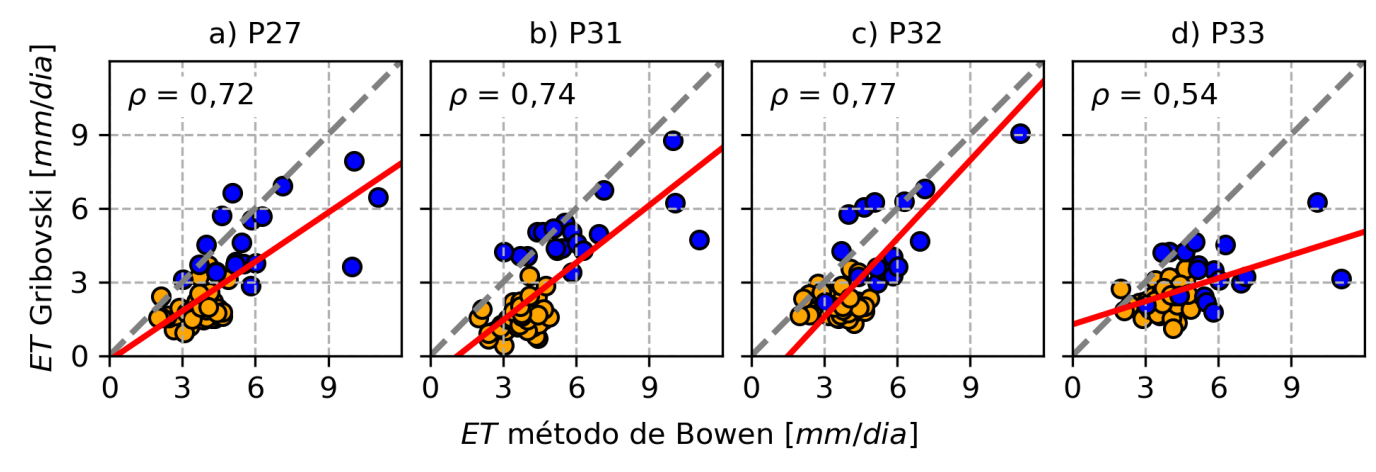

Fonte: Autor

Os erros entre as estimativas do método de Gribovski $(\overline{M A E}=1,77 \mathrm{~mm} / \mathrm{dia}$, $\overline{R M S E}=2,07 \mathrm{~mm} /$ dia e $\overline{M B E}=-1,63 \mathrm{~mm} /$ dia) mostraram que a diferença é devida, principalmente, à subestimativa das taxas de $E T$ pelo método $(\overline{M A E} \approx 1,1|\overline{M B E}|)$. Além disso, os pontos com grandes diferenças ortogonais da linha vermelha foram poucos $(\overline{M A E}=0,85 \overline{R M S E})$.

Dentre os métodos testados, o método de Gribovski apresentou os melhores coeficientes de correlação e simultaneamente, os menores erros quando compara-se suas estimativas com as do método de balanço de energia - Razão de Bowen. Os resultados evidenciam que entre os métodos avaliados, o método de Gribovski oferece a melhor representação da recarga lateral. A qual, baseia-se em que o gradiente hidráulico é mínimo, quando a zona ripária e sua vizinhança têm aproximadamente o mesmo nível, ou seja, o fluxo lateral é mínimo. Em contrapartida, quando o nível na zona ripária é mínimo, o gradiente hidráulico é máximo, ou seja, o fluxo lateral é máximo.

\subsubsection{Métricas da avaliação}

Os resultados de cada métrica de avaliação utilizada, foram organizados em forma de tabela, para uma melhor comparação do desempenho de cada um dos métodos.

Na Tabela 9, são apresentados os resultados do coeficiente de correlação do Pearson $(\rho)$. Como dito anteriormente, o método de Gribovski obteve os melhores resultados, seguido do método de Soylu, Loheide II, Hays e Dolan. Os menores coeficientes de correlação foram observados no método original de White e suas adaptações. 
5.4. Avaliação dos métodos baseados nas flutuações diárias do nível piezométrico usando o método de balanço de energia - Razão de Bowen

Tabela 9 - Resultados do coeficiente de correlação de Pearson $(\rho)$ entre o método de balanço de energia - Razão de Bowen e os métodos testados

\begin{tabular}{|c|c|c|c|c|c|c|}
\hline \multirow{2}{*}{ Métrica } & \multirow{2}{*}{ Método } & \multicolumn{5}{|c|}{ Poço } \\
\hline & & P27 & P31 & P32 & P33 & Média \\
\hline \multirow{10}{*}{$\begin{array}{l}\text { Coeficiente de } \\
\text { correlação de } \\
\text { Pearson }(\rho)\end{array}$} & White & 0,36 & 0,41 & 0,11 & 0,33 & 0,30 \\
\hline & White/Rushton & 0,45 & 0,44 & 0,36 & 0,44 & 0,42 \\
\hline & White/Hays & 0,47 & 0,59 & 0,38 & 0,60 & 0,51 \\
\hline & White/Loheide II & 0,24 & 0,49 & 0,29 & 0,53 & 0,39 \\
\hline & White/Miller & 0,34 & 0,48 & 0,34 & 0,53 & 0,42 \\
\hline & Dolan & 0,62 & 0,57 & 0,43 & 0,69 & 0,58 \\
\hline & Hays & 0,71 & 0,67 & 0,57 & 0,36 & 0,58 \\
\hline & Gribovski & 0,72 & 0,74 & 0,77 & 0,54 & 0,69 \\
\hline & Loheide II & 0,63 & 0,54 & 0,50 & 0,66 & 0,58 \\
\hline & Soylu & 0,69 & 0,63 & 0,56 & 0,68 & 0,64 \\
\hline
\end{tabular}

Fonte: Autor

Na Tabela 10, são apresentados os resultados do coeficiente de correlação de postos de Spearman $\left(\tau_{s}\right)$. Os melhores coeficientes foram observados no método de Soylu, seguido pelos métodos de Loheide II, Gribovski, Hays e Dolan. Semelhante ao coeficiente de correlação de Pearson $(\rho)$, os menores coeficientes de correlação de postos de Spearman foram obtidos no método original de White e suas adaptações.

Tabela 10 - Resultados do coeficiente de correlação de postos de Spearman $\left(\tau_{s}\right)$ entre o método de balanço de energia - Razão de Bowen e os métodos testados

\begin{tabular}{clccccc}
\hline \multirow{2}{*}{ Métrica } & \multirow{2}{*}{ Método } & \multicolumn{5}{c}{ Poço } \\
\cline { 3 - 7 } & White & P27 & P31 & P32 & P33 & Média \\
\hline & White/Rushton & 0,39 & 0,50 & 0,54 & 0,36 & 0,45 \\
& White/Hays & 0,38 & 0,64 & 0,38 & 0,47 & 0,47 \\
Coeficiente de & White/Loheide II & 0,16 & 0,50 & 0,38 & 0,37 & 0,35 \\
correlação de & White/Miller & 0,21 & 0,53 & 0,49 & 0,46 & 0,42 \\
postos de & Dolan & 0,55 & 0,63 & 0,55 & 0,43 & 0,54 \\
Spearman $\left(\tau_{s}\right)$ & Hays & 0,68 & 0,63 & 0,54 & 0,31 & 0,54 \\
& Gribovski & $\mathbf{0 , 6 0}$ & $\mathbf{0 , 6 3}$ & $\mathbf{0 , 4 7}$ & $\mathbf{0 , 5 1}$ & $\mathbf{0 , 5 5}$ \\
& Loheide II & $\mathbf{0 , 6 5}$ & $\mathbf{0 , 5 4}$ & $\mathbf{0 , 5 6}$ & $\mathbf{0 , 5 2}$ & $\mathbf{0 , 5 7}$ \\
& Soylu & $\mathbf{0 , 6 9}$ & $\mathbf{0 , 5 9}$ & $\mathbf{0 , 5 4}$ & $\mathbf{0 , 6 7}$ & $\mathbf{0 , 6 2}$ \\
\hline
\end{tabular}

Fonte: Autor

Na Tabela 11, são apresentados os resultados do erro absoluto médio $(M A E)$. Os menores erros correspondem ao método de Gribovski, seguido pelos métodos de Loheide II, Hays, Dolan. Já o método de Soylu, o qual apresentou o maior coeficiente de correlação por postos de Spearman $\left(\tau_{s}\right)$, ficou na sétima posição, sendo superado pelo método de White e pela adaptação de Rushton. 
Tabela 11 - Erro absoluto médio ( $M A E$ ) entre o método de balanço de energia - Razão de Bowen e os métodos testados

\begin{tabular}{clccccc}
\hline \multirow{2}{*}{ Métrica } & \multirow{2}{*}{ Método } & \multicolumn{5}{c}{ Poço } \\
\cline { 3 - 7 } & White & 3,00 & 2,63 & 2,72 & 3,25 & 2,90 \\
& White/Rushton & 2,84 & 2,57 & 2,83 & 3,89 & 3,04 \\
& White/Hays & 3,19 & 2,52 & 2,75 & 3,17 & 2,91 \\
& White/Loheide II & 3,20 & 2,99 & 3,16 & 3,57 & 3,23 \\
Erro absoluto & White/Miller & 3,11 & 2,86 & 3,10 & 3,59 & 3,17 \\
médio $(M A E)$ & Dolan & 3,04 & 2,45 & 2,63 & 3,01 & 2,78 \\
& Hays & $\mathbf{2 , 5 6}$ & $\mathbf{2 , 5 3}$ & $\mathbf{2 , 5 4}$ & $\mathbf{2 , 3 6}$ & $\mathbf{2 , 5 0}$ \\
& Gribovski & $\mathbf{1 , 7 4}$ & $\mathbf{1 , 9 4}$ & $\mathbf{1 , 6 7}$ & $\mathbf{1 , 7 3}$ & $\mathbf{1 , 7 7}$ \\
& Loheide II & $\mathbf{2 , 1 3}$ & $\mathbf{2 , 4 4}$ & $\mathbf{1 , 8 1}$ & $\mathbf{2 , 6 1}$ & $\mathbf{2 , 2 5}$ \\
& Soylu & 2,64 & 2,84 & 2,83 & 3,49 & 2,95 \\
\hline
\end{tabular}

Fonte: Autor

Na Tabela 12, foram apresentados os resultados da raiz do erro médio quadrático (RMSE). Os menores erros correspondem, novamente, ao método de Gribovski, seguido pelos métodos de Hays, Loheide II, Dolan e Soylu. Os maiores erros correspondem ao método original de White e suas adaptações.

Tabela 12 - Resultados da raiz do erro quadrático médio ( $R M S E$ ) entre o método de balanço de energia - Razão de Bowen e os métodos testados

\begin{tabular}{clccccc}
\hline \multirow{2}{*}{ Métrica } & \multirow{2}{*}{ Método } & \multicolumn{5}{c}{ Poço } \\
\cline { 3 - 7 } & White & P27 & P31 & P32 & P33 & Média \\
\hline & White/Rushton & 3,17 & 3,00 & 3,20 & 4,16 & 3,38 \\
& White/Hays & 3,53 & 2,87 & 3,10 & 3,42 & 3,23 \\
Raiz do erro & White/Loheide II & 3,60 & 3,33 & 3,49 & 3,84 & 3,56 \\
quadrático médio & White/Miller & 3,44 & 3,23 & 3,43 & 3,88 & 3,49 \\
$(R M S E)$ & Dolan & 3,34 & 2,81 & 2,98 & 3,21 & 3,09 \\
& Hays & $\mathbf{2 , 8 2}$ & $\mathbf{2 , 8 2}$ & $\mathbf{2 , 8 3}$ & $\mathbf{2 , 7 5}$ & $\mathbf{2 , 8 0}$ \\
& Gribovski & $\mathbf{2 , 0 4}$ & $\mathbf{2 , 2 2}$ & $\mathbf{1 , 9 1}$ & $\mathbf{2 , 1 1}$ & $\mathbf{2 , 0 7}$ \\
& Loheide II & $\mathbf{2 , 4 7}$ & $\mathbf{3 , 6 1}$ & $\mathbf{2 , 4 1}$ & $\mathbf{2 , 8 1}$ & $\mathbf{2 , 8 2}$ \\
& Soylu & 2,90 & 3,13 & 3,12 & 3,79 & 3,24 \\
\hline
\end{tabular}

Fonte: Autor

Na Tabela 13, foram apresentados os resultados do viés médio $(M B E)$. De forma geral, todos os métodos subestimaram a ET em comparação com as estimativas do método de balanço de energia - Razão de Bowen. Apenas para o poço P31 a ET foi superestimada pelo método de Loheide II, sendo o método com o menor $M B E$, seguido pelos métodos de Gribovski, Hays, Dolan e White. Os maiores erros foram obtidos no método de Soylu e as adaptações do método original de White. 
5.4. Avaliação dos métodos baseados nas flutuações diárias do nível piezométrico usando o método de balanço de energia - Razão de Bowen

Tabela 13 - Resultados do erro de viés médio $(M B E)$ entre o método de balanço de energia - Razão de Bowen e os métodos testados

\begin{tabular}{clccccc}
\hline \multirow{2}{*}{ Métrica } & \multicolumn{5}{c}{ Pétodo } & \multicolumn{5}{c}{ Poço } \\
\cline { 3 - 7 } & White & P27 & P31 & P32 & P33 & Média \\
\hline & White/Rushton & 2,84 & 2,59 & 2,72 & 3,25 & 2,89 \\
& White/Hays & 3,19 & 2,52 & 2,75 & 3,17 & 2,91 \\
Erro de viés médio & White/Loheide II & 3,20 & 2,99 & 3,16 & 3,57 & 3,23 \\
$($ MBE) & Dolan & 3,11 & 2,86 & 3,10 & 3,59 & 3,17 \\
& Hays & 3,04 & 2,45 & 2,63 & 3,01 & 2,78 \\
& Gribovski & $\mathbf{2 , 5 6}$ & $\mathbf{2 , 5 3}$ & $\mathbf{2 , 5 3}$ & $\mathbf{2 , 3 1}$ & $\mathbf{2 , 4 8}$ \\
& Loheide II & $\mathbf{1 , 6 3}$ & $\mathbf{1 , 8 5}$ & $\mathbf{1 , 3 4}$ & $\mathbf{1 , 6 8}$ & $\mathbf{1 , 6 3}$ \\
& Soylu & $\mathbf{1 , 8 9}$ & $\mathbf{- 0 , 5 4}$ & $\mathbf{0 , 6 0}$ & $\mathbf{2 , 5 2}$ & $\mathbf{1 , 1 2}$ \\
& 2,64 & 2,84 & 2,82 & 3,49 & 2,95 \\
\hline
\end{tabular}





\section{Conclusão}

Para avaliar as estimativas de evapotranspiração dos métodos baseados na flutuação diária do nível piezométrico mediante o método de balanço de energia - Razão de Bowen em zona ripária, foi construída uma torre de monitoramento para a coleta de dados meteorológicos (253 dias, 01/05/2018 - 09/01/2019) e 6 poços de monitoramento para a coleta de dados do nível piezométrico (264 dias, 20/04/2018 - 09/01/2019) na bacia hidrográfica do ribeirão da onça $(B R O)$.

O método de balanço de energia - Razão de Bowen resolve, de forma simples, a equação simplificada do balanço de energia para uma superfície vegetada, apartir dos gradientes de temperatura e pressão de vapor d'água no ar. Os únicos inconvenientes são o alto custo dos equipamentos necessários e as incertezas na determinação dos fluxos de energia quando as diferenças entre as pressões de vapor d'água no ar são mínimas. Essas incertezas nas medições devem ser removidas. Para tal fim, existem diversos tipos de critérios de rejeição, tais como os físicos, os baseados no valor da razão de Bowen e os baseados na propagação dos erros das medições.

$\mathrm{Na}$ zona ripária, os critérios físicos foram ineficientes, devido à existência de turbilhões, que criam combinações de gradientes sem coerência física, o que é inaceitável para esses tipos de critérios. O critério baseado unicamente no valor da razão de Bowen também foi ineficiente, pois a faixa fixa de rejeição de $\beta$ permitiu a permanência de taxas de ET muito discrepantes na série temporal. Por outro lado, o critério baseado na propagação dos erros mostrou bons resultados na zona ripária, dado que só as medições que produzem as taxas de ET com a menor incerteza são aceitadas, independente do sentido dos fluxos de energia.

Sendo assim, foi utilizado um critério baseado na propagação de erros, que permitiu definir o limite de rejeição das medições que deviam ser excluídas da série temporal. O valor do limite de rejeição foi escolhido após várias análises (item 5.2.2) com o método usado para a reconstrução das estimativas rejeitadas. Os melhores resultados $(N S E=0,77)$ foram atingidos com o limite de rejeição $\varepsilon=1\left(\frac{\sigma_{E T}}{|E T|}<1\right)$.

A reconstrução das estimativas rejeitadas foi feita mediante o método de amostragem direta $(D S)$, o qual apresentou resultados satisfatórios na reconstrução das estimativas rejeitadas na zona ripária. Uma boa reconstrução da série temporal, usando o método de amostragem direta, consiste em obter um balanço entre o grau de incerteza das taxas de ET e a percentagem de taxas confiáveis da série temporal. Esse balanço foi encontrado com a seguinte configuração: $50.8 \%$ de rejeição dos dados $(\varepsilon=1)$, 30 dias de raio de busca $(R=30), 10$ dados vizinhos $(n=10)$, um limite de aceitação entre os eventos de 0,001 
mm/15min $(\sigma=0,001)$ e a média de 10 simulações.

Os resultados de ET do método de balanço de energia - Razão de Bowen evidenciam o aumento da $E T$ com a disponibilidade hídrica. As taxas de ET variaram na faixa de $2-$ $6 \mathrm{~mm} /$ dia no período seco e de $2-8 \mathrm{~mm} /$ dia no período chuvoso. No período chuvoso, foram observadas as maiores $(\approx 12 \mathrm{~mm} / \mathrm{dia})$ e menores $(<1 \mathrm{~mm} / \mathrm{dia})$ taxas de $E T$. Para o período seco a $E T$ média estimada foi de 3,62 \pm 0,93 $\mathrm{mm} /$ dia e para o período chuvoso, a ET média estimada foi de 5,09 $\pm 2,34 \mathrm{~mm} /$ dia.

Os métodos baseados na flutuação diária do nível piezométrico mostraram ser uma boa alternativa para o cálculo da ET em zonas ripárias. Porém, devido ao alto número de incertezas envolvidas e à restrição de aplicação somente em dias sem eventos de precipitação, é necessário continuar pesquisando em nesse tema.

A restrição teórica de não aplicar esse tipo de métodos em dias com eventos de precipitação, deixa poucos dias úteis para sua aplicação. Devem ser excluídos os dias com eventos de precipitação e alguns dias posteriores, porque o nível piezométrico tarda vários dias para voltar ao comportamento ondulatório normal. Nas zonas riparias esse efeito é mais intenso, devido a que o nível piezométrico é muito superficial. Em consequência, a infiltração produto dos eventos de precipitação, atinge rapidamente a superfície freática, nos dados observados a resposta do nível foi imediata.

As taxas de ET calculadas nos primeiros dias após os eventos de precipitação, quando o nível piezométrico volta ao comportamento ondulatório normal, não correspondem às taxas reais de $E T$, pois, os diversos métodos calculam a $E T$ com base na amplitude diária do nível piezométrico, e nesse período, a amplitude está influenciada por uma alta taxa de recarga lateral, produto dos eventos de precipitação. Portanto as taxas de ET desses métodos são confiáveis, somente, se foram calculadas muitos dias após os eventos de precipitação. Sendo assim, as estimativas de ET no período seco são confiáveis, já no período chuvoso, as estimativas contém um alto grau de incerteza.

Uma das incertezas envolvidas nesses métodos, é a estimativa da recarga lateral, dado que, a equação global tem três variáveis e é conhecida apenas a diferença entre as outras duas $\left(\frac{d h}{d t}=r-E T\right)$. Fica evidente que as estimativas de $E T$ dependem de como é considerada a recarga lateral. Os métodos testados mostraram ampla variedade de considerações, que foram e que podem ser feitas ao respeito da recarga lateral.

Outra grande incerteza envolvida é a estimativa do rendimento específico transiente $\left(S_{y}^{*}\right)$. Dado que o objetivo do projeto era validar os métodos baseados na flutuação diária do nível piezométrico e não a estimativa do rendimento específico transiente, foi considerado um valor fixo para essa variável, mesmo sabendo que ele varia ao longo do dia e seu valor está estreitamente relacionado à profundidade do nível piezométrico, entre outras variáveis. Recomenda-se que o rendimento específico transiente seja avaliado em futuras pesquisas, 
para reduzir as incertezas nas estimativas de $E T$ na zona ripária.

Foi observado um alto impacto entre o grau de suavidade do nível piezométrico e os resultados de ET, principalmente nos métodos de Gribovski e Loheide II, os quais, consideram a taxa de recarga lateral como variável ao longo do dia. Foram obtidos os maiores coeficientes de correlação com as estimativas da torre, para maiores graus de suavidade.

Entre os métodos baseados na flutuação diária do nível piezométrico, as estimativas de $E T$ do método de Gribovski forneceram os melhores resultados $\left(\bar{\rho}=0.69, \overline{\tau_{s}}=0.55\right.$, $\overline{M A E}=1.77 \mathrm{~mm} /$ dia,$\overline{R M S E}=2.07 \mathrm{~mm} /$ dia e $\overline{M B E}=1.63 \mathrm{~mm} /$ dia $)$, devido à melhor estimativa da recarga lateral. A taxa de ET média estimada pelo método de Gribovski no

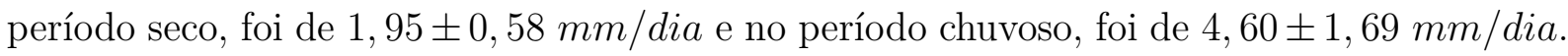

As diferenças entre as estimativas do método de balanço de energia - Razão de Bowen e as estimativas dos métodos baseados na flutuação diária do nível piezométrico, mostram a necessidade de continuar pesquisando em esta área, com o objetivo de aprimorar os métodos existentes ou criar novos métodos que possam ser aplicados também no período chuvoso. Uma ideia para solucionar essa limitação, seria encontrar uma forma de relacionar a precipitação com a recarga lateral.

Em futuros projetos poderia explorar-se a possibilidade de utilizar sensoriamento remoto para estimar o comportamento espacial da ET, dado que os métodos baseados na flutuação diária do nível piezométrico oferecem resultados de ET pontuais. Embora esses resultados de ET pontuais, são uteis para avaliar os resultados de ET espacial de algum modelo de sensoriamento remoto. Entre os modelos existentes, destacam-se os modelos físicos de balanço de energia superficial, os quais estão baseados na temperatura superficial do solo, permitindo assim, a obtenção de informações sobre o estado de umidade do solo.

Entre os principais modelos desse tipo destaca-se o modelo de duas fontes $A L E X I$ - DisALEXI, apresentado por primeira vez em 1997, o qual é aplicado extensamente nos Estados Unidos da América. Embora as estimativas de ET do modelo ALEXI-DisALEXI ainda não foram avaliadas em zonas ripárias. 



\section{Referências}

ALLEN, R. G. et al. Crop evapotranspiration: guidelines for computing crop water requirements. Food and Agriculture Organization of the United Nations, 1998. (FAO irrigation and drainage paper, No 56-57). ISBN 978-92-5-104219-9. Disponível em: $<$ https://books.google.com.br/books?id=42hRAAAAMAAJ $>$. Citado 2 vezes nas páginas 25 e 30.

ALLEN, R. G. et al. Evapotranspiration information reporting: I. Factors governing measurement accuracy. Agricultural Water Management, v. 98, n. 6, p. 899-920, abr. 2011. ISSN 0378-3774. Disponível em: < http://www.sciencedirect.com/science/article/pii/ S0378377411000023>. Citado na página 26.

ALTMAN, N. S. An Introduction to Kernel and Nearest-Neighbor Nonparametric Regression. The American Statistician, v. 46, n. 3, p. 175-185, ago. 1992. ISSN 0003-1305. Disponível em: <https://www.tandfonline.com/doi/abs/10.1080/00031305. 1992.10475879>. Citado na página 51.

AMBAUM, M. H. P. Thermal Physics of the Atmosphere. Wiley, 2010. ISBN 978-0-470-71037-1. Disponível em: <https://books.google.com.br/books?id= uZ4vcblxs9YC>. Citado na página 30.

BEESON, C.; DOYLE, P. F. COMPARISON OF BANK EROSION AT VEGETATED AND NON-VEGETATED CHANNEL BENDS1. JAWRA Journal of the American Water Resources Association, v. 31, n. 6, p. 983-990, dez. 1995. ISSN 1093-474X. Disponível em: <https://doi.org/10.1111/j.1752-1688.1995.tb03414.x>. Citado na página 26.

BEVInGTON, P. R. et al. Data Reduction and Error Analysis for the Physical Sciences. Computers in Physics, v. 7, n. 4, p. 415-416, jul. 1993. ISSN 0894-1866. Disponível em: $<$ https://aip.scitation.org/doi/abs/10.1063/1.4823194>. Citado na página 35.

BOWEN, I. S. The Ratio of Heat Losses by Conduction and by Evaporation from any Water Surface. Physical Review, v. 27, n. 6, p. 779-787, jun. 1926. Disponível em: < https://link.aps.org/doi/10.1103/PhysRev.27.779>. Citado 2 vezes nas páginas 28 e 29.

CABRERA, M. C. M. et al. Performance of evaporation estimation methods compared with standard $20 \mathrm{~m} 2$ tank. Revista Brasileira de Engenharia Agrícola e Ambiental, v. 20, p. 874-879, 2016. ISSN 1415-4366. Citado na página 46.

CELLIER, P.; OLIOSO, A. A simple system for automated long-term Bowen ratio measurement. Agricultural and Forest Meteorology, v. 66, n. 1, p. 81-92, set. 1993. ISSN 0168-1923. Disponível em: <http://www.sciencedirect.com/science/article/pii/ 016819239390083T>. Citado na página 33.

CHILDS, E. C. The nonsteady state of the water table in drained land. Journal of Geophysical Research (1896-1977), v. 65, n. 2, p. 780-782, fev. 1960. ISSN 0148-0227. Disponível em: <https://doi.org/10.1029/JZ065i002p00780>. Citado na página 44. 
CHOW, V. T.; MAIDMENT, D. R.; MAYS, L. W. Applied Hydrology. Tata McGraw-Hill Education, 2010. ISBN 978-0-07-070242-4. Disponível em: < https: //books.google.com.br/books?id=RRwidSsBJrEC $>$. Citado 2 vezes nas páginas 27 e 30 .

CLEVELAND, W. S. Robust Locally Weighted Regression and Smoothing Scatterplots. Journal of the American Statistical Association, v. 74, n. 368, p. 829-836, dez. 1979. ISSN 0162-1459. Disponível em: <https://www.tandfonline.com/doi/abs/10.1080/01621459. 1979.10481038>. Citado na página 51.

CLEVELAND, W. S.; DEVLIN, S. J. Locally Weighted Regression: An Approach to Regression Analysis by Local Fitting. Journal of the American Statistical Association, v. 83, n. 403, p. 596-610, set. 1988. ISSN 0162-1459. Disponível em: $<$ https://www.tandfonline.com/doi/abs/10.1080/01621459.1988.10478639>. Citado na página 51.

COMUNIAN, A. et al. Improving Bowen-ratio estimates of evaporation using a rejection criterion and multiple-point statistics. Journal of Hydrology, v. 563, p. 43-50, ago. 2018. ISSN 0022-1694. Disponível em: <http://www.sciencedirect.com/science/article/pii/ S0022169418303779>. Citado na página 36.

CROSBIE, R. S.; BINNING, P.; KALMA, J. D. A time series approach to inferring groundwater recharge using the water table fluctuation method. Water Resources Research, v. 41, n. 1, jan. 2005. ISSN 0043-1397. Disponível em: <https://doi.org/10.1029/2004WR003077>. Citado na página 43.

DEMEO, G. A. et al. Estimated ground-water discharge by evapotranspiration from Death Valley, California, 1997-2001. [S.l.], 2003. Disponível em: < http: //pubs.er.usgs.gov/publication/wri034254>. Citado na página 28.

DEVITT, D. A. et al. Evapotranspiration of mixed shrub communities in phreatophytic zones of the Great Basin region of Nevada (USA). Ecohydrology, v. 4, n. 6, p. 807-822, nov. 2011. ISSN 1936-0584. Disponível em: < https://doi.org/10.1002/eco.169>. Citado na página 27.

DEVITT, D. A. et al. Bowen Ratio estimates of evapotranspiration for Tamarix ramosissima stands on the Virgin River in southern Nevada. Water Resources Research, v. 34, n. 9, p. 2407-2414, set. 1998. ISSN 0043-1397. Disponível em: < https://doi.org/10.1029/98WR01551>. Citado 2 vezes nas páginas 21 e 27.

DOLAN, T. J. et al. Evapotranspiration of a Florida, U.S.A., freshwater wetland. Journal of Hydrology, v. 74, n. 3, p. 355-371, nov. 1984. ISSN 0022-1694. Disponível em: <http://www.sciencedirect.com/science/article/pii/0022169484900246>. Citado 3 vezes nas páginas 26, 39 e 41.

DOODY, T.; BENYON, R. Quantifying water savings from willow removal in Australian streams. Journal of Environmental Management, v. 92, n. 3, p. 926-935, mar. 2011. ISSN 0301-4797. Disponível em: <http://www.sciencedirect.com/science/article/pii/ S0301479710003932>. Citado na página 27.

DREXLER, J. Z. et al. A review of models and micrometeorological methods used to estimate wetland evapotranspiration. Hydrological Processes, v. 18, n. 11, p. 2071-2101, ago. 2004. ISSN 0885-6087. Disponível em: <https://doi.org/10.1002/hyp.1462>. Citado na página 38 . 
DUKE, H. R. Capillary properties of soils-influence upon specific yield. Amer Soc Agr Eng Trans ASAE, 1972. Disponível em: <http://agris.fao.org/agris-search/search.do? recordID $=$ US201302335007 $>$. Citado na página 44.

FAHLE, M.; DIETRICH, O. Estimation of evapotranspiration using diurnal groundwater level fluctuations: Comparison of different approaches with groundwater lysimeter data. Water Resources Research, v. 50, n. 1, p. 273-286, jan. 2014. ISSN 0043-1397. Disponível em: < https://doi.org/10.1002/2013WR014472>. Citado 3 vezes nas páginas 38, 40 e 43.

FANG, Y. et al. Monthly land cover-specific evapotranspiration models derived from global eddy flux measurements and remote sensing data. Ecohydrology, v. 9, n. 2, p. 248-266, mar. 2016. ISSN 1936-0584. Disponível em: < https://doi.org/10.1002/eco.1629>. Citado 2 vezes nas páginas 25 e 26.

FISHER, J. B.; WHITTAKER, R. J.; MALHI, Y. ET come home: potential evapotranspiration in geographical ecology. Global Ecology and Biogeography, v. 20, n. 1, p. 1-18, jan. 2011. ISSN 1466-822X. Disponível em: < https://doi.org/10.1111/j.1466-8238. 2010.00578.x>. Citado na página 25.

FORD, C. R. et al. A comparison of sap flux-based evapotranspiration estimates with catchment-scale water balance. Agricultural and Forest Meteorology, v. 145, n. 3, p. 176-185, ago. 2007. ISSN 0168-1923. Disponível em: <http://www.sciencedirect.com/ science/article/pii/S0168192307001116>. Citado na página 25.

GHOLZ, H. L.; CLARK, K. L. Energy exchange across a chronosequence of slash pine forests in Florida. Agricultural and Forest Meteorology, v. 112, n. 2, p. 87-102, ago. 2002. ISSN 0168-1923. Disponível em: <http://www.sciencedirect.com/science/article/pii/ S016819230200059X>. Citado na página 25.

GOODRICH, D. et al. Seasonal estimates of riparian evapotranspiration using remote and in situ measurements. Agricultural and Forest Meteorology, v. 105, n. 1, p. 281-309, nov. 2000. ISSN 0168-1923. Disponível em: < http://www.sciencedirect.com/science/article/pii/ S0168192300001970>. Citado 3 vezes nas páginas 26, 27 e 38.

GRIBOVSZKI, Z. et al. Riparian zone evapotranspiration estimation from diurnal groundwater level fluctuations. Journal of Hydrology, v. 349, n. 1, p. 6-17, jan. 2008. ISSN 0022-1694. Disponível em: <http://www.sciencedirect.com/science/article/pii/ S002216940700652X > . Citado 6 vezes nas páginas 26, 38, 39, 41, 42 e 76.

GUO, X. et al. Quality control and flux gap filling strategy for Bowen ratio method: revisiting the Priestley-Taylor evaporation model. Environmental Fluid Mechanics, v. 7, n. 5, p. 421-437, out. 2007. ISSN 1573-1510. Disponível em: <https://doi.org/10.1007/s10652-007-9033-8>. Citado 2 vezes nas páginas 27 e 35.

HAYS, K. B. Water use by saltcedar (Tamarix sp.) and associated vegetation on the Canadian, Colorado and Pecos Rivers in Texas. Tese (Thesis) - Texas A\&M University, 2003. Disponível em: <https://oaktrust.library.tamu.edu/handle/1969.1/ ETD-TAMU-2003-THESIS-H394> . Citado 4 vezes nas páginas 26, 39, 40 e 41.

HEALY, R.; COOK, P. Using groundwater levels to estimate recharge. Hydrogeology Journal, v. 10, n. 1, p. 91-109, 2002. Disponível em: <http://pubs.er.usgs.gov/publication/ $70025073>$. Citado na página 43. 
HEILMAN, J. L.; BRITTIN, C. L.; NEALE, C. M. U. Fetch requirements for bowen ratio measurements of latent and sensible heat fluxes. Agricultural and Forest Meteorology, Elsevier, v. 44, n. 3, p. 261-273, Jan 1989. ISSN 0168-1923. Citado na página 32.

HUXMAN, T. E. et al. ECOHYDROLOGICAL IMPLICATIONS OF WOODY PLANT ENCROACHMENT. Ecology, v. 86, n. 2, p. 308-319, fev. 2005. ISSN 0012-9658.

Disponível em: <https://doi.org/10.1890/03-0583>. Citado 2 vezes nas páginas 21 e 25.

II, S. P. L. A method for estimating subdaily evapotranspiration of shallow groundwater using diurnal water table fluctuations. Ecohydrology, v. 1, n. 1, p. 59-66, jan. 2008. ISSN 1936-0584. Disponível em: <https://doi.org/10.1002/eco.7>. Citado 6 vezes nas páginas 26, 38, 39, 40, 42 e 76.

II, S. P. L.; JR., J. J. B.; GORELICK, S. M. Estimation of groundwater consumption by phreatophytes using diurnal water table fluctuations: A saturated-unsaturated flow assessment. Water Resources Research, v. 41, n. 7, jul. 2005. ISSN 0043-1397. Disponível em: < https://doi.org/10.1029/2005WR003942>. Citado 2 vezes nas páginas 38 e 44.

JOHNSON, B. et al. Recognizing and modeling variable drawdown due to evapotranspiration in a semiarid riparian zone considering local differences in vegetation and distance from a river source. Water Resources Research, v. 49, n. 2, p. 1030-1039, fev. 2013. ISSN 0043-1397. Disponível em: < https://doi.org/10.1002/wrcr.20122>. Citado 2 vezes nas páginas 21 e 25.

JR., J. J. B. et al. A field investigation of phreatophyte-induced fluctuations in the water table. Water Resources Research, v. 43, n. 2, fev. 2007. ISSN 0043-1397. Disponível em: < https://doi.org/10.1029/2005WR004627>. Citado na página 26.

LAUTZ, L. K. Estimating groundwater evapotranspiration rates using diurnal water-table fluctuations in a semi-arid riparian zone. Hydrogeology Journal, v. 16, n. 3, p. 483-497, maio 2008. ISSN 1435-0157. Disponível em: <https://doi.org/10.1007/s10040-007-0239-0>. Citado 2 vezes nas páginas 26 e 38.

LOGSDON, S. D. et al. Field estimation of specific yield in a central Iowa crop field. Hydrological Processes, v. 24, n. 10, p. 1369-1377, maio 2010. ISSN 0885-6087. Disponível em: <https://doi.org/10.1002/hyp.7600>. Citado na página 44.

LU, J. et al. MODELING ACTUAL EVAPOTRANSPIRATION FROM FORESTED WATERSHEDS ACROSS THE SOUTHEASTERN UNITED STATES1. JAWRA Journal of the American Water Resources Association, v. 39, n. 4, p. 886-896, ago. 2003. ISSN 1093-474X. Disponível em: < https://doi.org/10.1111/j.1752-1688.2003.tb04413.x>. Citado na página 25.

LUPON, A. et al. The influence of riparian evapotranspiration on stream hydrology and nitrogen retention in a subhumid Mediterranean catchment. Hydrol. Earth Syst. Sci., v. 20, n. 9, p. 3831-3842, set. 2016. ISSN 1607-7938. Disponível em: <https://www.hydrol-earth-syst-sci.net/20/3831/2016/>. Citado 2 vezes nas páginas 25 e 26 .

LUPON, A.; LEDESMA, J. L. J.; BERNAL, S. Riparian evapotranspiration is essential to simulate streamflow dynamics and water budgets in a Mediterranean catchment. Hydrol. Earth Syst. Sci., v. 22, n. 7, p. 4033-4045, jul. 2018. ISSN 1607-7938. Disponível em: 
< https://www.hydrol-earth-syst-sci.net/22/4033/2018/>. Citado 3 vezes nas páginas 25, 26 e 38.

MARIETHOZ, G.; RENARD, P.; STRAUBHAAR, J. The Direct Sampling method to perform multiple-point geostatistical simulations. Water Resources Research, v. 46, n. 11, nov. 2010. ISSN 0043-1397. Disponível em: < https://doi.org/10.1029/2008WR007621>. Citado 2 vezes nas páginas 36 e 37.

MARIETHOZ, P. G.; CAERS, P. J. Multiple-point Geostatistics: Stochastic Modeling with Training Images. Wiley, 2014. ISBN 978-1-118-66275-5. Disponível em: $<$ https://books.google.com.br/books?id=Fe7sBQAAQBAJ>. Citado na página 36.

MARTINET, M. C. et al. On groundwater fluctuations, evapotranspiration, and understory removal in riparian corridors. Water Resources Research, v. 45, n. 5, maio 2009. ISSN 0043-1397. Disponível em: <https://doi.org/10.1029/2008WR007152>. Citado 3 vezes nas páginas 26,27 e 38 .

MEYBOOM, P. Three observations on streamflow depletion by phreatophytes. Journal of Hydrology, v. 2, n. 3, p. 248-261, mar. 1965. ISSN 0022-1694. Disponível em: <http://www.sciencedirect.com/science/article/pii/0022169465900405>. Citado na página 44.

MILLER, G. R. et al. Groundwater uptake by woody vegetation in a semiarid oak savanna. Water Resources Research, v. 46, n. 10, out. 2010. ISSN 0043-1397. Disponível em: < https://doi.org/10.1029/2009WR008902>. Citado 2 vezes nas páginas 39 e 41.

MONTEITH, J. L. Evaporation and surface temperature. Quarterly Journal of the Royal Meteorological Society, v. 107, n. 451, p. 1-27, jan. 1981. ISSN 0035-9009. Disponível em: <https://doi.org/10.1002/qj.49710745102>. Citado na página 25.

MOORE, G. W.; CLEVERLY, J. R.; OWENS, M. K. Nocturnal transpiration in riparian Tamarix thickets authenticated by sap flux, eddy covariance and leaf gas exchange measurements. Tree Physiology, v. 28, n. 4, p. 521-528, abr. 2008. ISSN 0829-318X. Disponível em: <https://dx.doi.org/10.1093/treephys/28.4.521>. Citado na página 27.

MUNRO, D. S.; OKE, T. R. Aerodynamic boundary-layer adjustment over a crop in neutral stability. Boundary-Layer Meteorology, Kluwer Academic Publishers, v. 9, n. 1, p. 53-61, Aug 1975. ISSN 1573-1472. Citado na página 32.

NACHABE, M. H. Analytical expressions for transient specific yield and shallow water table drainage. Water Resources Research, v. 38, n. 10, p. 11-1, out. 2002. ISSN 0043-1397. Disponível em: <https://doi.org/10.1029/2001WR001071>. Citado na página 44.

NAGLER, P. L. et al. Predicting riparian evapotranspiration from MODIS vegetation indices and meteorological data. Remote Sensing of Environment, v. 94, n. 1, p. 17-30, jan. 2005. ISSN 0034-4257. Disponível em: < http://www.sciencedirect.com/science/ article/pii/S0034425704002615> C Citado 2 vezes nas páginas 26 e 27.

NAGLER, P. L. et al. Evapotranspiration on western U.S. rivers estimated using the Enhanced Vegetation Index from MODIS and data from eddy covariance and Bowen ratio flux towers. Remote Sensing of Environment, v. 97, n. 3, p. 337-351, ago. 2005. ISSN 0034-4257. Disponível em: <http://www.sciencedirect.com/science/article/pii/ S0034425705001616>. Citado na página 26. 
NASH, J.; SUTCLIFFE, J. River flow forecasting through conceptual models part I - A discussion of principles. Journal of Hydrology, v. 10, n. 3, p. 282-290, abr. 1970. ISSN 0022-1694. Disponível em: <http://www.sciencedirect.com/science/article/pii/ 0022169470902556>. Citado na página 50.

NOSETTO, M. D.; JOBBáGY, E. G.; PARUELO, J. M. Land-use change and water losses: the case of grassland afforestation across a soil textural gradient in central Argentina. Global Change Biology, v. 11, n. 7, p. 1101-1117, jul. 2005. ISSN 1354-1013. Disponível em: < https://doi.org/10.1111/j.1365-2486.2005.00975.x>. Citado na página 21.

OHMURA, A. Objective Criteria for Rejecting Data for Bowen Ratio Flux Calculations. Journal of Applied Meteorology, v. 21, n. 4, p. 595-598, abr. 1982. ISSN 0021-8952. Disponível em: <https://doi.org/10.1175/1520-0450(1982)021<0595: OCFRDF $>2.0 . \mathrm{CO} ; 2>$. Citado 3 vezes nas páginas 33, 34 e 61 .

OLIVEIRA, J. C. M. et al. Improved Soil Particle-Size Analysis by Gamma-Ray Attenuation. Soil Science Society of America Journal, v. 61, n. 1, p. 23-26, 1997. Disponível em: <http://dx.doi.org/10.2136/sssaj1997.03615995006100010004x>. Citado na página 46.

ORIANI, F. et al. Missing data simulation inside flow rate time-series using multiple-point statistics. Environmental Modelling 63 Software, v. 86, p. 264-276, dez. 2016. ISSN 1364-8152. Disponível em: <http://www.sciencedirect.com/science/article/pii/ S1364815216307745>. Citado na página 36.

ORIANI, F. et al. Simulation of rainfall time series from different climatic regions using the direct sampling technique. Hydrol. Earth Syst. Sci., v. 18, n. 8, p. 3015-3031, ago. 2014. ISSN 1607-7938. Disponível em: < https://www.hydrol-earth-syst-sci.net/18/3015/2014/>. Citado 3 vezes nas páginas 33, 36 e 37.

ORTEGA-FARIAS, S. O.; CUENCA, R. H.; EK, M. Daytime variation of sensible heat flux estimated by the bulk aerodynamic method over a grass canopy. Agricultural and Forest Meteorology, v. 81, n. 1, p. 131-143, set. 1996. ISSN 0168-1923. Disponível em: $<$ http://www.sciencedirect.com/science/article/pii/0168192395022783>. Citado na página 33.

PAYERO, J. O. et al. GUIDELINES FOR VALIDATING BOWEN RATIO DATA. Transactions of the ASAE, v. 46, n. 4, p. 1051, 2003. ISSN 0001-2351. Disponível em: $<$ http://elibrary.asabe.org/abstract.asp?aid=13967\&t=3>. Citado na página 33.

PEREIRA, A. R.; SEDIYAMA, G. C.; NOVA, N. A. V. Evapotranspiração. Campinas, SP: Fundag: Fundag, 2013. Citado 6 vezes nas páginas 28, 29, 30, 32, 33 e 36.

PEREZ, P. et al. Assessment of reliability of Bowen ratio method for partitioning fluxes. Agricultural and Forest Meteorology, v. 97, n. 3, p. 141-150, nov. 1999. ISSN 0168-1923. Disponível em: <http://www.sciencedirect.com/science/article/pii/S0168192399000805>. Citado 5 vezes nas páginas 32, 33, 34, 35 e 61.

PETRONE, R. et al. Riparian zone equilibrium and actual evapotranspiration in a first order agricultural catchment in Southern Ontario, Canada. Agricultural Water Management, v. 86, n. 3, p. 240-248, dez. 2006. ISSN 0378-3774. Disponível em: 
< http://www.sciencedirect.com/science/article/pii/S0378377406001545>. Citado 2 vezes nas páginas 26 e 38.

POBLADOR, S. et al. Riparian forest transpiration under the current and projected Mediterranean climate: Effects on soil water and nitrate uptake. Ecohydrology, v. 12, n. 1, p. e2043, jan. 2019. ISSN 1936-0584. Disponível em: < https://doi.org/10.1002/eco.2043>. Citado 2 vezes nas páginas 21 e 26.

PONTON, H. F. A. Determinação empírica da evapotranspiração em zona ripária e áreas vizinhas (Cerrado stricto sensu e eucalipto). Tese (text) Universidade de São Paulo, São Carlos, SP, mar. 2017. Disponível em: < http: //www.teses.usp.br/teses/disponiveis/18/18138/tde-12042017-112932/>. Citado 2 vezes nas páginas 44 e 45.

PUSEY, B. J.; ARTHINGTON, A. H. Importance of the riparian zone to the conservation and management of freshwater fish: a review. Marine and Freshwater Research, v. 54, n. 1, p. 1-16, abr. 2003. Disponível em: < https://doi.org/10.1071/MF02041>. Citado 3 vezes nas páginas 25,26 e 38.

RAHGOZAR, M.; SHAH, N.; ROSS, M. Estimation of Evapotranspiration and Water Budget Components Using Concurrent Soil Moisture and Water Table Monitoring. ISRN Soil Science, v. 2012, p. 15, 2012. Disponível em: $<$ http://dx.doi.org/10.5402/2012/726806>. Citado na página 38.

ROMANO, E.; GIUDICI, M. On the use of meteorological data to assess the evaporation from a bare soil. Journal of Hydrology, v. 372, n. 1, p. 30-40, jun. 2009. ISSN 0022-1694. Disponível em: <http://www.sciencedirect.com/science/article/pii/S0022169409002133>. Citado 4 vezes nas páginas 33, 34, 35 e 61 .

RUSHTON, B. HYDROLOGIC BUDGET FOR A FRESHWATER MARSH IN FLORIDA1. JAWRA Journal of the American Water Resources Association, v. 32, n. 1, p. 13-21, fev. 1996. ISSN 1093-474X. Disponível em: <https: //doi.org/10.1111/j.1752-1688.1996.tb03430.x>. Citado 2 vezes nas páginas 39 e 40.

SAHA, G. C. A comparative study of evapotranspiration in riparian zone under coniferous and deciduous forest covers using groundwater table fluctuations: a case study in the Kiskatinaw River Watershed, Canada. International Journal of Hydrology Science and Technology, v. 5, n. 1, p. 16-33, jan. 2015. ISSN 2042-7808. Disponível em: $<$ https://www.inderscienceonline.com/doi/abs/10.1504/IJHST.2015.069277>. Citado na página 21.

SATCHITHANANTHAM, S.; WILSON, H. F.; GLENN, A. J. Contrasting patterns of groundwater evapotranspiration in grass and tree dominated riparian zones of a temperate agricultural catchment. Journal of Hydrology, v. 549, p. 654-666, jun. 2017. ISSN 0022-1694. Disponível em: <http://www.sciencedirect.com/science/article/pii/S0022169417302366>. Citado na página 38.

SCOTT, R. et al. Multiyear riparian evapotranspiration and groundwater use for a semiarid watershed. Journal of Arid Environments, v. 72, n. 7, p. 1232-1246, jul. 2008. ISSN 0140-1963. Disponível em: <http://www.sciencedirect.com/science/article/pii/ S0140196308000025>. Citado na página 26. 
SCOTT, R. L. et al. The water use of two dominant vegetation communities in a semiarid riparian ecosystem. Agricultural and Forest Meteorology, v. 105, n. 1, p. 241-256, nov. 2000. ISSN 0168-1923. Disponível em: < http://www.sciencedirect.com/science/article/pii/ S0168192300001817>. Citado na página 27.

SOYLU, M. E. et al. On evapotranspiration and shallow groundwater fluctuations: A Fourier-based improvement to the White method. Water Resources Research, v. 48, n. 6, jun. 2012. ISSN 0043-1397. Disponível em: < https://doi.org/10.1029/2011WR010964>. Citado 5 vezes nas páginas 26, 38, 39, 42 e 43.

SUN, G. et al. A comparison of the watershed hydrology of coastal forested wetlands and the mountainous uplands in the Southern US. Journal of Hydrology, v. 263, n. 1, p. 92-104, jun. 2002. ISSN 0022-1694. Disponível em: <http: //www.sciencedirect.com/science/article/pii/S0022169402000641>. Citado na página 25.

TANNER, B. D.; GREENE, J. P.; BINGHAM, G. E. A bowen ratio design for long term measurements. American Society of Agricultural Engineers (Microfiche collection) (USA), 1987. Disponível em: <http://agris.fao.org/agris-search/search.do?recordID=US8843412>. Citado 4 vezes nas páginas 28, 33, 34 e 61.

TRENBERTH, K. E.; FASUlLO, J. T.; KIEHL, J. Earth's Global Energy Budget. Bulletin of the American Meteorological Society, v. 90, n. 3, p. 311-324, mar. 2009. ISSN 0003-0007. Disponível em: < https://doi.org/10.1175/2008BAMS2634.1>. Citado na página 25.

TROXELL, H. C. The diurnal fluctuation in the ground-water and flow of the santa ana river and its meaning. Transactions, American Geophysical Union, v. 17, p. 496-504, 1936. Disponível em: <http://adsabs.harvard.edu/abs/1936TrAGU..17..496T>. Citado 3 vezes nas páginas 38,39 e 76 .

VERSTRAETEN, W. W.; VEROUSTRAETE, F.; FEYEN, J. Assessment of Evapotranspiration and Soil Moisture Content Across Different Scales of Observation. Sensors, v. 8, n. 1, 2008. ISSN 1424-8220. Citado 2 vezes nas páginas 25 e 26.

WANG, K.; DICKINSON, R. E. A review of global terrestrial evapotranspiration: Observation, modeling, climatology, and climatic variability. Reviews of Geophysics, v. 50, n. 2, jun. 2012. ISSN 8755-1209. Disponível em: < https://doi.org/10.1029/2011RG000373>. Citado 2 vezes nas páginas 21 e 25.

WHITE, W. N. A method of estimating ground-water supplies based on discharge by plants and evaporation from soil: Results of investigations in Escalante Valley, Utah. Washington, D.C., 1932. 115 p. Disponível em: < http://pubs.er.usgs.gov/publication/wsp659A>. Citado 5 vezes nas páginas 26, 38, 39, 40 e 41.

WILSON, K. B. et al. A comparison of methods for determining forest evapotranspiration and its components: sap-flow, soil water budget, eddy covariance and catchment water balance. Agricultural and Forest Meteorology, v. 106, n. 2, p. 153-168, jan. 2001. ISSN 0168-1923. Disponível em: < http://www.sciencedirect.com/science/article/pii/ S0168192300001994>. Citado na página 21.

YANG, Y. et al. Daily Landsat-scale evapotranspiration estimation over a forested landscape in North Carolina, USA, using multi-satellite data fusion. Hydrology 
and Earth System Sciences, v. 21, n. 2, p. 1017-1037, 2017. Disponível em: $<$ https://www.fs.usda.gov/treesearch/pubs/53946>. Citado na página 25.

YANG, Z.; ZHANG, Q.; HAO, X. Evapotranspiration Trend and Its Relationship with Precipitation over the Loess Plateau during the Last Three Decades. Advances in Meteorology, v. 2016, p. 10, 2016. Disponível em: <http://dx.doi.org/10.1155/2016/ $6809749>$. Citado 2 vezes nas páginas 21 e 25.

YEPEZ, E. A. et al. Partitioning overstory and understory evapotranspiration in a semiarid savanna woodland from the isotopic composition of water vapor. Agricultural and Forest Meteorology, v. 119, n. 1, p. 53-68, out. 2003. ISSN 0168-1923. Disponível em: <http://www.sciencedirect.com/science/article/pii/S0168192303001163>. Citado na página 25.

ZHANG, L.; DAWES, W. R.; WALKER, G. R. Response of mean annual evapotranspiration to vegetation changes at catchment scale. Water Resources Research, v. 37, n. 3, p. 701-708, mar. 2001. ISSN 0043-1397. Disponível em: < https://doi.org/10.1029/2000WR900325>. Citado 2 vezes nas páginas 21 e 25.

ZHU, J. et al. Interference of river level changes on riparian zone evapotranspiration estimates from diurnal groundwater level fluctuations. Journal of Hydrology, v. 403, n. 3, p. 381-389, jun. 2011. ISSN 0022-1694. Disponível em: <http: //www.sciencedirect.com/science/article/pii/S0022169411002563>. Citado na página 26.

ZWILLINGER, D.; KOKOSKA, S. CRC Standard Probability and Statistics Tables and Formulae. [S.l.]: Taylor \& Francis, 1999. Google-Books-ID: 1q9CnwEACAAJ. ISBN 978-1-58488-059-2. Citado na página 52. 

Apêndices 



\section{APÊNDICE A - Projeto da base da torre de monitoramento}

Figura 48 - Detalhes da base da torre de monitoramento
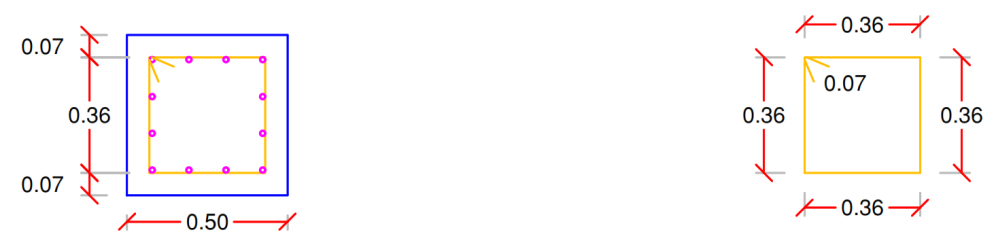

AÇO 3/8" CADA $0.17 \mathrm{~m}$

$\mathrm{L}=1.58 \mathrm{~m}$

SÃO 7
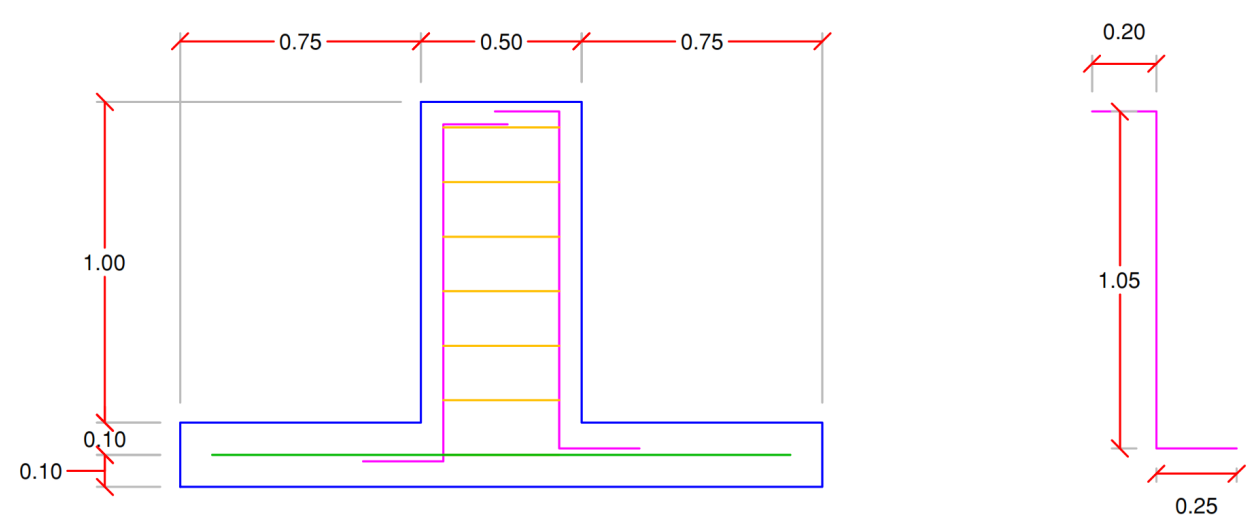

AÇO 1/2" CADA $0.11 \mathrm{~m}$ $\mathrm{L}=1.50 \mathrm{~m}$ SÃO 12
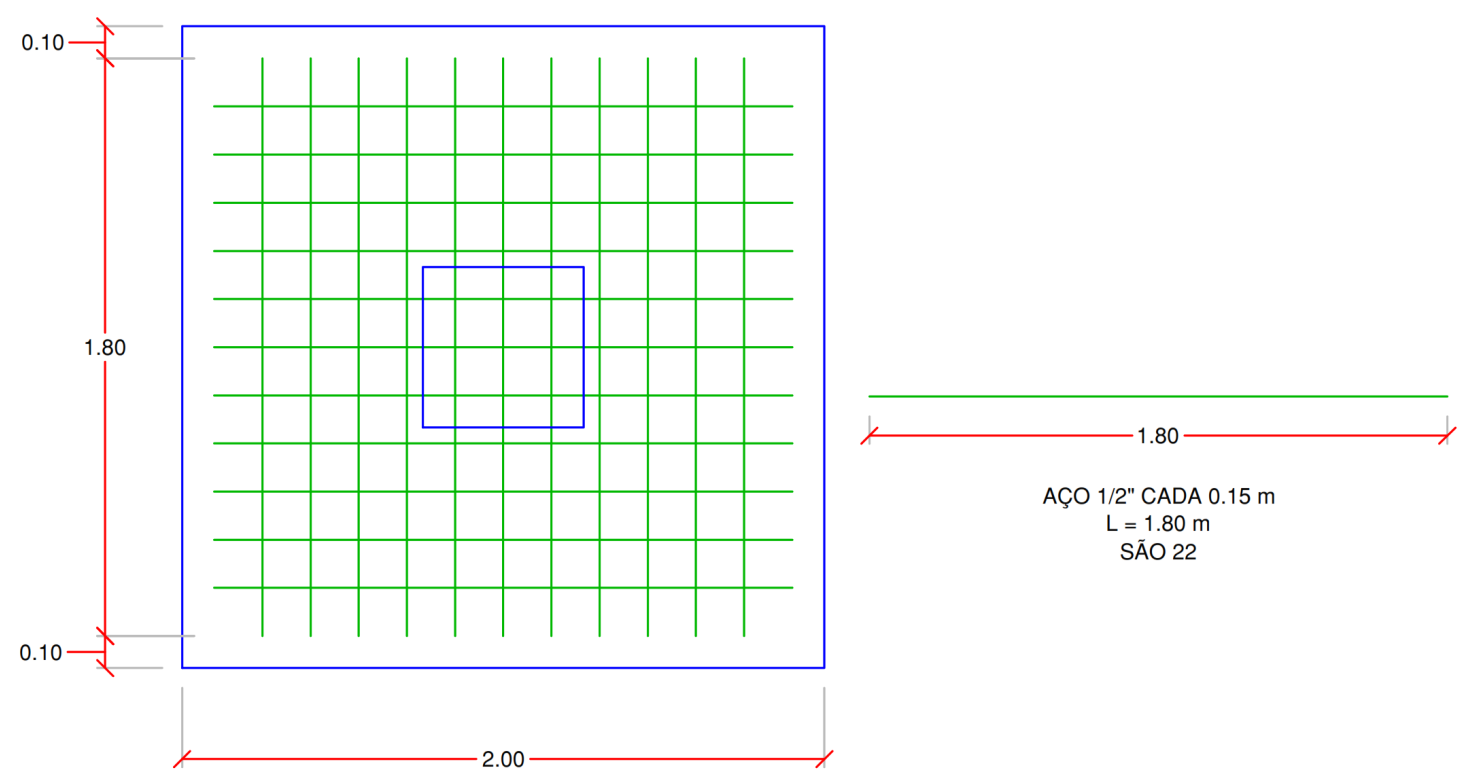

Fonte: Autor 



\section{APÊNDICE B - Dados coletados na torre de monitoramento para o dia 30/06/2018}

Tabela 14 - Dados coletados na torre de monitoramento no dia 30/06/2018

\begin{tabular}{c|cccccc}
\hline Timestamp & $R_{N}$ & $G$ & $T_{2}$ & $T_{1}$ & $R H_{2}$ & $R H_{1}$ \\
\hline 30/06/2018 00:45 & $-14,47$ & $-24,71$ & 7,76 & 7,46 & 98,60 & 97,60 \\
30/06/2018 01:00 & $-12,97$ & $-25,36$ & 7,57 & 7,31 & 98,80 & 97,60 \\
30/06/2018 01:15 & $-13,48$ & $-25,86$ & 7,55 & 7,35 & 98,40 & 97,20 \\
30/06/2018 01:30 & $-14,02$ & $-26,13$ & 7,63 & 7,34 & 98,90 & 97,70 \\
30/06/2018 01:45 & $-14,40$ & $-26,84$ & 7,45 & 7,17 & 98,40 & 97,10 \\
30/06/2018 02:00 & $-13,56$ & $-27,01$ & 6,96 & 6,79 & 99,00 & 97,60 \\
30/06/2018 02:15 & $-16,30$ & $-27,24$ & 6,63 & 6,39 & 98,60 & 96,90 \\
30/06/2018 02:30 & $-13,27$ & $-27,89$ & 6,51 & 6,24 & 99,40 & 98,10 \\
30/06/2018 02:45 & $-12,31$ & $-28,16$ & 6,52 & 6,31 & 99,50 & 98,20 \\
30/06/2018 03:00 & $-11,82$ & $-28,39$ & 6,98 & 6,72 & 99,60 & 98,40 \\
30/06/2018 03:15 & $-14,33$ & $-28,99$ & 7,00 & 6,81 & 98,90 & 97,60 \\
30/06/2018 03:30 & $-16,20$ & $-29,31$ & 6,56 & 6,28 & 98,50 & 97,10 \\
30/06/2018 03:45 & $-15,10$ & $-29,31$ & 6,21 & 5,94 & 98,70 & 97,30 \\
30/06/2018 04:00 & $-15,72$ & $-29,31$ & 5,96 & 5,69 & 99,10 & 97,90 \\
30/06/2018 04:15 & $-16,62$ & $-29,52$ & 5,65 & 5,36 & 99,50 & 97,80 \\
30/06/2018 04:30 & $-13,91$ & $-29,94$ & 5,73 & 5,41 & 99,70 & 98,40 \\
30/06/2018 04:45 & $-12,70$ & $-30,44$ & 5,78 & 5,57 & 99,70 & 98,60 \\
30/06/2018 05:00 & $\mathbf{- 1 2 , 7 3}$ & $\mathbf{- 3 0 , 4 7}$ & $\mathbf{5 , 7 6}$ & $\mathbf{5 , 5 7}$ & $\mathbf{9 9 , 7 0}$ & $\mathbf{9 8 , 5 0}$ \\
30/06/2018 05:15 & $-13,16$ & $-30,47$ & 5,76 & 5,57 & 99,70 & 98,60 \\
30/06/2018 05:30 & $-13,83$ & $-30,47$ & 5,70 & 5,51 & 99,50 & 98,40 \\
30/06/2018 05:45 & $-12,36$ & $-30,89$ & 5,62 & 5,43 & 99,60 & 98,50 \\
30/06/2018 06:00 & $-13,19$ & $-31,02$ & 5,72 & 5,49 & 99,50 & 98,40 \\
30/06/2018 06:15 & $-12,97$ & $-31,02$ & 5,64 & 5,42 & 99,70 & 98,50 \\
30/06/2018 06:30 & $-12,34$ & $-31,02$ & 5,74 & 5,57 & 99,70 & 98,60 \\
30/06/2018 06:45 & $-14,12$ & $-30,66$ & 5,69 & 5,47 & 99,70 & 98,40 \\
30/06/2018 07:00 & $-12,80$ & $-30,47$ & 5,53 & 5,36 & 99,70 & 98,50 \\
30/06/2018 07:15 & $-6,35$ & $-30,47$ & 5,51 & 5,28 & 99,60 & 98,30 \\
30/06/2018 07:30 & 18,88 & $-30,47$ & 5,66 & 5,49 & 99,70 & 98,40 \\
30/06/2018 07:45 & 53,50 & $-30,47$ & 6,69 & 6,58 & 99,20 & 97,70 \\
30/06/2018 08:00 & 85,50 & $-30,46$ & 7,90 & 7,75 & 98,00 & 96,80
\end{tabular}


Tabela 14 - Dados coletados na torre de monitoramento no dia 30/06/2018

\begin{tabular}{|c|c|c|c|c|c|c|}
\hline Timestamp & $R_{N}$ & $G$ & $T_{2}$ & $T_{1}$ & $\mathrm{RH}_{2}$ & $R H_{1}$ \\
\hline 30/06/2018 08:15 & 120,10 & $-30,29$ & 9,27 & 9,22 & 92,50 & 90,60 \\
\hline 30/06/2018 08:30 & 158,40 & $-29,42$ & 10,60 & 10,64 & 90,90 & 90,30 \\
\hline 30/06/2018 08:45 & 196,40 & $-28,81$ & 12,32 & 12,44 & 88,70 & 89,20 \\
\hline 30/06/2018 09:00 & 228,60 & $-27,77$ & 14,49 & 14,63 & 79,77 & 78,79 \\
\hline $30 / 06 / 2$ & 254,90 & $-26,50$ & 16,69 & 16,97 & 74,13 & 72,40 \\
\hline $30 / 06 / 2$ & 283,40 & $-25,11$ & 18,49 & 18,60 & 64,64 & 63,65 \\
\hline 30/06/2018 09:45 & 311,80 & $-23,50$ & 20,48 & 20,61 & 59,10 & 57,88 \\
\hline 30/06/2018 10:00 & 365,40 & $-21,79$ & 21,98 & 22,10 & 52,93 & 54,52 \\
\hline $30 / 06 / 2018$ 10:15 & 406,80 & $-19,88$ & 23,17 & 23,23 & 46,68 & 46,38 \\
\hline 30/06/2018 10:30 & 409,40 & $-17,85$ & 23,67 & 23,77 & 3,06 & 45,96 \\
\hline 30/06/2018 10:45 & 463,10 & $-15,55$ & 24,23 & 24,36 & 43,99 & 43,76 \\
\hline $30 / 06 / 2$ & 454,60 & $-13,00$ & 24,50 & 24,50 & 43,89 & 43,04 \\
\hline 30/06/2018 11:15 & 450,30 & $-10,19$ & 24,75 & 24,76 & 41,68 & 41,07 \\
\hline 30/06/2018 11:30 & 466,90 & $-6,62$ & 25,00 & 25,03 & 41,92 & 42,76 \\
\hline 30/06/2018 11:45 & 473,90 & $-0,94$ & 25,22 & 25,28 & 41,14 & 41,41 \\
\hline $30 / 06 / 2$ & 487,40 & 5,47 & 25,42 & 25,45 & 40,25 & 40,05 \\
\hline $30 / 06 / 2018$ 12:15 & 490,40 & 11,14 & 25,48 & 25 &, 52 & 39,71 \\
\hline 30/06/2018 12:30 & 490,50 & 16,53 & 25,71 & 25,80 & 37,75 & 37,68 \\
\hline $30 / 06 / 2018$ 12:45 & 488,10 & 21,48 & & 26,03 & & 37,68 \\
\hline $30 / 06 / 2$ & 487,20 & 25,96 & 26,35 & 26,36 & 36,63 & 37,00 \\
\hline $30 / 06 / 2018$ 13:15 & 478,50 & 29,91 & 26,8 & 26 , & 33,86 & 33,62 \\
\hline $30 / 06 / 201813: 30$ & 465,50 & 33,61 & 26,76 & 26,81 & 35,14 & 35,58 \\
\hline $30 / 06 / 2018$ 13:45 & 447,10 & 37,19 & 26,76 & 26,83 & 35,30 & 35,51 \\
\hline $30 / 06 / 20$ & 425,60 & 40,67 & 26,96 & 26,92 & 37,16 & 36,04 \\
\hline $30 / 06 / 2018$ 14:15 & 403,80 & 43,65 & 26,98 & 27,05 & 38,72 & 39,09 \\
\hline 30/06/2018 14:30 & 370,20 & 45,82 & 26,63 & & & \\
\hline $30 / 06 / 201814: 45$ & 343,90 & 47,10 & 26,77 & 26,77 & 35,57 & 35,03 \\
\hline $30 / 06 / 201815$ & 315 & 46, & & & & 34,52 \\
\hline $30 / 06 / 2018$ 15:15 & 284,30 & 45,65 & 26,92 & 26,93 & 35,13 & 34,83 \\
\hline 30/06/2018 15:30 & 255,70 & 43,35 & & & & 34,56 \\
\hline $30 / 06 / 2018$ 15:45 & 226,00 & 40,51 & 26,98 & 26,97 & 35,60 & 35,91 \\
\hline 30/06/2018 16: & 183,70 & 37 & & & & 31,28 \\
\hline $30 / 06 / 2018$ 16:15 & 140,60 & 34,43 & 27,13 & 26,98 & & 37,40 \\
\hline 30/06/2018 16:30 & 100,00 & 31,62 & 26,71 & & 35,57 & 37,19 \\
\hline $30 / 06 / 201816: 45$ & 63,19 & 28,93 & 26,12 & 26,07 & 44,09 & 46,36 \\
\hline 30/06/2018 17:00 & 27,68 & 26,22 & 24,99 & 24,32 & 47,75 & 53,40 \\
\hline
\end{tabular}


Tabela 14 - Dados coletados na torre de monitoramento no dia 30/06/2018

\begin{tabular}{c|cccccc}
\hline Timestamp & $R_{N}$ & $G$ & $T_{2}$ & $T_{1}$ & $R H_{2}$ & $R H_{1}$ \\
\hline 30/06/2018 17:15 & $-1,97$ & 23,66 & 22,66 & 21,70 & 58,41 & 59,56 \\
30/06/2018 17:30 & $-28,14$ & 21,10 & 20,37 & 19,62 & 66,91 & 71,89 \\
30/06/2018 17:45 & $-37,27$ & 18,51 & 18,27 & 17,68 & 78,20 & 80,60 \\
30/06/2018 18:00 & $-39,32$ & 15,85 & 16,51 & 15,95 & 83,80 & 86,50 \\
30/06/2018 18:15 & $-38,76$ & 13,16 & 15,26 & 14,62 & 87,50 & 86,20 \\
30/06/2018 18:30 & $-35,92$ & 10,50 & 14,32 & 13,73 & 90,70 & 90,20 \\
30/06/2018 18:45 & $-32,92$ & 7,94 & 13,77 & 13,07 & 90,50 & 91,10 \\
30/06/2018 19:00 & $-31,46$ & 6,01 & 13,65 & 12,79 & 91,50 & 93,10 \\
30/06/2018 19:15 & $-29,49$ & 3,58 & 13,10 & 12,27 & 93,30 & 94,80 \\
30/06/2018 19:30 & $-27,64$ & 1,32 & 12,68 & 11,89 & 94,10 & 93,70 \\
30/06/2018 19:45 & $-23,53$ & $-0,80$ & 12,23 & 11,61 & 93,80 & 92,00 \\
30/06/2018 20:00 & $-22,42$ & $-2,80$ & 11,86 & 11,21 & 94,60 & 93,50 \\
30/06/2018 20:15 & $-20,85$ & $-4,65$ & 11,44 & 10,70 & 96,10 & 96,30 \\
30/06/2018 20:30 & $-19,60$ & $-6,37$ & 11,38 & 10,93 & 95,70 & 95,20 \\
30/06/2018 20:45 & $-19,87$ & $-7,39$ & 11,45 & 11,10 & 94,80 & 93,90 \\
30/06/2018 21:00 & $-19,77$ & $-8,81$ & 11,13 & 10,58 & 95,60 & 95,30 \\
30/06/2018 21:15 & $-17,92$ & $-10,13$ & 10,49 & 9,95 & 97,60 & 95,90 \\
30/06/2018 21:30 & $-18,33$ & $-11,28$ & 10,19 & 9,59 & 97,30 & 96,60 \\
30/06/2018 21:45 & $-15,60$ & $-12,45$ & 9,93 & 9,45 & 97,90 & 96,30 \\
30/06/2018 22:00 & $-15,15$ & $-13,56$ & 9,76 & 9,28 & 97,70 & 96,60 \\
30/06/2018 22:15 & $-15,06$ & $-14,63$ & 9,57 & 9,19 & 97,70 & 96,70 \\
30/06/2018 22:30 & $-16,33$ & $-15,68$ & 9,47 & 9,05 & 97,90 & 96,10 \\
30/06/2018 22:45 & $-14,32$ & $-16,70$ & 9,26 & 8,75 & 98,30 & 97,30 \\
30/06/2018 23:00 & $-15,77$ & $-17,64$ & 9,05 & 8,59 & 98,50 & 96,30 \\
30/06/2018 23:15 & $-14,37$ & $-18,52$ & 8,82 & 8,29 & 98,10 & 97,30 \\
30/06/2018 23:30 & $-13,36$ & $-19,31$ & 8,58 & 8,18 & 98,60 & 97,80 \\
30/06/2018 23:45 & $-14,96$ & $-20,17$ & 8,34 & 8,06 & 98,10 & 96,30 \\
\hline
\end{tabular}





\section{APÊNDICE C - Profundidade do nível piezométrico}

C.1 Poço P27

Figura 49 - Nível piezométrico poço P27

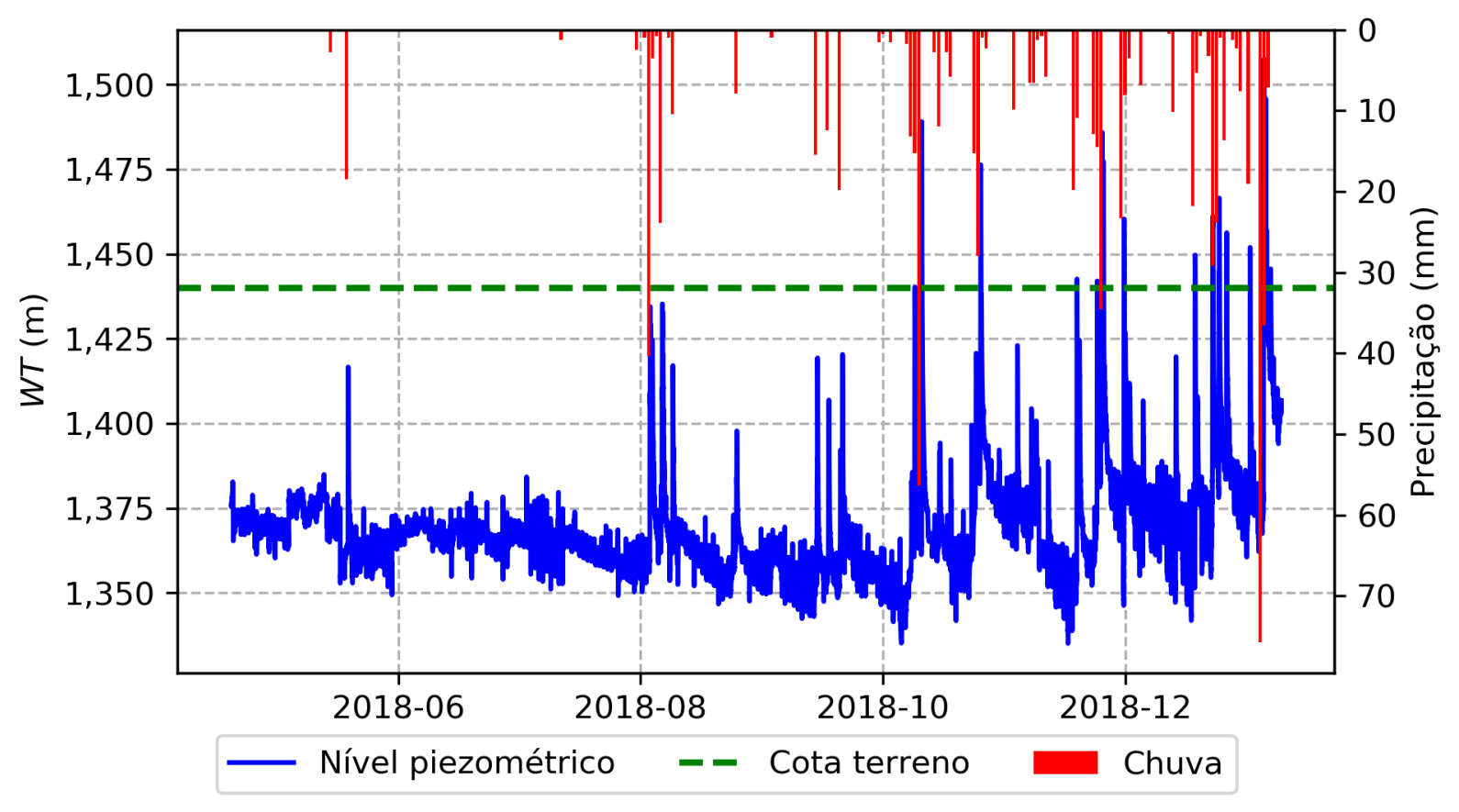

Fonte: Autor 


\section{C.2 Poço P30}

Figura 50 - Nível piezométrico poço P30

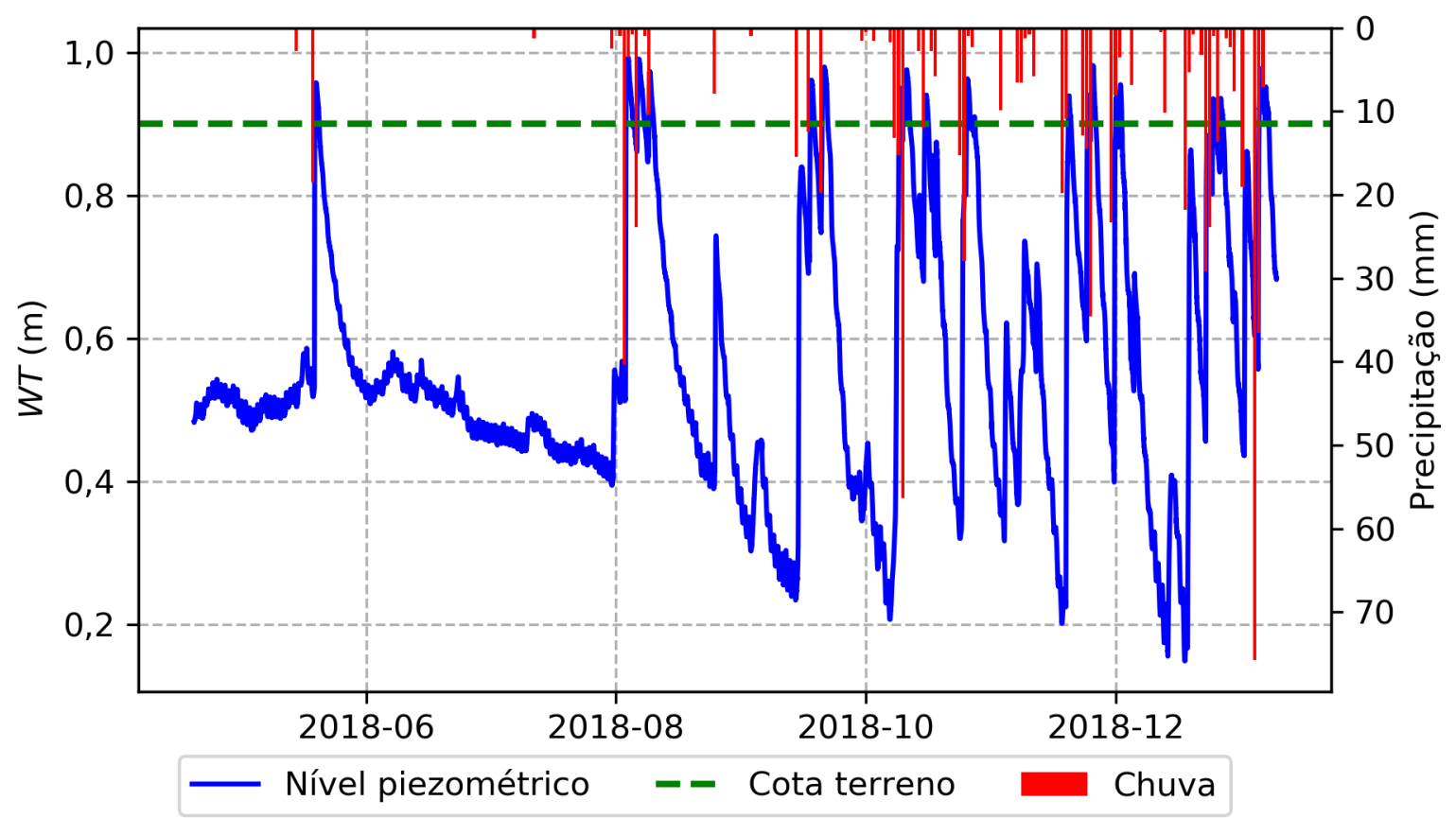

Fonte: Autor

\section{C.3 Poço P31}

Figura 51 - Nível piezométrico poço P31

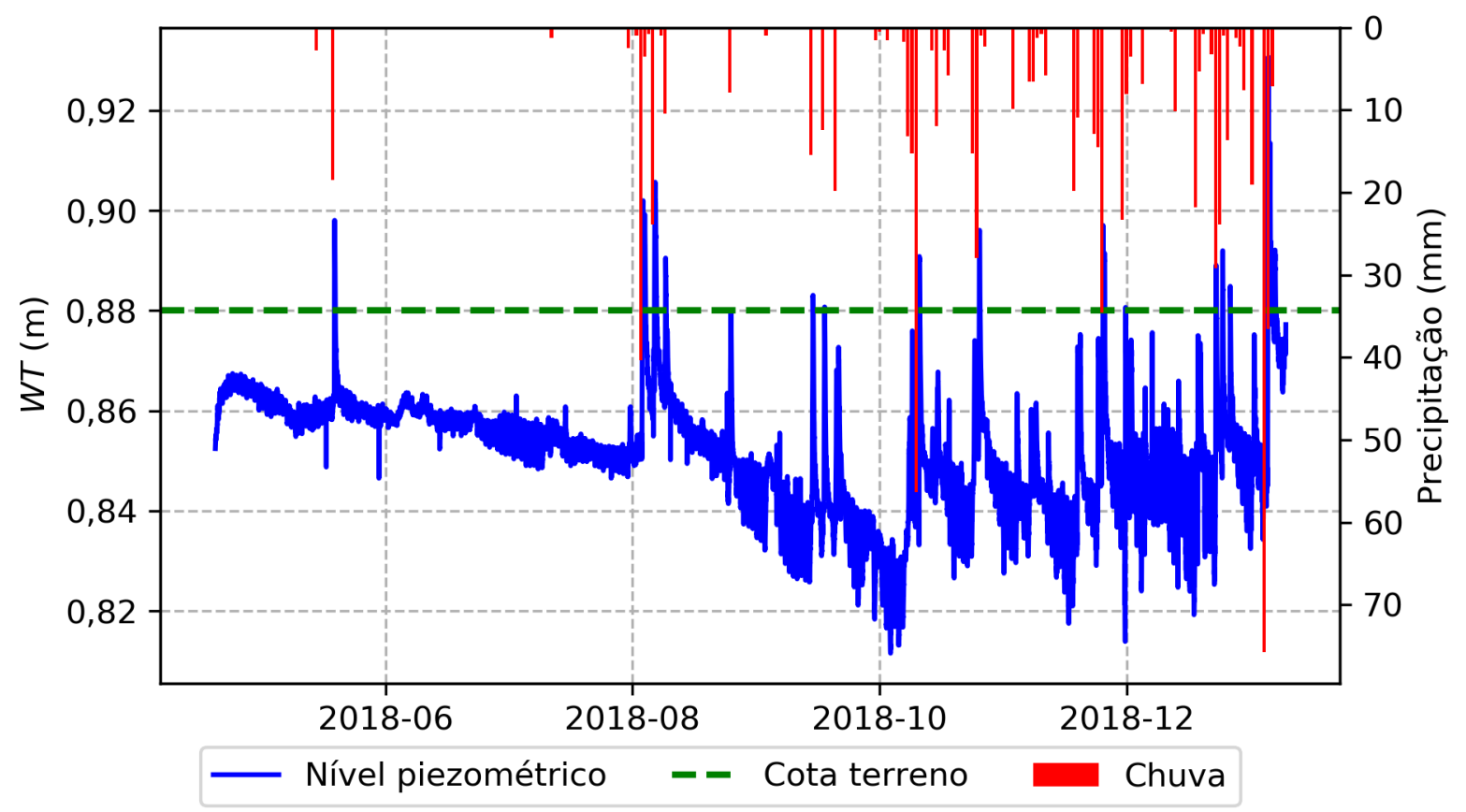

Fonte: Autor 


\section{C.4 Poço P32}

Figura 52 - Nível piezométrico poço P32

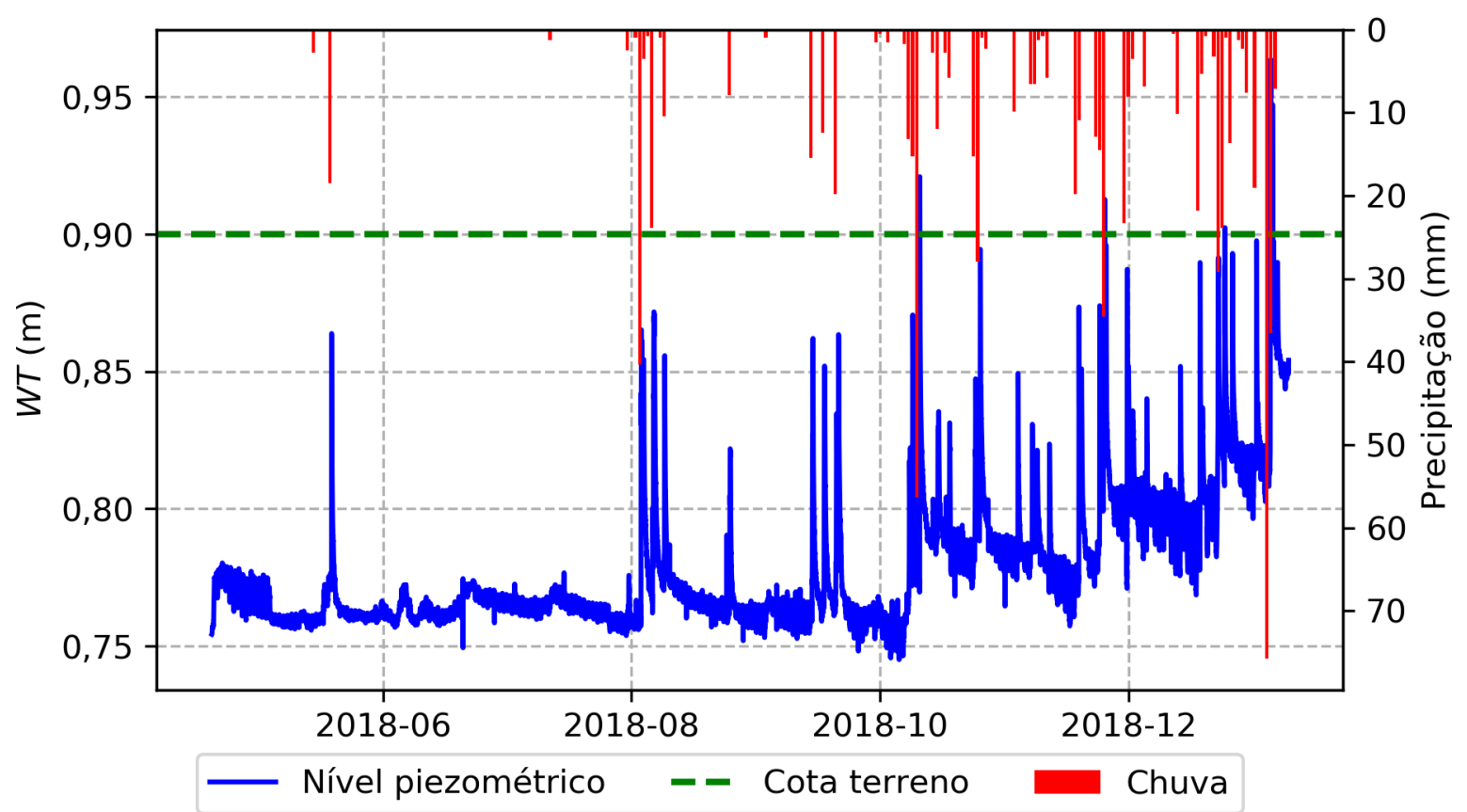

Fonte: Autor

\section{C.5 Poço P33}

Figura 53 - Nível piezométrico poço P33

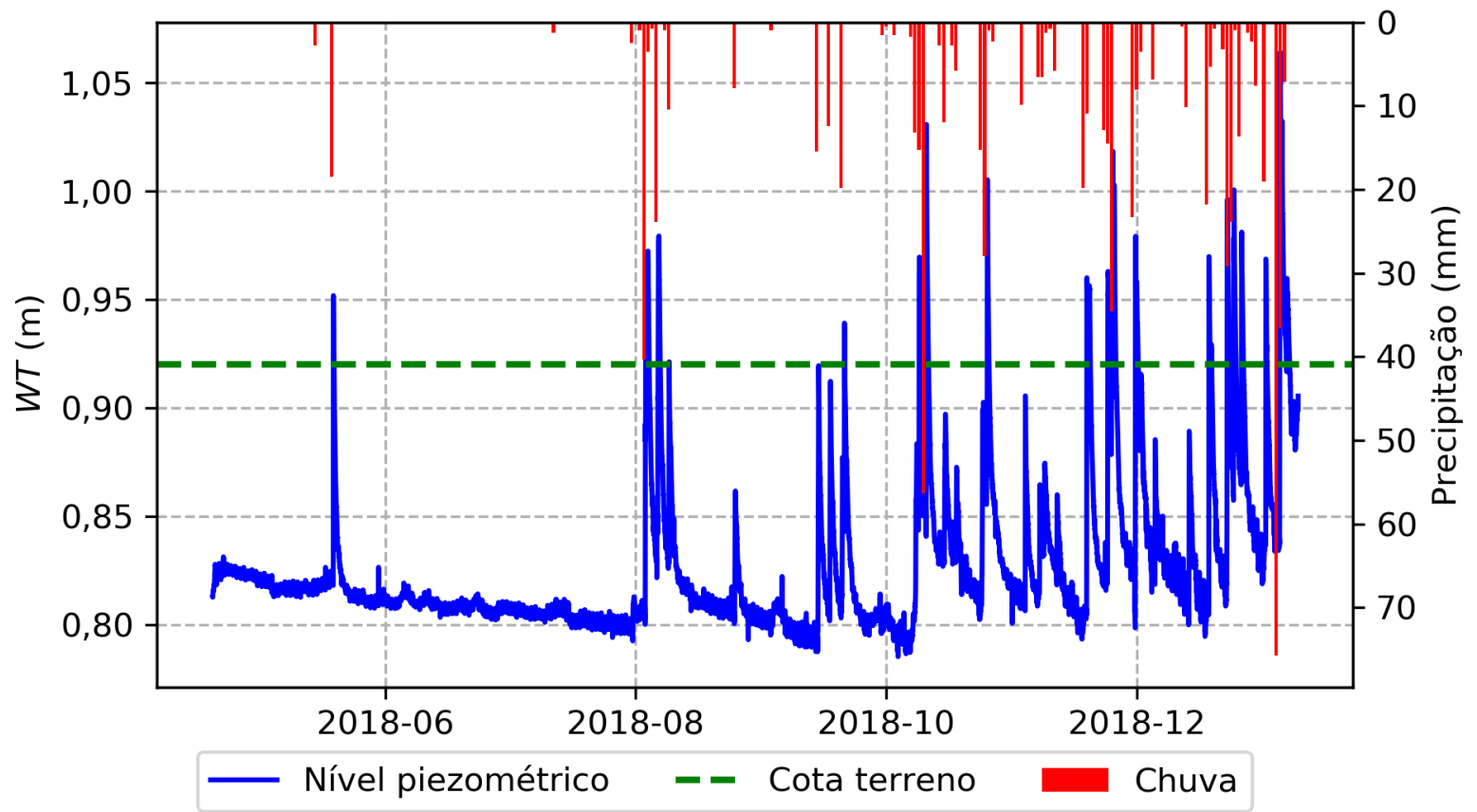

Fonte: Autor 


\section{C.6 Poço P35}

Figura 54 - Nível piezométrico poço P35

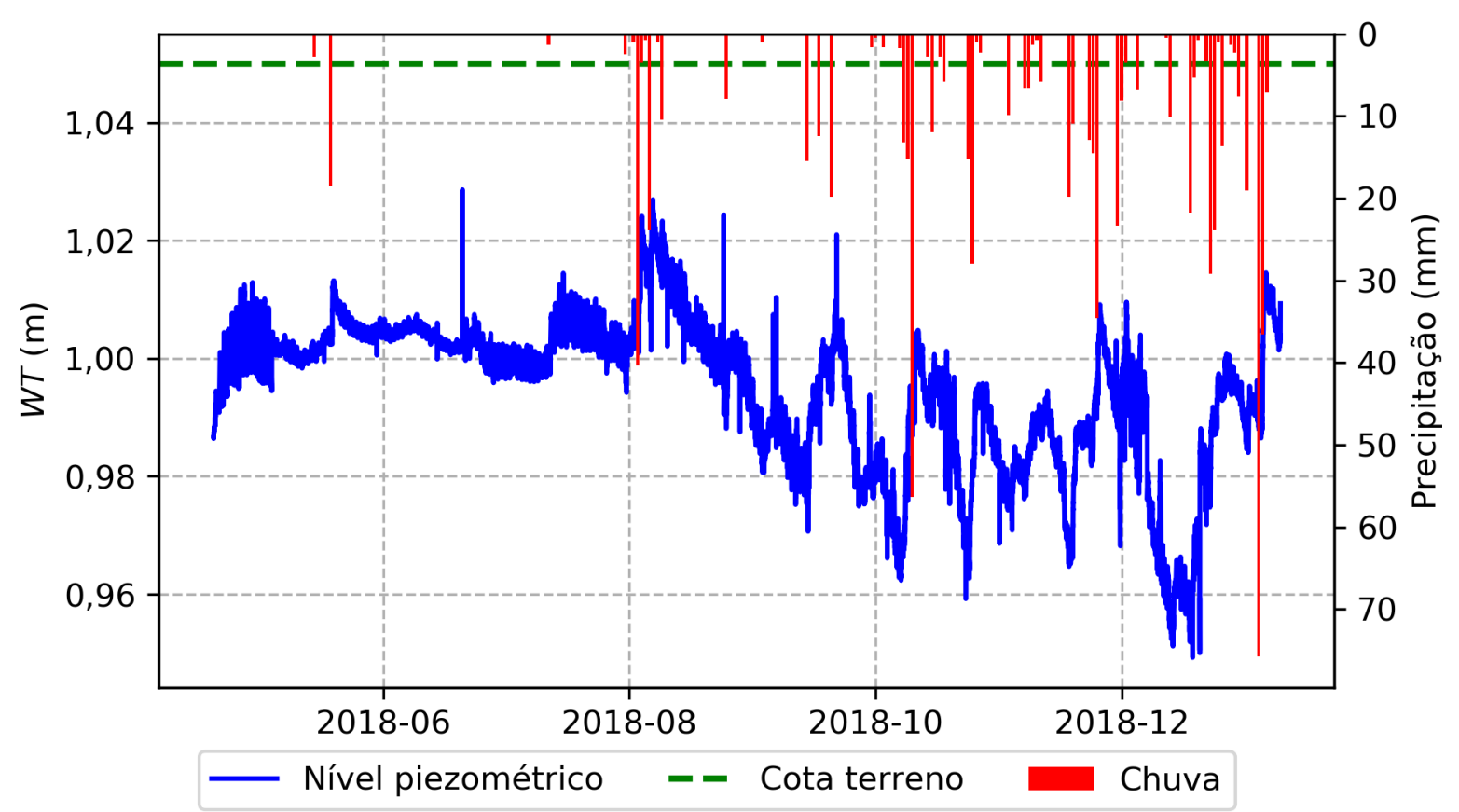

Fonte: Autor 


\section{APÊNDICE D - Código em Python}

Para visualizar o código e os dados de entrada, acessar o site https://github.com/login com os seguintes dados:

Username lhceescusp

Password et_riparian_zone_jcdc_2019

Finalmente, abrir o repositório jcdc1331/ET_LHC_EESC_USP. 



\section{APÊNDICE E - Resultados de evapotranspiração do método da razão de Bowen}

Tabela 15 - Resultados de evapotranspiração do método de balanço de energia - Razão de Bowen

\begin{tabular}{|c|c|c|c|c|c|}
\hline Data & $E T(m m)$ & Data & $E T(m m)$ & Data & $E T(m m)$ \\
\hline $30 / 05 / 2018$ & 2,57 & $13 / 08 / 2018$ & 4,07 & $27 / 10 / 2018$ & 2,84 \\
\hline $31 / 05 / 2018$ & 4,43 & $14 / 08 / 2018$ & 4,64 & $28 / 10 / 2018$ & 5,32 \\
\hline 01/06/2018 & 4,35 & $15 / 08 / 2018$ & 4,35 & $29 / 10 / 2018$ & 5,03 \\
\hline 02/06/2018 & 3,03 & $16 / 08 / 2018$ & 1,26 & $30 / 10 / 2018$ & 5,80 \\
\hline 03/06/2018 & 2,64 & $17 / 08 / 2018$ & 1,99 & $31 / 10 / 2018$ & 6,02 \\
\hline 04/06/2018 & 3,31 & $18 / 08 / 2018$ & 2,13 & $01 / 11 / 2018$ & 5,16 \\
\hline 05/06/2018 & 2,44 & $19 / 08 / 2018$ & 4,08 & $02 / 11 / 2018$ & 5,27 \\
\hline 06/06/2018 & 2,21 & $20 / 08 / 2018$ & 5,25 & $03 / 11 / 2018$ & 5,81 \\
\hline $07 / 06 / 2018$ & 2,62 & $21 / 08 / 2018$ & 5,63 & $04 / 11 / 2018$ & 5,88 \\
\hline 08/06/2018 & 1,96 & $22 / 08 / 2018$ & 3,70 & $05 / 11 / 2018$ & 3,44 \\
\hline 09/06/2018 & 4,27 & $23 / 08 / 2018$ & 4,74 & $06 / 11 / 2018$ & 5,25 \\
\hline $10 / 06 / 2018$ & 2,90 & $24 / 08 / 2018$ & 3,78 & $07 / 11 / 2018$ & 2,39 \\
\hline $11 / 06 / 2018$ & 2,89 & $25 / 08 / 2018$ & 2,18 & $08 / 11 / 2018$ & 3,89 \\
\hline $12 / 06 / 2018$ & 2,74 & $26 / 08 / 2018$ & 3,06 & 09/11/2018 & 5,13 \\
\hline $13 / 06 / 2018$ & 2,39 & $27 / 08 / 2018$ & 4,06 & $10 / 11 / 2018$ & 4,26 \\
\hline $14 / 06 / 2018$ & 3,41 & $28 / 08 / 2018$ & 4,62 & $11 / 11 / 2018$ & 4,73 \\
\hline $15 / 06 / 2018$ & 3,07 & $29 / 08 / 2018$ & 4,92 & $12 / 11 / 2018$ & 6,58 \\
\hline $16 / 06 / 2018$ & 2,37 & $30 / 08 / 2018$ & 5,25 & $13 / 11 / 2018$ & 5,96 \\
\hline $17 / 06 / 2018$ & 3,76 & $31 / 08 / 2018$ & 5,59 & $14 / 11 / 2018$ & 3,85 \\
\hline $18 / 06 / 2018$ & 2,87 & 01/09/2018 & 5,57 & $15 / 11 / 2018$ & 6,99 \\
\hline $19 / 06 / 2018$ & 3,30 & $02 / 09 / 2018$ & 5,68 & $16 / 11 / 2018$ & 7,12 \\
\hline $20 / 06 / 2018$ & 3,52 & 03/09/2018 & 1,51 & $17 / 11 / 2018$ & 3,33 \\
\hline $21 / 06 / 2018$ & 3,38 & 04/09/2018 & 2,01 & $18 / 11 / 2018$ & 2,46 \\
\hline $22 / 06 / 2018$ & 2,16 & $05 / 09 / 2018$ & 2,53 & $19 / 11 / 2018$ & 0,47 \\
\hline 23/06/2018 & 3,57 & 06/09/2018 & 3,81 & $20 / 11 / 2018$ & 2,43 \\
\hline $24 / 06 / 2018$ & 3,17 & $07 / 09 / 2018$ & 5,18 & $21 / 11 / 2018$ & 4,40 \\
\hline $25 / 06 / 2018$ & 4,21 & 08/09/2018 & 5,93 & $22 / 11 / 2018$ & 5,51 \\
\hline $26 / 06 / 2018$ & 4,12 & 09/09/2018 & 5,19 & $23 / 11 / 2018$ & 5,77 \\
\hline
\end{tabular}


Tabela 15 - Resultados de evapotranspiração do método de balanço de energia - Razão de Bowen

\begin{tabular}{|c|c|c|c|c|c|}
\hline Data & $E T(m m)$ & Data & $E T(m m)$ & Data & $E T(m m)$ \\
\hline $27 / 06 / 2018$ & 3,92 & $10 / 09 / 2018$ & 5,42 & $24 / 11 / 2018$ & 2,82 \\
\hline $28 / 06 / 2018$ & 3,31 & $11 / 09 / 2018$ & 3,99 & $25 / 11 / 2018$ & 2,22 \\
\hline $29 / 06 / 2018$ & 3,51 & $12 / 09 / 2018$ & 3,70 & $26 / 11 / 2018$ & 6,40 \\
\hline $30 / 06 / 2018$ & 4,30 & $13 / 09 / 2018$ & 5,44 & $27 / 11 / 2018$ & 9,96 \\
\hline $01 / 07 / 2018$ & 3,88 & $14 / 09 / 2018$ & 2,67 & $28 / 11 / 2018$ & 11,06 \\
\hline 02/07/2018 & 3,96 & $15 / 09 / 2018$ & 2,65 & $29 / 11 / 2018$ & 11,80 \\
\hline $03 / 07 / 2018$ & 4,08 & $16 / 09 / 2018$ & 4,19 & $30 / 11 / 2018$ & 10,16 \\
\hline $04 / 07 / 2018$ & 4,17 & $17 / 09 / 2018$ & 2,75 & $01 / 12 / 2018$ & 1,81 \\
\hline $05 / 07 / 2018$ & 3,90 & $18 / 09 / 2018$ & 1,87 & $02 / 12 / 2018$ & 4,47 \\
\hline $06 / 07 / 2018$ & 4,08 & $19 / 09 / 2018$ & 4,87 & $03 / 12 / 2018$ & 11,20 \\
\hline $07 / 07 / 2018$ & 3,69 & $20 / 09 / 2018$ & 2,05 & $04 / 12 / 2018$ & 10,56 \\
\hline 08/07/2018 & 4,13 & $21 / 09 / 2018$ & 6,33 & $05 / 12 / 2018$ & 5,83 \\
\hline $09 / 07 / 2018$ & 3,92 & $22 / 09 / 2018$ & 6,07 & $06 / 12 / 2018$ & 6,13 \\
\hline $10 / 07 / 2018$ & 2,18 & $23 / 09 / 2018$ & 6,28 & $07 / 12 / 2018$ & 6,29 \\
\hline $11 / 07 / 2018$ & 2,78 & $24 / 09 / 2018$ & 6,40 & $08 / 12 / 2018$ & 4,63 \\
\hline $12 / 07 / 2018$ & 4,03 & $25 / 09 / 2018$ & 5,51 & $09 / 12 / 2018$ & 5,05 \\
\hline $13 / 07 / 2018$ & 3,61 & $26 / 09 / 2018$ & 4,38 & $10 / 12 / 2018$ & 5,46 \\
\hline $14 / 07 / 2018$ & 4,30 & $27 / 09 / 2018$ & 3,03 & $11 / 12 / 2018$ & 5,98 \\
\hline $15 / 07 / 2018$ & 4,40 & $28 / 09 / 2018$ & 2,28 & $12 / 12 / 2018$ & 5,68 \\
\hline $16 / 07 / 2018$ & 4,36 & $29 / 09 / 2018$ & 4,72 & $13 / 12 / 2018$ & 5,57 \\
\hline $17 / 07 / 2018$ & 4,21 & $30 / 09 / 2018$ & 2,86 & $14 / 12 / 2018$ & 8,60 \\
\hline $18 / 07 / 2018$ & 4,46 & $01 / 10 / 2018$ & 4,94 & $15 / 12 / 2018$ & 11,15 \\
\hline $19 / 07 / 2018$ & 4,66 & $02 / 10 / 2018$ & 5,29 & $16 / 12 / 2018$ & 10,06 \\
\hline $20 / 07 / 2018$ & 4,46 & 03/10/2018 & 5,90 & $17 / 12 / 2018$ & 10,11 \\
\hline $21 / 07 / 2018$ & 4,00 & $04 / 10 / 2018$ & 4,96 & $18 / 12 / 2018$ & 7,06 \\
\hline $22 / 07 / 2018$ & 3,66 & $05 / 10 / 2018$ & 5,71 & $19 / 12 / 2018$ & 2,16 \\
\hline $23 / 07 / 2018$ & 3,98 & $06 / 10 / 2018$ & 4,20 & $20 / 12 / 2018$ & 10,02 \\
\hline $24 / 07 / 2018$ & 3,75 & $07 / 10 / 2018$ & 2,44 & $21 / 12 / 2018$ & 8,95 \\
\hline $25 / 07 / 2018$ & 3,39 & 08/10/2018 & 1,94 & $22 / 12 / 2018$ & 9,38 \\
\hline $26 / 07 / 2018$ & 4,87 & 09/10/2018 & 4,75 & $23 / 12 / 2018$ & 3,02 \\
\hline $27 / 07 / 2018$ & 4,65 & $10 / 10 / 2018$ & 4,97 & $24 / 12 / 2018$ & 4,30 \\
\hline $28 / 07 / 2018$ & 4,43 & $11 / 10 / 2018$ & 2,11 & $25 / 12 / 2018$ & 0,67 \\
\hline $29 / 07 / 2018$ & 3,74 & $12 / 10 / 2018$ & 5,35 & $26 / 12 / 2018$ & 0,80 \\
\hline $30 / 07 / 2018$ & 3,96 & $13 / 10 / 2018$ & 5,91 & $27 / 12 / 2018$ & 5,51 \\
\hline $31 / 07 / 2018$ & 2,69 & $14 / 10 / 2018$ & 4,77 & $28 / 12 / 2018$ & 6,31 \\
\hline $01 / 08 / 2018$ & 3,08 & $15 / 10 / 2018$ & 4,06 & $29 / 12 / 2018$ & 7,17 \\
\hline
\end{tabular}


Tabela 15 - Resultados de evapotranspiração do método de balanço de energia - Razão de Bowen

\begin{tabular}{cc|cc|cc}
\hline Data & $E T(m m)$ & Data & $E T(m m)$ & Data & $E T(m m)$ \\
\hline $02 / 08 / 2018$ & 4,12 & $16 / 10 / 2018$ & 4,88 & $30 / 12 / 2018$ & 4,33 \\
$03 / 08 / 2018$ & 4,27 & $17 / 10 / 2018$ & 4,67 & $31 / 12 / 2018$ & 5,77 \\
$04 / 08 / 2018$ & 3,13 & $18 / 10 / 2018$ & 5,87 & $01 / 01 / 2019$ & 3,34 \\
$05 / 08 / 2018$ & 1,66 & $19 / 10 / 2018$ & 6,02 & $02 / 01 / 2019$ & 5,68 \\
$06 / 08 / 2018$ & 3,67 & $20 / 10 / 2018$ & 5,61 & $03 / 01 / 2019$ & 6,60 \\
$07 / 08 / 2018$ & 1,93 & $21 / 10 / 2018$ & 5,83 & $04 / 01 / 2019$ & 4,02 \\
$08 / 08 / 2018$ & 2,89 & $22 / 10 / 2018$ & 6,93 & $05 / 01 / 2019$ & 0,63 \\
$09 / 08 / 2018$ & 3,91 & $23 / 10 / 2018$ & 5,54 & $06 / 01 / 2019$ & 2,82 \\
$10 / 08 / 2018$ & 2,92 & $24 / 10 / 2018$ & 3,35 & $07 / 01 / 2019$ & 6,65 \\
$11 / 08 / 2018$ & 4,26 & $25 / 10 / 2018$ & 3,76 & $08 / 01 / 2019$ & 7,51 \\
$12 / 08 / 2018$ & 1,97 & $26 / 10 / 2018$ & 4,21 & $09 / 01 / 2019$ & 0,72 \\
\hline
\end{tabular}





\section{APÊNDICE F - Resultados de}

\section{evapotranspiração dos métodos baseados na flutuação diária do nível piezométrico}

\section{F.1 Método de White}

Tabela 16 - Resultados de evapotranspiração do método de White

\begin{tabular}{|c|c|c|c|c|c|c|c|c|c|c|c|c|c|}
\hline Data & 27 & P30 & P31 & P32 & P33 & P35 & Data & P27 & P30 & P31 & P32 & P33 & $3 \mathrm{P3}$ \\
\hline 20/04/2018 &, 38 & 3,91 & & 5,07 & 3,36 & 1,86 & 4/06/2018 & 0,41 & 0,92 & 1,19 & 0,92 & 0,57 & \\
\hline $21 / 04 / 2018$ & 1,00 & & 1,81 & 2,19 & 1,91 & 0,70 & $25 / 06 / 2018$ & 0,52 & & 0,55 & 0,87 & 0,05 & \\
\hline $22 / 04 / 2018$ & 1,35 & 3,73 & 1,36 & 1,27 & 1,96 & 0,85 & $26 / 06 / 2018$ & 1,18 & & 1,27 & 1,73 & 0,51 & \\
\hline $23 / 04 / 2018$ & & 3,51 & 1,43 & 0,62 & 1,38 & 0,21 & $27 / 06 / 2018$ & & 0,72 & 1,30 & 1,63 & 0,79 & \\
\hline 4/04/2018 & 1,13 & 0,97 & 1,11 & & 1,19 & 0,11 & $28 / 06 / 2018$ & & 2,09 & 1,50 & 1,18 & 1,73 & \\
\hline $25 / 04 / 2018$ & & 0,97 & 0,90 & 0,08 & 1,19 & 0,19 & $29 / 06 / 2018$ & 1,60 & 0,67 & 1,60 & 1,38 & 0,90 & \\
\hline $26 / 04 / 2018$ & 3,49 & & 1,22 & 0,75 & 1,34 & 0,35 & $30 / 06 / 2018$ & 1,35 & 0,82 & 1,67 & 1,61 & 0,32 & \\
\hline $27 / 04 / 2018$ & 0,88 & & 0,55 & & 0,86 & & $01 / 07 / 2018$ & 0,81 & 1,26 & 1,82 & 1,69 & 0,90 & \\
\hline $28 / 04 / 2018$ & 0,04 & 1,13 & 0,97 & 0,68 & 1,24 & & $02 / 07 / 2018$ & 0,97 & 0,63 & 1,44 & 1,60 & 0,90 & \\
\hline $29 / 04 / 2018$ & 3,62 & 0,52 & 0,90 & & 0,98 & & 03/07/2018 & 1,00 & 1,46 & 2,06 & 1,80 & 1,03 & 30,1 \\
\hline $30 / 04 / 2018$ & 3,37 & 0,26 & 0,54 & & 0,49 & & $07 / 07 / 2018$ & & 0,78 & 1,97 & 1,64 & 0,63 & \\
\hline $01 / 05$ & 5,99 & & 1,64 & 2,74 & 1,22 & & $/ 2018$ & 1,61 & 0,45 & 1,73 & 1,43 & 0,18 & \\
\hline $02 / 05 /$ & & 2,03 & 0,87 & 1,39 & 1,23 & & $14 / 07 / 2018$ & 1,07 & & 0,76 & 1,45 & 0,37 & \\
\hline 03/05/2018 & 2,16 & & 1,00 & 0,19 & 1,12 & 0,51 & $15 / 07 / 2018$ & 0,46 & & 0,61 & 0,86 & & \\
\hline 04/05/2018 & 0,20 & 1,65 & 1,20 & & 0,57 & 0,62 & /2018 & 1,06 & & 1,63 & 2,14 & 0,27 & \\
\hline $05 / 0$ & 0,63 & 3,00 & 0,99 & 0,55 & 1,00 & 0,17 & $17 / 07 / 2018$ & 0,38 & & 1,20 & 1,67 & 0,34 & \\
\hline 06/05/2018 & 0,88 & 4,53 & 0,83 & 0,77 & 1,07 & 0,21 & $18 / 07 / 2018$ & 1,48 & 1,33 & 1,96 & 2,22 & 1,02 & \\
\hline & & 1,81 & 0,56 & 1,33 & 1,05 & 0,33 & & 0,94 & 2,05 & 1,45 & 1,33 & 0,79 & \\
\hline $08 / 05$ & & 2,62 & 0,95 & 1,09 & 0,99 & & $20 / 07 / 2018$ & 1,16 & 0,46 & 1,27 & 1,83 & 0,33 & \\
\hline 09/05/2018 & & 3,19 & 0,78 & 1,34 & 1,22 & 0,31 & $21 / 07 / 2018$ & & 1,19 & 0,85 & 1,40 & & \\
\hline $10 / 05 / 2018$ & 0,76 & 0,36 & 0,55 & 1,05 & 0,55 & 0,08 & $22 / 07 / 2018$ & 0,81 & 3,19 & 0,97 & 1,59 & 0,63 & \\
\hline $11 / 05 /$ & & 1,56 & 0,59 & 1,38 & 0,92 & 0,22 & $23 / 07 / 2018$ & 1,34 & 0,71 & 1,28 & 1,34 & 0,62 & \\
\hline $12 / 05 / 2018$ & 0,82 & 3,71 & & 0,44 & 0,05 & & $24 / 07 / 2018$ & 0,58 & & 1,47 & 1,61 & 0,64 & \\
\hline $13 / 05 / 2018$ & & 3,08 & & & & & $25 / 07 / 2018$ & 1,62 & 2,19 & 1,91 & 1,86 & 1,48 & \\
\hline $17 / 05 / 2018$ & & & 0,00 & & & 0,31 & $26 / 07 / 2018$ & 0,52 & 0,57 & 0,75 & 1,17 & 0,03 & \\
\hline $22 / 05 / 2018$ & 1,52 & & 0,58 & 0,22 & & 0,35 & $27 / 07 / 2018$ & 1,22 & & 2,36 & 2,20 & 0,99 & 0,29 \\
\hline
\end{tabular}


APÊNDICE F. Resultados de evapotranspiração dos métodos baseados na flutuação diária do nível 122 piezométrico

Tabela 16 - Resultados de evapotranspiração do método de White

\begin{tabular}{|c|c|c|c|c|c|c|c|c|c|c|c|c|c|}
\hline Data & 27 & P30 & P31 & P32 & P33 & P35 & Data & P27 & P30 & P31 & P32 & P33 & P35 \\
\hline $23 / 05 / 2018$ & & & 0,94 & 0,54 & & 0,31 & $3 / 07 / 2018$ & 1,16 & 1,00 & 1,79 & 2,03 & 1,05 & 0,07 \\
\hline $24 / 05 / 2018$ & 2,71 & & 0,95 & 1,00 & 0,53 & 0,33 & $29 / 07 / 2018$ & 1,39 & 0,55 & 1,63 & 1,82 & 0,73 & \\
\hline $25 / 05 / 2018$ & 3,23 & & 0,90 & 1,29 & 0,53 & 0,50 & $17 / 08 / 2018$ & 0,52 & & 1,55 & 1,11 & 1,38 & 0,3 \\
\hline $26 / 05 / 2018$ & 0,58 & & 0,92 & 1,05 & & 0,42 & 8/08/2018 & 1,36 & & 1,52 & 1,29 & 0,58 & \\
\hline $27 / 05 / 2018$ & 1,47 & & 1,06 & 1,46 & 0,32 & 0,59 & $22 / 08 / 2018$ & 1,02 & 3,15 & 1,89 & 1,44 & 0,45 & \\
\hline $28 / 05 / 2018$ & & & 0,63 & 1,34 & 0,52 & 0,33 & $23 / 08 / 2018$ & & 5,31 & 1,39 & & 1,04 & 0,20 \\
\hline $9 / 05 / 2018$ & & & 0,66 & 1,22 & 0,52 & & $27 / 08 / 2018$ & 0,87 & & 1,54 & 1,52 & & \\
\hline $30 / 05 / 2018$ & & & 0,85 & 1,29 & 0,82 & & $9 / 09 / 2018$ & 2,06 & 1,10 & 3,52 & 2,16 & 1,19 & \\
\hline $31 / 05 / 2018$ & 1,23 & & 1,36 & 2,00 & 1,14 & 0,42 & $10 / 09 / 2018$ & 1,54 & 4,67 & 3,67 & 2,16 & 0,93 & \\
\hline & & 1,85 & 0,34 & & & 0,44 & & 0,63 & 7,34 & 2,23 & 1,91 & 1,12 & \\
\hline $2 / 06 / 2018$ & 0,63 & 2,68 & 1,13 & & & 0,54 & /2018 & 1,62 & 7,87 & 3,13 & 2,62 & 2,69 & 0,6 \\
\hline $03 / 06 / 2018$ & 0,60 & 5,57 & & & & 0,52 & $25 / 09 / 2018$ & 1,32 & & 4,10 & 1,88 & 1,01 & \\
\hline 04/06/2018 & 0,91 & 1,08 & & & & & $26 / 09 / 2018$ & 2,48 & & 4,92 & 2,10 & 1,79 & \\
\hline & 1,39 & & & & & & 2018 & 1,61 & & 3,68 & 1,09 & 1,71 & 0,20 \\
\hline $9 / 06 / 2018$ & 0,94 & & & & & 0,21 & $/ 2018$ & 2,68 & & 3,09 & 1,75 & 1,34 & \\
\hline $10 / 06 / 2018$ & 1,83 & & 1,06 & 2,36 & 1,39 & 0,17 & $22 / 10 / 2018$ & & & 3,57 & 1,88 & 1,89 & \\
\hline $11 / 06 / 2018$ & 1,38 & 2,05 & 0,52 & 2,08 & 1,23 & 0,20 & $30 / 10 / 2018$ & 1,11 & & 0,91 & 1,15 & 0,45 & \\
\hline $12 / 06 / 2018$ & 1,37 & 0,76 & 1,04 & 1,81 & 0,87 & 0,11 & $/ 10 / 2018$ & 0,49 & & 1,24 & 1,05 & 0,90 & \\
\hline & & 8,10 & 0,19 & & 0,55 & 0,13 & $1 / 2018$ & 1,72 & & 2,93 & 2,78 & 2,78 & \\
\hline & & 4,24 & 0,70 & 0,62 & 0,42 & 0,28 & $16 / 11 / 2018$ & 2,59 & & 3,86 & 2,16 & 1,84 & \\
\hline $15 / 06 / 2018$ & 1,42 & & 0,48 & 0,66 & 0,21 & & $27 / 11 / 2018$ & & & 0,85 & 0,47 & & \\
\hline $16 / 06 / 2018$ & 0,67 & 1,29 & 0,99 & 2,22 & 1,32 & 0,20 & $28 / 11 / 2018$ & 1,26 & & 2,15 & 2,10 & 0,95 & \\
\hline & & & 0,86 & 0,77 & & & & 1,49 & & 2,49 & 1,74 & 1,93 & \\
\hline $18 / 06 / 2018$ & 1,23 & 1,81 & 1,23 & 1,64 & 1,11 & & $08 / 12 / 2018$ & 1,95 & & 3,49 & 1,96 & 2,54 & \\
\hline $22 / 06 / 2018$ & 2,30 & & & & & & 09/12/2018 & 2,82 & & 4,94 & 3,32 & 4,46 & \\
\hline 23/06/2018 & 0,03 & 3,87 & 0,28 & 0,37 & 0,69 & 0,28 & $16 / 12 / 2018$ & 3,17 & & 4,97 & & 3,49 & 0,0 \\
\hline
\end{tabular}

\section{F.1.1 Adaptação de Rushton}

Tabela 17 - Resultados de evapotranspiração da adaptação de Rushton

\begin{tabular}{c|rrrrrrr|lllllll}
\hline Data & P27 & P30 & P31 & P32 & P33 & P35 & & Data & P27 & P30 & P31 & P32 & P33 & P35 \\
\hline 20/04/2018 & & 4,21 & & 4,36 & 3,07 & 1,77 & & $24 / 06 / 2018$ & 0,67 & & 1,04 & 0,93 & \\
21/04/2018 & 1,01 & & 1,70 & 1,09 & & 0,30 & & $25 / 06 / 2018$ & 0,64 & & 0,75 & 0,94 &
\end{tabular}


Tabela 17 - Resultados de evapotranspiração da adaptação de Rushton

\begin{tabular}{|c|c|c|c|c|c|c|c|c|c|c|c|c|}
\hline Data & $\mathrm{P} 27$ & P30 & P31 & P32 & P33 & P35 & Data & $\mathrm{P} 27$ & P30 & P31 & P32 & P33 P35 \\
\hline $22 / 04 / 2018$ & 0,81 & 0,95 & 1,09 & 0,51 & 0,21 & & $26 / 06 / 2018$ & 1,57 & & 1,05 & 1,46 & \\
\hline $23 / 04 / 2018$ & & 1,40 & 1,02 & & 0,39 & & $27 / 06 / 2018$ & & & 1,29 & 1,66 & 0,01 \\
\hline $24 / 04 / 2018$ & 0,83 & & 0,92 & & 0,58 & & $28 / 06 / 2018$ & & & 1,32 & 1,16 & 0,78 \\
\hline $25 / 04 / 2018$ & & & 0,53 & & 0,39 & & $29 / 06 / 2018$ & 1,55 & & 1,69 & 1,30 & 0,07 \\
\hline $26 / 04 / 2018$ & & & 0,71 & & 0,41 & & $30 / 06 / 2018$ & 1,51 & & 1,71 & 1,23 & \\
\hline $27 / 04 / 2018$ & & & 0,39 & & 0,16 & & 01/07/2018 & 0,94 & & 1,80 & 1,37 & \\
\hline $28 / 04 / 2018$ & & & 0,70 & & 0,39 & & 02/07/2018 & 0,84 & & 1,66 & 1,25 & \\
\hline $29 / 04 / 2018$ & 0,72 & & 0,56 & & 0,48 & & 03/07/2018 & 1,10 & & 2,22 & 1,56 & 0,06 \\
\hline $30 / 04 / 2018$ & 0,99 & & 0,47 & & & & $07 / 07 / 2018$ & 0,60 & & 2,10 & 1,42 & \\
\hline $01 / 05 / 2018$ & 1,22 & & 1,18 & & 0,28 & & 08/07/2018 & 0,95 & & 2,06 & 1,49 & \\
\hline $02 / 05 / 2018$ & 0,24 & & 0,61 & & 0,43 & & $14 / 07 / 2018$ & 1,00 & & 0,52 & 1,13 & \\
\hline 03/05/2018 & 1,14 & & 0,84 & & 0,20 & & $15 / 07 / 2018$ & 1,09 & & 0,60 & 0,92 & \\
\hline $04 / 05 / 2018$ & & & 1,01 & & & & $16 / 07 / 2018$ & 0,90 & & 0,93 & 1,10 & \\
\hline $05 / 05 / 2018$ & 0,35 & 0,26 & 0,81 & 0,37 & 0,29 & 0,04 & $17 / 07 / 2018$ & 1,02 & & 1,16 & 1,39 & \\
\hline $06 / 05 / 2018$ & & 1,30 & 0,62 & 0,34 & 0,31 & 0,13 & $18 / 07 / 2018$ & 1,25 & & 1,41 & 1,61 & \\
\hline $07 / 05 / 2018$ & & & 0,25 & 0,10 & & 0,19 & $19 / 07 / 2018$ & 1,15 & & 1,24 & 1,17 & \\
\hline $08 / 05 / 2018$ & & & 0,74 & 0,64 & 0,15 & & $20 / 07 / 2018$ & 1,14 & & 1,16 & 1,26 & \\
\hline $09 / 05 / 2018$ & 0,22 & & 0,47 & 0,48 & & & $21 / 07 / 2018$ & 0,61 & & 0,91 & 1,24 & \\
\hline $10 / 05 / 2018$ & 0,38 & & 0,48 & 0,31 & & 0,01 & $22 / 07 / 2018$ & 1,10 & 0,26 & 0,74 & 1,07 & \\
\hline $11 / 05 / 2018$ & & & 0,29 & 0,79 & 0,11 & 0,01 & $23 / 07 / 2018$ & 1,06 & & 0,95 & 1,07 & \\
\hline $12 / 05 / 2018$ & 0,61 & 0,50 & & & & & $24 / 07 / 2018$ & 0,91 & & 1,09 & 1,56 & \\
\hline $13 / 05 / 2018$ & & 0,82 & & & & & $25 / 07 / 2018$ & 1,41 & & 1,35 & 1,42 & 0,25 \\
\hline $17 / 05 / 2018$ & & & & & & 0,43 & $26 / 07 / 2018$ & 0,73 & & 0,56 & 0,77 & \\
\hline $22 / 05 / 2018$ & 0,49 & & 0,90 & 0,23 & & 0,43 & $27 / 07 / 2018$ & 1,63 & & 1,76 & 1,47 & \\
\hline $23 / 05 / 2018$ & & & 1,09 & 0,42 & & 0,37 & $28 / 07 / 2018$ & 1,20 & & 1,21 & 1,52 & \\
\hline $24 / 05 / 2018$ & & & 0,94 & 0,68 & & 0,27 & $29 / 07 / 2018$ & 1,33 & & 1,38 & 1,52 & \\
\hline $25 / 05 / 2018$ & 2,00 & & 0,51 & 0,82 & & 0,33 & $17 / 08 / 2018$ & 0,77 & & 1,09 & 0,98 & 0,33 \\
\hline $26 / 05 / 2018$ & 0,34 & & 0,49 & 0,55 & & 0,38 & $18 / 08 / 2018$ & 1,61 & & 1,42 & 1,46 & \\
\hline $27 / 05 / 2018$ & 1,50 & & 0,48 & 0,30 & & 0,41 & $22 / 08 / 2018$ & 1,66 & & 2,30 & 1,84 & \\
\hline $28 / 05 / 2018$ & & & 0,46 & 0,76 & & 0,31 & $23 / 08 / 2018$ & & 1,34 & 1,75 & & 0,36 \\
\hline $29 / 05 / 2018$ & & & 0,66 & 0,78 & & & $27 / 08 / 2018$ & 0,83 & & 1,83 & 1,30 & \\
\hline $30 / 05 / 2018$ & & & 0,51 & 0,25 & & & $09 / 09 / 2018$ & 2,40 & & 3,94 & 2,65 & 0,20 \\
\hline $31 / 05 / 2018$ & 1,02 & & 1,10 & 1,33 & 0,28 & 0,49 & $10 / 09 / 2018$ & 2,79 & & 4,42 & 3,08 & 0,52 \\
\hline $01 / 06 / 2018$ & 0,54 & & 0,15 & & & 0,36 & $11 / 09 / 2018$ & 1,46 & 0,90 & 3,24 & 2,28 & 0,43 \\
\hline $02 / 06 / 2018$ & 0,64 & 0,11 & 0,76 & & & 0,40 & $12 / 09 / 2018$ & 2,12 & 0,01 & 3,54 & 2,85 & 1,17 \\
\hline 03/06/2018 & 0,29 & 3,23 & & & & 0,34 & $25 / 09 / 2018$ & 2,23 & & 4,50 & 2,64 & 0,29 \\
\hline
\end{tabular}


APÊNDICE F. Resultados de evapotranspiração dos métodos baseados na flutuação diária do nível 124 piezométrico

Tabela 17 - Resultados de evapotranspiração da adaptação de Rushton

\begin{tabular}{|c|c|c|c|c|c|c|c|c|c|c|c|}
\hline Data & $\mathrm{P} 27$ & P30 & P31 & P32 & P33 & P35 & Data & P27 P30 & P31 & P32 & P33 P35 \\
\hline $04 / 06 / 2018$ & 0,71 & & & & & & $26 / 09 / 2018$ & 2,90 & 5,21 & 2,98 & 1,09 \\
\hline $05 / 06 / 2018$ & 0,97 & 3,32 & & & & & $27 / 09 / 2018$ & 2,39 & 4,58 & 2,39 & 1,74 \\
\hline 09/06/2018 & 0,23 & & & & 0,23 & 0,30 & $21 / 10 / 2018$ & 2,91 & 4,30 & 3,13 & 1,35 \\
\hline $10 / 06 / 2018$ & 1,25 & & 0,83 & 1,21 & 0,33 & 0,23 & $22 / 10 / 2018$ & & 4,43 & 2,95 & 1,45 \\
\hline $11 / 06 / 2018$ & 0,64 & & 0,13 & 0,37 & & 0,14 & $30 / 10 / 2018$ & 1,38 & 2,15 & 1,59 & 0,06 \\
\hline $12 / 06 / 2018$ & 1,27 & & 0,63 & 0,10 & & 0,06 & $31 / 10 / 2018$ & 1,38 & 2,57 & 1,76 & 0,62 \\
\hline $13 / 06 / 2018$ & & 5,15 & 0,17 & & & 0,21 & $01 / 11 / 2018$ & 2,52 & 4,33 & 3,72 & 1,94 \\
\hline $14 / 06 / 2018$ & & 1,77 & 0,47 & 0,05 & & 0,22 & $16 / 11 / 2018$ & 2,57 & 4,11 & 2,52 & 0,68 \\
\hline $15 / 06 / 2018$ & 1,58 & & 0,75 & 0,31 & & & $27 / 11 / 2018$ & & 0,70 & 0,17 & \\
\hline $16 / 06 / 2018$ & 0,60 & & 0,93 & 0,56 & 0,12 & 0,18 & $28 / 11 / 2018$ & 1,03 & 2,17 & 2,14 & \\
\hline $17 / 06 / 2018$ & & & 0,77 & 0,05 & & & $07 / 12 / 2018$ & 1,79 & 3,13 & 2,18 & 0,99 \\
\hline $18 / 06 / 2018$ & 1,46 & & 1,10 & 0,08 & & & 08/12/2018 & 3,07 & 4,70 & 3,07 & 2,04 \\
\hline $22 / 06 / 2018$ & 1,57 & & & & & & 09/12/2018 & 3,80 & 5,19 & 4,12 & 3,54 \\
\hline $23 / 06 / 2018$ & & 2,65 & 0,13 & 0,20 & 0,11 & 0,02 & $16 / 12 / 2018$ & 4,21 & 5,37 & & 2,75 \\
\hline
\end{tabular}

\section{F.1.2 Adaptação de Hays}

Tabela 18 - Resultados de evapotranspiração da adaptação de Hays

\begin{tabular}{|c|c|c|c|c|c|c|c|c|c|c|c|c|c|}
\hline Data & P27 & P30 & P31 & P32 & P33 & P35 & Data & P27 & P30 & P31 & P32 & P33 & P35 \\
\hline $20 / 04 / 2018$ & 0,40 & 1,34 & & 4,59 & 2,60 & 1,39 & $24 / 06 / 2018$ & 0,62 & & 0,64 & 0,82 & 0,04 & \\
\hline $21 / 04 / 2018$ & 1,21 & 0,91 & 1,46 & 1,61 & 1,85 & 0,54 & $25 / 06 / 2018$ & 0,84 & & 1,18 & 1,61 & 0,41 & \\
\hline $22 / 04 / 2018$ & 0,09 & 4,48 & 1,50 & 0,80 & 1,68 & 0,24 & $26 / 06 / 2018$ & 1,30 & & 1,20 & 1,62 & 0,65 & \\
\hline $23 / 04 / 2018$ & 0,70 & 2,38 & 1,18 & & 1,32 & 0,43 & $27 / 06 / 2018$ & & 1,59 & 1,50 & 1,48 & 1,45 & \\
\hline $24 / 04 / 2018$ & & 0,69 & 0,99 & & 1,28 & 0,33 & $28 / 06 / 2018$ & & 1,24 & 1,60 & 1,12 & 1,03 & \\
\hline $25 / 04 / 2018$ & 2,06 & & 1,17 & 0,66 & 1,25 & & $29 / 06 / 2018$ & 1,44 & 0,85 & 1,81 & 1,67 & 0,65 & \\
\hline $26 / 04 / 2018$ & 0,89 & & 0,60 & & 0,87 & 0,17 & $30 / 06 / 2018$ & 0,93 & 0,81 & 1,71 & 1,61 & 0,79 & \\
\hline $27 / 04 / 2018$ & 0,48 & & 0,88 & & 1,02 & & $01 / 07 / 2018$ & 1,02 & 1,50 & 1,57 & 1,66 & 1,03 & \\
\hline $28 / 04 / 2018$ & 3,67 & 2,12 & 0,96 & & 1,23 & & $02 / 07 / 2018$ & 0,90 & 0,48 & 1,92 & 1,79 & 0,80 & 0,00 \\
\hline $29 / 04 / 2018$ & 3,79 & 1,19 & 0,69 & 0,47 & 0,71 & & $03 / 07 / 2018$ & 0,74 & 2,58 & 1,89 & 1,75 & 1,00 & \\
\hline $30 / 04 / 2018$ & 4,59 & & 1,44 & 1,47 & 0,92 & & $07 / 07 / 2018$ & 1,39 & 0,47 & 1,85 & 1,44 & 0,21 & \\
\hline $01 / 05 / 2018$ & 0,37 & 1,10 & 1,01 & 1,15 & 1,22 & & 08/07/2018 & 1,23 & 1,74 & 1,98 & 1,47 & 0,98 & \\
\hline $02 / 05 / 2018$ & 2,40 & 0,52 & 0,92 & 0,64 & 1,13 & 0,60 & $14 / 07 / 2018$ & 0,51 & & 0,47 & 0,87 & & \\
\hline $03 / 05 / 2018$ & & & 1,01 & & 1,11 & & $15 / 07 / 2018$ & 0,97 & & 1,45 & 1,92 & & \\
\hline
\end{tabular}


Tabela 18 - Resultados de evapotranspiração da adaptação de Hays

\begin{tabular}{|c|c|c|c|c|c|c|c|c|c|c|c|c|c|}
\hline Data & $\mathrm{P} 27$ & P30 & P31 & P32 & P33 & P35 & Data & P27 & P30 & P31 & P32 & P33 & P35 \\
\hline $04 / 05 / 2018$ & 1,76 & 3,23 & 1,22 & & 0,33 & 0,80 & $16 / 07 / 2018$ & 0,50 & & 1,28 & 1,65 & 0,20 & \\
\hline $05 / 05 / 2018$ & 0,57 & 3,48 & 0,77 & 0,76 & 0,97 & 0,12 & $17 / 07 / 2018$ & 1,34 & 0,47 & 1,73 & 2,17 & 0,81 & \\
\hline $06 / 05 / 2018$ & 0,82 & 4,69 & 0,73 & 1,37 & 1,34 & 0,50 & $18 / 07 / 2018$ & 1,00 & 2,18 & 1,69 & 1,52 & 1,11 & \\
\hline $07 / 05 / 2018$ & & 1,72 & 0,87 & 1,06 & 0,96 & & $19 / 07 / 2018$ & 1,21 & 1,17 & 1,23 & 1,73 & 0,35 & \\
\hline $08 / 05 / 2018$ & & 2,85 & 0,83 & 1,23 & 1,00 & 0,20 & $20 / 07 / 2018$ & & 0,19 & 0,84 & 1,35 & & \\
\hline $09 / 05 / 2018$ & 0,59 & 0,91 & 0,17 & 1,13 & 0,79 & 0,17 & $21 / 07 / 2018$ & 0,97 & 2,33 & 1,13 & 1,64 & 0,62 & \\
\hline $10 / 05 / 2018$ & & 0,73 & 0,50 & 1,04 & 0,51 & 0,19 & $22 / 07 / 2018$ & 1,09 & 3,02 & 1,17 & 1,41 & 0,61 & \\
\hline $11 / 05 / 2018$ & 1,00 & 2,58 & 0,20 & 0,90 & 0,48 & 0,11 & $23 / 07 / 2018$ & 0,79 & & 1,49 & 1,48 & 0,61 & \\
\hline $12 / 05 / 2018$ & 0,46 & 3,59 & & & & & $24 / 07 / 2018$ & 1,26 & 1,07 & 1,75 & 1,90 & 1,34 & \\
\hline $13 / 05 / 2018$ & & 1,55 & 0,54 & 1,15 & 0,82 & & $25 / 07 / 2018$ & 1,25 & 1,94 & 1,03 & 1,62 & 0,48 & \\
\hline $17 / 05 / 2018$ & & & 1,23 & & 0,90 & 0,42 & $26 / 07 / 2018$ & 0,58 & & 2,08 & 1,66 & 0,69 & 0,09 \\
\hline $22 / 05 / 2018$ & 0,32 & & 1,00 & 0,60 & & 0,31 & $27 / 07 / 2018$ & 1,36 & 0,51 & 1,82 & 2,07 & 0,90 & 0,03 \\
\hline $23 / 05 / 2018$ & 2,08 & & 0,93 & 0,81 & 0,15 & 0,33 & $28 / 07 / 2018$ & 1,34 & 0,50 & 1,70 & 1,88 & 0,82 & \\
\hline $24 / 05 / 2018$ & 2,93 & & 0,77 & 1,28 & 0,59 & 0,41 & $29 / 07 / 2018$ & 0,93 & 0,68 & 1,48 & 1,32 & 0,52 & \\
\hline $25 / 05 / 2018$ & 1,11 & & 0,99 & 1,17 & 0,37 & 0,42 & $17 / 08 / 2018$ & 1,41 & & 1,56 & 1,23 & 0,83 & \\
\hline $26 / 05 / 2018$ & 1,46 & & 1,07 & 1,41 & 0,21 & 0,57 & $18 / 08 / 2018$ & 0,09 & & 1,28 & 1,45 & 0,09 & \\
\hline $27 / 05 / 2018$ & & & 0,63 & 1,19 & 0,37 & 0,34 & $22 / 08 / 2018$ & 2,68 & 6,73 & 1,91 & 1,42 & 1,50 & 0,42 \\
\hline $28 / 05 / 2018$ & 1,27 & & 0,60 & 1,17 & 0,44 & 0,28 & $23 / 08 / 2018$ & & 1,52 & 1,86 & & 0,79 & \\
\hline $29 / 05 / 2018$ & & & 0,90 & 1,58 & 0,97 & & $27 / 08 / 2018$ & 0,36 & & 1,99 & 1,13 & & \\
\hline $30 / 05 / 2018$ & & & 1,21 & 1,27 & 0,80 & & 09/09/2018 & 1,50 & 3,18 & 3,55 & 2,03 & 0,57 & \\
\hline $31 / 05 / 2018$ & 0,02 & 1,63 & 0,67 & 0,95 & 0,54 & 0,37 & $10 / 09 / 2018$ & 0,85 & 7,35 & 2,50 & 2,16 & 1,49 & \\
\hline $01 / 06 / 2018$ & 0,32 & 0,71 & 0,85 & 0,25 & 0,15 & 0,55 & $11 / 09 / 2018$ & 1,42 & 8,02 & 3,00 & 2,42 & 2,49 & 0,45 \\
\hline $02 / 06 / 2018$ & 0,63 & 4,88 & 0,40 & & 0,18 & 0,42 & $12 / 09 / 2018$ & 1,32 & 9,08 & 3,58 & 2,38 & 1,89 & 0,29 \\
\hline $03 / 06 / 2018$ & 0,79 & 2,98 & & & & 0,25 & $25 / 09 / 2018$ & 2,18 & & 4,39 & 1,86 & 1,46 & \\
\hline 04/06/2018 & 1,54 & 3,28 & & & & & $26 / 09 / 2018$ & 1,66 & & 3,73 & 1,14 & 1,47 & \\
\hline 05/06/2018 & 1,06 & 3,60 & & & & & $27 / 09 / 2018$ & & 2,09 & 1,83 & 0,89 & 1,24 & 0,16 \\
\hline 09/06/2018 & 1,62 & & & & 1,60 & 0,16 & $21 / 10 / 2018$ & 1,61 & & 3,46 & 1,78 & 1,73 & \\
\hline $10 / 06 / 2018$ & 1,41 & 3,03 & 0,83 & 2,31 & 1,46 & 0,22 & $22 / 10 / 2018$ & & & 2,69 & 1,41 & 2,13 & \\
\hline $11 / 06 / 2018$ & 1,36 & & 0,79 & 1,96 & 0,84 & 0,11 & $30 / 10 / 2018$ & 0,71 & & 1,49 & 1,21 & 0,96 & \\
\hline $12 / 06 / 2018$ & 0,05 & 4,40 & 0,30 & & 0,30 & & $31 / 10 / 2018$ & 1,45 & & 2,45 & 2,33 & 2,20 & \\
\hline $13 / 06 / 2018$ & & 8,05 & 0,37 & 0,45 & 0,89 & 0,44 & $01 / 11 / 2018$ & 1,45 & & 2,24 & 1,65 & 2,44 & \\
\hline $14 / 06 / 2018$ & & & 0,67 & 0,57 & & & $16 / 11 / 2018$ & 3,20 & & 6,10 & 3,08 & 2,65 & \\
\hline $15 / 06 / 2018$ & 0,89 & & 0,84 & 2,00 & 1,12 & 0,11 & $27 / 11 / 2018$ & 1,00 & & 2,15 & 1,93 & & \\
\hline $16 / 06 / 2018$ & 0,21 & 0,30 & 1,05 & 0,88 & 0,33 & 0,20 & $28 / 11 / 2018$ & 1,89 & & 2,51 & 2,33 & 2,20 & \\
\hline $17 / 06 / 2018$ & 0,87 & & 1,06 & 1,49 & 0,86 & & $07 / 12 / 2018$ & 1,88 & & 4,04 & 1,62 & 2,43 & \\
\hline $18 / 06 / 2018$ & 0,73 & 2,15 & 0,89 & 1,53 & 0,80 & & $08 / 12 / 2018$ & 2,81 & & 4,74 & 3,23 & 4,05 & \\
\hline
\end{tabular}


APÊNDICE F. Resultados de evapotranspiração dos métodos baseados na flutuação diária do nível 126 piezométrico

Tabela 18 - Resultados de evapotranspiração da adaptação de Hays

\begin{tabular}{c|cccccccccccccc}
\hline Data & P27 & P30 & P31 & P32 & P33 & P35 & & Data & P27 & P30 & P31 & P32 & P33 & P35 \\
\hline 22/06/2018 & 0,75 & & & & & 0,49 & & $09 / 12 / 2018$ & 1,74 & & 2,72 & 1,42 & 3,08 & \\
$23 / 06 / 2018$ & 0,03 & & 0,93 & 0,62 & 0,21 & & & & $16 / 12 / 2018$ & 3,08 & & 5,59 & & 3,86 \\
\hline
\end{tabular}

\section{F.1.3 Adaptação de Loheide II}

Tabela 19 - Resultados de evapotranspiração da adaptação de Loheide II

\begin{tabular}{|c|c|c|c|c|c|c|c|c|c|c|c|c|}
\hline Data & P27 & P30 & P31 & P32 & P33 & P35 & Data & $\mathrm{P} 27$ & P30 & P31 & P32 & P33 P35 \\
\hline $20 / 04 / 2018$ & 0,49 & 3,15 & & 3,72 & 2,71 & 1,45 & $24 / 06 / 2018$ & 0,57 & 1,11 & 0,58 & 0,56 & \\
\hline $21 / 04 / 2018$ & 0,95 & 1,11 & 1,35 & 0,77 & 1,76 & 0,42 & $25 / 06 / 2018$ & 0,71 & & 0,53 & 0,92 & \\
\hline $22 / 04 / 2018$ & 0,75 & 4,74 & 1,16 & 0,16 & 1,82 & 0,45 & $26 / 06 / 2018$ & 1,04 & 0,13 & 0,88 & 1,42 & 0,35 \\
\hline $23 / 04 / 2018$ & 0,38 & 3,46 & 1,10 & & 1,33 & 0,15 & $27 / 06 / 2018$ & & 2,26 & 0,98 & 1,30 & 0,75 \\
\hline $24 / 04 / 2018$ & 0,92 & 1,50 & 0,87 & & 1,20 & & $28 / 06 / 2018$ & & 2,76 & 1,19 & 0,97 & 1,06 \\
\hline $25 / 04 / 2018$ & 0,34 & 1,02 & 0,82 & & 1,20 & & $29 / 06 / 2018$ & 1,51 & 1,85 & 1,51 & 1,45 & 0,70 \\
\hline $26 / 04 / 2018$ & 1,70 & & 0,85 & & 1,16 & 0,30 & $30 / 06 / 2018$ & 1,22 & 1,92 & 1,52 & 1,47 & 0,41 \\
\hline $27 / 04 / 2018$ & 0,83 & 0,30 & 0,73 & & 1,06 & & 01/07/2018 & 1,01 & 2,50 & 1,61 & 1,41 & 0,64 \\
\hline $28 / 04 / 2018$ & 1,58 & 2,26 & 0,95 & & 1,32 & & $02 / 07 / 2018$ & 1,29 & 1,93 & 1,85 & 1,64 & 0,78 \\
\hline $29 / 04 / 2018$ & 2,84 & 1,69 & 0,77 & & 0,95 & & $03 / 07 / 2018$ & 1,22 & 3,34 & 2,00 & 1,67 & $1,02 \quad 0,18$ \\
\hline $30 / 04 / 2018$ & 3,07 & 0,34 & 0,92 & & 0,84 & & $07 / 07 / 2018$ & 0,66 & 1,59 & 1,59 & 1,22 & 0,13 \\
\hline $01 / 05 / 2018$ & 2,94 & 1,05 & 1,21 & & 1,33 & & 08/07/2018 & 1,30 & 2,16 & 1,56 & 1,23 & 0,33 \\
\hline $02 / 05 / 2018$ & 0,91 & 2,41 & 0,88 & & 1,30 & 0,39 & $14 / 07 / 2018$ & 0,91 & & 0,43 & 0,66 & \\
\hline $03 / 05 / 2018$ & 0,04 & 0,79 & 1,12 & & 1,19 & 0,22 & $15 / 07 / 2018$ & 0,77 & & 0,82 & 0,88 & \\
\hline $04 / 05 / 2018$ & 1,40 & 3,40 & 1,25 & & 0,40 & 0,63 & $16 / 07 / 2018$ & 0,78 & 0,77 & 1,14 & 1,42 & \\
\hline $05 / 05 / 2018$ & 0,51 & 4,20 & 0,90 & 0,20 & 0,83 & 0,20 & $17 / 07 / 2018$ & 0,76 & 1,13 & 1,13 & 1,42 & 0,20 \\
\hline $06 / 05 / 2018$ & 0,04 & 5,34 & 0,74 & 0,47 & 0,85 & 0,36 & $18 / 07 / 2018$ & 1,00 & 2,88 & 1,44 & 1,38 & 0,55 \\
\hline $07 / 05 / 2018$ & & 2,59 & 0,56 & 0,60 & 0,60 & 0,16 & $19 / 07 / 2018$ & 0,97 & 2,76 & 1,03 & 1,14 & 0,15 \\
\hline $08 / 05 / 2018$ & & 3,65 & 0,71 & 0,50 & 0,63 & 0,12 & $20 / 07 / 2018$ & 0,76 & 1,44 & 0,75 & 1,28 & \\
\hline $09 / 05 / 2018$ & & 2,85 & 0,19 & 0,39 & 0,53 & 0,23 & $21 / 07 / 2018$ & 0,88 & 2,92 & 0,59 & 1,13 & \\
\hline $10 / 05 / 2018$ & 0,31 & 1,59 & 0,12 & 0,47 & 0,23 & 0,18 & $22 / 07 / 2018$ & 1,17 & 4,18 & 0,58 & 1,01 & 0,15 \\
\hline $11 / 05 / 2018$ & 0,77 & 3,15 & & 0,60 & 0,48 & 0,20 & $23 / 07 / 2018$ & 1,09 & 0,49 & 0,88 & 1,01 & 0,03 \\
\hline $12 / 05 / 2018$ & 0,74 & 4,58 & & & & & $24 / 07 / 2018$ & 0,87 & 1,04 & 1,06 & 1,32 & 0,26 \\
\hline $13 / 05 / 2018$ & & 3,15 & & & 0,18 & & $25 / 07 / 2018$ & 1,67 & 3,18 & 1,03 & 1,31 & 0,45 \\
\hline $17 / 05 / 2018$ & & & 0,49 & & & 0,30 & $26 / 07 / 2018$ & 0,96 & 0,91 & 0,94 & 0,90 & \\
\hline $22 / 05 / 2018$ & 0,69 & & 0,61 & 0,01 & & 0,23 & $27 / 07 / 2018$ & 1,31 & 0,78 & 1,52 & 1,55 & 0,25 \\
\hline
\end{tabular}


Tabela 19 - Resultados de evapotranspiração da adaptação de Loheide II

\begin{tabular}{|c|c|c|c|c|c|c|c|c|c|c|c|c|}
\hline Data & P27 & P30 & P31 & P32 & P33 & P35 & Data & P27 & P30 & P31 & P32 & P33 P35 \\
\hline $23 / 05 / 2018$ & 0,05 & & 0,66 & 0,23 & & 0,22 & $28 / 07 / 2018$ & 1,04 & 1,97 & 1,25 & 1,48 & 0,26 \\
\hline $24 / 05 / 2018$ & 1,28 & & 0,54 & 0,71 & 0,17 & 0,30 & $29 / 07 / 2018$ & 1,24 & 1,91 & 1,11 & 1,21 & \\
\hline $25 / 05 / 2018$ & 1,64 & & 0,50 & 0,70 & & 0,38 & $17 / 08 / 2018$ & 1,20 & & 1,31 & 1,19 & 0,62 \\
\hline $26 / 05 / 2018$ & 1,34 & & 0,48 & 0,58 & & 0,33 & $18 / 08 / 2018$ & 1,24 & & 1,07 & 1,29 & \\
\hline $27 / 05 / 2018$ & 1,08 & & 0,35 & 0,72 & & 0,31 & $22 / 08 / 2018$ & 1,64 & 5,96 & 1,34 & 1,21 & 0,34 \\
\hline $28 / 05 / 2018$ & 0,33 & & 0,24 & 0,80 & & 0,19 & $23 / 08 / 2018$ & & 4,37 & 0,98 & & 0,06 \\
\hline $29 / 05 / 2018$ & & & 0,53 & 1,04 & 0,47 & & $27 / 08 / 2018$ & 0,54 & & 1,41 & 0,80 & \\
\hline $30 / 05 / 2018$ & & & 0,87 & 0,91 & 0,62 & & 09/09/2018 & 1,85 & 3,37 & 2,97 & 1,44 & 0,01 \\
\hline $31 / 05 / 2018$ & 0,48 & 0,50 & 0,84 & 0,83 & 0,45 & 0,41 & $10 / 09 / 2018$ & 0,89 & 7,19 & 2,69 & 1,37 & 0,64 \\
\hline 01/06/2018 & & 1,92 & 0,42 & & & 0,48 & $11 / 09 / 2018$ & 0,19 & 8,53 & 2,09 & 1,16 & 0,76 \\
\hline 02/06/2018 & 0,67 & 4,58 & 0,58 & & 0,06 & 0,37 & $12 / 09 / 2018$ & 1,60 & 9,41 & 2,86 & 1,75 & 1,02 \\
\hline 03/06/2018 & 0,88 & 4,78 & & & & 0,30 & $25 / 09 / 2018$ & 1,68 & & 3,29 & 1,28 & 0,58 \\
\hline 04/06/2018 & 1,25 & 2,79 & & & & & $26 / 09 / 2018$ & 1,75 & & 3,42 & 1,05 & 0,93 \\
\hline $05 / 06 / 2018$ & 1,11 & 5,59 & & & & & $27 / 09 / 2018$ & 0,63 & 1,26 & 2,10 & 0,62 & 0,87 \\
\hline 09/06/2018 & 1,35 & & & & 0,71 & 0,11 & $21 / 10 / 2018$ & 2,69 & & 2,68 & 1,68 & 1,39 \\
\hline $10 / 06 / 2018$ & 1,52 & 2,36 & 0,52 & 1,45 & 0,85 & 0,09 & $22 / 10 / 2018$ & & & 2,09 & 1,02 & 1,25 \\
\hline $11 / 06 / 2018$ & 1,22 & 1,90 & 0,22 & 1,00 & 0,50 & 0,08 & $30 / 10 / 2018$ & 0,52 & & 0,75 & 0,59 & 0,89 \\
\hline $12 / 06 / 2018$ & 0,71 & 3,72 & 0,49 & 0,56 & 0,41 & 0,03 & $31 / 10 / 2018$ & 0,71 & & 1,16 & 1,14 & 1,55 \\
\hline $13 / 06 / 2018$ & & 8,92 & 0,20 & 0,22 & 0,69 & 0,22 & $01 / 11 / 2018$ & 1,24 & & 1,84 & 1,70 & 2,33 \\
\hline $14 / 06 / 2018$ & & 2,13 & 0,54 & 0,16 & & 0,03 & $16 / 11 / 2018$ & 2,51 & & 3,80 & 2,11 & 2,35 \\
\hline $15 / 06 / 2018$ & 1,28 & & 0,58 & 0,65 & 0,23 & & $27 / 11 / 2018$ & 0,27 & & 1,24 & 0,77 & \\
\hline $16 / 06 / 2018$ & 0,53 & 1,72 & 0,90 & 0,92 & 0,42 & 0,18 & $28 / 11 / 2018$ & 1,23 & & 1,81 & 1,61 & 1,34 \\
\hline $17 / 06 / 2018$ & 0,29 & 0,14 & 0,76 & 0,47 & 0,03 & & $07 / 12 / 2018$ & 1,40 & & 2,64 & 1,25 & 2,10 \\
\hline $18 / 06 / 2018$ & 1,13 & 2,84 & 0,78 & 0,76 & 0,49 & & $08 / 12 / 2018$ & 2,15 & & 2,86 & 2,07 & 3,11 \\
\hline $22 / 06 / 2018$ & 1,42 & & & & & & 09/12/2018 & 2,43 & & 2,82 & 2,01 & 3,76 \\
\hline $23 / 06 / 2018$ & 0,00 & 2,57 & 0,18 & 0,17 & 0,01 & & $16 / 12 / 2018$ & 2,58 & & 3,79 & & 3,43 \\
\hline
\end{tabular}

\section{F.1.4 Adaptação de Miller}

Tabela 20 - Resultados de evapotranspiração da adaptação de Miller

\begin{tabular}{c|lllllll|lllllll}
\hline Data & P27 & P30 & P31 & P32 & P33 & P35 & & Data & P27 & P30 & P31 & P32 & P33 & P35 \\
\hline 20/04/2018 & 0,26 & 2,96 & & 3,56 & 2,62 & 1,45 & & $24 / 06 / 2018$ & 0,58 & 0,32 & 0,65 & 0,65 & \\
21/04/2018 & 0,94 & 0,49 & 1,36 & 0,53 & 1,56 & 0,39 & & $25 / 06 / 2018$ & 0,75 & & 0,58 & 0,94 &
\end{tabular}


APÊNDICE F. Resultados de evapotranspiração dos métodos baseados na flutuação diária do nível 128 piezométrico

Tabela 20 - Resultados de evapotranspiração da adaptação de Miller

\begin{tabular}{|c|c|c|c|c|c|c|c|c|c|c|c|c|}
\hline Data & P27 & P30 & P31 & P32 & P33 & P35 & Data & P27 & P30 & P31 & P32 & P33 P35 \\
\hline $22 / 04 / 2018$ & 0,49 & 4,19 & 1,08 & & 1,65 & 0,36 & $26 / 06 / 2018$ & 1,20 & & 0,93 & 1,40 & 0,23 \\
\hline $23 / 04 / 2018$ & 0,13 & 3,03 & 1,03 & & 1,24 & 0,22 & $27 / 06 / 2018$ & & 1,63 & 1,10 & 1,35 & 0,71 \\
\hline $24 / 04 / 2018$ & 0,75 & 0,98 & 0,83 & & 1,06 & 0,00 & $28 / 06 / 2018$ & & 2,10 & 1,29 & 1,01 & 1,00 \\
\hline $25 / 04 / 2018$ & & 0,39 & 0,76 & & 0,99 & & $29 / 06 / 2018$ & 1,47 & 1,11 & 1,53 & 1,37 & 0,52 \\
\hline $26 / 04 / 2018$ & 1,18 & & 0,76 & & 0,96 & & $30 / 06 / 2018$ & 1,17 & 1,19 & 1,49 & 1,33 & 0,15 \\
\hline $27 / 04 / 2018$ & 0,37 & & 0,62 & & 0,85 & & $01 / 07 / 2018$ & 0,89 & 1,86 & 1,62 & 1,37 & 0,42 \\
\hline $28 / 04 / 2018$ & 0,81 & 1,73 & 0,82 & & 1,12 & & $02 / 07 / 2018$ & 1,21 & 1,27 & 1,88 & 1,65 & 0,61 \\
\hline $29 / 04 / 2018$ & 1,84 & 1,06 & 0,70 & & 0,82 & & $03 / 07 / 2018$ & 1,28 & 2,62 & 1,99 & 1,62 & $0,81 \quad 0,04$ \\
\hline $30 / 04 / 2018$ & 1,94 & & 0,83 & & 0,61 & & $07 / 07 / 2018$ & 0,87 & 1,00 & 1,72 & 1,29 & 0,16 \\
\hline $01 / 05 / 2018$ & 2,35 & 0,14 & 1,11 & & 1,07 & & 08/07/2018 & 1,23 & 1,45 & 1,67 & 1,29 & 0,30 \\
\hline $02 / 05 / 2018$ & 0,71 & 1,50 & 0,83 & & 1,09 & 0,02 & $14 / 07 / 2018$ & 1,04 & & 0,56 & 0,98 & \\
\hline $03 / 05 / 2018$ & & 0,04 & 1,06 & & 1,02 & & $15 / 07 / 2018$ & 0,94 & & 0,85 & 1,03 & \\
\hline $04 / 05 / 2018$ & 1,30 & 2,79 & 1,18 & & 0,29 & 0,55 & $16 / 07 / 2018$ & 0,89 & 0,14 & 1,12 & 1,35 & \\
\hline $05 / 05 / 2018$ & 0,29 & 3,52 & 0,82 & 0,35 & 0,76 & 0,15 & $17 / 07 / 2018$ & 0,87 & 0,48 & 1,12 & 1,44 & 0,05 \\
\hline $06 / 05 / 2018$ & & 4,66 & 0,65 & 0,40 & 0,72 & 0,30 & $18 / 07 / 2018$ & 1,04 & 2,12 & 1,34 & 1,40 & 0,34 \\
\hline $07 / 05 / 2018$ & & 1,89 & 0,51 & 0,57 & 0,50 & 0,11 & $19 / 07 / 2018$ & 0,98 & 2,00 & 0,96 & 1,12 & \\
\hline $08 / 05 / 2018$ & & 2,82 & 0,68 & 0,62 & 0,55 & 0,04 & $20 / 07 / 2018$ & 0,64 & 0,73 & 0,76 & 1,23 & \\
\hline $09 / 05 / 2018$ & 0,14 & 2,09 & 0,29 & 0,47 & 0,44 & 0,16 & $21 / 07 / 2018$ & 0,75 & 2,24 & 0,62 & 1,10 & \\
\hline $10 / 05 / 2018$ & 0,20 & 0,88 & 0,32 & 0,49 & 0,16 & 0,13 & $22 / 07 / 2018$ & 1,01 & 3,56 & 0,58 & 0,98 & \\
\hline $11 / 05 / 2018$ & 0,31 & 2,43 & & 0,50 & 0,31 & 0,11 & $23 / 07 / 2018$ & 1,08 & & 0,90 & 1,08 & \\
\hline $12 / 05 / 2018$ & 0,45 & 3,97 & & & & & $24 / 07 / 2018$ & 0,86 & 0,41 & 1,09 & 1,44 & 0,23 \\
\hline $13 / 05 / 2018$ & & 2,59 & & & 0,06 & & $25 / 07 / 2018$ & 1,53 & 2,56 & 1,04 & 1,36 & 0,33 \\
\hline $17 / 05 / 2018$ & & & 0,43 & & & 0,29 & $26 / 07 / 2018$ & 0,92 & 0,29 & 0,94 & 0,86 & \\
\hline $22 / 05 / 2018$ & 0,62 & & 0,73 & 0,20 & & 0,28 & $27 / 07 / 2018$ & 1,25 & 0,10 & 1,54 & 1,53 & 0,04 \\
\hline $23 / 05 / 2018$ & & & 0,72 & 0,30 & & 0,25 & $28 / 07 / 2018$ & 0,93 & 1,27 & 1,31 & 1,51 & 0,19 \\
\hline $24 / 05 / 2018$ & 1,01 & & 0,51 & 0,64 & 0,03 & 0,25 & $29 / 07 / 2018$ & 1,13 & 1,23 & 1,17 & 1,30 & \\
\hline $25 / 05 / 2018$ & 1,53 & & 0,43 & 0,64 & & 0,34 & $17 / 08 / 2018$ & 1,18 & & 1,34 & 1,26 & 0,60 \\
\hline $26 / 05 / 2018$ & 1,01 & & 0,39 & 0,47 & & 0,31 & $18 / 08 / 2018$ & 1,15 & & 1,17 & 1,34 & \\
\hline $27 / 05 / 2018$ & 0,79 & & 0,30 & 0,57 & & 0,30 & $22 / 08 / 2018$ & 1,30 & 5,12 & 1,55 & 1,33 & 0,30 \\
\hline $28 / 05 / 2018$ & 0,45 & & 0,28 & 0,76 & & 0,24 & $23 / 08 / 2018$ & & 3,59 & 1,20 & & 0,24 \\
\hline $29 / 05 / 2018$ & & & 0,52 & 0,91 & 0,28 & & $27 / 08 / 2018$ & 0,55 & & 1,60 & 0,98 & \\
\hline $30 / 05 / 2018$ & & & 0,79 & 0,74 & 0,37 & & $09 / 09 / 2018$ & 1,88 & 2,28 & 3,28 & 1,88 & 0,40 \\
\hline $31 / 05 / 2018$ & 0,60 & & 0,80 & 0,75 & 0,34 & 0,38 & $10 / 09 / 2018$ & 1,39 & 6,14 & 3,19 & 1,92 & 1,07 \\
\hline $01 / 06 / 2018$ & & 1,37 & 0,34 & & & 0,43 & $11 / 09 / 2018$ & 0,69 & 7,53 & 2,55 & 1,64 & 1,08 \\
\hline $02 / 06 / 2018$ & 0,53 & 4,06 & 0,52 & & & 0,35 & $12 / 09 / 2018$ & 1,58 & 8,25 & 3,05 & 2,12 & 1,34 \\
\hline $03 / 06 / 2018$ & 0,73 & 4,45 & & & & 0,30 & $25 / 09 / 2018$ & 1,56 & & 3,81 & 1,82 & 0,96 \\
\hline
\end{tabular}


Tabela 20 - Resultados de evapotranspiração da adaptação de Miller

\begin{tabular}{|c|c|c|c|c|c|c|c|c|c|c|c|}
\hline Data & P27 & P30 & P31 & P32 & P33 & P35 & Data & P27 P30 & P31 & P32 & P33 P35 \\
\hline 04/06/2018 & 1,19 & 2,39 & & & & & $26 / 09 / 2018$ & 1,82 & 3,98 & 1,68 & 1,41 \\
\hline 05/06/2018 & 1,08 & 5,10 & & & & & $27 / 09 / 2018$ & $1,04 \quad 0,60$ & 2,59 & 1,13 & 1,29 \\
\hline 09/06/2018 & 1,09 & & & & 0,58 & 0,15 & $21 / 10 / 2018$ & 2,33 & 3,12 & 2,03 & 1,69 \\
\hline $10 / 06 / 2018$ & 1,27 & 1,60 & 0,44 & 1,08 & 0,56 & 0,11 & $22 / 10 / 2018$ & & 2,73 & 1,44 & 1,61 \\
\hline $11 / 06 / 2018$ & 1,15 & 1,11 & 0,16 & 0,57 & 0,18 & 0,07 & $30 / 10 / 2018$ & 0,50 & 1,08 & 0,73 & 0,72 \\
\hline $12 / 06 / 2018$ & 0,81 & 2,90 & 0,44 & 0,19 & 0,12 & 0,03 & $31 / 10 / 2018$ & 0,72 & 1,60 & 1,36 & 1,47 \\
\hline $13 / 06 / 2018$ & & 8,24 & 0,16 & 0,02 & 0,48 & 0,23 & $01 / 11 / 2018$ & 1,29 & 2,35 & 1,96 & 2,35 \\
\hline $14 / 06 / 2018$ & & 1,67 & 0,60 & 0,27 & & 0,06 & $16 / 11 / 2018$ & 2,15 & 3,99 & 2,03 & 1,88 \\
\hline $15 / 06 / 2018$ & 1,28 & & 0,68 & 0,66 & 0,25 & 0,03 & $27 / 11 / 2018$ & & 1,04 & 0,66 & \\
\hline $16 / 06 / 2018$ & 0,56 & 1,08 & 0,93 & 0,81 & 0,35 & 0,18 & $28 / 11 / 2018$ & 0,89 & 1,75 & 1,58 & 1,05 \\
\hline $17 / 06 / 2018$ & 0,41 & & 0,78 & 0,40 & 0,01 & & $07 / 12 / 2018$ & 1,20 & 2,85 & 1,18 & 1,90 \\
\hline $18 / 06 / 2018$ & 1,12 & 2,35 & 0,81 & 0,49 & 0,38 & & $08 / 12 / 2018$ & 2,01 & 3,23 & 2,01 & 2,95 \\
\hline $22 / 06 / 2018$ & 1,40 & & & & & & $09 / 12 / 2018$ & 2,30 & 3,30 & 2,13 & 3,80 \\
\hline $23 / 06 / 2018$ & 0,16 & 1,98 & 0,22 & 0,20 & & & $16 / 12 / 2018$ & 2,45 & 4,29 & & 3,42 \\
\hline
\end{tabular}

\section{F.2 Método de Dolan}

Tabela 21 - Resultados de evapotranspiração do método de Dolan

\begin{tabular}{c|llllllll|lllllll}
\hline Data & P27 & P30 & P31 & P32 & P33 & P35 & & Data & P27 & P30 & P31 & P32 & P33 & P35 \\
\hline 20/04/2018 & 1,63 & 0,16 & & & 1,11 & 0,15 & & $24 / 06 / 2018$ & 0,62 & 2,99 & 1,06 & 1,18 & 0,76 \\
$21 / 04 / 2018$ & 1,14 & 1,03 & 1,12 & 1,12 & 1,39 & 0,53 & & $25 / 06 / 2018$ & 0,99 & 2,71 & 1,18 & 1,44 & 0,66 \\
$22 / 04 / 2018$ & 0,48 & & 1,12 & 0,95 & 1,12 & & & $26 / 06 / 2018$ & 0,86 & 2,08 & 1,36 & 1,64 & 0,80 \\
$23 / 04 / 2018$ & 0,60 & & 1,14 & 0,33 & 1,25 & & & $27 / 06 / 2018$ & & 1,67 & 1,32 & 1,50 & 1,07 \\
$24 / 04 / 2018$ & 0,01 & 0,68 & 1,03 & 0,10 & 1,40 & 0,22 & & $28 / 06 / 2018$ & & 1,17 & 1,46 & 1,69 & 0,77 \\
$25 / 04 / 2018$ & 2,50 & & 1,20 & 0,57 & 1,56 & 0,30 & & $29 / 06 / 2018$ & 1,31 & 1,40 & 1,61 & 1,54 & 0,43 \\
$26 / 04 / 2018$ & 1,53 & 0,85 & 0,98 & 0,06 & 1,26 & & & $30 / 06 / 2018$ & 1,10 & 1,51 & 1,88 & 1,75 & 0,86 \\
$27 / 04 / 2018$ & 0,05 & 1,27 & 0,88 & 0,45 & 1,12 & & & $01 / 07 / 2018$ & 1,12 & 1,17 & 1,66 & 1,65 & 1,04 \\
$28 / 04 / 2018$ & 2,10 & 0,25 & 0,96 & & 0,98 & & & $02 / 07 / 2018$ & 1,23 & 2,09 & 1,90 & 1,78 & 1,18 & 0,04 \\
$29 / 04 / 2018$ & 4,06 & 2,69 & 0,91 & & 1,09 & & & $03 / 07 / 2018$ & 0,97 & 1,58 & 1,92 & 1,84 & 0,88 \\
$30 / 04 / 2018$ & 5,19 & 3,06 & 1,39 & 2,52 & 1,40 & & & $07 / 07 / 2018$ & 1,01 & 1,63 & 1,85 & 1,55 & 0,49
\end{tabular}


APÊNDICE F. Resultados de evapotranspiração dos métodos baseados na flutuação diária do nível 130 piezométrico

Tabela 21 - Resultados de evapotranspiração do método de Dolan

\begin{tabular}{|c|c|c|c|c|c|c|c|c|c|c|c|c|c|}
\hline Data & 27 & P30 & P31 & P32 & P33 & P35 & Data & P27 & P30 & P31 & P32 & P33 & P35 \\
\hline 03/05/2018 & 1,01 & 1,79 & 1,12 & & 1,20 & 0,30 & $15 / 07 / 2018$ & 0,98 & 1,50 & 1,29 & 1,91 & 0,40 & \\
\hline $04 / 05 / 2018$ & & 0,42 & 0,96 & 1,48 & 1,62 & & $16 / 07 / 2018$ & 0,87 & 1,32 & 1,37 & 1,97 & 0,48 & \\
\hline $05 / 05 / 2018$ & 0,37 & 1,68 & 1,09 & 0,73 & 0,83 & 0,19 & $17 / 07 / 2018$ & 1,20 & 1,52 & 1,55 & 1,96 & 0,54 & \\
\hline $06 / 05 / 2018$ & 0,01 & 0,95 & 0,86 & 1,11 & 0,84 & 0,22 & $18 / 07 / 2018$ & 1,30 & 1,45 & 1,45 & 1,80 & 0,62 & \\
\hline $07 / 05 / 2018$ & & 3,86 & 1,14 & 1,32 & 1,22 & 0,33 & $19 / 07 / 2018$ & 1,25 & 1,56 & 1,45 & 1,85 & 0,76 & \\
\hline 08/05/2018 & & 3,02 & 1,15 & 1,23 & 1,16 & 0,27 & $20 / 07 / 2018$ & 0,79 & 1,70 & 1,08 & 1,71 & 0,22 & \\
\hline 09/05/2018 & & 1,67 & 0,83 & 1,10 & 0,72 & 0,21 & $21 / 07 / 2018$ & 0,52 & 1,15 & 1,00 & 1,54 & 0,32 & \\
\hline $10 / 05 / 2018$ & & 1,26 & 0,12 & 1,06 & 0,72 & 0,29 & $22 / 07 / 2018$ & 1,32 & 0,78 & 1,39 & 1,61 & 0,76 & \\
\hline $11 / 05 / 2018$ & & 1,12 & & 0,47 & 0,07 & 0,25 & $23 / 07 / 2018$ & 0,93 & 1,72 & 1,50 & 1,66 & 0,73 & \\
\hline $12 / 05 / 2018$ & 0,44 & 0,44 & 0,11 & 0,42 & 0,23 & & $24 / 07 / 2018$ & 1,21 & 1,04 & 1,77 & 1,74 & 1,04 & \\
\hline $13 / 05 / 2018$ & & 0,12 & 0,37 & 1,08 & 0,61 & & $25 / 07 / 2018$ & 1,01 & 0,98 & 1,30 & 1,81 & 0,75 & \\
\hline $17 / 05 / 2018$ & & 5,39 & 0,59 & & 0,87 & 0,23 & $26 / 07 / 2018$ & 1,57 & 1,65 & 1,81 & 2,39 & 1,02 & 0,10 \\
\hline $22 / 05 / 2018$ & 0,96 & & 0,95 & 0,66 & 0,21 & 0,58 & $27 / 07 / 2018$ & 1,04 & 2,05 & 1,93 & 2,02 & 1,01 & 0,23 \\
\hline $23 / 05 / 2018$ & 2,07 & & 1,22 & 1,06 & 0,60 & 0,57 & $28 / 07 / 2018$ & 1,39 & 2,00 & 1,65 & 1,92 & 0,71 & \\
\hline $24 / 05 / 2018$ & 2,69 & & 1,09 & 1,14 & 0,49 & 0,61 & $29 / 07 / 2018$ & 1,20 & 1,77 & 1,59 & 1,65 & 0,58 & \\
\hline $25 / 05 / 2018$ & 1,43 & & 0,91 & 1,22 & 0,49 & 0,53 & $17 / 08 / 2018$ & 1,04 & 5,17 & 1,55 & 1,33 & 0,95 & \\
\hline $26 / 05 / 2018$ & 1,34 & 1,03 & 1,09 & 1,45 & 0,68 & 0,57 & $18 / 08 / 2018$ & 0,90 & 4,58 & 1,47 & 1,40 & 0,68 & \\
\hline $27 / 05 / 2018$ & 0,72 & 1,56 & 0,96 & 1,44 & 0,62 & 0,50 & $22 / 08 / 2018$ & 2,04 & 5,71 & 1,52 & 1,09 & 0,55 & \\
\hline $28 / 05 / 2018$ & 0,56 & 1,88 & 0,73 & 1,07 & 0,45 & 0,36 & $23 / 08 / 2018$ & & 7,02 & 2,30 & & 1,41 & 0,56 \\
\hline $29 / 05 / 2018$ & & 1,50 & 0,77 & 1,11 & 0,57 & & $27 / 08 / 2018$ & 0,73 & & 1,92 & 1,35 & 0,95 & \\
\hline $30 / 05 / 2018$ & & 1,20 & 1,12 & 1,57 & 0,94 & & 09/09/2018 & 1,88 & 7,06 & 3,65 & 2,22 & 1,23 & \\
\hline $31 / 05 / 2018$ & 0,43 & 2,73 & 0,80 & 0,30 & 0,29 & 0,59 & $10 / 09 / 2018$ & 1,22 & 7,96 & 2,96 & 2,04 & 0,86 & \\
\hline 01/06/2018 & 0,51 & 3,62 & 1,04 & 0,85 & 0,84 & 0,55 & $11 / 09 / 2018$ & 1,49 & 9,66 & 3,04 & 2,54 & 2,20 & 0,44 \\
\hline 02/06/2018 & 0,52 & 2,19 & 0,65 & & 0,42 & 0,56 & $12 / 09 / 2018$ & 1,54 & 10,76 & 3,52 & 2,47 & 2,28 & 0,70 \\
\hline 03/06/2018 & 0,64 & 1,30 & & & & 0,26 & $25 / 09 / 2018$ & 2,11 & & 4,67 & 2,12 & 1,87 & 0,79 \\
\hline 04/06/2018 & 0,93 & 3,00 & & & & & $26 / 09 / 2018$ & 1,83 & & 3,69 & 1,40 & 1,60 & 0,58 \\
\hline $05 / 06 / 2018$ & 1,22 & 0,49 & & & & & $27 / 09 / 2018$ & 0,38 & 4,83 & 2,21 & 0,88 & 0,97 & 0,36 \\
\hline 09/06/2018 & 1,73 & 2,76 & & & 0,77 & 0,37 & $21 / 10 / 2018$ & 2,00 & & 3,49 & 1,93 & 2,27 & 0,97 \\
\hline $10 / 06 / 2018$ & 1,66 & 2,05 & 0,99 & 1,85 & 1,36 & 0,36 & $22 / 10 / 2018$ & & & 3,13 & 1,61 & 2,44 & $=0,49$ \\
\hline $11 / 06 / 2018$ & 1,47 & 3,58 & 1,31 & 2,00 & 1,43 & 0,36 & $30 / 10 / 2018$ & 1,19 & & 1,61 & 1,38 & 1,84 & \\
\hline $12 / 06 / 2018$ & 0,79 & 3,45 & 0,84 & 1,08 & 0,92 & 0,25 & $31 / 10 / 2018$ & 1,69 & & 2,74 & 2,20 & 2,79 & 0,50 \\
\hline $13 / 06 / 2018$ & & 1,56 & 0,66 & 0,63 & 0,57 & 0,20 & $01 / 11 / 2018$ & 1,76 & & 2,52 & 1,83 & 2,68 & 0,12 \\
\hline $14 / 06 / 2018$ & & 2,72 & 0,41 & 0,84 & 0,94 & 0,32 & $16 / 11 / 2018$ & 4,03 & 9,00 & 6,45 & 3,47 & 4,23 & \\
\hline $15 / 06 / 2018$ & 0,61 & 2,64 & 0,77 & 1,40 & 0,78 & 0,23 & $27 / 11 / 2018$ & 1,62 & & 1,85 & 1,54 & & \\
\hline $16 / 06 / 2018$ & 0,34 & 0,93 & 0,84 & 1,18 & 0,53 & 0,25 & $28 / 11 / 2018$ & 2,19 & & 2,68 & 2,21 & 3,55 & 0,38 \\
\hline $17 / 06 / 2018$ & 1,06 & 2,22 & 1,16 & 0,98 & 0,59 & & $07 / 12 / 2018$ & 2,00 & & 2,46 & 2,47 & 3,57 & \\
\hline
\end{tabular}


Tabela 21 - Resultados de evapotranspiração do método de Dolan

\begin{tabular}{|c|c|c|c|c|c|c|c|c|c|c|}
\hline Data & P27 P30 & P31 & P32 & P33 & P35 & Data & P27 P30 & P31 P32 & P33 & P35 \\
\hline $18 / 06 / 2018$ & $0,98 \quad 0,53$ & 0,92 & 1,13 & 0,54 & & $08 / 12 / 2018$ & 2,55 & $4,41 \quad 2,70$ & 4,45 & 0,69 \\
\hline $22 / 06 / 2018$ & 0,94 & & & & & $09 / 12 / 2018$ & 2,43 & $3,72 \quad 2,30$ & 4,10 & \\
\hline $23 / 06 / 2018$ & $0,88 \quad 7,21$ & 1,29 & 1,41 & 1,63 & 0,27 & $16 / 12 / 2018$ & 3,31 & 5,32 & 5,04 & 0,38 \\
\hline
\end{tabular}

\section{F.3 Método de Hays}

Tabela 22 - Resultados de evapotranspiração do método de Hays

\begin{tabular}{|c|c|c|c|c|c|c|c|c|c|c|c|c|c|}
\hline & & & & & & & & 27 & P30 & P31 & P32 & 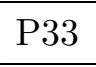 & \\
\hline 8 & & 70 & & & & & & 02 & 5,87 & 1,08 & 1,07 & 0,81 & 060 \\
\hline & & & & & & & & & & & & & \\
\hline & & 42 & 46 & 3,68 & 68 & 1,99 & & 1,35 & ,24 & 0,96 & 1,30 & 0,83 & 1,9 \\
\hline & & & & & & & & & 5,21 & 0,67 & & 0,87 & 155 \\
\hline & & & & & & & & & & & & & 1,50 \\
\hline & & & & & & & & & & & & 88 & 1,76 \\
\hline & & 74 & & 5,94 & & 3,09 & & 1,09 & 4,98 & 1,62 & 1,25 & 0 & 1,69 \\
\hline & & & & & & & & 1,08 & & & & & 1,00 \\
\hline & & 5,7 & & 78 & & & & & & 66 & 1 & ( & $1,9 ؛$ \\
\hline & & & & 3,63 & & & & 1,47 & & & 50 & 0,99 & 0,58 \\
\hline & & & & & & & & & & & & & 1,0 \\
\hline & & & & & & & & & & & & & 1,5 \\
\hline & & & & & & & & & & & & & 4,60 \\
\hline & & & & & & & & & & & & & 1,73 \\
\hline & & & & & & & & 1,25 & & & & & 3,06 \\
\hline & & & & 0,50 & & & & 1,25 & & & 1,19 & 3,19 & 2,55 \\
\hline & & & & & & & & & & & & & 2,58 \\
\hline & & & & & & & & 1,23 & & & & & 2,54 \\
\hline & & 6,1 & 0,81 & 0,64 & 1,08 & 0,42 & & 1,20 & 5,10 & 0,97 & 1,04 & 2,57 & 2,47 \\
\hline & & 5,84 & & & & & & & & & & & 2,62 \\
\hline & & & & & & & & 1,26 & & & & & 2,51 \\
\hline & 1,91 & 7,3 & 2,00 & 2,10 & 3,15 & 0,29 & & 1,21 & 5,75 & 1,23 & 1,06 & 2,53 & 2,25 \\
\hline & 0,52 & 7,87 & & & & & & & & 1,26 & & & 2,71 \\
\hline $13 / 05 / 2018$ & & 6,09 & 0,84 & 1,94 & 2,61 & & $25 / 07 / 2018$ & 0,99 & 6,14 & 0,69 & 0,94 & 2,52 & 1,34 \\
\hline
\end{tabular}


APÊNDICE F. Resultados de evapotranspiração dos métodos baseados na flutuação diária do nível 132 piezométrico

Tabela 22 - Resultados de evapotranspiração do método de Hays

\begin{tabular}{|c|c|c|c|c|c|c|c|c|c|c|c|c|c|}
\hline Data & 27 & P30 & P31 & P32 & P33 & P35 & Data & P27 & P30 & P31 & P32 & P33 & P35 \\
\hline $17 / 05 / 2018$ & & 7,79 & 0,46 & & 3,71 & 1,21 & $6 / 07 / 2018$ & 2,02 & 5,40 & 1,01 & 1,57 & 1,22 & 2,10 \\
\hline $22 / 05 / 2018$ & 1,40 & & 1,10 & 1,08 & 0,51 & 0,57 & $27 / 07 / 2018$ & 1,22 & 5,32 & 0,83 & 1,06 & 3,05 & 0,82 \\
\hline $23 / 05 / 2018$ & 2,36 & & 1,08 & 0,84 & 1,30 & 0,50 & $28 / 07 / 2018$ & 1,36 & 5,71 & 1,24 & 1,16 & 3,09 & 1,55 \\
\hline $24 / 05 / 2018$ & 1,39 & & 0,68 & 0,74 & 2,05 & 0,47 & $29 / 07 / 2018$ & 1,56 & 5,76 & 1,39 & 1,25 & 2,57 & 1,36 \\
\hline $25 / 05 / 2018$ & 1,33 & & 0,38 & 0,38 & 2,35 & 0,45 & $17 / 08 / 2018$ & 1,37 & 5,91 & 1,31 & 1,30 & 3,02 & 2,01 \\
\hline $26 / 05 / 2018$ & 1,63 & 4,01 & 0,71 & 1,13 & 1,14 & 0,43 & $18 / 08 / 2018$ & 1,60 & 5,90 & 1,34 & 1,32 & 1,07 & 1,35 \\
\hline $27 / 05 / 2018$ & 0,91 & 4,62 & 0,69 & 0,89 & 1,65 & 0,36 & $22 / 08 / 2018$ & 1,70 & 7,10 & 1,82 & 1,22 & 3,26 & 2,78 \\
\hline $28 / 05 / 2018$ & 1,10 & 4,61 & 0,72 & 0,52 & 1,93 & 0,36 & $23 / 08 / 2018$ & & 9,29 & 2,48 & & 1,64 & 0,96 \\
\hline $29 / 05 / 2018$ & & 4,43 & 0,39 & 0,73 & 2,42 & & $27 / 08 / 2018$ & 1,35 & & 2,02 & 1,28 & 1,08 & 1,83 \\
\hline $30 / 05 / 2018$ & & 4,49 & 0,88 & 1,29 & 3,21 & & 09/09/2018 & 2,87 & 10,36 & 3,40 & 2,45 & 1,67 & 2,16 \\
\hline $31 / 05 / 2018$ & 1,42 & 4,34 & 1,04 & 2,00 & 1,15 & 0,50 & $10 / 09 / 2018$ & 3,03 & 10,85 & 3,12 & 2,60 & 2,33 & 2,17 \\
\hline 01/06/2018 & 1,21 & 5,66 & 0,77 & 0,73 & 0,80 & 0,43 & $11 / 09 / 2018$ & 2,53 & 11,52 & 3,46 & 2,68 & 2,43 & 1,31 \\
\hline $02 / 06 / 2018$ & 0,80 & 6,61 & 0,39 & & 1,82 & 0,40 & $12 / 09 / 2018$ & 2,58 & 10,50 & 3,22 & 2,38 & 1,70 & 2,10 \\
\hline 03/06/2018 & 0,51 & 6,14 & & & & 0,18 & $25 / 09 / 2018$ & 2,86 & & 4,02 & 2,63 & 1,40 & 1,27 \\
\hline $04 / 06 / 2018$ & 0,42 & 4,84 & & & & & $26 / 09 / 2018$ & 2,52 & & 3,16 & 2,13 & 1,45 & 0,86 \\
\hline $05 / 06 / 2018$ & 0,86 & 8,19 & & & & & $27 / 09 / 2018$ & 1,53 & 6,96 & 1,76 & 1,07 & 1,39 & 0,42 \\
\hline 09/06/2018 & 1,36 & 6,33 & & & 3,35 & 0,41 & $21 / 10 / 2018$ & 2,96 & & 4,04 & 3,07 & 2,18 & 1,48 \\
\hline $10 / 06 / 2018$ & 0,89 & 5,14 & 0,40 & 3,14 & 2,94 & 0,32 & $22 / 10 / 2018$ & & & 3,51 & 2,85 & 2,01 & 0,99 \\
\hline $11 / 06 / 2018$ & 1,21 & 6,07 & 1,17 & 1,25 & 0,86 & 0,29 & $30 / 10 / 2018$ & 2,30 & & 2,84 & 2,77 & 1,82 & 0,61 \\
\hline $12 / 06 / 2018$ & 0,82 & 5,65 & 0,53 & 0,85 & 0,67 & 0,28 & $31 / 10 / 2018$ & 3,09 & & 3,87 & 3,62 & 2,38 & 1,03 \\
\hline $13 / 06 / 2018$ & & 10,07 & 0,61 & 0,68 & 0,88 & 0,18 & $01 / 11 / 2018$ & 2,92 & & 3,24 & 2,54 & 1,94 & 0,71 \\
\hline $14 / 06 / 2018$ & & 5,43 & 0,87 & 0,86 & 1,14 & 0,27 & $16 / 11 / 2018$ & 4,92 & 12,21 & 5,77 & 4,42 & 3,48 & \\
\hline $15 / 06 / 2018$ & 1,65 & 5,70 & 0,69 & 0,79 & 0,81 & 0,25 & $27 / 11 / 2018$ & 2,43 & & 2,30 & 2,59 & & \\
\hline $16 / 06 / 2018$ & 0,59 & 4,30 & 0,62 & 0,94 & 0,85 & 0,19 & $28 / 11 / 2018$ & 3,23 & & 3,39 & 3,45 & 2,84 & 0,70 \\
\hline $17 / 06 / 2018$ & 1,34 & 5,68 & 0,95 & 2,70 & 2,09 & & $07 / 12 / 2018$ & 3,99 & & 3,37 & 4,33 & 2,95 & \\
\hline $18 / 06 / 2018$ & 0,53 & 6,02 & 0,54 & 3,12 & 2,78 & & 08/12/2018 & 4,26 & & 4,48 & 4,49 & 3,41 & 1,41 \\
\hline $22 / 06 / 2018$ & 0,65 & & & & & 2,81 & 09/12/2018 & 4,47 & & 3,89 & 4,23 & 3,63 & \\
\hline $23 / 06 / 2018$ & 1,25 & 9,12 & 1,34 & 1,27 & 1,10 & 1,31 & $16 / 12 / 2018$ & 5,63 & & 5,50 & & 4,42 & 0,66 \\
\hline
\end{tabular}

\section{F.4 Método de Gribovski}


Tabela 23 - Resultados de evapotranspiração do método de Gribovski

\begin{tabular}{|c|c|c|c|c|c|c|c|c|c|c|c|c|c|}
\hline & & 30 & & 32 & 33 & P35 & & P27 & P30 & P31 & P32 & P33 & P35 \\
\hline$/ 04 / 2018$ & & 5,11 & & & & 1,73 & & & 9,29 & 1,47 & 1,63 & 1,89 & 1,45 \\
\hline$/ 2018$ & 60 & 3,74 & 1,08 & & & & & & 18 & 1,16 & 31 & & 1,71 \\
\hline /04/2018 & 54 & 9,38 & 0,64 & 3,91 & 73 & 3,77 & $26 / 06 / 2018$ & 08 & 6,91 & 1,54 & 1,68 & 2,60 & 167 \\
\hline 018 & 46 & 7,09 & 1,25 & 5,25 & 1,30 & 3,82 & $27 / 06 / 2018$ & & 5,45 & 1,39 & 1,90 & 2,51 & 1 1. 1 \\
\hline & 04 & 8,45 & & & & & & & 7,71 & 54 & 1,88 & & 1,69 \\
\hline $5 / 04 / 2018$ & 43 & 6,63 & 1,06 & 5,59 &, 57 & 3,10 & $29 / 06 / 2018$ & 1,86 & 6,01 & 1,73 & 1,56 & 1,69 & 1,59 \\
\hline$/ 04 / 2018$ & 6 & 5,75 & 1,23 & 5,77 & & 5,63 & & 1,67 & 7,73 & 1,87 & 1,82 & 1,35 & 1,84 \\
\hline 018 & & 9,5 & & & & 5,63 & & 1,45 & 4,89 & 1,87 & 1,68 & & 1,01 \\
\hline 018 & 96 & 4,56 & & 5,31 & 36 & 3,92 & & 66 &, 36 & 14 & 74 & & 1,82 \\
\hline $29 / 04 / 2018$ & 4,33 & 7,15 & 1,13 & 6,17 & 1,62 & 4,14 & $7 / 2018$ & 3,68 & 7,47 & 3,24 & 3,53 & 1,51 & 1,32 \\
\hline & 87 & & & 13,30 & & 3,22 & & 3,23 & 7,55 & & & & 1,1 \\
\hline$/ 2018$ &, 27 & 9,6 & & 8,73 & 69 & 6,24 & & 2,59 & 7,17 & 2,40 & 1,81 & & 1,57 \\
\hline 02/05/2018 & 1,36 & 10,83 & 1,34 & 6,42 & 1,95 & 5,33 & /2018 & 1,78 & 7,65 & 1,33 & 1,94 & 2 & 3,80 \\
\hline 03/05/2018 & 8,21 & 9,69 & 1,40 & 5,90 & 1,73 & 3,18 & & 3,43 & 7,95 & 2,38 & & & 25 \\
\hline & 90 & 11, & 1,24 & 2,27 & & 2,30 & & 1,83 & 7,34 & & & & 3,25 \\
\hline 2018 & 2,49 & 9,62 & 1,26 & 1,45 & 2,35 & 0,46 & 2018 & 1,66 & 6,81 & 1,33 & 1,77 & & 2,81 \\
\hline $06 / 05 / 2018$ & 1,50 & 5,72 & 1,07 & 1,60 & 1,43 & 0,65 & $18 / 07 / 2018$ & 1,69 & 7,15 & 1,45 & 2,03 & 2,91 & 2,85 \\
\hline & & 7,36 & 1,26 & & 1,49 & 0,70 & & 1,61 & 5,35 & 1,47 & 1,82 & & 2,65 \\
\hline & & 8,89 & 1,39 & 2,42 &, 50 & 1,05 & & 1,91 & 5,49 & 1,28 & 1,97 & & 2,42 \\
\hline 09/05/2018 & 3,41 & 6,43 & 0,99 & 2,58 & 2,72 & 0,98 & /2018 & 1,56 & 7,25 & 1,04 & 1,50 & 3,13 & 2,70 \\
\hline $10 / 05 / 2018$ & 1,46 & 6,42 & 2,06 & 2,04 & 2,85 & 1,02 & & 1,87 & 4,80 & 1,26 & 1,67 & 2,61 & 2,29 \\
\hline$/ 2018$ & 2,09 & 10,13 & 1,43 & 1,63 & 99 & 0,60 & 2018 & 1,86 & 7,30 & 1,46 & 1,76 & & 2,86 \\
\hline 018 & 0,88 & 9,43 & 1,49 & 1,24 & 1,96 & & 2018 & 1,94 & 6,95 & 1,60 & 1,85 & 2,72 & 2,51 \\
\hline $13 / 05 / 2018$ & & 4,86 & 0,92 & 2,10 & 2,06 & & $25 / 07 / 2018$ & 1,48 & 5,33 & 1,80 & 1,97 & 2,23 & 2,17 \\
\hline $17 / 05 / 2018$ & & 11,47 & 1,03 & & & & & 3,12 & 7,11 & 1,57 & & & 1,64 \\
\hline $22 / 05 / 2018$ & 2,56 & & 1,27 & 1,16 & 1,84 & 0,75 & 2018 & 1,78 & 7,54 & 1,90 & 2,01 & 3,5 & 1,24 \\
\hline $23 / 05 / 2018$ & 2,46 & & 1,37 & 1,22 & 3,88 & 0,69 & $28 / 07 / 2018$ & 1,76 & 7,44 & 1,66 & 1,94 & 2,91 & 2,22 \\
\hline & 3,18 & & & & & & & & & & & & 1,59 \\
\hline $25 / 05 / 2018$ & 3,13 & & & & & & & 1,56 & & & 1,64 & & 2,66 \\
\hline $26 / 05$ & 1,97 & & & 1,23 & 2,17 & 0,49 & 2018 & 2,40 & 6,37 & 1,89 & 2,33 & 1,84 & 1,96 \\
\hline $27 / 05 / 2018$ & 2,92 & 7,67 & 1,05 & 1,44 & 1,67 & 0,58 & $22 / 08 / 2018$ & 2,54 & 8,54 & 2,02 & 2,84 & 2,11 & 2,05 \\
\hline $28 / 05 / 2018$ & 2,58 & 7,42 & 0,82 & 1,53 & 1,95 & 0,46 & $23 / 08 / 2018$ & & 10,59 & 2,85 & & 2,51 & 1,97 \\
\hline $29 / 05 / 2018$ & & 6,73 & 0, & 1,31 & 1,82 & & $27 / 08 / 2018$ & 1,98 & & 2,45 & 2,34 & 2,48 & 2,30 \\
\hline & & 8,67 & & 2,37 & 1,94 & & & 3,81 & & 4,28 & 2,96 & 3,69 & 3,07 \\
\hline & 1,73 & 7,97 & & 2,08 & 2,60 & 0,72 & & 4,60 & 12,08 & 4,39 & 3,49 & 2,40 & 1,08 \\
\hline 01/06/2018 & 1,52 & 4,24 & 0,78 & 1,92 & 1,85 & 0,59 & $11 / 09 / 2018$ & 4,53 & 15,30 & 4,05 & 5,77 & 4,22 & 2,32 \\
\hline
\end{tabular}


APÊNDICE F. Resultados de evapotranspiração dos métodos baseados na flutuação diária do nível 134 piezométrico

Tabela 23 - Resultados de evapotranspiração do método de Gribovski

\begin{tabular}{|c|c|c|c|c|c|c|c|c|c|c|c|c|c|}
\hline Data & P27 & P30 & P31 & P32 & P33 & P 35 & Data & $\mathrm{P} 27$ & P30 & P31 & P32 & P33 & P35 \\
\hline $02 / 06 / 2018$ & 1,76 & 10,27 & 0,41 & & 2,00 & 0,61 & $12 / 09 / 2018$ & 3,71 & 12,99 & 4,04 & 4,27 & 4,21 & 2,94 \\
\hline 03/06/2018 & 1,07 & 5,66 & & & & 0,39 & $25 / 09 / 2018$ & 3,73 & & 5,43 & 3,49 & 2,19 & 2,69 \\
\hline $04 / 06 / 2018$ & 1,20 & 2,73 & & & & & $26 / 09 / 2018$ & 3,39 & & 5,02 & 3,22 & 2,44 & 2,09 \\
\hline $05 / 06 / 2018$ & 1,54 & 11,03 & & & & & $27 / 09 / 2018$ & 3,11 & 5,97 & 4,22 & 2,17 & 2,06 & 1,35 \\
\hline 09/06/2018 & 2,21 & 9,56 & & & 2,14 & 0,53 & $21 / 10 / 2018$ & 5,53 & & 5,04 & 4,03 & 3,49 & 2,15 \\
\hline $10 / 06 / 2018$ & 1,89 & 8,87 & 1,27 & 2,32 & 2,18 & 0,45 & $22 / 10 / 2018$ & & & 4,95 & 4,66 & 2,95 & 1,76 \\
\hline $11 / 06 / 2018$ & 1,61 & 10,01 & 1,11 & 2,81 & 1,66 & 0,42 & $30 / 10 / 2018$ & 2,86 & & 3,40 & 3,25 & 1,78 & 1,46 \\
\hline $12 / 06 / 2018$ & 1,64 & 6,55 & 1,06 & 2,93 & 2,16 & 0,36 & $31 / 10 / 2018$ & 3,78 & & 4,58 & 3,63 & 3,08 & 1,82 \\
\hline $13 / 06 / 2018$ & & 6,79 & 0,67 & 1,67 & 2,01 & 0,23 & $01 / 11 / 2018$ & 3,71 & & 4,38 & 3,60 & 3,52 & 1,44 \\
\hline $14 / 06 / 2018$ & & 9,36 & 2,17 & 2,47 & 3,08 & 0,50 & $16 / 11 / 2018$ & 6,91 & 9,60 & 6,75 & 6,80 & 3,21 & \\
\hline $15 / 06 / 2018$ & 0,95 & 8,38 & 1,03 & 2,41 & 2,24 & 0,31 & $27 / 11 / 2018$ & 3,62 & & 8,75 & 14,85 & & \\
\hline $16 / 06 / 2018$ & 1,63 & 6,70 & 0,90 & 2,49 & 2,08 & 0,28 & $28 / 11 / 2018$ & 6,46 & & 4,73 & 9,04 & 3,14 & 1,60 \\
\hline $17 / 06 / 2018$ & 1,80 & 6,98 & 1,20 & 2,39 & 2,10 & & $07 / 12 / 2018$ & 5,68 & & 4,28 & 6,27 & 4,53 & \\
\hline $18 / 06 / 2018$ & 1,95 & 4,78 & 1,14 & 2,57 & 1,51 & & $08 / 12 / 2018$ & 5,71 & & 5,05 & 6,04 & 4,22 & 1,02 \\
\hline $22 / 06 / 2018$ & 1,54 & & & & & 1,41 & 09/12/2018 & 6,63 & & 5,17 & 6,27 & 4,64 & \\
\hline $23 / 06 / 2018$ & 2,20 & 10,89 & 1,17 & 1,53 & 1,65 & 1,53 & $16 / 12 / 2018$ & 7,93 & & 6,22 & & 6,26 & 1,40 \\
\hline
\end{tabular}

\section{F.5 Método de Loheide II}

Tabela 24 - Resultados de evapotranspiração do método de Loheide II

\begin{tabular}{c|ccccccc|cccccccc}
\hline Data & P27 & P30 & P31 & P32 & P33 & P35 & & Data & P27 & P30 & P31 & P32 & P33 & P35 \\
\hline 20/04/2018 & 3,00 & 3,75 & & 1,66 & 1,43 & 0,79 & & $24 / 06 / 2018$ & 1,45 & 6,89 & 2,56 & 2,63 & 0,83 & 0,70 \\
$21 / 04 / 2018$ & 1,95 & 7,80 & 1,91 & 1,33 & 1,37 & 1,01 & & $25 / 06 / 2018$ & 1,35 & 7,27 & 2,95 & 2,61 & 0,83 & 0,52 \\
$22 / 04 / 2018$ & 1,63 & 5,13 & 2,11 & 1,12 & 1,64 & 0,63 & & $26 / 06 / 2018$ & 2,71 & 8,96 & 2,97 & 2,98 & 0,91 & 0,08 \\
$23 / 04 / 2018$ & 0,48 & 11,21 & 1,71 & 0,37 & 1,46 & 2,03 & & $27 / 06 / 2018$ & & 10,90 & 4,12 & 3,58 & 1,31 & 0,77 \\
$24 / 04 / 2018$ & 0,68 & 6,46 & 1,58 & 0,57 & 1,47 & 1,51 & & $28 / 06 / 2018$ & & 12,71 & 3,95 & 3,10 & 1,02 & 1,01 \\
$25 / 04 / 2018$ & 1,94 & 10,17 & 1,80 & 0,96 & 1,48 & 1,88 & & $29 / 06 / 2018$ & 1,50 & 10,70 & 3,29 & 2,26 & 0,63 & 0,18 \\
$26 / 04 / 2018$ & 1,23 & 10,62 & 1,18 & 1,28 & 1,37 & 0,07 & & $30 / 06 / 2018$ & 1,69 & 11,12 & 3,19 & 2,33 & 0,91 & 0,31 \\
$27 / 04 / 2018$ & 0,60 & 13,67 & 1,16 & 1,72 & 1,33 & 1,37 & & $01 / 07 / 2018$ & 1,56 & 11,20 & 3,24 & 2,95 & 1,08 & 0,59 \\
$28 / 04 / 2018$ & 1,58 & 7,40 & 1,39 & 1,08 & 1,24 & 0,01 & & $02 / 07 / 2018$ & 1,16 & 12,84 & 2,16 & 1,66 & 1,28 & 0,69 \\
$29 / 04 / 2018$ & 3,60 & 8,21 & 1,37 & 0,91 & 1,35 & 0,04 & & $03 / 07 / 2018$ & 1,81 & 12,49 & 2,62 & 2,07 & 1,43 & 1,28 \\
$30 / 04 / 2018$ & 3,73 & 11,05 & 1,64 & 1,65 & 1,48 & 1,52 & & $07 / 07 / 2018$ & 1,54 & 9,53 & 4,75 & 3,52 & 1,13 & 0,47
\end{tabular}


Tabela 24 - Resultados de evapotranspiração do método de Loheide II

\begin{tabular}{|c|c|c|c|c|c|c|c|c|c|c|c|c|c|}
\hline Data & 27 & P30 & P31 & P32 & P33 & P35 & Data & $\mathrm{P} 27$ & P30 & P31 & P32 & P33 & P35 \\
\hline $01 / 05 / 2018$ & & 10,26 & & & & 1,42 & $/ 07 / 2018$ & & 43 & & 3,45 & 1,0 & 0,0 \\
\hline 02/05/2018 & 35 & 13,18 & 1,69 & 2,16 & 1,58 & 3,01 & $/ 2018$ & 09 & 11,13 & 1,05 & 1,43 & 1.37 & 0,31 \\
\hline 03/05/2018 & 63 & 12,43 & 1,60 & 1,32 & 1,75 & 2,52 & $5 / 07 / 2018$ & 1,85 & 12,46 & 1,68 & 2,36 & 191 & 131 \\
\hline 018 & & 10,5 & & & & 0,70 & & & & & & & 0,26 \\
\hline 2018 & 4 & 11,5 & 1, & & & 0,32 & $/ 2018$ & 57 & 12,07 & & 3,19 & 99 & 0,01 \\
\hline $06 / 05 / 2018$ & 0,67 & 7,53 & 1,38 & 1,69 & 0,82 & 0,30 & $18 / 07 / 2018$ & 2,93 & 11,43 & 3,17 & 3,29 & 0,93 & 0,15 \\
\hline $7 / 05 / 2018$ & & 7,92 & 1,73 & & & 0,53 & $/ 2018$ & 1,74 & 12,11 & 3,01 & 2,90 & & 0,17 \\
\hline $8 / 05 / 2018$ & & 8,85 & 1,53 & & & 0,45 & $/ 2018$ & 1,05 & 11,33 & 3,06 & 2,28 & & 0,05 \\
\hline $09 / 05 / 2018$ & 0,62 & 8,79 & 0,77 & 1,73 & 0,92 & 0,42 & $/ 2018$ & 0,68 & 10 & 3,67 & 2,17 & & 0,11 \\
\hline $10 / 05 / 2018$ & 0,72 & 11,35 & 1,01 & 2,09 & 1,18 & 0,54 & $22 / 07 / 2018$ & 1,20 & 12,80 & 3,23 & 2,66 & & 0,22 \\
\hline$/ 2018$ & 59 & 13,50 & 0,45 & 0,58 & 1,29 & 0,39 & $/ 2018$ & 1,18 & 15,15 & 3,45 & 3,17 & & 0,61 \\
\hline $12 / 05 / 2018$ & 0,53 & 10,34 & 0,45 & 0,62 & 1,93 & & $24 / 07 / 2018$ & 1,54 & 14,00 & 3,68 & 3,40 & 1 , & 1,06 \\
\hline $13 / 05 / 2018$ & & 11,40 & 0,50 & 1,27 & 0,83 & & $/ 2018$ & 1,18 & 13,62 & 2,34 & 3,29 & 0,97 & 1,91 \\
\hline 2018 & & 6,75 & 0,42 & & 0,98 & 0,31 & $26 / 07 / 2018$ & 1,56 & & 2,71 & 3,32 & & 0,56 \\
\hline $22 / 05 / 2018$ & 0,96 & & 2,81 & 2,45 & 0,3 & 1,63 & $/ 2018$ & 1,84 & 10,43 & 2,84 & 3,01 & & 0,57 \\
\hline $23 / 05 / 2018$ & 1,13 & & 2,29 & 2,89 & 0,59 & 1,44 & $28 / 07 / 2018$ & 2,92 & 12,79 & 3,47 & 3,44 & 0,91 & 0,61 \\
\hline $24 / 05 / 2018$ & 3,13 & & 1,83 & 2,32 & 0,70 & 1,04 & & 1,92 & & & 3,78 & & 0,60 \\
\hline 2018 & 1,66 & & 2,77 & 2,04 & 0,88 & 1,06 & & 1,30 & 7,10 & 2,8 & 2,11 & & 0,63 \\
\hline 018 & 0,99 & 5,40 & 2,06 & 2,01 & 1,14 & 1,28 & /2018 & 1,46 & 5,99 & 3,10 & 2,61 & & 0,89 \\
\hline $27 / 05 / 2018$ & 1,57 & 4,03 & 2,47 & 2,67 & 0,65 & 1,20 & $22 / 08 / 2018$ & 2,30 & 10,18 & 5,76 & 2,63 & 0,88 & 0,21 \\
\hline $28 / 05 / 2018$ & 1,65 & 4,50 & & & & 1,98 & $23 / 08 / 2018$ & & 11,73 & 7,23 & & & 0,93 \\
\hline $29 / 05 / 2018$ & & 6,12 & 2,14 & 1,74 & 0,86 & & $27 / 08 / 2018$ & 2,15 & & 4,69 & 3,36 & & 0,97 \\
\hline 018 & & 8,49 & 1,39 & 1,01 & 0,87 & & $/ 2018$ & 2,46 & & 8,09 & 6,90 & 1,73 & 1,25 \\
\hline $31 / 05 / 2018$ & 1,15 & 5,36 & 1,23 & 0,71 & & & & 2,20 & 13,74 & 5,09 & 3,01 & & 0,25 \\
\hline $01 / 06 / 2018$ & 0,92 & 6,62 & 1,56 & & 0,82 & 0,81 & $/ 2018$ & 2,45 & & 7,51 & 5,86 & 3,03 & 1,34 \\
\hline $02 / 06 / 2018$ & 0,66 & 6,86 & 0,67 & & 0,51 & 0,72 & $12 / 09 / 2018$ & 4,64 & 12,75 & 9,24 & 11,11 & 4,39 & 1,00 \\
\hline $3 / 06 / 2018$ & 0,45 & 5,51 & & & & 0,54 & $25 / 09 / 2018$ & 4,19 & & 11,70 & 10,12 & 3,63 & 0,78 \\
\hline & 0,94 & 5,19 & & & & & & 3,09 & & & 5,71 & & 0,86 \\
\hline 05/06/2018 & 1,30 & 12,13 & & & & & $27 / 09 / 2018$ & 1,13 & 7,30 & 4,79 & 2,12 & 1,31 & 0,36 \\
\hline 09/06/2018 & 1,62 & 8,23 & & & 0,78 & 0,76 & $21 / 10 / 2018$ & 2,80 & & 12,70 & 8,17 & 4,10 & 1,41 \\
\hline $10 / 06 / 2018$ & 1,68 & 9,37 & 2,47 & 2,09 & 1,38 & 0,83 & $22 / 10 / 2018$ & & & 15,27 & & & 0,85 \\
\hline $11 / 06 / 2018$ & 2,14 & 10,91 & 3,04 & 2,44 & & 0,66 & $30 / 10 / 2018$ & 5,95 & & & 5,59 & & 0,83 \\
\hline $12 / 06 / 2018$ & 0,98 & 7,94 & 1,36 & 1,34 & 0,88 & 0,34 & $31 / 10 / 2018$ & 6,67 & & 13,45 & 7,69 & 3,20 & 0,61 \\
\hline $13 / 06 / 2018$ & & 9,44 & 1,10 & 1,08 & 0,95 & 0,31 & $01 / 11 / 2018$ & 7,61 & & 15,28 & 8,72 & 3,72 & 0,47 \\
\hline $14 / 06 / 2018$ & & 9,70 & 1,93 & 1,52 & 1,02 & 0,54 & $16 / 11 / 2018$ & 6,41 & 14,22 & 13,86 & 7,49 & 4,57 & \\
\hline $15 / 06 / 2018$ & 0,80 & 6,73 & 1,35 & 1,55 & 0,89 & 0,61 & $27 / 11 / 2018$ & 1,83 & & 2,39 & 2,15 & & \\
\hline
\end{tabular}


APÊNDICE F. Resultados de evapotranspiração dos métodos baseados na flutuação diária do nível 136 piezométrico

Tabela 24 - Resultados de evapotranspiração do método de Loheide II

\begin{tabular}{|c|c|c|c|c|c|c|c|c|c|c|c|c|c|}
\hline Data & 27 & P30 & P31 & P32 & P33 & P 35 & Data & $\mathrm{P} 27$ & P30 & P31 & P32 & P33 & P35 \\
\hline $16 / 06 /$ & & 9,50 & 1,52 & 1,02 & 0,61 & 0,40 & & 4,66 & & 6,94 & 7,04 & 3,60 & 0,46 \\
\hline & & 8,76 & 2,15 & 0,91 & 0,70 & & & 51 & & & 8,42 & 3,66 & \\
\hline $18 / 06 / 2018$ & 1,28 & 10,21 & 1,88 & 0,93 & 0,76 & & 08/12/2018 & 6,69 & & 16,83 & 9,21 & 6,38 & 0,85 \\
\hline $22 / 06 / 2018$ & 1,57 & & & & & 0,33 & & 2,70 & & 5,18 & 2,71 & 3,80 & \\
\hline $23 / 06 / 2018$ & 1,75 & 11,55 & 2,82 & 2,74 & 1,31 & 0,68 & $16 / 12 / 2018$ & 11,46 & & 17,94 & & 7,47 & 0,78 \\
\hline
\end{tabular}

\section{F.6 Método de Soylu}

Tabela 25 - Resultados de evapotranspiração do método de Soylu

\begin{tabular}{|c|c|c|c|c|c|c|c|c|c|c|c|c|c|}
\hline Data & $\mathrm{P} 27$ & P30 & P31 & P32 & P33 & P35 & Data & $\mathrm{P} 27$ & P30 & P31 & P32 & P33 & P35 \\
\hline $20 / 04 / 2018$ & 0,64 & & & & & & $25 / 06 / 2018$ & 0,87 & 0,62 & 1,04 & 0,56 & & 0,04 \\
\hline $21 / 04 / 2018$ & 0,67 & & 0,54 & & & & $26 / 06 / 2018$ & 1,31 & 0,62 & 1,01 & 0,56 & & 0,69 \\
\hline $22 / 04 / 2018$ & 0,27 & & 0,54 & & & & $27 / 06 / 2018$ & & 0,63 & 0,55 & 1,18 & & \\
\hline $23 / 04 / 2018$ & 0,75 & & 0,68 & 0,10 & 0,02 & & $28 / 06 / 2018$ & & & 0,85 & 0,67 & & \\
\hline $24 / 04 / 2018$ & 0,62 & & 0,54 & 0,56 & 0,80 & & $29 / 06 / 2018$ & 1,19 & & 1,34 & 1,61 & & \\
\hline $25 / 04 / 2018$ & 0,56 & & 0,54 & & 0,85 & & $30 / 06 / 2018$ & 1,17 & & 1,58 & 0,57 & & \\
\hline $26 / 04 / 2018$ & & & 0,54 & & 0,91 & & $01 / 07 / 2018$ & 1,21 & & 1,48 & 1,33 & & \\
\hline $27 / 04 / 2018$ & & 0,62 & 0,54 & 1,86 & 1,00 & & 02/07/2018 & 1,28 & & 1,76 & 1,22 & & \\
\hline $28 / 04 / 2018$ & & & 0,54 & & 0,18 & & 03/07/2018 & 1,31 & & 1,74 & 1,42 & & \\
\hline 29/04/2018 & 0,68 & & 0,54 & & 0,13 & & $07 / 07 / 2018$ & 0,95 & & 1,72 & 1,54 & & \\
\hline $30 / 04 / 2018$ & 0,87 & 5,14 & 0,55 & 0,06 & 0,85 & & 08/07/2018 & 1,15 & 0,63 & 1,68 & 0,56 & & \\
\hline $01 / 05 / 2018$ & 0,18 & & 0,55 & & 1,36 & & $14 / 07 / 2018$ & 1,46 & 0,63 & 1,16 & 0,56 & & \\
\hline 02/05/2018 & 0,20 & & 0,56 & & & & $15 / 07 / 2018$ & 1,10 & 0,63 & 1,15 & 1,81 & & \\
\hline 03/05/2018 & 0,41 & & 0,55 & 0,56 & 0,55 & & $16 / 07 / 2018$ & 0,95 & 6,72 & 1,23 & 0,57 & & \\
\hline 04/05/2018 & & & 0,73 & 2,62 & 0,55 & & $17 / 07 / 2018$ & 1,35 & & 0,92 & 1,39 & & \\
\hline 05/05/2018 & & & 0,55 & & & & $18 / 07 / 2018$ & 1,33 & & 0,72 & 0,56 & & \\
\hline 06/05/2018 & & & 0,55 & & & & $19 / 07 / 2018$ & 1,36 & & 0,81 & 0,56 & & \\
\hline $07 / 05 / 2018$ & & & 0,39 & & 0,62 & 0,10 & $20 / 07 / 2018$ & 1,25 & & 0,91 & 1,34 & & \\
\hline 08/05/2018 & & & 0,55 & 0,56 & & & $21 / 07 / 2018$ & 1,31 & & 0,74 & 0,57 & & \\
\hline 09/05/2018 & 0,06 & & 0,98 & 0,56 & 0,06 & & $22 / 07 / 2018$ & 1,13 & & 0,70 & 1,11 & & \\
\hline $11 / 05 / 2018$ & & & 0,58 & & & & $23 / 07 / 2018$ & 1,37 & & 0,81 & 0,56 & & \\
\hline $12 / 05 / 2018$ & & & 0,65 & & & & $24 / 07 / 2018$ & 1,27 & & 0,86 & 1,18 & & \\
\hline
\end{tabular}


Tabela 25 - Resultados de evapotranspiração do método de Soylu

\begin{tabular}{|c|c|c|c|c|c|c|c|c|c|c|c|c|c|}
\hline Data & $\mathrm{P} 27$ & P30 & P31 & P32 & P33 & P35 & Data & $\mathrm{P} 27$ & P30 & P31 & P32 & P33 & P35 \\
\hline $13 / 05 / 2018$ & & & & 0,56 & & & $25 / 07 / 2018$ & 0,50 & & 0,79 & 0,56 & & \\
\hline $17 / 05 / 2018$ & & 10,52 & 0,55 & & 0,56 & 0,03 & $26 / 07 / 2018$ & 2,13 & & 0,69 & 1,56 & & \\
\hline $22 / 05 / 2018$ & 1,15 & & 1,00 & 0,56 & 0,56 & 0,48 & $27 / 07 / 2018$ & 1,72 & & 0,75 & 0,56 & 0,56 & \\
\hline $23 / 05 / 2018$ & 1,15 & & 0,55 & 0,56 & 0,56 & 0,51 & $28 / 07 / 2018$ & 1,27 & & 0,86 & 1,25 & & \\
\hline $24 / 05 / 2018$ & 1,48 & & 0,55 & 0,56 & & 0,36 & $29 / 07 / 2018$ & 1,43 & & 0,58 & 1,41 & & \\
\hline $25 / 05 / 2018$ & 0,74 & & 0,55 & 0,56 & & 0,38 & $17 / 08 / 2018$ & 1,32 & 8,11 & 0,96 & 0,56 & & \\
\hline $26 / 05 / 2018$ & 0,79 & 0,59 & 0,27 & 0,56 & & 0,31 & $18 / 08 / 2018$ & 1,50 & 1,87 & 1,12 & 1,16 & & \\
\hline $27 / 05 / 2018$ & 1,08 & 0,60 & 0,52 & 0,56 & 0,06 & 0,24 & $22 / 08 / 2018$ & 1,77 & 4,95 & 1,00 & 1,03 & 0,55 & 0,96 \\
\hline $28 / 05 / 2018$ & 0,69 & 0,60 & 0,55 & 0,56 & & 0,18 & $23 / 08 / 2018$ & & 7,13 & 1,54 & & & \\
\hline $29 / 05 / 2018$ & & & 0,42 & 0,27 & & & $27 / 08 / 2018$ & 1,42 & & 1,71 & 1,24 & 0,55 & \\
\hline $30 / 05 / 2018$ & & & 0,40 & 0,56 & & & 09/09/2018 & 2,44 & 1,30 & 2,89 & 2,63 & 0,56 & \\
\hline $31 / 05 / 2018$ & 1,21 & & 0,55 & 0,56 & & 0,64 & $10 / 09 / 2018$ & 2,52 & 0,89 & 3,01 & 2,43 & & \\
\hline 01/06/2018 & 1,21 & 5,02 & 0,53 & 0,56 & & 0,21 & $11 / 09 / 2018$ & 2,43 & 0,66 & 0,53 & 2,62 & & \\
\hline 02/06/2018 & 1,08 & 5,40 & 0,36 & & 0,10 & 0,15 & $12 / 09 / 2018$ & 2,07 & & 3,25 & 2,41 & 1,99 & \\
\hline 03/06/2018 & 0,33 & & & & & 0,09 & $25 / 09 / 2018$ & 2,95 & & 0,56 & 2,81 & 0,29 & 0,54 \\
\hline 04/06/2018 & 0,50 & & & & & & $26 / 09 / 2018$ & 2,95 & & 3,51 & 2,71 & 0,56 & \\
\hline 05/06/2018 & 0,50 & & & & & & $27 / 09 / 2018$ & 1,78 & 0,64 & 1,98 & 1,64 & 0,56 & 0,77 \\
\hline 09/06/2018 & 1,32 & 0,62 & & & & 0,50 & $21 / 10 / 2018$ & 2,23 & & 3,69 & 2,77 & 2,58 & 1,55 \\
\hline $10 / 06 / 2018$ & 0,96 & & 0,55 & & & 0,26 & $22 / 10 / 2018$ & & & 3,78 & 3,02 & 2,48 & 0,54 \\
\hline $11 / 06 / 2018$ & 0,95 & & 0,55 & & & & $30 / 10 / 2018$ & 2,27 & & 2,91 & 2,55 & 1,87 & \\
\hline $12 / 06 / 2018$ & 1,13 & & 0,67 & 0,56 & 0,24 & & $31 / 10 / 2018$ & 2,76 & & 3,08 & 2,79 & 2,71 & 0,47 \\
\hline $13 / 06 / 2018$ & & & 0,55 & 0,02 & & 0,09 & $01 / 11 / 2018$ & 3,22 & & 3,69 & 2,19 & 2,71 & 1,35 \\
\hline $14 / 06 / 2018$ & & & 0,55 & 0,57 & 0,04 & & $16 / 11 / 2018$ & 5,00 & 13,21 & 5,28 & 4,95 & 0,99 & \\
\hline $15 / 06 / 2018$ & 0,24 & & 0,67 & & 0,76 & 0,17 & $27 / 11 / 2018$ & 2,83 & & 2,47 & 2,59 & & \\
\hline $16 / 06 / 2018$ & 0,42 & & 0,51 & 0,56 & & 0,09 & $28 / 11 / 2018$ & 2,93 & & 2,45 & 2,72 & 2,94 & \\
\hline $17 / 06 / 2018$ & 0,07 & & 1,03 & & & & $07 / 12 / 2018$ & 4,26 & & 2,29 & 4,82 & 3,35 & \\
\hline $18 / 06 / 2018$ & 1,06 & & 0,79 & & & & 08/12/2018 & 4,52 & & 3,88 & 4,84 & 3,26 & 0,54 \\
\hline $22 / 06 / 2018$ & 0,27 & & & & & & 09/12/2018 & 4,70 & & 4,01 & 4,60 & 3,30 & \\
\hline $23 / 06 / 2018$ & 1,24 & 11,46 & 1,15 & 1,75 & 0,50 & & $16 / 12 / 2018$ & 5,42 & & 4,93 & & 5,15 & \\
\hline
\end{tabular}

